\title{
Implications of Variability of Electromyographic Measurements for Assessing Localized Muscle Fatigue
}

\author{
Hamad Nasser Alasim \\ West Virginia University, hnalasim@mix.wvu.edu
}

Follow this and additional works at: https://researchrepository.wvu.edu/etd

Part of the Ergonomics Commons, Industrial Engineering Commons, Industrial Technology Commons, and the Risk Analysis Commons

\section{Recommended Citation}

Alasim, Hamad Nasser, "Implications of Variability of Electromyographic Measurements for Assessing Localized Muscle Fatigue" (2020). Graduate Theses, Dissertations, and Problem Reports. 7597.

https://researchrepository.wvu.edu/etd/7597

This Dissertation is protected by copyright and/or related rights. It has been brought to you by the The Research Repository @ WVU with permission from the rights-holder(s). You are free to use this Dissertation in any way that is permitted by the copyright and related rights legislation that applies to your use. For other uses you must obtain permission from the rights-holder(s) directly, unless additional rights are indicated by a Creative Commons license in the record and/ or on the work itself. This Dissertation has been accepted for inclusion in WVU Graduate Theses, Dissertations, and Problem Reports collection by an authorized administrator of The Research Repository @ WVU.

For more information, please contact researchrepository@mail.wvu.edu. 
Implications of Variability of Electromyographic Measurements for Assessing Localized Muscle Fatigue

Hamad Nasser Alasim

Follow this and additional works at: https://researchrepository.wvu.edu/etd

Part of the Ergonomics Commons, Industrial Engineering Commons, Industrial Technology Commons, and the Risk Analysis Commons 


\title{
Implications of Variability of Electromyographic Measurements for Assessing Localized Muscle Fatigue
}

\author{
Hamad Nasser Alasim \\ Dissertation submitted to the \\ West Virginia University \\ in partial fulfillment of the requirement for the degree of

\section{Doctor of Philosophy \\ in \\ Industrial Engineering} \\ Ashish D. Nimbarte, Ph.D., Chairperson \\ Anna Allen, MD, MPH \\ Hongwei Hsiao, Ph.D. \\ Gary Winn, Ph.D. \\ Feng Yang, Ph.D.
}

Benjamin M. Statler College of Engineering and Mineral Resources at

Department of Industrial and Management Systems Engineering

\author{
Morgantown, West Virginia \\ April 2020
}

Keywords: shoulder, localized muscle fatigue, musculoskeletal disorders

Copyright 2020 Hamad Alasim 


\section{Abstract \\ Implications of Variability of Electromyographic Measurements for Assessing Localized Muscle Fatigue}

\section{Hamad Nasser Alasim}

The impact of work-related musculoskeletal disorders (WMSDs) is enormous due to a combination of direct and indirect costs associated with healthcare, lost workdays and human suffering. Because of the established relationship between Localized Muscle Fatigue (LMF) development and WMSDs, and in order to reduce and/or prevent WMSDs in workplaces, different fatigue assessment methods have been developed. Surface Electromyography (SEMG) is a commonly used LMF assessment technique. The SEMG signals are typically analyzed in time and frequency domains to predict LMF based on a relative change with respect to initial, or under nofatigue conditions. Quantifying such change, however, relies on the assumption that the SEMG measures without fatigue present, under different muscular demands, can serve as an appropriate reference within the joint range-of-motion. To our knowledge, the assumption that the electromyographic measures do not change/vary due to factors other than LMF has not been thoroughly tested. Therefore, the objective of this study was to quantify variability of various SEMG measures in non-fatigued shoulder muscles and its implication for assessing muscle fatigue.

In the first Specific Aim, an experiment was performed to quantify variability of six EMG measures (RMS, MAV, ZC, MnPF, MdPF, and PFB $11-22 \mathrm{~Hz}$ ) in seven non-fatigued shoulder muscles. Twelve human participants performed 120 occupationally relevant static holding tasks. The variability in SEMG data was quantified using Mean Square Error ( $\sqrt{\mathrm{MSE}}$ ) obtained from ANOVA models. The SEMG measures were found to vary between $5.32 \%$ to $12.25 \%$ due to factors other than muscle fatigue. The narrowest range of variability was observed for ZC $(10.20 \%$ to $11.00 \%$ ), and the largest range of variability was observed for MdPF (8.72\% to $12.25 \%$ ).

In the second Specific Aim, a relationship between SEMG variability and LMF based on perceived exertion ratings was studied. Twelve human participants performed 8 fatigue inducing exertions for 10-45 seconds. The data were analyzed to identify muscle fatigue onset based on the perceived exertion ratings and the corresponding relative changes in SEMG measures. A good agreement was observed between the definition of LMF based on perceived exertion ratings and the relative change in the SEMG measures (quantified in Aim 1) for ZC, MnPF, and MdPF. And the study concludes that for the shoulder muscles a change higher than $11.00 \%, 11.45 \%$, and $12.25 \%$ in $\mathrm{ZC}, \mathrm{MnPF}$, and MdPF, respectively, can be an indication of LMF.

In conclusion, the study findings suggest that a change higher than $11.00 \%, 11.45 \%$, and $12.25 \%$ in ZC, MnPF, and MdPF, respectively, can be an indication of LMF. These findings could be useful in improving real-time fatigue predication models and/or methods to curtail the incidence of LMF based WMSDs in workplaces. 


\section{Acknowledgments}

I would like to express my deepest gratitude to my advisor, Dr. Ashish D. Nimbarte for the continuous encouragement, guidance, and support throughout the years. His invaluable recommendations paved my path to reach this point, and his patience and support helped me overcome many crisis situations throughout this journey. I would also like to express my profound gratitude to my advisory committee: Dr. Anna Allen, Dr. Hongwei Hsiao, Dr. Gary Winn, and Dr. Feng Yang for their insightful comments and encouragement throughout this process. I would also like to thank my colleagues in the Ergonomics Laboratory for their assistance in the experimental setup and data collection.

A special word of thanks goes to my parents, Hind and Nasser, for their continuous support and encouragement; and for their faith in me. I am also grateful for the love, encouragement, and tolerance of my wife Atheer, the woman who has made all the difference in my life. Without her support, I could not have completed this Dissertation. Finally, I dedicate this work to my parents, lovely wife, and my sweet little daughter Hind.

Finally, special thanks to my country, Saudi Arabia, represented by Majmaah University for providing me this priceless opportunity to pursue my graduate education in the United States. I really hope that my fellow Saudi scholars and I can pay our intangible debt back to this giving country by significantly contributing to our national growth in every aspect and committing towards a new phase of development. As a wise man once said, "the sky is the limit." 


\section{Table of Contents}

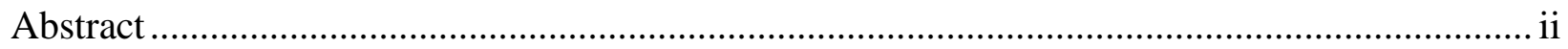

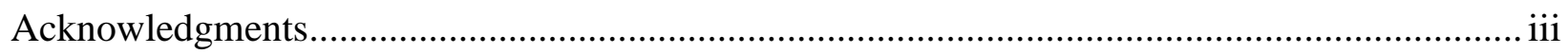

Table of Contents .......................................................................................................... iv

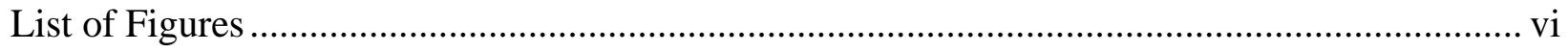

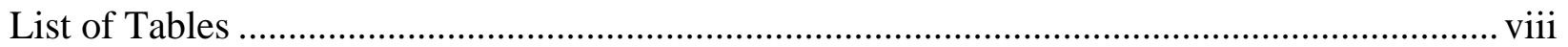

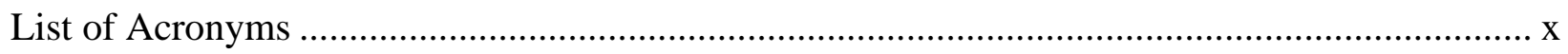

Chapter 1. Background \& Significance ………………….................................................. 1

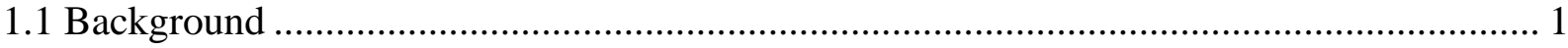

1.1.1 Studies based on EMG spectral frequency ……....................................................... 2

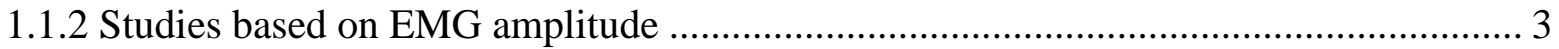

1.1.3 Studies based on Power Frequency Bands (PFB) of EMG signal................................... 5

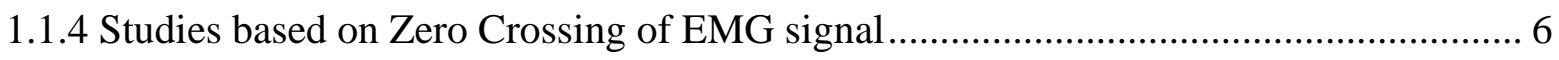

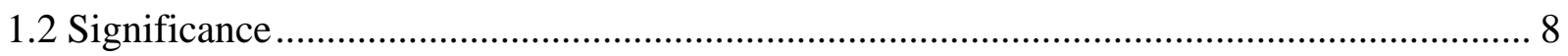

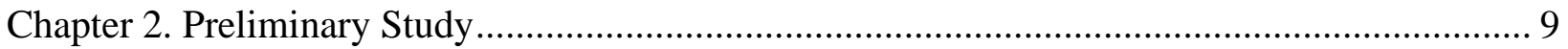

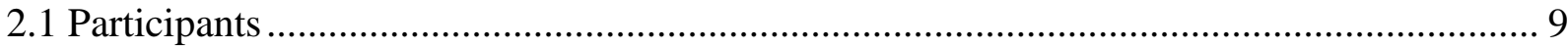

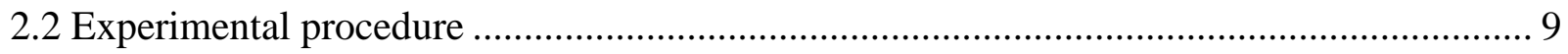

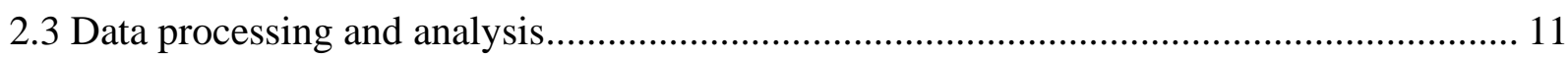

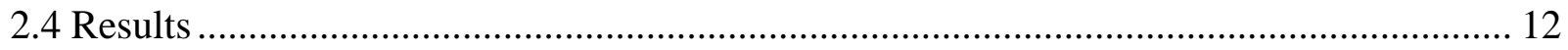

2.4.1 Pull back direction ......................................................................................... 12

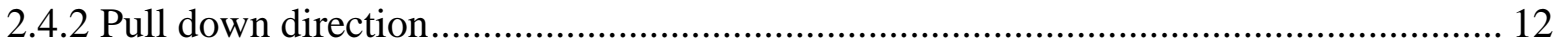

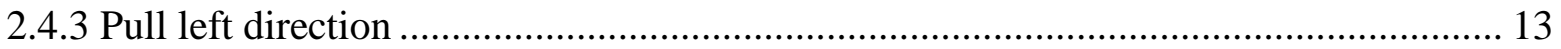

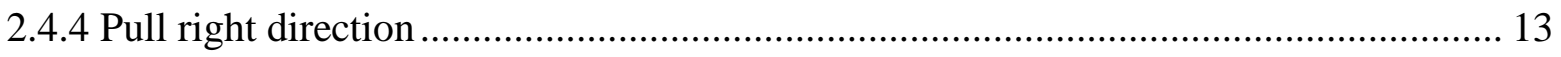

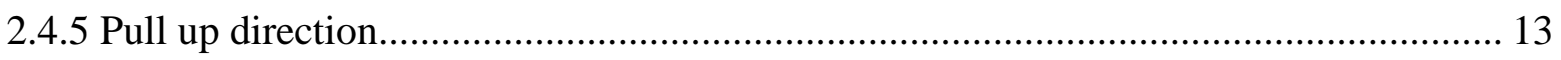

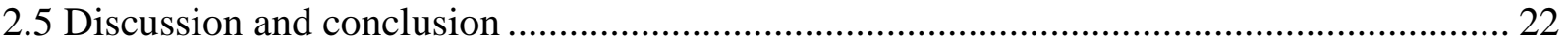

Chapter 3. Specific Aim \#1 …………............................................................................... 25

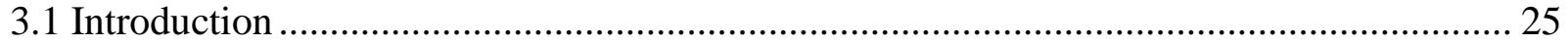

3.1.1 Work-related/independent factors ........................................................................ 27

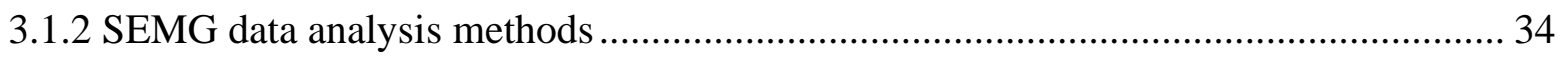

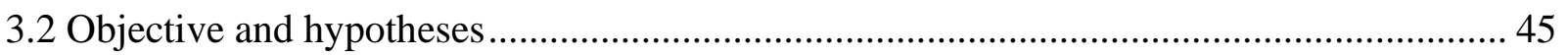

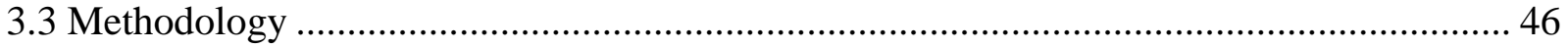




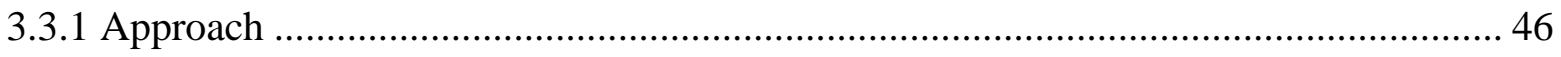

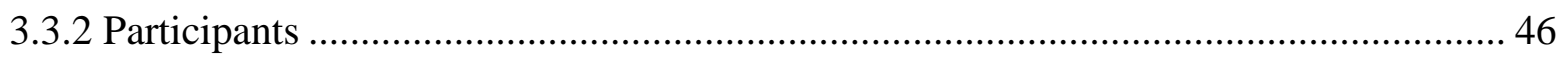

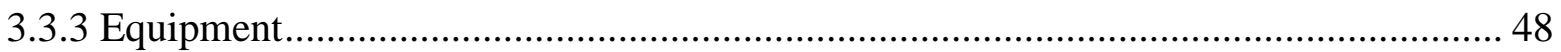

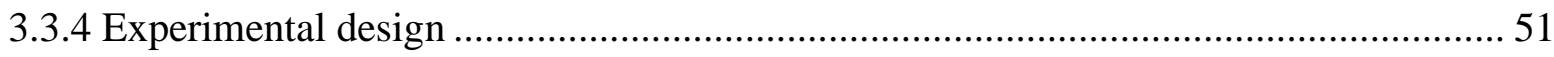

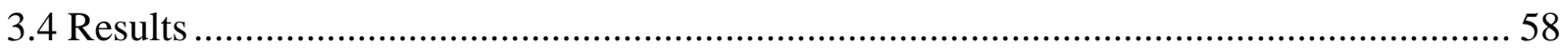

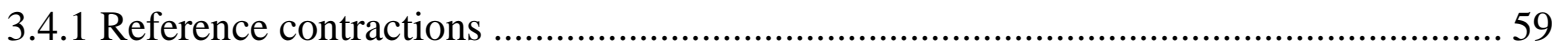

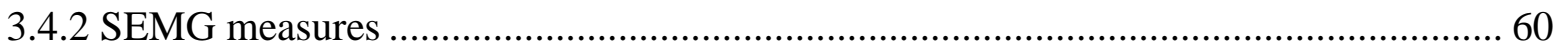

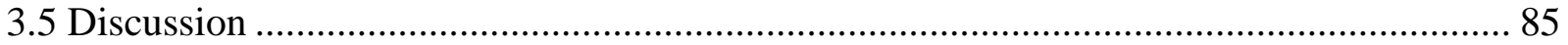

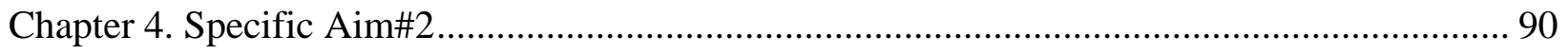

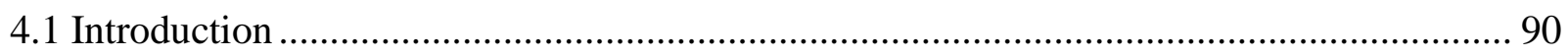

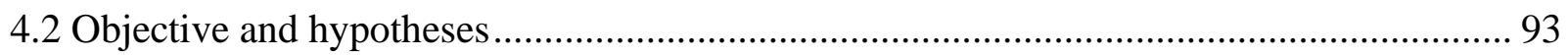

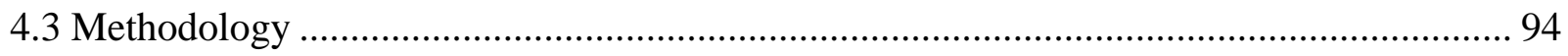

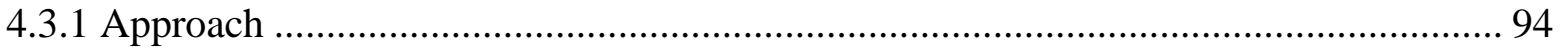

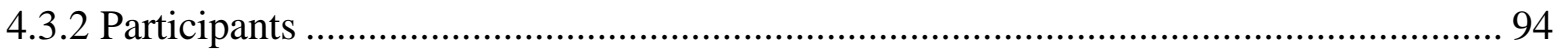

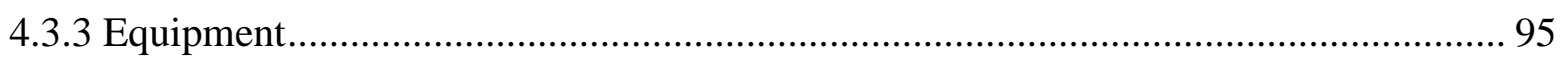

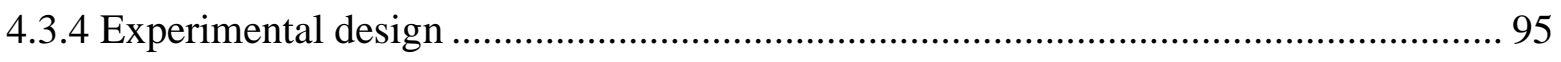

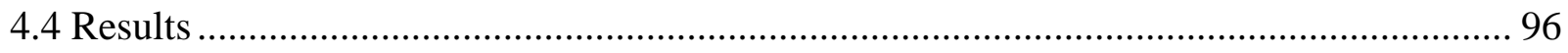

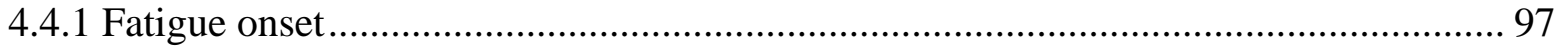

4.4.2 Relative change of SEMG measures with respect to fatigue occurrence ..................... 98

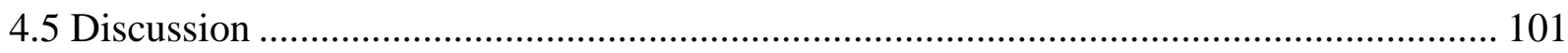

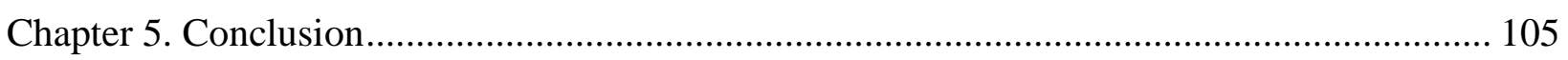

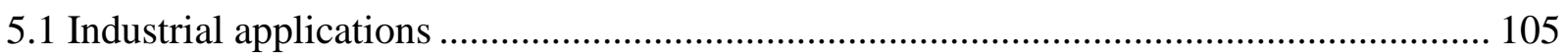

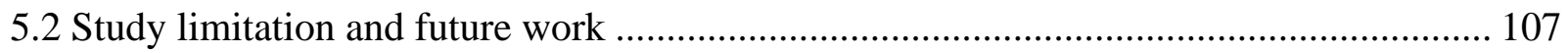

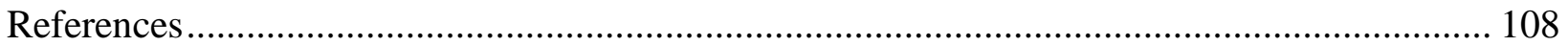

Appendix A: IRB approved consent form for the preliminary study ....................................... 120

Appendix B: IRB approved consent form for Aim \#1 study .................................................. 125

Appendix C: IRB approved consent form for Aim \#2 study ................................................. 130

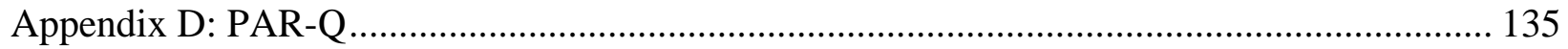

Appendix E: Analysis of Variance …………................................................................... 137 


\section{List of Figures}

Figure 1: (A) An illustration of the experimental design: (1) pulling in a backward direction (PB), (2) pulling in a downward direction (PD), (3) pulling towards the left (PL), (4) pulling towards the right (PR), and (5) pulling in an upward direction (PU); (B) The rope and pulley system used to perform the PB pulling exertion.

Figure 2: Regression of normalized MnPF with respect to force level in pull back (PB), pull down (PD), pull left (PL), pull right (PR), and pull up (PU) directions. 20

Figure 3: Regression of normalized MdPF with respect to force level in pull back (PB), pull down (PD), pull left (PL), pull right (PR), and pull up (PU) directions.

Figure 4: Comparison of variations in MnPF and MdPF for each shoulder muscle in the different pull directions. 22

Figure 5: Adjustable custom-made force exertion device. A) at low height, B) at high height. .. 49 Figure 6: Pulley locations in the custom-made force exertion device. These locations facilitate force exertion in different directions 1) pull right direction, 2) pull down direction, 3) pull left direction, and 4) pull back direction. Note: there is no need to have a pulley for pull up direction.

Figure 7: Parts of the Bagnoli -16 EMG system (a) EMG sensor, (b) main amplifier unit, (c) input modules, (d) input module cable, and (e) power supply. 50

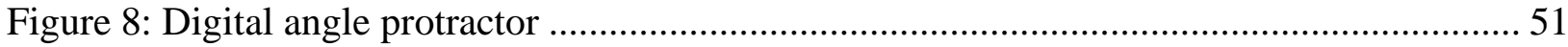

Figure 9: Independent factors and their levels 53

Figure 10: A participant performing pull up (PU) exertion in two different postures: (A) shoulder angle is elevated $120^{\circ}$ in the scapular plane and (B) shoulder angle is elevated $60^{\circ}$ in the sagittal plane 55

Figure 11: A participant performing a pull right (PR) direction while shoulder angle is elevated $120^{\circ}$ in the sagittal plane...... 56

Figure 12: A participant performing a pull left (PL) direction while shoulder angle is elevated $60^{\circ}$ in the sagittal plane. 56

Figure 13: MdPF interval plot for Anterior deltoid. Error bars represent standard deviation ...... 60 Figure 14: RMS interval plot. Error bars represent standard deviation. Note: Plane axis label represent 1) sagittal $\left(90^{\circ}\right)$ 2) scapular $\left(135^{\circ}\right)$ 
Figure 15: MAV interval plot for each muscle. Error bars represent standard deviation. Note:

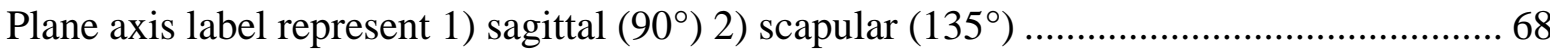

Figure 16: ZC interval plot for each muscle. Error bars represent standard deviation. Note: Plane

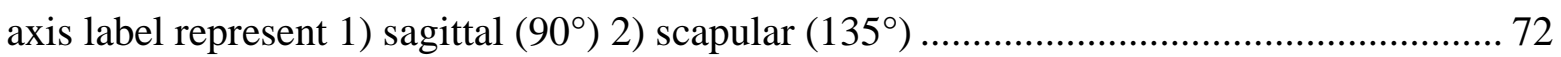

Figure 17: MnPF interval plot for each muscle. Error bars represent standard deviation. Note: Plane axis label represent 1) sagittal $\left(90^{\circ}\right)$ 2) scapular $\left(135^{\circ}\right)$........................................ 76

Figure 18: MdPF interval plot for each muscle. Error bars represent standard deviation. Note:

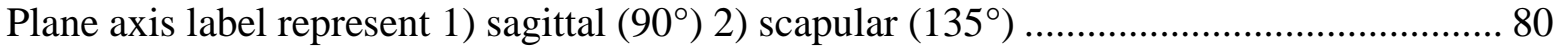

Figure 19: PFB interval plot for each muscle. Error bars represent standard deviation. Note:

Plane axis label represent 1) sagittal $\left.\left(90^{\circ}\right) 2\right)$ scapular $\left(135^{\circ}\right)$...................................... 84

Figure 20:Comparison of variability in RMS, MAV, ZC, MnPF, MdPF, and PFB for the shoulder muscles

Figure 21: Comparison of variability in RMS, MAV, ZC, MnPF, MdPF, and PFB for the shoulder muscles 85

Figure 22: Fatigue onset in second based on a rating of 4 using the subjective perceived exertion ratings 98

Figure 23: Relative change as a percentage when participants reported a "4" subjective rating compared to the start point 


\section{List of Tables}

Table 1: The influence of force level in the pull back direction on normalized MnPF and MdPF.

Statistically significant $p$-values are highlighted in bold font. 15

Table 2: The influence of force level in the pull down direction on normalized MnPF and MdPF.

Statistically significant $p$-values are highlighted in bold font. 16

Table 3: The influence of force level in the pull left direction on normalized MnPF and MdPF.

Statistically significant $p$-values are highlighted in bold font. 17

Table 4: The influence of force level in the pull right direction on normalized MnPF and MdPF.

Statistically significant $p$-values are highlighted in bold font. 18

Table 5: The influence of force level in the pull up direction on normalized MnPF and MdPF.

Statistically significant $p$-values are highlighted in bold font. 19

Table 6: Summary of shoulder muscles fatigue studies while using EMG signals................... 40

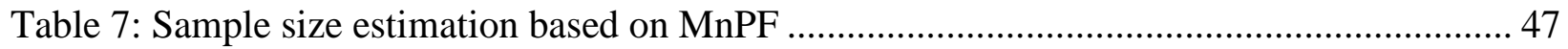

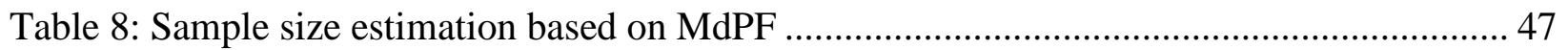

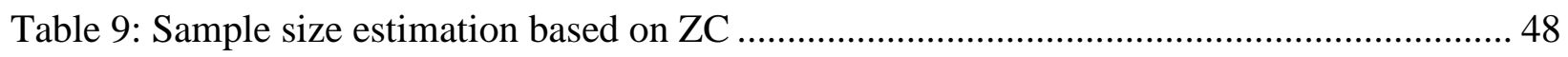

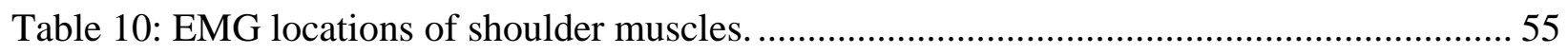

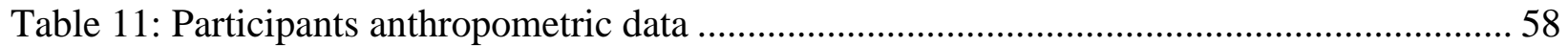

Table 12: Results of one-way ANOVA analysis for reference contractions ............................. 59

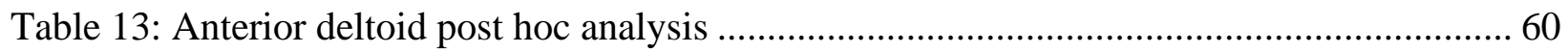

Table 14: Main effect of joint angle, shoulder plane, force level, and force direction on RMS, and variation based on MSE. Statistically significant $\mathrm{p}$-values are highlighted in bold font....... 62

Table 15: Main effect of joint angle, shoulder plane, force level, and force direction on MAV, and variation based on MSE. Statistically significant p-values are highlighted in bold font 66

Table 16: Main effect of joint angle, shoulder plane, force level, and force direction on ZC, and variation based on $M S E$. Statistically significant $\mathrm{p}$-values are highlighted in bold font...... 70 Table 17: Main effect of joint angle, shoulder plane, force level, and force direction on MnPF, and variation based on MSE. Statistically significant p-values are highlighted in bold font 74

Table 18: Main effect of joint angle, shoulder plane, force level, and force direction on MdPF, and variation based on MSE. Statistically significant p-values are highlighted in bold font 78 
Table 19: Main effect of joint angle, shoulder plane, force level, and force direction on PFB, and variation based on MSE. Statistically significant $\mathrm{p}$-values are highlighted in bold font....... 82

Table 20: musculoskeletal parameters for the selected muscles including physiological crosssectional areas (PCSA), muscle volumes, muscle length, and muscle fiber type ............... 89

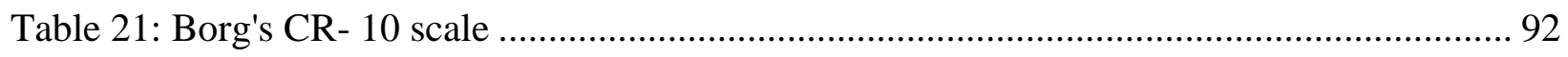

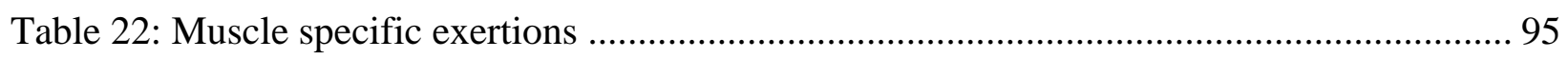

Table 23: Exertions used to develop muscle fatigue ............................................................ 96

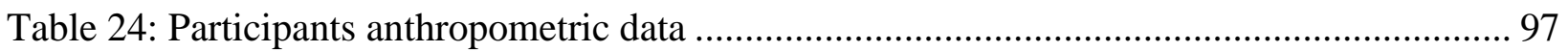

Table 25: Fatigue onset in seconds based on subjective perceived exertion ratings of "4" using

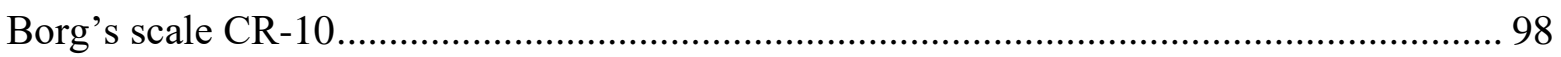

Table 26: Relative change -in percent- when participants reported a "4" subjective rating

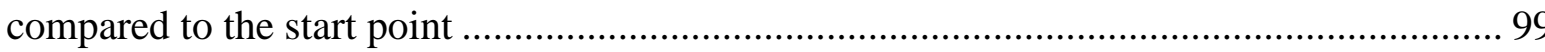




\section{List of Acronyms}

WMSDs Work-related Musculoskeletal Disorders

LMF Localized Muscle Fatigue

SEMG Surface electromyography

RMS Root Mean Square

MAV Mean Absolute Value

MnPF Mean Power Frequency

MdPF Median Power Frequency

MVC Maximum Voluntary Contraction

EMG Electromyography

PFB Power Frequency Bands

ZC Zero Crossing

PAR-Q Physical Activity Readiness Questionnaire

PB Pulling up

PD Pulling down

PL Pulling left

PR Pulling right

PU Pulling up

BLS Bureau of Labor Statistics

HSE Health and Safety Executive

EMG Electromyography

ARV Average Rectified Value

IAV Integral of Absolute Value

AAV Averaged Absolute Value

V1 first order of v-Order features

OC curves Operating Characteristics curves

ANOVA Analysis of variance

SE Standard Error

MSE Mean Square Error

PCSA Physiological Cross-Sectional Areas

CR-10 Borg's category ratio scale

$\mathrm{Hz} \quad$ Hertz

m Meter

$\mathrm{kg} \quad$ Kilogram

lb. Pound 


\section{Chapter 1. Background \& Significance}

\subsection{Background}

Localized Muscle Fatigue (LMF) has been defined as “...reduction in the maximum capacity to generate force or power output" (Vøllestad, 1997). LMF and a lack of recovery have been proposed as important mechanisms involved in the causation of Work-related Musculoskeletal Disorders (WMSDs) (Byström \& Fransson-Hall, 1994). Direct methods based on measurements of Maximum Voluntary Contraction (MVC), and indirect methods based on alterations in Electromyography (EMG) data, are the most popular LMF assessment methods among ergonomists (Ebaugh, McClure, \& Karduna, 2006a, 2006b; Iridiastadi \& Nussbaum, 2006a, 2006b; Motabar, Nimbarte, \& Raub, 2019; Sood, Nussbaum, \& Hager, 2007; Yassierli \& Nussbaum, 2008; Zhang, Li, Zhang, Ma, \& Chen, 2014). Time- and frequency-domain analyses are typically employed to assess LMF using EMG data.

During a sustained static exertion, the high frequency, fast-twitch fibers drop out, while low frequency slow-twitch fibers continue to be recruited, causing the power spectrum of the EMG data to shift towards the left (i.e., lower frequency components) (LeVeau \& Anderson, 1992). This skew in the power spectrum can be measured using a relative change in SEMG measures. Numerous studies have documented a relative change in the SEMG measures in the time and frequency domain with the development of LMF. We reviewed existing EMG-based LMF studies of the shoulder. Although multiple studies using EMG exist, we found that only a few focused on quantifying shoulder muscle fatigue using SEMG measures. Each of these studies is distinct in terms of the independent variables and conditions tested, with the only common aspect being the use of a relative change in the SEMG measures to assess fatigue. We briefly review these studies below, in chronological order. 


\subsubsection{Studies based on EMG spectral frequency:}

Chaffin (1973) compared different fatigue states and the corresponding spectral changes in the biceps muscle. For Class I fatigue, or "realization of Tightness or Slight Cramping", a 19\% increase in the low-frequency content of the EMG data was reported. This number increased to 49\% during Class IV fatigue, "Unable to sustain activity". The high-frequency content during Class I and Class IV conditions decreased by 5-9\% and 20\%, respectively. When monitoring the supraspinatus muscle during an overhead welding task, Herberts and Kadefors (1976) observed a significant decline in the high-frequency component of its EMG data. In a follow-up investigation based on a similar observation of spectral components, Herberts, Kadefors, and Broman (1980) reported LMF in shoulder muscles during overhead, shoulder-level, and waist-level work. Christensen (1986) measured EMG from the trapezius muscle of pillar drill operators during the first two hours of their workday and reported a significant reduction in Mean Power Frequency (MnPF). Jensen, Schibye, Søgaard, Simonsen, and Sjøgaard (1993) reported development of muscle fatigue in the bilateral trapezius muscles of industrial sewing-machine operators, based on changes in MnPF during the workday. Sundelin and Hagberg (1992) and Sundelin (1993) reported signs of muscle fatigue based on a decrease in MnPF during continuous standardized repetitive work, performed with or without pause activities. Takala, Lammi, Nieminen, and Viikari-Juntura (1993) measured changes in Median Power Frequency (MdPF) of shoulder muscles during arm elevation performed in the scapular plane at $60 \%$ MVC. All of the muscles measured showed a decrease in MdPF, with a decrease most apparent in the middle deltoid and upper trapezius muscles, while the serratus anterior and lower trapezius muscles showed less change. Hermans and Spaepen (1997) compared sustained and intermittent exertions of the right arm, noting a larger decrease in the MnPF of shoulder muscles during sustained exertions compared to intermittent exertions. 
For intermittent overhead exertions performed over a duration of three hours, Nussbaum (2001) found a decrease in MnPF and MdPF. Low variability was observed for MnPF during static test contractions compared to MdPF, and to MnPF in the dynamic tasks. Hummel et al. (2005) reported a decrease in MnPF during shoulder elevation endurance tasks performed at 30\% MVC. Iridiastadi and Nussbaum (2006) quantified the effect of task parameters (contraction level, duty cycle, and cycle time), finding that cycle time had a significant effect on the rates-of-change in MnPF and MdPF. Garg, Hegmann, and Kapellusch (2006) found a small decrease in the MdPF of the upper trapezius and middle deltoid muscles after 50 minutes of short-cycle overhead work. Minning, Eliot, Uhl, and Malone (2007) quantified shoulder muscle fatigue during resisted isometric shoulder elevation, with the study participants performing exertions at $60 \%$ MVC. A decrease in average MdPF was notable in the middle deltoid and upper trapezius muscles, with the serratus anterior and lower trapezius exhibiting slightly less change. In a similar study, Kai, Gotoh, Nagata, and Shiba (2012) compared the fatigability of the infraspinatus and deltoid muscles during resisted arm elevation in various postures, noting a significantly larger decrease in MnPF for the infraspinatus muscles in the sagittal plane compared to the anterior and posterior portions of the deltoid.

\subsubsection{Studies based on EMG amplitude:}

Time domain analysis based on the amplitude has also been widely used to assess muscle fatigue. Previous studies suggested that the Root Mean Square (RMS) of EMG signal increase with sustained static exertions and, therefore, can be considered as an indicator of LMF (Dickerson, Meszaros, Cudlip, Chopp-Hurley, \& Langenderfer, 2015; Marina, Torrado, Busquets, Ríos, \& Angulo-Barroso, 2013; Masuda, Masuda, Sadoyama, Mitsuharu Inaki, \& Katsuta, 1999; Nussbaum, 2001; Yung, Mathiassen, \& Wells, 2012). However, only a handful of these studies 
were focused on shoulder muscle fatigue assessment. In repetitive reaching and pointing tasks performed at shoulder height, Fuller, Lomond, Fung, and Côté (2009) and Fedorowich, Emery, Gervasi, and Côté (2013) reported that shoulder muscle fatigue was detected based on a significant increase of RMS amplitude. They also provided evidence of a good correlation between total muscle contraction and RMS amplitude. In another study, Bartuzi and Roman-Liu (2014) evaluated the effect of muscle load and fatigue on EMG signals while performing different submaximal exertions. They reported that RMS amplitude had a high sensitivity to changes in the EMG signal produced by muscle load and fatigue. Yassierli and Nussbaum (2008) evaluated different fatigue assessment methods during low to moderate isometric exertions. The authors reported an inconsistent performance for RMS amplitude as fatigue indicator compared to other fatigue assessment methods. In non-occupational studies, Balasubramanian and Jagannath (2014) and Balasubramanian, Jagannath, and Adalarasu (2014) evaluated the effect of motorcycle riding and different bicycle designs on LMF using RMS amplitude. They reported that each bicycle design showed different muscle activity, and the sport bicycle design caused higher LMF compared to other bicycle designs. In addition, the results revealed that participants developed LMF for latissimus dorsi (medial) and erector spinae muscles.

Some studies used RMS amplitude only for assessing muscle load instead of using it as an indicator of muscle fatigue. Lee, Lu, Sung, and Liao (2015) investigated the influence of workplace layout on the activity of upper limb and the development of LMF. LMF was only acknowledged when a combination of significant increase in RMS amplitude and significant decrease in MdPF was observed. Alizadehkhaiyat, Fisher, Kemp, Vishwanathan, and Frostick (2011) evaluated shoulder muscle fatigue and activation during hand gripping tasks. Even when there was a significant increase in the RMS amplitude for supraspinatus and infraspinatus muscles, 
the authors relied on MdPF as a muscle fatigue indicator to conclude that there was no sign of LMF. Ringheim, Indahl, and Roeleveld (2014) also trusted MdPF to report a lack of muscle fatigue even when there was a small increase in the RMS amplitude. In addition, they reported that RMS amplitude was influenced by gender, where male participants had higher RMS amplitude than female participants.

\subsubsection{Studies based on Power Frequency Bands (PFB) of EMG signal:}

The Power Frequency Bands (PFBs) of EMG signal were also used to measure and predict fatigue in a few studies. An increase in the power of lower PFBs and a decrease in the power of higher PFBs were observed with the development of LMF (Bosch, de Looze, \& van Dieën, 2007). Allison and Fujiwara (2002) compared changes in a lower PFBs (15-45 Hz) and a high PFB (>95 $\mathrm{Hz}$ ) with respect to changes in MdPF during sustained static exertions. They reported a high correlation between lower PFB (15-45 Hz) with MdPF. Sparto, Parnianpour, Barria, and Jagadeesh (2000) evaluated changes in signal power within specific frequency range during an isometric upper limb extension, and they reported a significant increase in PFB (13-22 Hz) and a significant decrease in MdPF with muscle fatigue. In a non-shoulder related study, Cardozo, Gonçalves, and Dolan (2011) compared different PFBs with MdPF, and reported that the lower PFB (20-50 Hz) is a good fatigue indicator for back muscles during static exertions. They observed higher sensitivity of lower PFB to MdPF. In a non-occupational study, Balasubramanian and Jagannath (2014) and Balasubramanian et al. (2014) considered that lower PFB (15-30 Hz) is a reliable fatigue indicator, and used it to evaluate the effect of motorcycle riding and different bicycle designs on LMF. On the other hand, Roman-Liu and Konarska (2009) quantified changes in PFBs in addition to other fatigue indicators such as $\mathrm{MnPF}, \mathrm{MdPF}$, and zero-crossings while performing sub-maximal isometric exertions, and they evaluated these fatigue indicators' dependencies on 
muscle force. They reported a strong dependency of MnPF, MdPF, and zero-crossings on muscle force, and that PFB (76-140 Hz) has the lowest dependency on muscle force compared to other PFBs.

\subsubsection{Studies based on Zero Crossing of EMG signal:}

Researchers and practitioners have used Zero Crossing (ZC) to evaluate LMF by simply counting the zero line crossings of the EMG signals. ZC is affected by muscle activity, therefore, high muscle activity is associated with more action potentials, which will result in more zero crossings in the EMG signals. The number of zero crossings drops with fatigue occurrence due to the reduction in muscle activity, therefore, it has been concluded that $\mathrm{ZC}$ decreases with the onset of LMF (Al-Mulla \& Sepulveda, 2010; Al-Mulla, Sepulveda, Colley, \& Kattan, 2009). Some papers have stated that ZC showed similar behavior as that of MnPF and MdPF (Cifrek, Medved, Tonković, \& Ostojić, 2009; Hägg \& Suurküla, 1991). Suurküla and Hägg (1987) evaluated shoulder muscles during sustained arm abduction for female assembly workers, and they reported a correlation between drop in ZC and neck/shoulder pain. In a non-shoulder study, Christensen, Monaco, and Fuglsang-Frederiksen (1991) evaluated maximal foot exertions to quantify changes in various electromyographic measures and reported that there were no significant differences between MnPF, MdPF, mean amplitude, and ZC. Also, they reported that the anterior tibialis muscle fatigue based on drop in ZC. Unfortunately, the use of ZC as an LMF indicator has been on decline over the years (Cifrek et al., 2009; Konrad, 2005), but to our knowledge, there is no established reason for such decline.

In summary, the studies reviewed above share the conclusion that LMF was associated with a relative change in electromyographic measures. These relative changes were with respect to initial values, or under no-fatigue conditions. Quantifying such change, however, relies on the 
assumption that the electromyographic measures without fatigue present, can serve as an appropriate reference within the joint range-of-motion and/or functional ability. This assumption is even more critical when evaluating short-term exertions performed under varying force and/or posture conditions for a region such as the shoulder, with a range of motion covering nearly $65 \%$ of a sphere. Only a few studies, though, have tested this assumption by quantifying variation of electromyographic measures. Öberg, Sandsjö, and Kadefors (1990) examined variation in the MnPF of EMG power spectrum for a non-fatigued trapezius muscle caused by exertions performed using multiple glenohumeral joint angles $\left(0^{\circ}, 30^{\circ}, 60^{\circ}, 90^{\circ}\right.$, and $\left.135^{\circ}\right)$, in different planes (sagittal and scapular), and using various hand loads (0,1, and $2 \mathrm{~kg}$ ). The largest MnPF variation, 7.8\%, was found at joint angles between $30^{\circ}-135^{\circ}$, and the authors concluded that the relative decrease in $\mathrm{MnPF}$ due to fatigue is significant if it exceeds $8 \%$ of the initial value. In a similar study, Gerdle, Eriksson, Brundin, and Edstrfim (1988) tested the effect of shoulder flexion angle and found a significant difference in the MnPF for the infraspinatus and deltoid muscles, but no significant difference for the biceps and trapezius muscles.

Öberg et al. (1990) concluding that “...there is a need for an initial calibration contraction, to which other MnPF values can be related. Changes within $\pm 8 \%$ of this initial value cannot be regarded as clinically significant." (p.368) This recommendation of $\pm 8 \%$ of initial MnPF was based on the variation of $\pm 7.8 \%$ observed in MnPF for changes in joint torque. The recommended $\pm 8 \%$ was then used in several studies to quantify shoulder muscle fatigue (Borstad, Szucs, \& Navalgund, 2009; Chopp, O’Neill, Hurley, \& Dickerson, 2010; Ebaugh et al., 2006a, 2006b; Lin, Liang, Lin, \& Hwang, 2004; Szucs, Navalgund, \& Borstad, 2009; Tsai, McClure, \& Karduna, 2003). 


\subsection{Significance}

The ability to exert forces of various magnitudes in any direction in various planes is a notable feature of the shoulder. The main shoulder joint, glenohumeral joint, has a range of motion that can cover nearly $65 \%$ of a sphere (Engin \& Chen, 1986). The infinite functional degrees of freedom of this joint allows the workers to adopt multitude of working postures while performing exertions of various magnitudes and in various directions using shoulder complex. Our understanding of how these occupationally relevant exertions can influence the variability in the electromyographic measures is limited. Previous studies on the variability of electromyographic measures were limited in terms of the number of muscles, electromyographic measures, occupationally relevant factors as Öberg et al. (1990) only studied one shoulder muscle and Gerdle et al. (1988) studied four shoulder muscles. To address this knowledge gap, the current study aims to quantify the variation in electromyographic measures in non-fatigued shoulder muscles caused by occupationally relevant exertions. Furthermore, implications of variation in the electromyographic measures for the prediction of LMF are studied based on the relationship between fatigue-induced change in the electromyographic measures and subjective discomfort ratings. This is a significant contribution as it is expected to improve SEMG based LMF quantification and prediction methods. Ergonomics researchers, as well as practitioners, need precise LMF estimation methods to curtail the incidence of shoulder WMSDs. 


\section{Chapter 2. Preliminary Study}

The preliminary study examined the variation in mean (MnPF) and median frequency (MdPF) of the EMG power spectrum in non-fatigued shoulder muscles, using exertions performed in five directions and at three force levels. Surface electromyography (SEMG) data were recorded from several major shoulder muscles. It was hypothesized that the variability of MnPF and MdPF values under non-fatigued conditions would not be affected by changes in the level or direction of force exertion.

\subsection{Participants}

A convenience sample of 10 male graduate students was used for data collection. The force levels used in this study are generally observed during heavy manual material handling activities, which are typically performed by male workers. Therefore, only male participants were recruited for data collection. The participants' mean (standard deviation) height, body mass, and age were $1.7(0.05) \mathrm{m}, 76.2(8.2) \mathrm{kg}$ and 26.9 (2.4) years, respectively. The primary inclusion criteria for this study were that the participants did not have any type of musculoskeletal, degenerative, or neurological disorders, any history of shoulder pain, or any current pain. The Physical Activity Readiness Questionnaire (PAR-Q, Canadian Society for Exercise Physiology) was used to screen participants for cardiac and other health problems (e.g., dizziness, chest pain and heart trouble). Copy of the questionnaire is included in Appendix C. All participants who met the inclusion criteria, read and signed a consent form approved by the WVU Institutional Review Board prior to their participation in the study. Copy of the consent form is included in Appendix A.

\subsection{Experimental procedure:}

Each participant performed a total of 30 randomized experimental trials using their right $\operatorname{arm}(3$ force levels $\times 5$ force directions $\times 2$ repetitions): pulling $2.26 \mathrm{~kg}(5 \mathrm{lb}), 3.40 \mathrm{~kg}(7.5 \mathrm{lb})$, 
and $4.53 \mathrm{~kg}(10 \mathrm{lb})$ to the left, right, up, down and backward. The three force levels were determined by conducting a preliminary study, as force exertion ability varied considerably between the participants, particularly in different directions. During the preliminary study, we found that a force greater than $4.53 \mathrm{~kg}$ was very difficult for some participants to pull in certain directions. We also found that forces smaller than $2.26 \mathrm{~kg}$ did not produce noticeable activation of all shoulder muscles. Thus, the three noted force levels were used in this study.

The participants performed all of the exertions in a seated posture. A wooden chair equipped with a four-point harness was used to secure participants in a standard sitting posture. Upper extremity posture was controlled so that the elbow joint was flexed $70^{\circ}-80^{\circ}$ and the glenohumeral joint was flexed $15^{\circ}-20^{\circ}$ (Figure 1). These flexion angles were with respect to the standard anatomical neutral (i.e., all joint angles were considered zero in a relaxed standing posture). Once seated, the participants were instructed to resist a pulling force created by metal weights attached to a D-handle using a rope and a pulley system. A 2-minute rest time was provided between trials.

EMG data were recorded from the shoulder muscles accessible by SEMG: supraspinatus, infraspinatus, deltoid, biceps, and triceps (long head). SEMG data for the deltoid muscle were recorded from three separate locations (middle, anterior and posterior), as these compartments of the deltoid muscle are sensitive to the direction of force exertion (Alasim, Nimbarte, \& Jaridi, 2019). Guidance from the literature was used to determine the skin locations of SEMG electrodes (Decker, Hintermeister, Faber, \& Hawkins, 1999; Hintermeister, Lange, Schultheis, Bey, \& Hawkins, 1998; Sporrong, Palmerud, Kadefors, \& Herberts, 1998; Xu, McGorry, \& Lin, 2014). Bipolar, $\mathrm{Ag} / \mathrm{AgCl}$, pre-gelled surface electrodes (Noraxon Inc., AZ, USA), with a $1 \mathrm{~cm}$ diameter and an inter-electrode distance of $2 \mathrm{~cm}$, were used for data collection. The electrodes were attached 
to pre-amplified lead wires with a band-pass of 10-1000 Hz (gain of 500), CMRR >100 dB, and input impedance $>100 \mathrm{M} \Omega$. A wireless EMG system (Telemyo $2400 \mathrm{~T}$ G2, Noraxon Inc., AZ, USA) was used for SEMG data collection at a sampling rate of $1500 \mathrm{~Hz}$. Adequate skin preparation (i.e., shaving and cleaning using 70\% rubbing alcohol) was used prior to data collection.

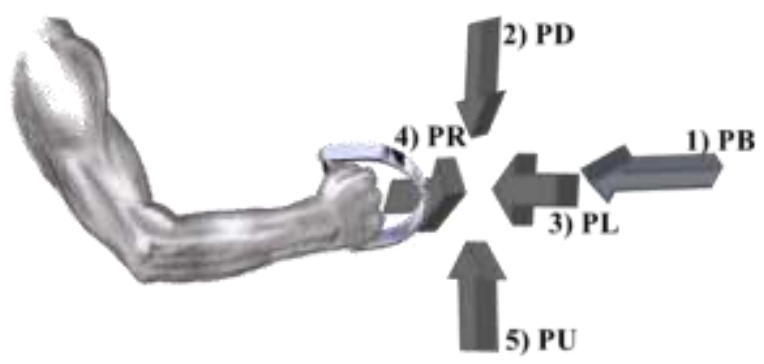

(A)

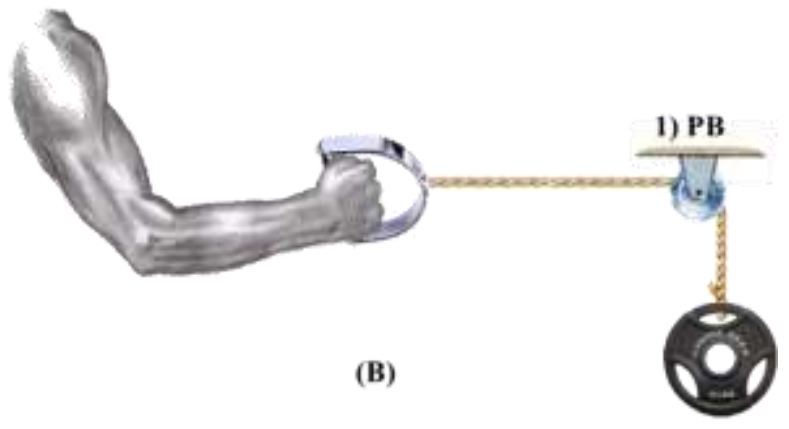

Figure 1: (A) An illustration of the experimental design: (1) pulling in a backward direction (PB), (2) pulling in a downward direction (PD), (3) pulling towards the left (PL), (4) pulling towards the right (PR), and (5) pulling in an upward direction (PU); (B) The rope and pulley system used to perform the PB pulling exertion.

\subsection{Data processing and analysis:}

For each experimental trial, EMG data recorded over a duration of 10 seconds were subjected to spectral analysis using a window size of 0.5 second. Thus, a total of $20 \mathrm{MnPF}$ and MdPF values were estimated per trial, with the $1^{\text {st }}$ and $20^{\text {th }}$ values discarded from further analysis. MnPF and MdPF data for each participant were normalized with respect to the mean of all trials. Linear regression analysis was performed by regressing normalized MnPF and MdPF data with respect to force level. Separate regression models were used for each force direction (i.e., for a given muscle and spectral measure, there were five different regression models, one per direction). Student's $t$-tests were used to test hypotheses of zero slopes, with statistical significance set as $p \leq$ 0.05. Based on the previous work by Öberg et al. $(1990,1991)$, the variability in MnPF and MdPF 
was estimated by using the confidence intervals of residual error $( \pm 2 \mathrm{SE})$. Statistical analyses were performed using Minitab ${ }^{\mathrm{TM}}$ (v17, Minitab Inc., PA, USA).

\subsection{Results:}

\subsubsection{Pull back direction:}

MnPF had a minor negative relationship with force level, for all muscles except for the supraspinatus, anterior deltoid, and biceps. Regression coefficients were significantly non-zero for the supraspinatus, anterior deltoid, and triceps. The biceps showed the largest variation in MnPF at $4.2 \%$, followed by the middle and anterior deltoid (3.9\%) (Figure 4). Variations for the other muscles ranged from $1.8 \%$ to $3.7 \%$ (Table 1 and Figure 2). MdPF had slightly positive relationships with force level for all muscles. Regression coefficients were significantly non-zero only for the infraspinatus, anterior deltoid, and triceps muscles. The biceps showed the largest variation in MdPF at 5.1\%, followed by the anterior deltoid (4.4\%) and posterior deltoid (4.1\%) (Figure 4). Variation for all other muscles ranged from $2.1 \%$ to $4.0 \%$ (Table 1 and Figure 3).

\subsubsection{Pull down direction:}

MnPF had a minor positive relationship with force level, for all muscles except for the infraspinatus, posterior deltoid, and biceps. Regression coefficients were significantly non-zero for all muscles except for the supraspinatus and middle deltoid. The biceps showed the largest variation in $\mathrm{MnPF}$ at 4.4\%, followed by the anterior deltoid (3.6\%) (Figure 4). Variation for the other muscles ranged from $1.9 \%$ to $3.3 \%$ (Table (2) and Figure (2)). MdPF had a slightly positive relationship with force level for all muscles. Regression coefficients were significantly non-zero for all muscles except for the posterior deltoid. The biceps showed the largest variation in MdPF at $4.4 \%$, followed by the anterior deltoid (4.0\%) (Figure 4). Variation for the other muscles ranged from $2.1 \%$ to $3.4 \%$ (Table (2) and Figure (3)). 


\subsubsection{Pull left direction:}

MnPF had a minor negative relationship with force level, for all muscles except for the supraspinatus and infraspinatus. Regression coefficients were significantly non-zero for all muscles except for the biceps. The posterior deltoid showed the largest variation in MnPF at 5.2\%, followed by the middle deltoid (4.9\%) (Figure 4). Variation for the other muscles ranged from $1.6 \%$ to $4.4 \%$ (Table (3) and Figure (2)). MdPF had a slightly negative relationship with force level for all muscles except for the supraspinatus, infraspinatus, and triceps. Regression coefficients were significantly non-zero for all muscles except for the biceps and triceps. The middle and posterior deltoid showed the largest variation in MdPF at $6.0 \%$, followed by the infraspinatus (5.9\%) (Figure 4). Variation for the other muscles ranged from $1.8 \%$ to $4.2 \%$ (Table (3) and Figure (3)).

\subsubsection{Pull right direction:}

MnPF had a minor negative relationship with force level, for all muscles except for the posterior deltoid. Regression coefficients were significantly non-zero for all muscles except for the supraspinatus, middle deltoid, and posterior deltoid. The posterior deltoid showed the largest variation in $\mathrm{MnPF}$ at $4.6 \%$ (Figure 4). Variation for the other muscles ranged from $1.6 \%$ to $2.8 \%$ (Table (4) and Figure (2)). MdPF had a slightly positive relationship with force level for all muscles except for the infraspinatus and biceps. Regression coefficients were significantly nonzero only for the infraspinatus and middle deltoid muscles. The posterior deltoid showed the largest variation in MdPF at $5.8 \%$ (Figure 4). Variation for all other muscles ranged from $2.2 \%$ to $3.3 \%$ (Table (4) and Figure (3)).

\subsubsection{Pull up direction:}


MnPF had a minor negative relationship with force level, for all muscles except for the supraspinatus, middle deltoid, and posterior deltoid. Regression coefficients were significantly non-zero only for the anterior deltoid, and triceps muscles. The middle deltoid showed the largest variation in $\mathrm{MnPF}$ at 3.3\%, followed by the posterior deltoid (2.9\%) (Figure 4). Variation for the other muscles ranged from $1.8 \%$ to $2.7 \%$ (Table (5) and Figure (2)). MdPF had a slightly positive relationship with force level for all muscles except for the anterior deltoid. Regression coefficients were significantly non-zero for all muscles except for the supraspinatus, posterior deltoid, and biceps. The anterior deltoid showed the largest variation in MdPF at 3.7\%, followed by the middle and posterior deltoid (3.6\%) (Figure 4). Variation for the other muscles ranged from $2.3 \%$ to $2.5 \%$ (Table (5) and Figure (3)). 
Table 1: The influence of force level in the pull back direction on normalized MnPF and MdPF. Statistically significant $p$-values are highlighted in bold font.

\begin{tabular}{|c|c|c|c|c|c|c|c|c|c|}
\hline Muscle & $\begin{array}{l}\text { Force } \\
\text { level (kg) }\end{array}$ & MnPF & $\begin{array}{l}\text { Regression } \\
\text { coefficient }\end{array}$ & $\begin{array}{l}t \text {-test } \\
p \text {-value }\end{array}$ & $\begin{array}{l}\text { Variation } \\
(\%)\end{array}$ & MdPF & $\begin{array}{l}\text { Regression } \\
\text { coefficient }\end{array}$ & $\begin{array}{l}t \text {-test } \\
p \text {-value }\end{array}$ & $\begin{array}{l}\text { Variation } \\
(\%)\end{array}$ \\
\hline \multirow{3}{*}{ Supraspinatus } & 2.26 & 0.93236 & \multirow{3}{*}{+0.00507} & \multirow{3}{*}{0.006} & \multirow{3}{*}{ \pm 1.8} & 0.97063 & \multirow{3}{*}{+0.00221} & \multirow{3}{*}{0.293} & \multirow{3}{*}{ \pm 2.1} \\
\hline & 3.4 & 0.96388 & & & & 0.98596 & & & \\
\hline & 4.5 & 0.9577 & & & & 0.98167 & & & \\
\hline \multirow{3}{*}{ Infraspinatus } & 2.26 & 0.86238 & \multirow{3}{*}{-0.00436} & \multirow{3}{*}{0.076} & \multirow{3}{*}{ \pm 2.4} & 0.7949 & \multirow{3}{*}{+0.01105} & \multirow{3}{*}{$\leq 0.001$} & \multirow{3}{*}{ \pm 2.8} \\
\hline & 3.4 & 0.8579 & & & & 0.802 & & & \\
\hline & 4.5 & 0.84058 & & & & 0.8501 & & & \\
\hline \multirow{3}{*}{$\begin{array}{l}\text { Middle } \\
\text { deltoid }\end{array}$} & 2.26 & 0.92929 & \multirow{3}{*}{-0.00450} & \multirow{3}{*}{0.256} & \multirow{3}{*}{ \pm 3.9} & 0.8087 & \multirow{3}{*}{+0.00711} & \multirow{3}{*}{0.080} & \multirow{3}{*}{ \pm 4.0} \\
\hline & 3.4 & 1.0183 & & & & 0.9092 & & & \\
\hline & 4.5 & 0.9068 & & & & 0.8443 & & & \\
\hline \multirow{3}{*}{$\begin{array}{l}\text { Anterior } \\
\text { deltoid }\end{array}$} & 2.26 & 0.8459 & \multirow{3}{*}{+0.03239} & \multirow{3}{*}{$\leq 0.001$} & \multirow{3}{*}{ \pm 3.9} & 0.6093 & \multirow{3}{*}{+0.05034} & \multirow{3}{*}{$\leq 0.001$} & \multirow{3}{*}{ \pm 4.4} \\
\hline & 3.4 & 0.8192 & & & & 0.6173 & & & \\
\hline & 4.5 & 1.0079 & & & & 0.861 & & & \\
\hline \multirow{4}{*}{$\begin{array}{l}\text { Posterior } \\
\text { deltoid }\end{array}$} & 2.26 & 0.99803 & \multirow{3}{*}{-0.00640} & \multirow{3}{*}{0.053} & \multirow{3}{*}{ \pm 3.3} & 0.9481 & \multirow{3}{*}{+0.00042} & & \\
\hline & 3.4 & 1.0395 & & & & 1.0266 & & 0.919 & \pm 4.1 \\
\hline & 4.5 & 0.96601 & & & & 0.95018 & & & \\
\hline & 2.26 & 0.9464 & & & & 0.9278 & & & \\
\hline Biceps & 3.4 & 0.9944 & +0.00514 & 0.231 & \pm 4.2 & 0.9926 & +0.00467 & 0.364 & \pm 5.1 \\
\hline & 4.5 & 0.97208 & & & & 0.9511 & & & \\
\hline & 2.26 & 0.9943 & & & & 0.8577 & & & \\
\hline Triceps & 3.4 & 0.9521 & -0.00757 & 0.042 & \pm 3.7 & 0.8655 & +0.01384 & $\leq 0.001$ & \pm 3.6 \\
\hline & 4.5 & 0.9565 & & & & 0.9269 & & & \\
\hline
\end{tabular}


Table 2: The influence of force level in the pull down direction on normalized MnPF and MdPF. Statistically significant $p$-values are highlighted in bold font.

\begin{tabular}{|c|c|c|c|c|c|c|c|c|c|}
\hline Muscle & $\begin{array}{l}\text { Force } \\
\text { level (kg) }\end{array}$ & MnPF & $\begin{array}{l}\text { Regression } \\
\text { coefficient }\end{array}$ & $\begin{array}{l}t \text {-test } \\
p \text {-value }\end{array}$ & $\begin{array}{l}\text { Variation } \\
(\%)\end{array}$ & MdPF & $\begin{array}{l}\text { Regression } \\
\text { coefficient }\end{array}$ & $\begin{array}{l}t \text {-test } \\
p \text {-value }\end{array}$ & $\begin{array}{l}\text { Variation } \\
(\%)\end{array}$ \\
\hline \multirow{3}{*}{ Supraspinatus } & 2.26 & 0.9351 & \multirow{3}{*}{+0.00395} & \multirow{3}{*}{0.239} & \multirow{3}{*}{ \pm 3.3} & 0.8362 & \multirow{3}{*}{+0.01703} & \multirow{3}{*}{$\leq 0.001$} & \multirow{3}{*}{ \pm 3.4} \\
\hline & 3.4 & 0.98376 & & & & 0.9252 & & & \\
\hline & 4.5 & 0.95487 & & & & 0.92137 & & & \\
\hline \multirow{3}{*}{ Infraspinatus } & 2.26 & 0.8448 & \multirow{3}{*}{-0.00914} & \multirow{3}{*}{0.002} & \multirow{3}{*}{ \pm 2.9} & 0.7297 & \multirow{3}{*}{+0.01386} & \multirow{3}{*}{$\leq 0.001$} & \multirow{3}{*}{ \pm 3.4} \\
\hline & 3.4 & 0.77042 & & & & 0.7483 & & & \\
\hline & 4.5 & 0.79908 & & & & 0.79903 & & & \\
\hline \multirow{3}{*}{$\begin{array}{l}\text { Middle } \\
\text { deltoid }\end{array}$} & 2.26 & 0.84924 & \multirow{3}{*}{+0.00270} & \multirow{3}{*}{0.223} & \multirow{3}{*}{ \pm 2.2} & 0.78961 & \multirow{3}{*}{+0.02038} & \multirow{3}{*}{$\leq 0.001$} & \multirow{3}{*}{ \pm 2.6} \\
\hline & 3.4 & 0.84075 & & & & 0.83715 & & & \\
\hline & 4.5 & 0.86277 & & & & 0.89151 & & & \\
\hline \multirow{3}{*}{$\begin{array}{l}\text { Anterior } \\
\text { deltoid }\end{array}$} & 2.26 & 0.8659 & \multirow{3}{*}{+0.02354} & \multirow{3}{*}{$\leq 0.001$} & \multirow{3}{*}{ \pm 3.6} & 0.713 & \multirow{3}{*}{+0.05432} & \multirow{3}{*}{$\leq 0.001$} & \multirow{3}{*}{ \pm 4.0} \\
\hline & 3.4 & 0.8782 & & & & 0.8164 & & & \\
\hline & 4.5 & 0.9836 & & & & 0.9846 & & & \\
\hline \multirow{4}{*}{$\begin{array}{l}\text { Posterior } \\
\text { deltoid }\end{array}$} & 2.26 & 0.94959 & \multirow{3}{*}{-0.01093} & \multirow{3}{*}{$\leq 0.001$} & \multirow{3}{*}{ \pm 1.9} & 0.92978 & \multirow{3}{*}{+0.00190} & & \\
\hline & 3.4 & 0.93463 & & & & 0.96114 & & 0.398 & \pm 2.2 \\
\hline & 4.5 & 0.89496 & & & & 0.93927 & & & \\
\hline & 2.26 & 1.1989 & & & & 0.9904 & & & \\
\hline Biceps & 3.4 & 1.1318 & -0.01146 & 0.010 & \pm 4.4 & 0.9878 & +0.01063 & 0.016 & \pm 4.4 \\
\hline & 4.5 & 1.1416 & & & & 1.0436 & & & \\
\hline & 2.26 & 1.0767 & & & & 1.1141 & & & \\
\hline Triceps & 3.4 & 1.1185 & +0.00438 & 0.022 & \pm 1.9 & 1.1711 & +0.01491 & $\leq 0.001$ & \pm 2.1 \\
\hline & 4.5 & 1.0986 & & & & 1.1886 & & & \\
\hline
\end{tabular}


Table 3: The influence of force level in the pull left direction on normalized MnPF and MdPF. Statistically significant $p$-values are highlighted in bold font.

\begin{tabular}{|c|c|c|c|c|c|c|c|c|c|}
\hline Muscle & $\begin{array}{l}\text { Force } \\
\text { level (kg) }\end{array}$ & MnPF & $\begin{array}{l}\text { Regression } \\
\text { coefficient }\end{array}$ & $\begin{array}{l}t \text {-test } \\
p \text {-value }\end{array}$ & $\begin{array}{l}\text { Variation } \\
(\%)\end{array}$ & MdPF & $\begin{array}{l}\text { Regression } \\
\text { coefficient }\end{array}$ & $\begin{array}{l}t \text {-test } \\
p \text {-value }\end{array}$ & $\begin{array}{l}\text { Variation } \\
(\%)\end{array}$ \\
\hline \multirow{3}{*}{ Supraspinatus } & 2.26 & 1.013 & \multirow{3}{*}{+0.02678} & \multirow{3}{*}{$\leq 0.001$} & \multirow{3}{*}{ \pm 4.4} & 0.8061 & \multirow{3}{*}{+0.04395} & \multirow{3}{*}{$\leq \mathbf{0 . 0 0 1}$} & \multirow{3}{*}{ \pm 4.2} \\
\hline & 3.4 & 1.129 & & & & 0.928 & & & \\
\hline & 4.5 & 1.1469 & & & & 1.0259 & & & \\
\hline \multirow{3}{*}{ Infraspinatus } & 2.26 & 0.9923 & \multirow{3}{*}{+0.03628} & \multirow{3}{*}{$\leq 0.001$} & \multirow{3}{*}{ \pm 4.2} & 0.8131 & \multirow{3}{*}{+0.06603} & \multirow{3}{*}{$\leq 0.001$} & \multirow{3}{*}{ \pm 5.9} \\
\hline & 3.4 & 1.1077 & & & & 1.0234 & & & \\
\hline & 4.5 & 1.1737 & & & & 1.1433 & & & \\
\hline \multirow{3}{*}{$\begin{array}{l}\text { Middle } \\
\text { deltoid }\end{array}$} & 2.26 & 1.1918 & \multirow{3}{*}{-0.04748} & \multirow{3}{*}{$\leq 0.001$} & \multirow{3}{*}{ \pm 4.9} & 1.1177 & \multirow{3}{*}{-0.04695} & \multirow{3}{*}{$\leq 0.001$} & \multirow{3}{*}{ \pm 6.0} \\
\hline & 3.4 & 1.0264 & & & & 0.9604 & & & \\
\hline & 4.5 & 0.9543 & & & & 0.883 & & & \\
\hline \multirow{3}{*}{$\begin{array}{l}\text { Anterior } \\
\text { deltoid }\end{array}$} & 2.26 & 1.0338 & \multirow{3}{*}{-0.01907} & \multirow{3}{*}{$\leq 0.001$} & \multirow{3}{*}{ \pm 2.5} & 1.0489 & \multirow{3}{*}{-0.01322} & \multirow{3}{*}{$\leq 0.001$} & \multirow{3}{*}{ \pm 3.8} \\
\hline & 3.4 & 0.9719 & & & & 0.9747 & & & \\
\hline & 4.5 & 0.93843 & & & & 0.9828 & & & \\
\hline \multirow{4}{*}{$\begin{array}{l}\text { Posterior } \\
\text { deltoid }\end{array}$} & 2.26 & 1.1261 & \multirow{3}{*}{-0.03775} & \multirow{3}{*}{$\leq 0.001$} & \multirow{3}{*}{ \pm 5.2} & 1.008 & \multirow{3}{*}{-0.03451} & & \\
\hline & 3.4 & 0.9787 & & & & 0.8719 & & $\leq \mathbf{0 . 0 0 1}$ & \pm 6.0 \\
\hline & 4.5 & 0.9373 & & & & 0.8354 & & & \\
\hline & 2.26 & 0.90746 & & & & 0.97748 & & & \\
\hline Biceps & 3.4 & 0.89171 & -0.00093 & 0.563 & \pm 1.6 & 0.94644 & -0.00235 & 0.210 & \pm 1.8 \\
\hline & 4.5 & 0.90279 & & & & 0.96573 & & & \\
\hline & 2.26 & 0.9386 & & & & 0.86949 & & & \\
\hline Triceps & 3.4 & 0.89532 & -0.01299 & $\leq 0.001$ & \pm 2.4 & 0.85561 & +0.00249 & 0.300 & \pm 2.4 \\
\hline & 4.5 & 0.87362 & & & & 0.88193 & & & \\
\hline
\end{tabular}


Table 4: The influence of force level in the pull right direction on normalized MnPF and MdPF. Statistically significant $p$-values are highlighted in bold font.

\begin{tabular}{|c|c|c|c|c|c|c|c|c|c|}
\hline Muscle & $\begin{array}{l}\text { Force } \\
\text { level (kg) }\end{array}$ & MnPF & $\begin{array}{l}\text { Regression } \\
\text { coefficient }\end{array}$ & $\begin{array}{l}t \text {-test } \\
p \text {-value }\end{array}$ & $\begin{array}{l}\text { Variation } \\
(\%)\end{array}$ & MdPF & $\begin{array}{l}\text { Regression } \\
\text { coefficient }\end{array}$ & $\begin{array}{l}t \text {-test } \\
p \text {-value }\end{array}$ & $\begin{array}{l}\text { Variation } \\
(\%)\end{array}$ \\
\hline \multirow{3}{*}{ Supraspinatus } & 2.26 & 0.97675 & \multirow{3}{*}{-0.00306} & \multirow{3}{*}{0.052} & \multirow{3}{*}{ \pm 1.6} & 1.0623 & \multirow{3}{*}{+0.00167} & \multirow{3}{*}{0.463} & \multirow{3}{*}{ \pm 2.2} \\
\hline & 3.4 & 0.96816 & & & & 1.0456 & & & \\
\hline & 4.5 & 0.96147 & & & & 1.0706 & & & \\
\hline \multirow{3}{*}{ Infraspinatus } & 2.26 & 1.1312 & \multirow{3}{*}{-0.01847} & \multirow{3}{*}{$\leq \mathbf{0 . 0 0 1}$} & \multirow{3}{*}{ \pm 2.0} & 1.1915 & \multirow{3}{*}{-0.01448} & \multirow{3}{*}{$\leq 0.001$} & \multirow{3}{*}{ \pm 2.7} \\
\hline & 3.4 & 1.0657 & & & & 1.1143 & & & \\
\hline & 4.5 & 1.0388 & & & & 1.119 & & & \\
\hline \multirow{3}{*}{$\begin{array}{l}\text { Middle } \\
\text { deltoid }\end{array}$} & 2.26 & 1.0355 & \multirow{3}{*}{-0.00353} & \multirow{3}{*}{0.198} & \multirow{3}{*}{ \pm 2.7} & 1.0919 & \multirow{3}{*}{+0.00724} & \multirow{3}{*}{0.028} & \multirow{3}{*}{ \pm 3.3} \\
\hline & 3.4 & 1.0743 & & & & 1.1631 & & & \\
\hline & 4.5 & 1.0179 & & & & 1.1281 & & & \\
\hline \multirow{3}{*}{$\begin{array}{l}\text { Anterior } \\
\text { deltoid }\end{array}$} & 2.26 & 1.0358 & \multirow{3}{*}{-0.00992} & \multirow{3}{*}{$\leq 0.001$} & \multirow{3}{*}{ \pm 2.0} & 1.1118 & \multirow{3}{*}{+0.00138} & \multirow{3}{*}{0.627} & \multirow{3}{*}{ \pm 2.8} \\
\hline & 3.4 & 0.99957 & & & & 1.086 & & & \\
\hline & 4.5 & 0.98621 & & & & 1.1187 & & & \\
\hline \multirow{4}{*}{$\begin{array}{l}\text { Posterior } \\
\text { deltoid }\end{array}$} & 2.26 & 1.0213 & \multirow{3}{*}{+0.00057} & \multirow{3}{*}{0.903} & \multirow{3}{*}{ \pm 4.6} & 1.0677 & \multirow{3}{*}{+0.01047} & & \\
\hline & 3.4 & 1.1149 & & & & 1.2161 & & 0.073 & \pm 5.8 \\
\hline & 4.5 & 1.0241 & & & & 1.12 & & & \\
\hline & 2.26 & 0.9848 & & & & 0.9783 & & & \\
\hline Biceps & 3.4 & 0.95319 & -0.00972 & $\leq 0.001$ & \pm 2.7 & 0.948 & -0.00001 & 0.997 & \pm 2.7 \\
\hline & 4.5 & 0.9362 & & & & 0.97821 & & & \\
\hline & 2.26 & 1.1306 & & & & 1.1184 & & & \\
\hline Triceps & 3.4 & 1.1217 & -0.01282 & $\leq 0.001$ & \pm 2.8 & 1.129 & +0.00318 & 0.258 & \pm 2.8 \\
\hline & 4.5 & 1.0665 & & & & 1.1344 & & & \\
\hline
\end{tabular}


Table 5: The influence of force level in the pull up direction on normalized MnPF and MdPF. Statistically significant $p$-values are highlighted in bold font.

\begin{tabular}{|c|c|c|c|c|c|c|c|c|c|}
\hline Muscle & $\begin{array}{l}\text { Force } \\
\text { level (kg) }\end{array}$ & MnPF & $\begin{array}{l}\text { Regression } \\
\text { coefficient }\end{array}$ & $\begin{array}{l}t \text {-test } \\
p \text {-value }\end{array}$ & $\begin{array}{l}\text { Variation } \\
(\%)\end{array}$ & MdPF & $\begin{array}{l}\text { Regression } \\
\text { coefficient }\end{array}$ & $\begin{array}{l}t \text {-test } \\
p \text {-value }\end{array}$ & $\begin{array}{l}\text { Variation } \\
(\%)\end{array}$ \\
\hline \multirow{3}{*}{ Supraspinatus } & 2.26 & 1.0133 & \multirow{3}{*}{+0.00135} & \multirow{3}{*}{0.462} & \multirow{3}{*}{ \pm 1.8} & 1.136 & \multirow{3}{*}{+0.00015} & \multirow{3}{*}{0.952} & \multirow{3}{*}{ \pm 2.4} \\
\hline & 3.4 & 1.0436 & & & & 1.1678 & & & \\
\hline & 4.5 & 1.0201 & & & & 1.1367 & & & \\
\hline \multirow{3}{*}{ Infraspinatus } & 2.26 & 1.1711 & \multirow{3}{*}{-0.00197} & \multirow{3}{*}{0.328} & \multirow{3}{*}{ \pm 2.0} & 1.2688 & \multirow{3}{*}{+0.00521} & \multirow{3}{*}{0.042} & \multirow{3}{*}{ \pm 2.5} \\
\hline & 3.4 & 1.1832 & & & & 1.3078 & & & \\
\hline & 4.5 & 1.1613 & & & & 1.2948 & & & \\
\hline \multirow{3}{*}{$\begin{array}{l}\text { Middle } \\
\text { deltoid }\end{array}$} & 2.26 & 1.0833 & \multirow{3}{*}{+0.00505} & \multirow{3}{*}{0.132} & \multirow{3}{*}{ \pm 3.3} & 1.1703 & \multirow{3}{*}{+0.00729} & \multirow{3}{*}{0.048} & \multirow{3}{*}{ \pm 3.6} \\
\hline & 3.4 & 1.101 & & & & 1.1983 & & & \\
\hline & 4.5 & 1.1085 & & & & 1.2067 & & & \\
\hline \multirow{3}{*}{$\begin{array}{l}\text { Anterior } \\
\text { deltoid }\end{array}$} & 2.26 & 1.2286 & \multirow{3}{*}{-0.00537} & \multirow{3}{*}{0.046} & \multirow{3}{*}{ \pm 2.7} & 1.391 & \multirow{3}{*}{-0.00803} & \multirow{3}{*}{$\mathbf{0 . 0 3 0}$} & \multirow{3}{*}{ \pm 3.7} \\
\hline & 3.4 & 1.2033 & & & & 1.3338 & & & \\
\hline & 4.5 & 1.2017 & & & & 1.3509 & & & \\
\hline \multirow{3}{*}{$\begin{array}{l}\text { Posterior } \\
\text { deltoid }\end{array}$} & 2.26 & 0.9903 & \multirow{3}{*}{+0.00144} & \multirow{3}{*}{0.626} & \multirow{3}{*}{ \pm 2.9} & 1.0105 & \multirow{3}{*}{+0.00546} & & \\
\hline & 3.4 & 1.0272 & & & & 1.0775 & & 0.132 & \pm 3.6 \\
\hline & 4.5 & 0.99745 & & & & 1.0378 & & & \\
\hline & 2.26 & 1.0185 & & & & 1.0967 & & & \\
\hline Biceps & 3.4 & 1.0188 & -0.00237 & 0.224 & \pm 1.9 & 1.1166 & +0.00185 & 0.470 & \pm 2.5 \\
\hline & 4.5 & 1.0067 & & & & 1.1059 & & & \\
\hline & 2.26 & 0.93497 & & & & 0.92229 & & & \\
\hline Triceps & 3.4 & 0.93588 & -0.00578 & 0.002 & \pm 1.8 & 0.98553 & +0.01144 & $\leq \mathbf{0 . 0 0 1}$ & \pm 2.3 \\
\hline & 4.5 & 0.90608 & & & & 0.97948 & & & \\
\hline
\end{tabular}


PB
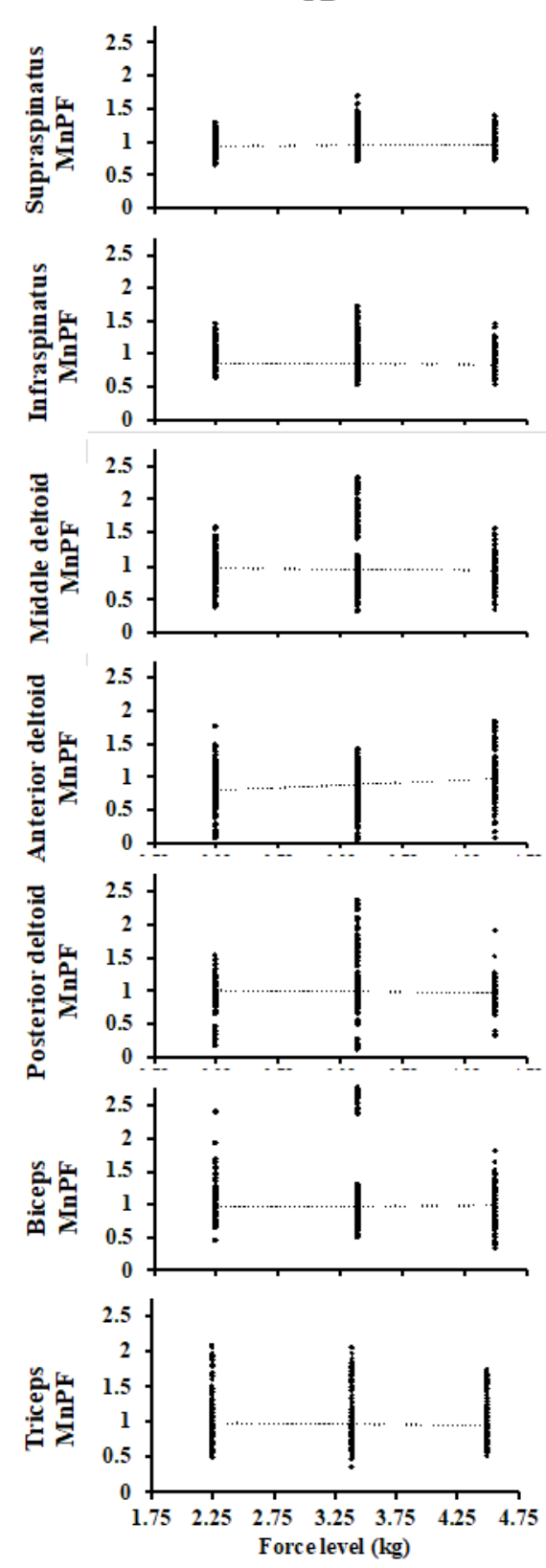

PD
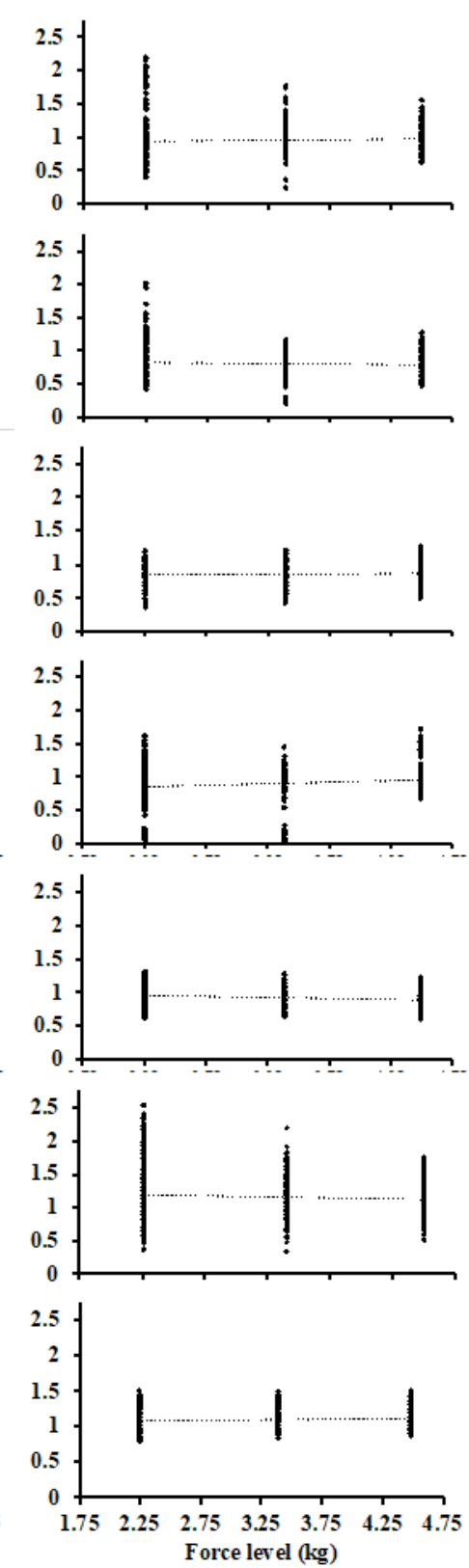

PL
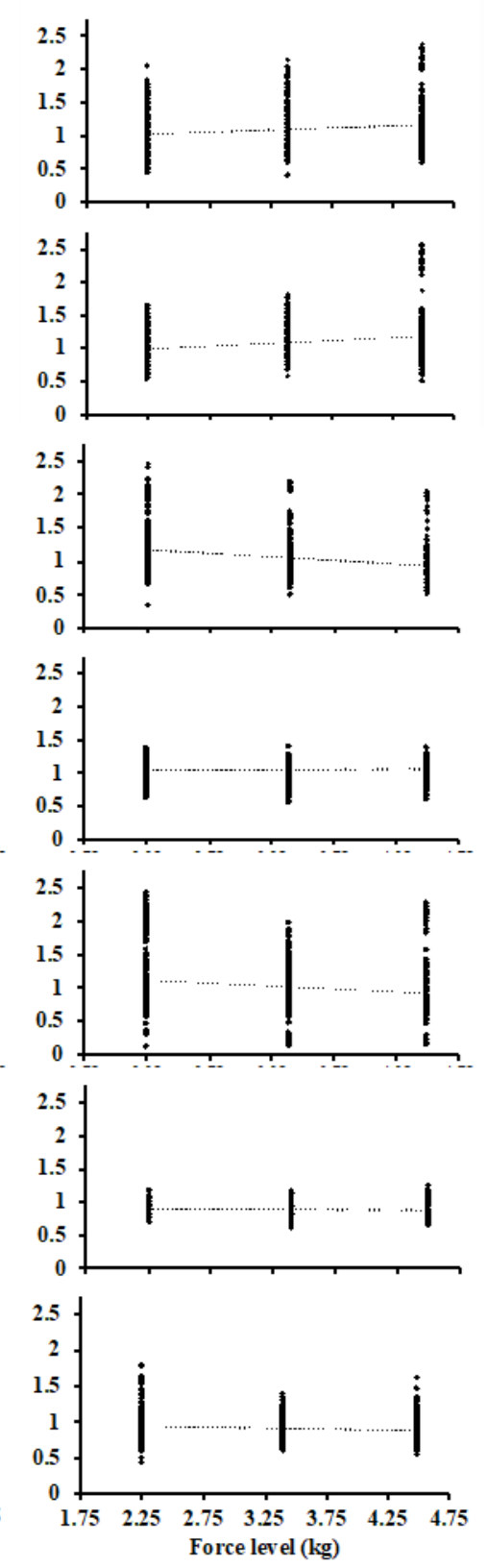

PR
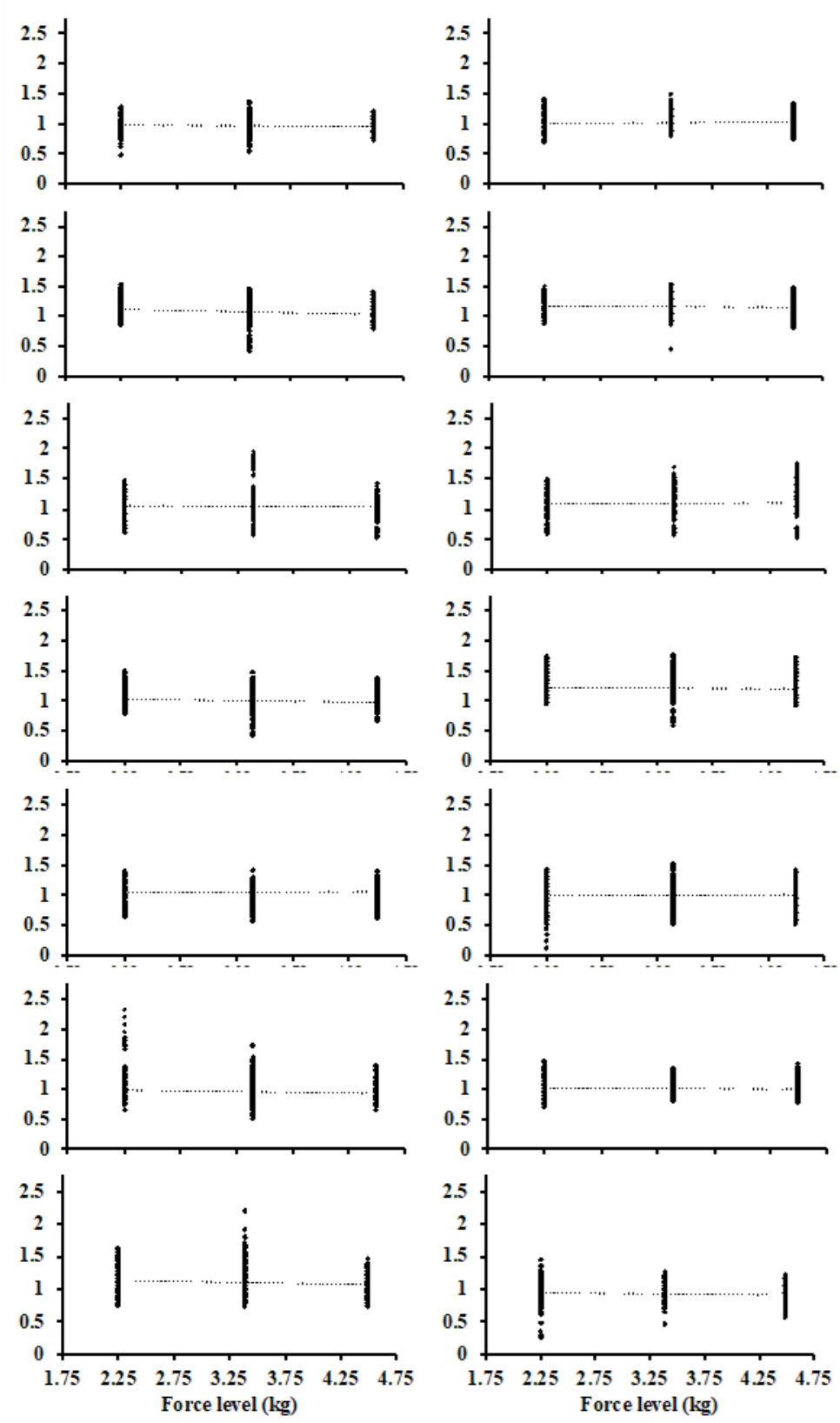

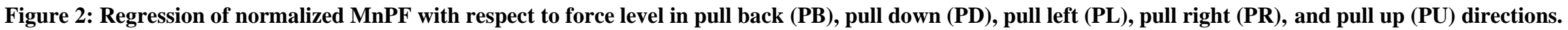



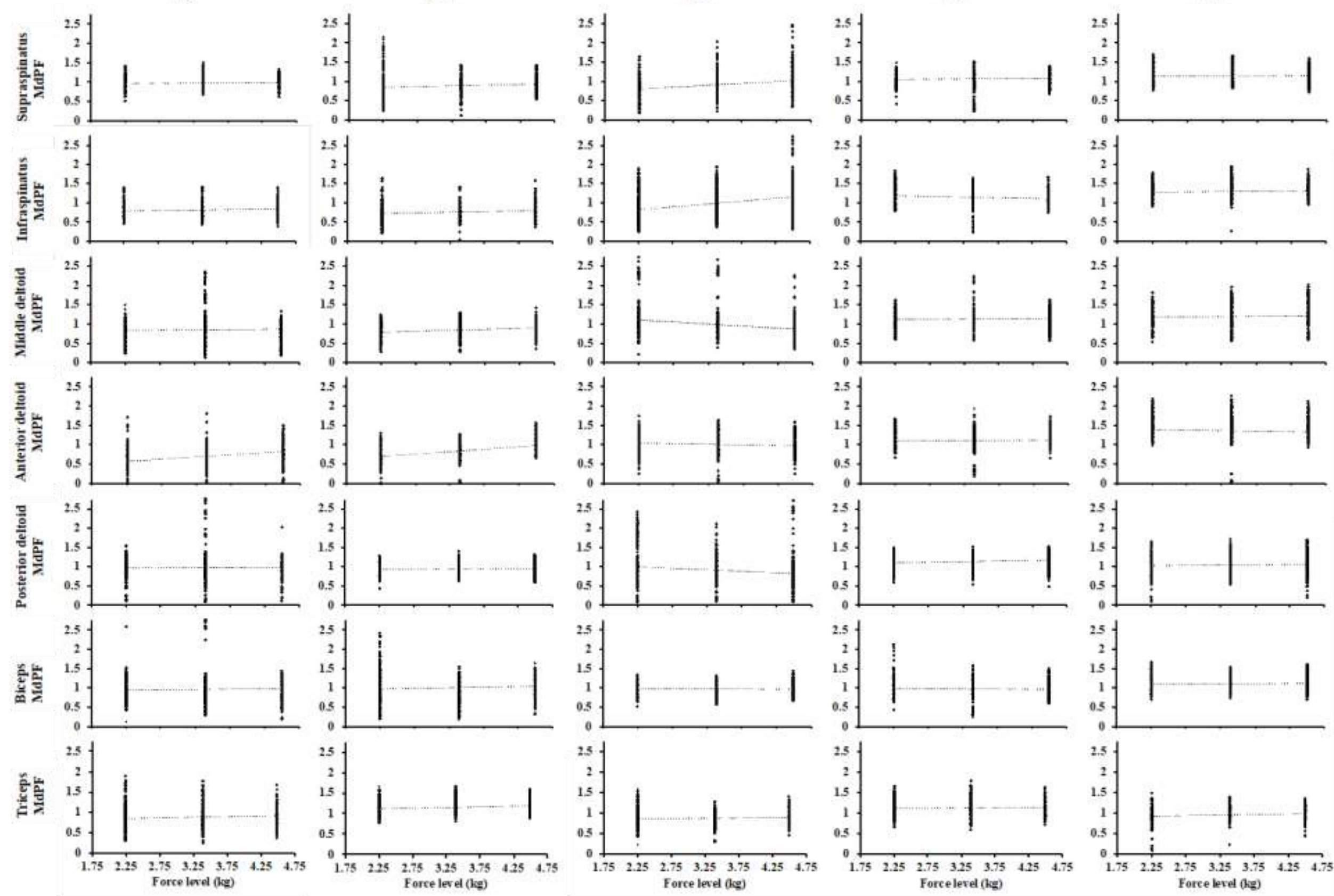

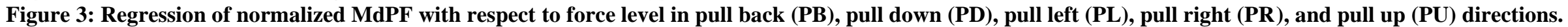



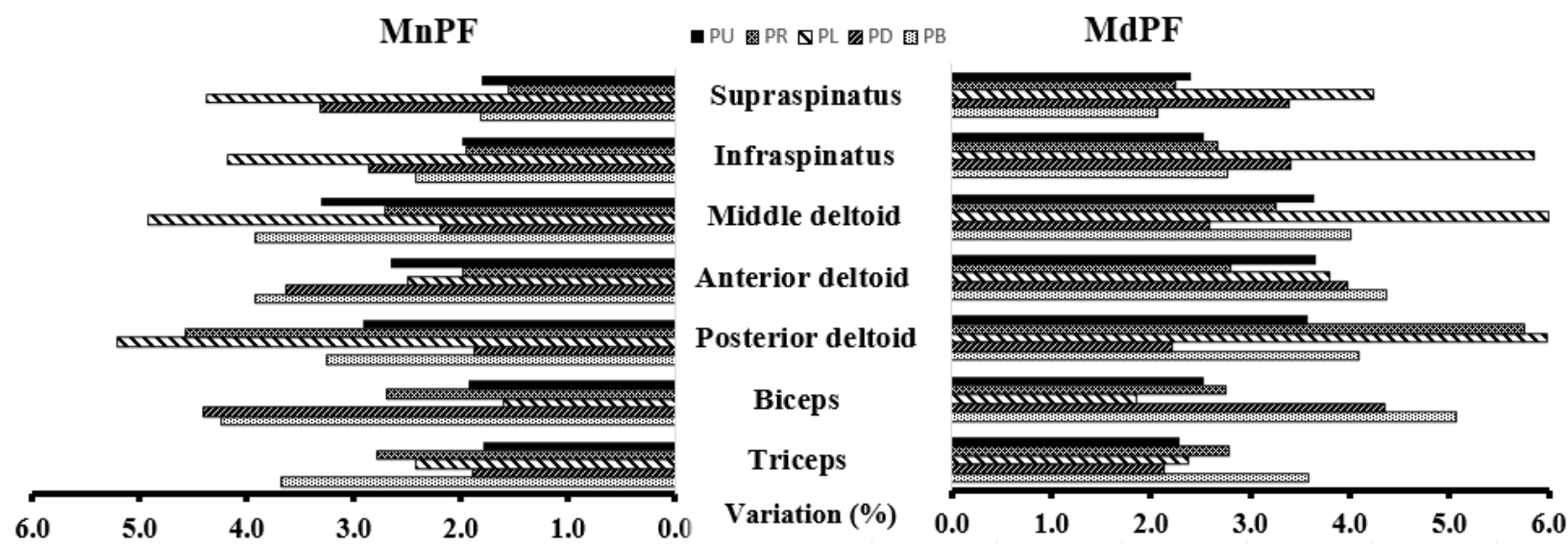

Figure 4: Comparison of variations in MnPF and MdPF for each shoulder muscle in the different pull directions.

\subsection{Discussion and conclusion}

The results of this study indicate that MnPF and MdPF values can change/vary due to factors other than muscle fatigue. Ranges of variability for MnPF and MdPF were 1.6 to 5.2\% and 1.8 to $6.0 \%$, respectively. Changes in the MnPF and MdPF with respect to increases in force level were mixed: a decreasing trend was observed in $62 \%$ of the cases for MnPF, and an increasing trend in $77 \%$ of the cases for MdPF. An increase in spectral measures with an increase in force level is likely due to the expansion of the EMG frequency spectrum caused by the recruitment of additional motor units and muscle fibers. However, the inconsistent trends in spectral measures with an increase in the force level is not a new result. In a review presented by Roman-Liu (2016), earlier studies have reported no change, an increase, or a decrease in MnPF and MdPF values with an increase in forces (as a \%MVC level). The highest values of MdPF were reported to be at 50$80 \%$ MVC, whereas the highest values of MnPF were at 40-80\% MVC, followed by a plateau or even decreasing tendencies depending on the muscle and experimental conditions. In our study, force levels were not controlled using individualized \%MVC values, but were maintained at fixed 
levels. The 3.4, $4.53 \mathrm{~kg}$ conditions used here may have activated a few muscles in the \%MVC range mentioned above, but not to the same \%MVC levels for all participants.

MnPF values were slightly lower than MdPF values, but overall similar variabilities were observed for MnPF ( 2 to 5\%) and MdPF ( 2 to 6\%) values under no-fatigue condition. The maximum differences of $1.7 \%$ and $1.3 \%$ were observed for the infraspinatus and anterior deltoid muscles, respectively. A few previous studies have reported lower variability for MnPF compared with MdPF post-fatigue. Nussbaum (2001) found that variability was low for MnPF, slightly higher for MdPF, and the highest for RMS amplitude when expressed as a percent of initial value during a combination of static and dynamic exertions performed over a period of three hours. Other studies also found lower variability in MnPF compared to MdPF, post-fatigue (Bartuzi and Roman-Liu, 2014; Van Dieen and Vrielink, 1996). These studies did not provide physiological explanations for lower variability in MnPF values, but recommended MnPF over MdPF due to its high sensitivity to fatigue-related changes.

As discussed previously, several studies have considered a decrease in MnPF and/or MdPF as a sign of LMF (e.g., Chaffin, 1973; Christensen, 1986; P. Herberts and Kadefors, 1976; Herberts et al., 1980; Hermans and Spaepen, 1997; Jensen et al., 1993; Sundelin and Hagberg, 1992; Sundelin, 1993; Takala et al., 1993). The results of our preliminary study, however, indicate that MnPF and/or MdPF can be altered due to factors other than fatigue. Öberg et al. (1990) performed a study somewhat similar to ours, concluding that "...there is a need for an initial calibration contraction, to which other MnPF values can be related. Changes within $\pm 8 \%$ of this initial value cannot be regarded as clinically significant." (p.368) This recommendation of $\pm 8 \%$ of initial MnPF was based on the variation of $\pm 7.8 \%$ observed in MnPF for changes in joint torque. The recommended $\pm 8 \%$ was then used in several studies to quantify shoulder muscle fatigue (Borstad 
et al., 2009; Chopp et al., 2010; Ebaugh et al., 2006a, 2006b; Lin et al., 2004; Szucs et al., 2009; Tsai et al., 2003). While $\pm 8 \%$ encompasses the range of variabilities observed in our study, it may be a high approximation for a few muscles. The maximum variabilities in MnPF and MdPF due to changes in force level were $\pm 5.2 \%$ and $\pm 6.0 \%$, respectively. It is likely that these values of variability could be further altered as additional factors such as posture are combined with direction and magnitude of force exertion. 


\section{Chapter 3. Specific Aim \#1}

\subsection{Introduction}

In 2015, the United States Bureau of Labor Statistics (BLS) reported that over 356,910 Work-related Musculoskeletal Disorder (WMSD) cases caused a lost day or more, with a median of 12 lost days, which represent $31 \%$ of overall worker cases (Bureau of Labor Statistics, 2016). Among the WMSD cases, shoulder disorders accounted for 92,850 cases with one or more lost days, with a median of 23 lost days. The cost per general WMSD claim varied from a few hundred to several thousand dollars, and roughly $80 \%$ of WMSD cases happened in the private industry sector. Industries with a high prevalence of WMSDs include manufacturing and production, service, construction, and office work (Malmqvist, Ekholm, Lindström, Petersen, \& Örtengren, 1981; Sommerich, McGlothun, \& Marras, 1993; Vasseljen, Holte, \& Westgaard, 2001; Veiersted, 1993).

The economic impact of WMSDs is staggering. In the United Kingdom, Health and Safety Executive (HSE) stated that more than 6.6 million working days were lost due to WMSDs in 2017, with an average of 14 days lost per case. Work-related upper limb disorders - which include shoulder, arm, wrist, and hand - accounted for 2.6 million days lost which represent around $40 \%$ of the total days lost due to WMSDs (HSE, 2018). The economic impact of WMSDs in the United States is also enormous. In 2011, direct and indirect costs associated with WMSDs and diseases accounted for roughly $5.7 \%$ of the national gross domestic product. WMSDs accounted for 280,000 injuries that involve one or more days lost. Specifically, work-related upper limb disorder accounted for 285,650 days lost which represents around $31.4 \%$ of the total days lost due to WMSDs (USBJI, 2015). In Ontario, Canada, The Workplace Safety and Insurance Board (WSIB) stated that WMSD was ranked as the top reason for lost time claims between 1996-2004, with 
382,000 approved claims. WMSD approved claims cost around $\$ 3.3$ billion and 27,000,000 losttime days. Meanwhile, Employers spent around $\$ 12$ billion, which represents the total for direct and indirect WMSD costs (WSIB, 2007). Overall, WMSDs accounted for $42 \%$ of all lost-time claims and all lost-time claim costs, and 50\% of all lost-time days (El ahrache \& Imbeau, 2009).

Localized Muscle Fatigue (LMF) is believed to be one of the precursors for WMSD (Byström and Fransson-Hall, 1994). Byström (1994) stated that, "fatigue and lack of recovery have been proposed as crucial elements in the mechanisms for causation of long term effects on the musculoskeletal system.” Developing LMF does not mean simultaneously developing WMSDs, however, cumulative LMF and ignoring its signs can lead to WMSDs (Armstrong et al., 1993). Öberg (1994) discussed the relationship between cumulative LMF and WMSDs, and how fatigue is considered a major cause of work-related chronic muscle pain. In short, accurate quantification of LMF is necessary to be able to mitigate the risk of developing WMSDs (Bartuzi and RomanLiu, 2014; Nussbaum, 2001; Rashedi and Nussbaum, 2015).

The simplest method to measure mechanical manifestation of muscle fatigue is by measuring the time for an individual until failing to perform the required task; however, this method has several limitations, and one of them is the variability in the physical abilities of users. Another method is evaluating blood lactate concentration by performing a blood sampling test. The performance of this method is difficult in the absence of a specialist to conduct the blood sampling. Another method for determining muscle fatigue is by recording muscle's myoelectric activity by using electromyography (EMG). Myoelectric signals are affected by biochemical and physical changes during fatigue. EMG data can be recorded using two types of electrodes: intramuscular electrodes (using a fine-wire or needle inserted directly into the muscle) and surface 
electrodes (which will be used in this research). EMG has major advantages such as noninvasiveness, high precision and easy to use for fatigue monitoring (Cifrek et al., 2009).

Previous studies were conducted by other researchers on shoulder muscle activation and fatigue estimation using SEMG. We performed a systematic analysis of literature to identify and examine such studies. Around 32 studies were identified (Table 6). Quantification of muscle activation or fatigue using SEMG data was the common denominator in these studies and the studies differed from each other in terms of (1) work-related/independent factors (2) SEMG data analysis methods. We summarized our literature review below based on these two factors:

\subsubsection{Work-related/independent factors}

Fagarasanu and Kumar (2003) listed 15 work-related factors that might lead to WMSD and muscle fatigue. Some of these factors include shoulder posture at overhead levels, working for short cycles, shoulder at flexion and abduction postures, load away from worker's body, repetition, constrained working position and tool weight. A few common work-related factors that emerged out of our review are listed below:

\subsubsection{Shoulder joint angles}

Nineteen out of 32 studies (Table 6) evaluated work-related factors that were associated with shoulder joint angles. Sigholm, Herberts, Almström, and Kadefors (1984) studied the effect of arm position and hand tool on shoulder muscle activity. They defined arm position as a combination of the following angles: upper arm flexion $\left(0^{\circ}, 45^{\circ}\right.$, and $\left.90^{\circ}\right)$, upper arm abduction $\left(45^{\circ}\right.$ and $\left.90^{\circ}\right)$, elbow flexion $\left(90^{\circ}\right.$ and $\left.120^{\circ}\right)$, and upper arm rotation (neutral and $\left.20^{\circ}\right)$. They found that the upper arm elevation angle was the highest influential factor in shoulder muscle activity. Gerdle et al. (1988) investigated the influence of shoulder flexion angles $\left(45^{\circ}, 65^{\circ}\right.$, and $\left.90^{\circ}\right)$ on 
MnPF during static shoulder exertions, and reported a significant difference between MnPF value at $90^{\circ}$ and $45^{\circ}$ for the infraspinatus and anterior deltoid muscles. Also, they reported a positive relationship between shoulder joint flexion angle and MnPF. Öberg et al. (1990) quantified the impact of force level, shoulder plane, torque, and shoulder joint angles $\left(0^{\circ}, 30^{\circ}, 60^{\circ}, 90^{\circ}\right.$, and $\left.135^{\circ}\right)$ on MnPF for the trapezius muscle under a non-fatigue condition. The highest MnPF variation (7.8\%) was found in joint angle between $30^{\circ}-135^{\circ}$, and they concluded the relative decrease in $\mathrm{MnPF}$ due to fatigue is significant if it exceeds $8 \%$ of the initial value. Wiker, Chaffin, and Langolf (1990) evaluated the impact of arm reach, plane, and elevation angle $\left(45^{\circ}\right.$ and $\left.135^{\circ}\right)$ on shoulder fatigue and discomfort, and they reported that shoulder muscle fatigue was higher while the hand was elevated to $135^{\circ}\left(45^{\circ}\right.$ above the shoulder). On the other hand, changes in the plane, arm range of reach, task duration, and all remaining interactions had no impact on shoulder fatigue. Sporrong, Palmerud, and Herberts (1995) investigated if grip force, plane, and shoulder joint angle ( $30^{\circ}, 60^{\circ}$, $90^{\circ}, 120^{\circ}$ ) can increase shoulder muscle activity. They reported an increase in the supraspinatus muscle activity in shoulder joint flexion from and above $60^{\circ}$, and a decrease in the infraspinatus muscle activity in shoulder joint abduction at $30^{\circ}$. Moreover, the middle deltoid activity decreased in both shoulder joint flexion and abduction. Straker, Pollock, and Mangharam (1997) investigated the effect of shoulder joint flexion angle $\left(0^{\circ}\right.$ and $\left.30^{\circ}\right)$ on workers' performance. In contrast to $0^{\circ}$ shoulder joint flexion, shoulder joint flexion at $30^{\circ}$ was associated with poor performance, high discomfort ratings, and higher fatigue. Mamaghani, Shimomura, Iwanaga, and Katsuura (2002) evaluated the impact of contraction level, elbow joint angle, and shoulder joint angle $\left(0^{\circ}, 30^{\circ}, 60^{\circ}\right)$ on changes in the EMG signal frequency and amplitude for shoulder muscle, and they compare it with the subjective measurements represented by perceived exertion ratings. A significant relationship was found between EMG signal parameters with both shoulder and elbow angles, and 
another significant relationship was found between the perceived exertion ratings and the shoulder joint angle. During isometric and dynamic contractions, Antony and Keir (2010) evaluated the effect of force level, plane, and shoulder joint angle $\left(30^{\circ}, 60^{\circ}, 90^{\circ}\right)$ on the activity of shoulder muscle. They reported evidence of a positive relationship between muscle activity and shoulder joint angle. Brookham, Wong, and Dickerson (2010) evaluated the impact of shoulder joint flexion $\left(0^{\circ}, 60^{\circ}, 70^{\circ}, 80^{\circ}, 90^{\circ}\right)$ and humeral rotation on shoulder muscle activity while using a light tool, and reported a positive relationship between shoulder flexion angle and shoulder muscle activity. Furthermore, the inferior trapezius muscle activity at $80^{\circ}$ and $90^{\circ}$ shoulder joint flexion exceded the suggested recommendation for maximum muscle activity in workplaces (10-14\% MVC).

\subsubsection{Shoulder plane}

Nineteen out of 32 studies (Table 6) evaluated work-related factors that were associated with shoulder plane. Sigholm et al. (1984) studied the effect of arm position and hand tool on shoulder muscle activity. They defined arm position as a combination of the following angles: upper arm elevation (flexion/sagittal and abduction/frontal plane), elbow flexion, and upper arm rotation. They reported that the anterior deltoid muscle activity in the sagittal plane was significantly different than the frontal plane, and medial deltoid muscle activity in the frontal plane was significantly different than the sagittal plane. Sporrong et al. (1995) investigated if grip force, plane (sagittal and scapular plane) and shoulder joint angle can increase shoulder muscle activity. They reported an increase in the supraspinatus muscle activity in the sagittal plane from and above $60^{\circ}$, and a decrease in the supraspinatus muscle activity in the scapular plane. Moreover, the middle deltoid muscle activity decreased in both shoulder joint flexion and abduction. During a fatiguing submaximal arm exertion in the sagittal plane, Nieminen, Takala, Niemi, and ViikariJuntura (1995) investigated muscles that exhibit signs of fatigue. They reported that first fatigue 
onset occurred for deltoid, infraspinatus, and supraspinatus muscles. Minning et al. (2007) studied shoulder muscle fatigue during resisted isometric shoulder elevation using $60 \% \mathrm{MVC}$ in the scapular plane. They reported that shifts in MdPF to lower values were most apparent in the middle deltoid and upper trapezius muscles. On the other hand, the serratus anterior and lower trapezius exhibited slightly lower changes. During isometric and dynamic contractions, Antony and Keir (2010) evaluated the effect of force level, plane (sagittal/flexion, scapular/mid-abduction, and frontal/abduction), and shoulder joint angle on the activity of the shoulder muscle. Even when muscle activity was affected by different planes, the researchers failed to find a clear and specific trend that can link muscle activity with different planes. Kai et al. (2012) compared shoulder muscle fatigability during resisted arm elevation in different planes (sagittal and scapular planes). They reported that plane has a significant effect on the fatigability of the infraspinatus muscle, and faster muscle fatigue was found in the sagittal plane compared to the scapular plane. On the other hand, plane does not affect the anterior deltoid, middle deltoid, and posterior deltoid muscles' fatigability.

\subsubsection{Force level}

Twenty-six out of 32 studies (Table 6) evaluated work-related factors that were associated with force level. Sigholm et al. (1984) quantified the effect of arm position and force level $(0 \mathrm{~kg}$, $1 \mathrm{~kg}, 2 \mathrm{~kg}$ ) on shoulder muscle activity. They defined arm position as a combination of the following angles: upper arm joint flexion and abduction angles, elbow joint flexion angles, and upper arm joint rotation. They reported a positive relationship between muscle activity and force level. Moreover, they reported that the dependency of three compartments of deltoid muscles on

force level was lower than the dependency of the infraspinatus and supraspinatus muscles. Öberg (1994) evaluated the impact of force level $(0$ and $2 \mathrm{~kg}$ ) on shoulder muscle activity and fatigue 
using objective and subjective measures, and reported a positive relationship between RMS and muscle activity and a significant correlation between $\mathrm{MnPF}$ and perceived exertion ratings at high force level. At low force levels, MnPF and perceived exertion ratings exhibited different fatigue information; therefore, the author concluded that MnPF has low reliability as a fatigue indicator in situations with low load levels. Öberg (1995) evaluated the impact of force level $(0,1,2 \mathrm{~kg})$ on trapezius muscle fatigue, and compared RMS and MnPF as fatigue indicators. The author reported a positive relationship between force level and RMS, and a negative relationship between force level and MnPF. Moreover, MnPF has low reliability for lower force levels, $0 \mathrm{~kg}$, as fatigue indicators. Mamaghani et al. (2002) evaluated the impact of contraction level, elbow joint angle, and shoulder joint angle $\left(0^{\circ}, 30^{\circ}, 60^{\circ}\right)$ on changes in the signal's frequency and amplitude for shoulder muscle, and compared it with the subjective measurements represented by perceived exertion ratings. A significant relationship was found between EMG signal parameters with both shoulder and elbow angles. An additional significant relationship was found between the shoulder angle and the perceived exertion ratings. During simulated automotive assembly operations, Garg et al. (2006) evaluated the impact of different combinations of work configurations including work-piece weight (1.36 and $2.73 \mathrm{~kg})$, hand tool weight $(0.45,0.91$, and $1.82 \mathrm{~kg})$, exertion time, and shoulder joint and elbow angles on shoulder muscle fatigue. They reported that muscle fatigue increased concurrently with the increase of work-piece weights and hand tool weight. In a nonoccupational study, Piscione and Gamet (2006) studied the effect of backpack load on shoulder muscle fatigue. Three different load levels were used $(0,10,20 \mathrm{~kg})$. The authors reported an increase in muscle fatigue with the increase in load level, and no significant differences were found when they compared the fatigability of the right and left middle deltoid and upper trapezius muscles. During isometric and dynamic contractions, Antony and Keir (2010) evaluated the effect 
of force level $(0,0.5 \mathrm{~kg}$ and $30 \% \mathrm{MVC})$, plane, and shoulder joint angle on the activity of shoulder muscles. They reported that force level had a significant effect on muscle activity. Ferguson, Allread, Le, Rose, and Marras (2013) evaluated the effect of force (2.27 kg and $4.54 \mathrm{~kg})$, repetition, and posture on shoulder muscle fatigue, and reported a negative relationship between muscle fatigue and force level. Moreover, they reported that force level has a significant effect on the anterior deltoid muscle. Alasim et al. (2019) evaluated the impact of force direction and force level $(2.27,3.4$, and $4.54 \mathrm{~kg}$ ) on shoulder muscle activation, and reported that force level has a significant effect on muscle activation. Furthermore, there was a positive relationship between muscle activity and force level.

\subsubsection{Force direction}

Three out of 32 studies (Table 6) evaluated work-related factors that were associated with force direction. Chopp et al. (2010) evaluated the effect of hand force direction (forward, backward, downward, upward, left, and right), target angle $\left(-15^{\circ}, 0^{\circ}, 15^{\circ}\right.$, and $\left.30^{\circ}\right)$ and overhead work configurations (fixed height or stature specific) on shoulder muscles activity. Among all factors affecting muscle activation, they reported that hand force direction was the most influential factor. Pushing backward at a fixed height configuration exhibited the total highest muscle activation followed by pushing in the left and right directions. Specifically, pushing backward at angles of $-15^{\circ}$ and $0^{\circ}$ exhibited a high muscle activation. Cudlip, Meszaros, and Dickerson (2016) quantified the effect of 14 overhead work locations (spaced evenly in 15-cm distances in an asymmetric grid pattern) and hand force direction (forward, backward, downward, upward, left, and right) on shoulder muscle activity and reported a higher muscle activation in pushing backward followed by pushing in the left direction. In addition, pushing downward had the lowest muscle activation. Alasim et al. (2019) evaluated the impact of force direction (pull right, pull left, pull 
back, pull down and pull up) and force level on shoulder muscle activation, and reported that force direction has a significant effect on muscle activation. Out of five directions tested in their study, pulling right and pulling up have caused the highest muscle activity, followed by pulling left.

\subsubsection{Other factors}

Fifteen of 32 studies (Table 6) evaluated work-related factors that were associated with factors such as overhead postures, duty cycle, and cycle time. Herberts and Kadefors (1976) studied the effect of overhead static exertions on EMG of shoulder muscles among older welders, and reported that the power spectral shifts toward lower values for the supraspinatus muscle among the workers during sustained task performance. Malmqvist et al. (1981) investigated the impact of five different overhead building and construction tasks on EMG activation of shoulder muscles, and they reported that signs of muscle fatigue were evident during overhead static tasks even when the force exerted was small. The authors thus suggested to introduce a rotation routine between construction tasks in order to avoid the negative effects of sustained overhead work tasks. Christensen (1986) evaluated the impact of repetitive work on shoulder muscle activity and fatigue during a whole working day using a pillar drill. The author reported a significant reduction in MnPF for trapezius muscle during the first two hours of the workday. Hermans and Spaepen (1997) compared sustained and intermittent exertions of the right arm, and found higher shoulder muscle fatigue during sustained exertions represented by a reduction in MnPF. Nussbaum (2001) investigated if SEMG measures can serve as fatigue indicators during intermittent dynamic exertions. For the intermittent overhead exertions performed over a duration of 3 hours, the author observed a decrease in MnPF and MdPF; low variability also was observed for MnPF during static test contraction compared to MdPF. Anton et al. (2001) studied the effect of different overhead reaching positions (close, middle, and far) and ladder height on shoulder muscle activity. They 
reported no significant difference in the MdPF between the first and the last values. In contrast to the far reach position, the RMS was significantly decreased in the anterior deltoid and biceps muscles and increased in the triceps in the close reach position. Hummel et al. (2005) compared objective and subjective fatigue measurements during shoulder elevation endurance tasks. During shoulder elevation endurance tasks performed at 30\% MVC level, the researchers observed a linear correlation between the increase of perceived exertion ratings and the decrease of MnPF. During static shoulder abductions, Iridiastadi and Nussbaum (2006) quantified the effect of task parameters such as contraction level, duty cycle, and cycle time on muscle fatigue and endurance time. They found that cycle time had a significant effect on MnPF and MdPF slopes. Cudlip, Callaghan, and Dickerson (2015) investigated the effect of different work configurations (sitting and standing) while performing static exertions (pushing and pulling tasks) and dynamic exertions (transfer and light assembly tasks) on upper limb muscle activity. They reported that pulling tasks exhibited the lowest muscle activation overall, followed by pushing tasks. Also, in contrast to the sitting configuration, standing exhibited lower muscle activation levels and lower body discomfort.

\subsubsection{SEMG data analysis methods}

\subsubsection{Root mean square (RMS)}

RMS represents the signals' overall magnitude by quantifying the average power square root of the EMG signal, and therefore, there is no need of using a full wave rectification for the signal (Gerleman \& Cook, 1992). RMS has been used to assess muscle load; it is known to increase with the development of muscle fatigue. However, RMS depends on external loads and is interpreted to have lower reliability than other EMG based LMF analysis parameters (Marras, 1992; Nargol, Jones, Kelly, \& Greenough, 1999). Mathematically RMS is expressed as: 


$$
R M S=\sqrt{\frac{1}{N} \sum_{i=1}^{N} X_{i}^{2}}
$$

Where, $X_{i}$ is the EMG signal at $i^{\text {th }}$ time instance

$N$ is the total number of EMG data points

Eleven out of 32 studies from Table 6 analyzed the SEMG signal using RMS. We also reviewed a few non shoulder studies $(\mathrm{N}=7)$ that used RMS to estimate muscle activation and/or LMF (Alizadehkhaiyat et al., 2011; Christensen et al., 1991; Fedorowich et al., 2013; Fuller et al., 2009; Lee et al., 2015; Ringheim et al., 2014; Yassierli \& Nussbaum, 2008). A general trend observed in these studies is that RMS value increases with the development of LMF. In addition, a positive relationship between RMS and force level is often reported. On the other hand, it was reported that RMS is highly dependent on force level. Some of these studies used RMS only for the purpose of evaluating muscle activity and relied on other fatigue indicators to assess muscle fatigue.

\subsubsection{Mean absolute value (MAV)}

MAV is also known as average rectified value (ARV), integral of absolute value (IAV), averaged absolute value (AAV), and the first order of v-Order features (V1) (Phinyomark, Phukpattaranont, \& Limsakul, 2012). MAV is the average absolute value of the EMG signal. Similar to RMS, MAV parameter has been used to assess muscle load, and MAV is also known to increase with the development of muscle fatigue. MAV can be mathematically expressed as:

$$
M A V=\frac{1}{N} \sum_{i=1}^{N}\left|X_{i}\right|
$$


Where, $X_{i}$ is the EMG signal at $i^{\text {th }}$ time instance

$N$ is the total number of EMG data points

Six out of 32 studies (Table 6) analyzed the SEMG signal using MAV. These studies used MAV to assess shoulder muscle activity and found a positive relationship between MAV and force level. MAV was seldom used to assess muscle fatigue.

\subsubsection{Zero crossing (ZC)}

$\mathrm{ZC}$ is also known as zero crossing frequency. ZC measures EMG signal frequency in the time domain. ZC is defined as the total number of instances the signal's amplitude crosses the zero level (LeVeau \& Anderson, 1992; Phinyomark et al., 2012). When a muscle is in an active condition, it will produce more ZC. However, with fatigue occurrence, ZC will drop gradually. ZC can be mathematically expressed as:

$$
\begin{gathered}
Z C=\sum_{i=1}^{N-1}\left[\operatorname{sgn}\left(x_{i} \times x_{i+1}\right) \cap\left|x_{i}-x_{i+1}\right| \geq \text { threshold }\right] \\
\operatorname{sgn}(x)=\left\{\begin{array}{c}
1, \text { if } x \geq \text { threshold } \\
0, \text { otherwise }
\end{array}\right.
\end{gathered}
$$

Where, $x_{i}$ is the EMG signal at $i^{\text {th }}$ time instance

$N$ is the total number of EMG data points

Threshold condition is implemented in order to avoid background noises.

One out of 32 studies analyzed the SEMG signal using ZC. We also reviewed a few non shoulder studies (N=2) that used ZC to estimate LMF (Christensen et al., 1991; Suurküla \& Hägg, 1987). A general trend observed in these studies is that $\mathrm{ZC}$ decreases with the development of 
LMF. It was stated that ZC's reaction to muscle fatigue is similar to MnPF and MdPF. However, the use of ZC to study LMF has reduced over time.

\subsubsection{Mean power frequency $(\mathrm{MnPF})$}

It is also known as the central frequency or spectral center of gravity (LeVeau \& Anderson, 1992; Phinyomark et al., 2012). MnPF is an index used to study the spectral shifts and can be defined as the average frequency of the power spectrum. Muscle fatigue has been shown to cause a decrease in $\mathrm{MnPF}$ due to a shift in the power spectral density to lower frequencies. $\mathrm{MnPF}$ mathematically can be expressed as:

$$
M n P F=\frac{\sum_{i=1}^{M} f_{i} P_{i}}{\sum_{i=1}^{M} P_{i}}
$$

Where $M$ is the frequency length

$$
\begin{aligned}
& f_{i} \text { is spectrum frequency at frequency } i \\
& P_{i} \text { is the } i^{t h} \text { line of the power spectrum }
\end{aligned}
$$

Eighteen out of 32 studies (Table 6) analyzed the SEMG signal using MnPF. We also reviewed a few non shoulder studies that used MnPF to estimate LMF (Christensen et al., 1991). A general trend observed in these studies is that MnPF decreases with muscle fatigue. The use of MnPF was only for the purpose of assessing muscle fatigue. Some studies compare the first value (reference point) and last value in the same trial looking for significant difference, and others use the regression slope to indicate if there is muscle fatigue. In addition, it has been stated that MnPF has lower variability compared to MdPF. 


\subsubsection{Median power frequency (MdPF)}

Alike MnPF, MdPF is also used to study the spectral shifts and can be defined as the frequency that divides the power spectrum into two equaled areas (LeVeau \& Anderson, 1992). Muscle fatigue will result in a decrease in MdPF caused by a shift in the power spectral density to lower frequencies. MdPF mathematically can be expressed as:

$$
\sum_{i=1}^{M d P F} P_{i}=\sum_{i=M d P F}^{M} P_{i}=\frac{1}{2} \sum_{i=1}^{M} P_{i}
$$

Where $M$ is the frequency length

$P_{i}$ is the $i^{\text {th }}$ line of the power spectrum

Eleven out of 32 studies (Table 6) analyzed the SEMG signal using MdPF. We also reviewed a few non shoulder studies $(\mathrm{N}=6)$ that used MdPF to estimate LMF (Alizadehkhaiyat et al., 2011; Cardozo et al., 2011; Christensen et al., 1991; Lee et al., 2015; Ringheim et al., 2014; Sparto et al., 2000). A general trend observed in these studies is that MdPF decreases with the development of LMF. The use of MdPF was only for the purpose of assessing muscle fatigue, and an approach similar MnPF was used to estimate LMF. Because of MdPF's high reliability to assess muscle fatigue, it has been used in studies that evaluated shoulder, upper arm, upper limb, lower back, and lower limb muscle fatigue.

\subsubsection{Power frequency band (PFB)}

In the frequency domain, frequencies can be categorized into low, mid and high frequency bands. During muscle fatigue, power spectral density shifts to lower frequencies. Therefore, 
muscle fatigue can be evaluated by monitoring changes within frequency bands (Cifrek et al., 2009).

Two out of 32 studies (Table 6) analyzed the SEMG signal using PFBs. We also reviewed a few non shoulder studies $(\mathrm{N}=4)$ that used PFBs to estimate LMF (Balasubramanian \& Jagannath, 2014; Balasubramanian et al., 2014; Cardozo et al., 2011; Sparto et al., 2000). A general trend observed in these studies is that the power of lower PFBs increases with fatigue occurrence. Furthermore, it was found that lower PFBs sensitivity to fatigue is higher than other bands. Some of the lower PFBs used in these studies are $13-22 \mathrm{~Hz}, 15-30 \mathrm{~Hz}, 15-45 \mathrm{~Hz}$, and $20-50 \mathrm{~Hz}$. 
Table 6: Summary of shoulder muscles fatigue studies while using EMG signals.

\begin{tabular}{|c|c|c|c|c|c|c|c|c|c|c|c|c|}
\hline & \multirow[b]{2}{*}{ Study } & \multicolumn{5}{|c|}{ Work-related/independent factors } & \multicolumn{6}{|c|}{ SEMG data analysis methods } \\
\hline & & Joint angle & Plane & Force level & $\begin{array}{c}\text { Force } \\
\text { direction }\end{array}$ & Other factors & RMS & MA V & $\mathbf{Z C}$ & MnPF & MdPF & PFBs \\
\hline 1 & $\begin{array}{c}\text { Herberts and } \\
\text { Kadefors } \\
(1976)\end{array}$ & - & - & - & - & $\begin{array}{l}\text { Overhead } \\
\text { posture }\end{array}$ & & & & $\checkmark$ & & \\
\hline 2 & $\begin{array}{c}\text { Malmqvist et } \\
\text { al. (1981) }\end{array}$ & - & - & - & - & $\begin{array}{c}5 \text { different } \\
\text { overhead } \\
\text { posture }\end{array}$ & & & & & $\checkmark$ & \\
\hline 3 & $\begin{array}{l}\text { Sigholm et } \\
\text { al. (1984) }\end{array}$ & $\begin{array}{c}\text { Upper arm } \\
\text { flexion } \\
\left(0^{\circ}, 45^{\circ}, \text { and }\right. \\
\left.90^{\circ}\right), \\
\text { upper arm } \\
\text { abduction }\left(45^{\circ}\right. \\
\left.\text { and } 90^{\circ}\right), \\
\text { elbow flexion } \\
\left(90^{\circ} \text { and } 120^{\circ}\right), \\
\text { and upper arm } \\
\text { rotation } \\
\text { (neutral and } \\
\left.20^{\circ}\right)\end{array}$ & $\begin{array}{l}\text { Sagittal } \\
\text { and } \\
\text { frontal } \\
\text { plane }\end{array}$ & $0,1,2 \mathrm{~kg}$ & - & - & $\checkmark$ & $\checkmark$ & & & & \\
\hline 4 & $\begin{array}{c}\text { Christensen } \\
\text { (1986) }\end{array}$ & - & - & - & - & Work repetition & & & & $\checkmark$ & & \\
\hline 5 & $\begin{array}{c}\text { Gerdle et al. } \\
(\mathbf{1 9 8 8})\end{array}$ & $\begin{array}{c}45^{\circ}, 65^{\circ}, \text { and } \\
90^{\circ}\end{array}$ & $\begin{array}{l}\text { Sagittal } \\
\text { plane }\end{array}$ & $100 \% \mathrm{MVC}$ & - & - & & & & $\checkmark$ & & \\
\hline 6 & $\begin{array}{c}\text { Öberg et al. } \\
\text { (1990) }\end{array}$ & $\begin{array}{c}0^{\circ}, 30^{\circ}, 60^{\circ}, \\
90^{\circ}, \text { and } 135^{\circ}\end{array}$ & $\begin{array}{l}\text { Sagittal } \\
\text { and }\end{array}$ & $0,1,2 \mathrm{~kg}$ & - & - & & & & $\checkmark$ & & \\
\hline
\end{tabular}




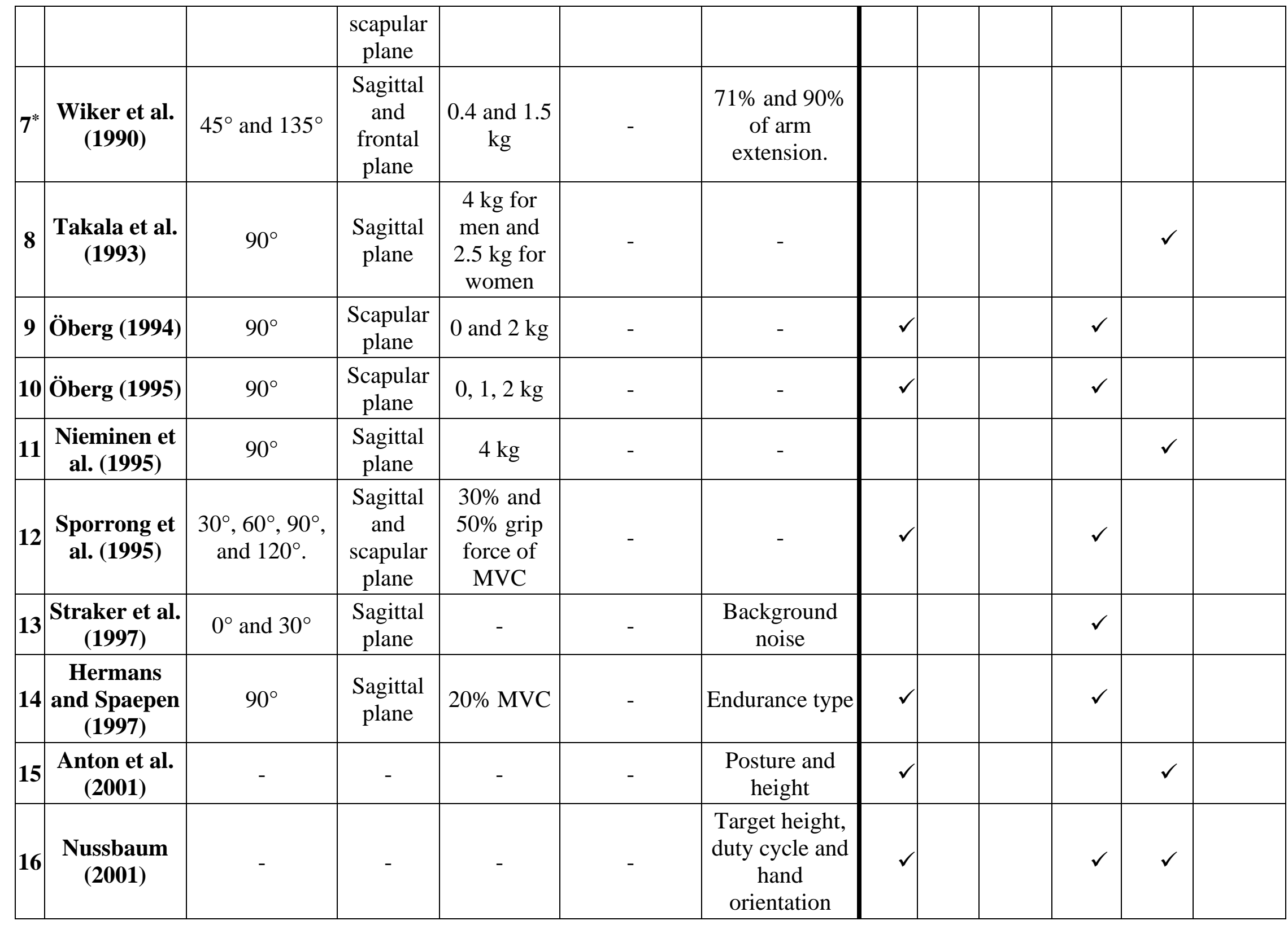




\begin{tabular}{|c|c|c|c|c|c|c|c|c|c|c|c|}
\hline 17 & $\begin{array}{c}\text { Allison and } \\
\text { Fujiwara } \\
\text { (2002) }\end{array}$ & - & - & $60 \% \mathrm{MVC}$ & - & - & & & & $\checkmark$ & $\checkmark$ \\
\hline 18 & $\begin{array}{l}\text { Mamaghani } \\
\text { et al. (2002) }\end{array}$ & $\begin{array}{c}\text { Shoulder angle } \\
\left(0^{\circ}, 30^{\circ} \text {, and }\right. \\
\left.60^{\circ}\right) \text { and elbow } \\
\text { angle }\left(60^{\circ},\right. \\
\left.90^{\circ} \text {, and } 120^{\circ}\right)\end{array}$ & $\begin{array}{l}\text { Sagittal } \\
\text { plane }\end{array}$ & $\begin{array}{c}20 \%, 40 \% \\
\text { and } 60 \% \\
\text { MVC }\end{array}$ & - & - & $\checkmark$ & & $\checkmark$ & & \\
\hline 19 & $\begin{array}{l}\text { Hummel et } \\
\text { al. (2005) }\end{array}$ & - & - & $30 \% \mathrm{MVC}$ & - & - & & & $\checkmark$ & & \\
\hline 20 & $\begin{array}{l}\text { Iridiastadi } \\
\text { and } \\
\text { Nussbaum } \\
(2006)\end{array}$ & $90^{\circ}$ & $\begin{array}{l}\text { Frontal } \\
\text { plane }\end{array}$ & $\begin{array}{l}12 \% \text { and } \\
28 \% \text { MVC }\end{array}$ & - & $\begin{array}{l}\text { Duty cycle and } \\
\text { cycle time }\end{array}$ & $\checkmark$ & & $\checkmark$ & $\checkmark$ & \\
\hline 21 & $\begin{array}{c}\text { Piscione and } \\
\text { Gamet } \\
(2006)\end{array}$ & $90^{\circ}$ & $\begin{array}{l}\text { Frontal } \\
\text { plane }\end{array}$ & $\begin{array}{l}0,10, \text { and } \\
20 \mathrm{~kg}\end{array}$ & - & - & $\checkmark$ & & $\checkmark$ & & \\
\hline 22 & $\begin{array}{l}\text { Garg et al. } \\
\text { (2006) }\end{array}$ & $\begin{array}{c}\text { Shoulder angle } \\
\left(60^{\circ}, 90^{\circ} \text {, and }\right. \\
\left.120^{\circ}\right) \text { and } \\
\text { elbow angle } \\
\left(90^{\circ}, 120^{\circ} \text {, and }\right. \\
\left.150^{\circ}\right)\end{array}$ & $\begin{array}{l}\text { Sagittal } \\
\text { plane }\end{array}$ & $\begin{array}{l}\text { Work piece } \\
\text { weight }(3 \\
\text { or } 6 \mathrm{lb} .) \\
\text { and tool } \\
\text { weight was } \\
(1,2 \text { or } 4 \\
\text { lb. }) \\
\end{array}$ & - & Exertion time & & & & $\checkmark$ & \\
\hline 23 & $\begin{array}{c}\text { Minning et } \\
\text { al. (2007) }\end{array}$ & $90^{\circ}$ & $\begin{array}{l}\text { Scapular } \\
\text { plane }\end{array}$ & $60 \%$ MVC & - & - & & & & $\checkmark$ & \\
\hline 24 & $\begin{array}{l}\text { Roman-Liu } \\
\text { and } \\
\text { Konarska } \\
(2009)\end{array}$ & - & - & $\begin{array}{c}0.5,1,2.5, \\
5,10,15, \\
20,25, \text { and } \\
30 \% \text { MVC }\end{array}$ & - & - & & $\checkmark$ & $\checkmark$ & $\checkmark$ & $\checkmark$ \\
\hline
\end{tabular}




\begin{tabular}{|c|c|c|c|c|c|c|c|c|c|c|c|}
\hline 25 & $\begin{array}{c}\text { Chopp et al. } \\
(2010)\end{array}$ & - & - & $30 \mathrm{~N}$ & \begin{tabular}{|c|} 
Forward, \\
backward, \\
downward, \\
upward, left, \\
and right \\
\end{tabular} & $\begin{array}{c}\text { Work } \\
\text { configuration } \\
\text { and target angle }\end{array}$ & & $\checkmark$ & & & \\
\hline 26 & $\begin{array}{l}\text { Antony and } \\
\text { Keir (2010) }\end{array}$ & $\begin{array}{c}30^{\circ}, 60^{\circ}, 90^{\circ} \\
\text { and } 120^{\circ} \text {. }\end{array}$ & $\begin{array}{l}\text { Sagittal, } \\
\text { scapular, } \\
\text { and } \\
\text { frontal } \\
\text { plane }\end{array}$ & $\begin{array}{c}\text { no load, } \\
0.5 \mathrm{~kg} \text {, and } \\
30 \% \mathrm{MVC}\end{array}$ & - & $\begin{array}{l}\text { Movement } \\
\text { speed }\end{array}$ & & $\checkmark$ & & & \\
\hline 27 & $\begin{array}{c}\text { Kai et al. } \\
\text { (2012) }\end{array}$ & $90^{\circ}$ & $\begin{array}{l}\text { Sagittal } \\
\text { and } \\
\text { scapular } \\
\text { plane }\end{array}$ & $30 \% \mathrm{MVC}$ & - & - & & & & $\checkmark$ & \\
\hline 28 & $\begin{array}{c}\text { Ferguson et } \\
\text { al. }(2013)\end{array}$ & $\begin{array}{c}25^{\circ}, 60^{\circ} \text { and } \\
110^{\circ}\end{array}$ & $\begin{array}{l}\text { Sagittal } \\
\text { plane }\end{array}$ & $\begin{array}{c}2.27 \text { and } \\
4.54 \mathrm{~kg}\end{array}$ & - & Work repetition & & & & & $\checkmark$ \\
\hline 29 & \begin{tabular}{|c|} 
Bartuzi and \\
Roman-Liu \\
$(\mathbf{2 0 1 4})$
\end{tabular} & - & - & $\begin{array}{c}10 \%, 20 \% \\
\text { and } 30 \% \\
\text { MVC }\end{array}$ & - & - & $\checkmark$ & & & $\checkmark$ & \\
\hline 30 & Cudlip et al. & - & - & $40 \mathrm{~N}$ & - & \begin{tabular}{|} 
Static tasks, \\
dynamic tasks, \\
and work \\
configuration
\end{tabular} & & $\checkmark$ & & & \\
\hline 31 & Cudlip et al. & - & - & $40 \mathrm{~N}$ & $\begin{array}{c}\text { Forward, } \\
\text { backward, } \\
\text { downward, } \\
\text { upward, left, } \\
\text { and right }\end{array}$ & $\begin{array}{c}\text { Overhead work } \\
\text { location }\end{array}$ & & $\checkmark$ & & $\checkmark$ & \\
\hline 32 & $\begin{array}{c}\text { Alasim et al. } \\
(2019)\end{array}$ & - & - & $\begin{array}{c}2.27,3.4 \\
\text { and } 4.54 \mathrm{~kg}\end{array}$ & $\begin{array}{c}\text { pull back, pull } \\
\text { down, pull }\end{array}$ & - & & $\checkmark$ & & & \\
\hline
\end{tabular}




\begin{tabular}{|l|l|l|l|l|l|l|l|l|l|}
\hline & & & $\begin{array}{c}\text { left, pull right, } \\
\text { and pull up }\end{array}$ & & & & & \\
\hline
\end{tabular}

*Only used subjective measurements to assess LMF 


\subsection{Objective and hypotheses}

Several work-related factors were examined in the previous EMG based shoulder WMSD studies. A few factors that were found to be influential in terms of their effect on EMG muscle activation and LMF development include force level, shoulder joint angle, plane of exertion and direction of force application. These factors were identified as significant contributors based on various SEMG measures such as RMS, MAV, ZC, MnPF, $\mathrm{MdPF}$, and PFB.

The conclusion on the development of LMF is always made based on a relative change with respect to initial values, or under no-fatigue conditions. As noted earlier, quantifying such change, however, relies on the assumption that the SEMG measures without fatigue present, can serve as an appropriate reference within the joint range-ofmotion and/or functional ability. This assumption has been sparingly tested in the literature. Therefore, the objective in this Specific Aim \# 1 was to quantify the variability of SEMG measures in non-fatigued shoulder muscles. Specifically, four work-related factors (shoulder joint angle, shoulder plane, force level, and force direction) were systematically altered to create 120 occupationally relevant static holding tasks and the variabilities in 6

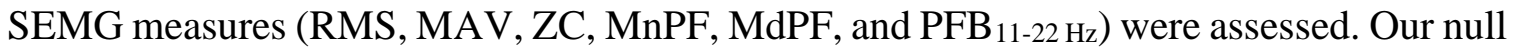
hypothesis was that the factors such as shoulder joint angle, shoulder plane, force level, and force direction will have no effect on the values of RMS, MAV, ZC, MnPF, MdPF, and $\mathrm{PFB}_{11-22 \mathrm{~Hz}}$ values under non-fatigued conditions. 


\subsection{Methodology}

\subsubsection{Approach}

An experiment was performed in the laboratory settings to quantify the variability in various SEMG measures (RMS, MAV, $\mathrm{ZC}, \mathrm{MnPF}, \mathrm{MdPF}$, and $\mathrm{PFB}_{11-22 \mathrm{~Hz}}$ ) for nonfatigued shoulder muscles. Human subjects performed 120 static arm exertions characterized by two shoulder joint angles, two planes, three force levels, and five force directions. SEMG data was recorded from seven shoulder muscles.

\subsubsection{Participants}

A total of 12 right-hand dominant participants were recruited for this study, of which 4 were female participants and the remaining 8 were male participants. The primary inclusion criteria required for this study were that the participants were free from any type of musculoskeletal, degenerative or neurological disorder and that they had neither a history of shoulder pain nor any current pain. The Physical Activity Readiness Questionnaire (PAR-Q, Canadian Society for Exercise Physiology) was used to screen participants for cardiac and other health problems (e.g., dizziness, chest pain and heart trouble). Copy of the questionnaire is included in Appendix D. All participants, who meet the inclusion criteria, read and signed a consent form approved by the local Institutional Review Board prior to their participation in the study. Copy of the consent form is included in Appendix B.

The statistical power for the sample size of 12 was estimated using the operating characteristics curves (OC curves) based on the following equation:

$$
\Phi^{2}=\frac{n D^{2}}{2 a \sigma^{2}}
$$


Where, $\Phi$ : noncentrality parameter

$n$ : number of participants

$D$ : meaningful (maximum) differences between the force levels

$\alpha$ : number of force levels $=3$

$\sigma^{2}$ : estimate of the variance

We knew from our previous study that there was a major effect of force level on majority of SEMG measures. Therefore, the force level was used as a representative variable in estimating the required sample size. Three SEMG measures - MnPF, MdPF, and $\mathrm{ZC}$ - were used to estimate the statistical power. Using the data recorded during this study, the standard deviations for MnPF, MdPF, and ZC were estimated to be $0.19,0.21$, 0.18 , respectively.

Table 7: Sample size estimation based on MnPF

\begin{tabular}{ccccccc}
\hline $\mathbf{n}$ & $\boldsymbol{\Phi}^{\mathbf{2}}$ & $\boldsymbol{\Phi}$ & $\mathbf{v 1}$ & $\mathbf{v 2 =} \mathbf{a}(\mathbf{n}-\mathbf{1})$ & $\boldsymbol{\beta}$ & Power $(\mathbf{1 - \beta})$ \\
\hline 3 & 2.669563 & 1.63388 & 2 & 6 & 0.55 & 0.45 \\
4 & 3.559418 & 1.886642 & 2 & 9 & 0.33 & 0.67 \\
5 & 4.449272 & 2.10933 & 2 & 12 & 0.18 & 0.82 \\
6 & 5.339126 & 2.310655 & 2 & 15 & 0.08 & 0.92 \\
7 & 6.228981 & 2.495793 & 2 & 18 & 0.06 & 0.94 \\
$\mathbf{8}$ & 7.118835 & 2.668115 & 2 & 21 & 0.033 & $\mathbf{0 . 9 6 7}$ \\
$\mathbf{9}$ & 8.00869 & 2.829963 & 2 & 24 & 0.01 & $\mathbf{0 . 9 9}$ \\
\hline
\end{tabular}

Table 8: Sample size estimation based on MdPF

\begin{tabular}{ccccccc}
\hline $\mathbf{n}$ & $\boldsymbol{\Phi}^{2}$ & $\boldsymbol{\Phi}$ & $\mathbf{v 1}$ & $\mathbf{v 2}=\mathbf{a}(\mathbf{n}-\mathbf{1})$ & $\boldsymbol{\beta}$ & Power $(\mathbf{1}-\boldsymbol{\beta})$ \\
\hline 3 & 2.060324 & 1.435383 & 2 & 6 & 0.65 & 0.35 \\
4 & 2.747099 & 1.657437 & 2 & 9 & 0.45 & 0.55 \\
5 & 3.433874 & 1.853071 & 2 & 12 & 0.27 & 0.73
\end{tabular}




\begin{tabular}{ccccccc}
6 & 4.120648 & 2.029938 & 2 & 15 & 0.17 & 0.83 \\
7 & 4.807423 & 2.192584 & 2 & 18 & 0.14 & 0.86 \\
8 & 5.494198 & 2.343971 & 2 & 21 & 0.065 & 0.935 \\
$\mathbf{9}$ & 6.180972 & 2.486156 & 2 & 24 & 0.035 & $\mathbf{0 . 9 6 5}$ \\
$\mathbf{1 0}$ & 6.867747 & 2.620639 & 2 & 27 & 0.018 & $\mathbf{0 . 9 8 2}$ \\
$\mathbf{1 1}$ & 7.554522 & 2.748549 & 2 & 30 & 0.01 & $\mathbf{0 . 9 9}$ \\
\hline
\end{tabular}

Table 9: Sample size estimation based on ZC

\begin{tabular}{ccccccc}
\hline $\mathbf{n}$ & $\boldsymbol{\Phi}^{\mathbf{2}}$ & $\boldsymbol{\Phi}$ & $\mathbf{v 1}$ & $\mathbf{v 2}=\mathbf{a}(\mathbf{n}-\mathbf{1})$ & $\boldsymbol{\beta}$ & Power $(\mathbf{1 - \beta})$ \\
\hline 3 & 2.391598 & 1.546479 & 2 & 6 & 0.6 & 0.4 \\
4 & 3.188797 & 1.78572 & 2 & 9 & 0.35 & 0.65 \\
5 & 3.985996 & 1.996496 & 2 & 12 & 0.19 & 0.81 \\
6 & 4.783195 & 2.187052 & 2 & 15 & 0.12 & 0.88 \\
7 & 5.580395 & 2.362286 & 2 & 18 & 0.065 & 0.935 \\
$\mathbf{8}$ & 6.377594 & 2.52539 & 2 & 21 & 0.04 & $\mathbf{0 . 9 6}$ \\
$\mathbf{9}$ & 7.174793 & 2.67858 & 2 & 24 & 0.015 & $\mathbf{0 . 9 8 5}$ \\
\hline
\end{tabular}

As shown in tables 7, 8, and 9, sample sizes of 8,9 and 8 are sufficient to provide statistical power of $>95 \%$ based on the observed variances of $\mathrm{MnPF}, \mathrm{MdPF}$, and ZC, respectively. To guard against possible errors in the variance estimation/experimental data collection methods, we increased the sample size to 12 participants.

\subsubsection{Equipment}

\subsubsection{Custom-Made Force Exertion Device}

A custom-made force exertion device was used to simulate the static exertion tasks (Figures 5-6). This device consisted of a column and base setup. A peripheral assembly consisting of a set of perforated steel tubes, wood boards, and pulleys were mounted on the column. This peripheral assembly is height adjustable (with respect to column) and provide means to hang weights of different magnitudes using rope and pulleys. The pulleys 
mounted on perforated steel tubes allowed the experimenter to control the locations (shoulder angle, plane) and direction of force exertion for individual participants.
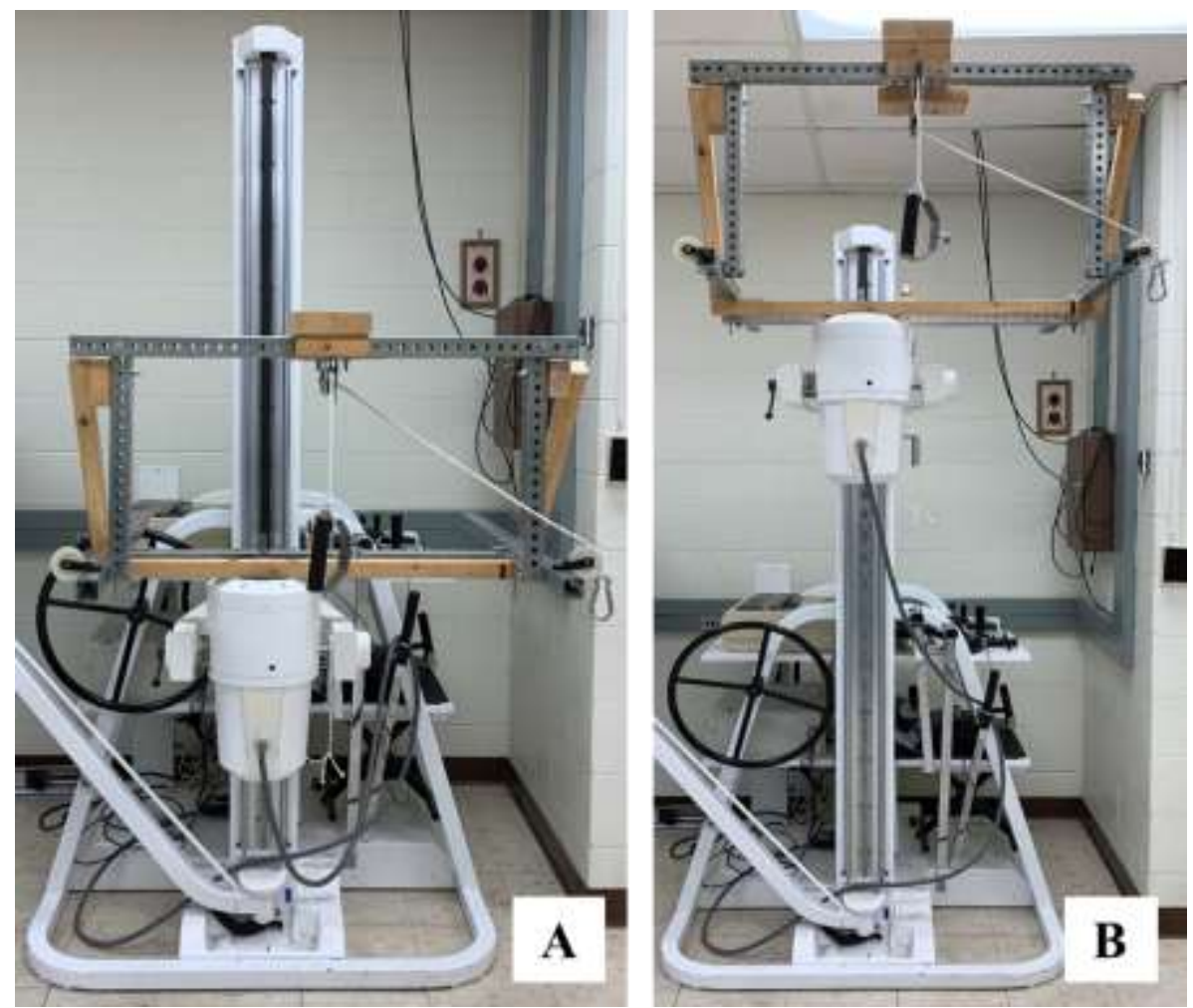

Figure 5: Adjustable custom-made force exertion device. A) at low height, B) at high height.

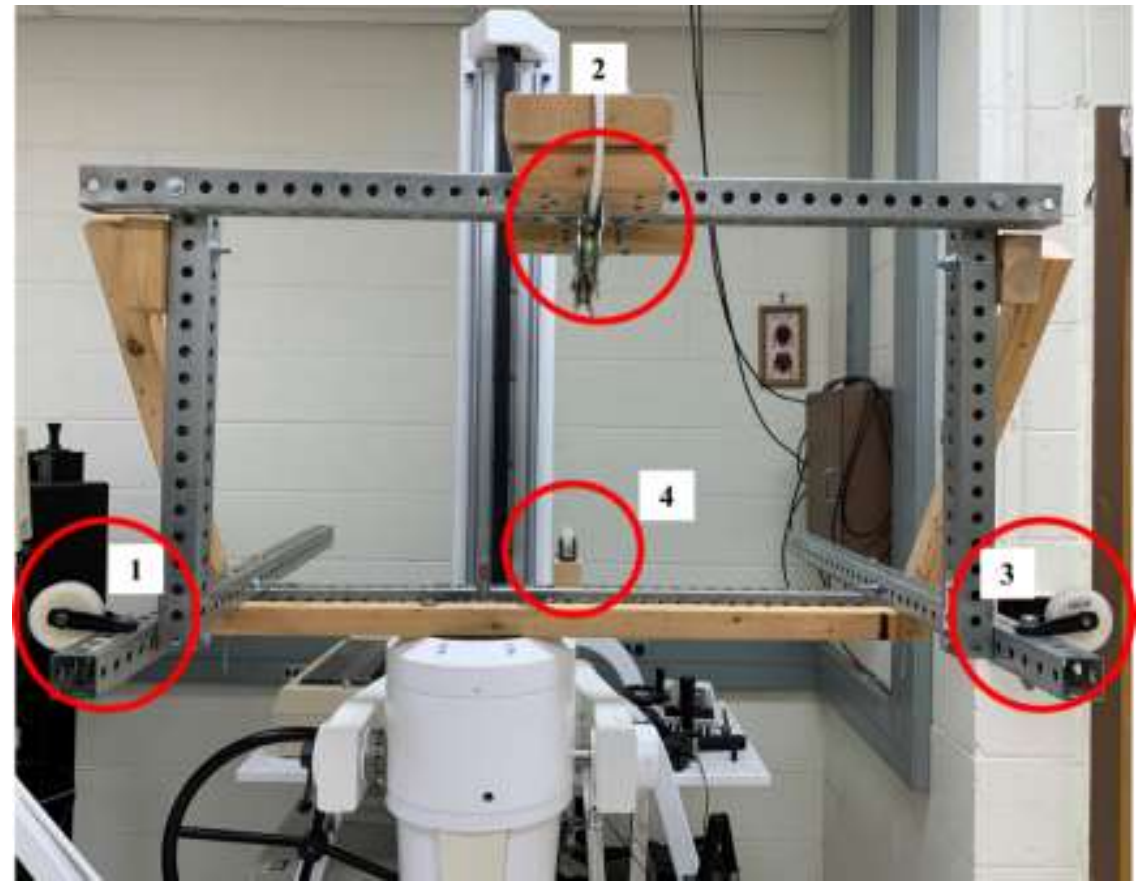


Figure 6: Pulley locations in the custom-made force exertion device. These locations facilitate force exertion in different directions 1) pull right direction, 2) pull down direction, 3) pull left direction, and 4) pull back direction. Note: there is no need to have a pulley for pull up direction.

\subsubsection{Surface Electromyography (SEMG) System}

The EMG data can be recorded using surface or intramuscular electrodes. Intramuscular (wire or needle) electrodes are used to record EMG data from deep muscles. Appropriate training is necessary to insert the electrodes into the muscles of interest. On the other hand, the surface electrodes are used to record EMG data from superficial muscles (Marras, 1992). In the current study, surface electrodes were used to record EMG data from shoulder muscles.

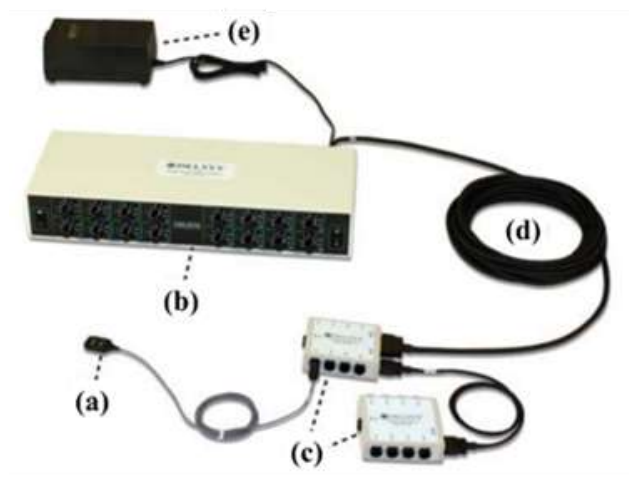

Figure 7: Parts of the Bagnoli -16 EMG system (a) EMG sensor, (b) main amplifier unit, (c) input modules, (d) input module cable, and (e) power supply.

Bagnoli -16 desktop EMG system (Delsys Inc., Boston, USA) was used to collect shoulder muscles SEMG data (Figure 7). The system mainly consisted of EMG electrodes (parallel bars from 99.9\% pure silver and $92 \mathrm{~dB}$ of Common-mode rejection ratio), the main amplifier unit, input modules, input cable, power supply, and other peripheral cables. To record the data, the EMG electrodes were placed on the muscles of interest and then 
connected to the input module, which can carry up to eight electrodes. Signals were then transferred from the input module to the amplifier and from there to the computer. The SEMG data were recorded at a frequency of $1000 \mathrm{~Hz}$.

\subsubsection{Other Equipment}

Three weights ( 0 lb., 2.5 lb., and 5 lb.) were used to create different force level conditions. A digital angle finder (7-inch protractor with high accuracy \pm 0.3 degree) were used for shoulder angle measurements. Figure 8 shows the angle protractor.
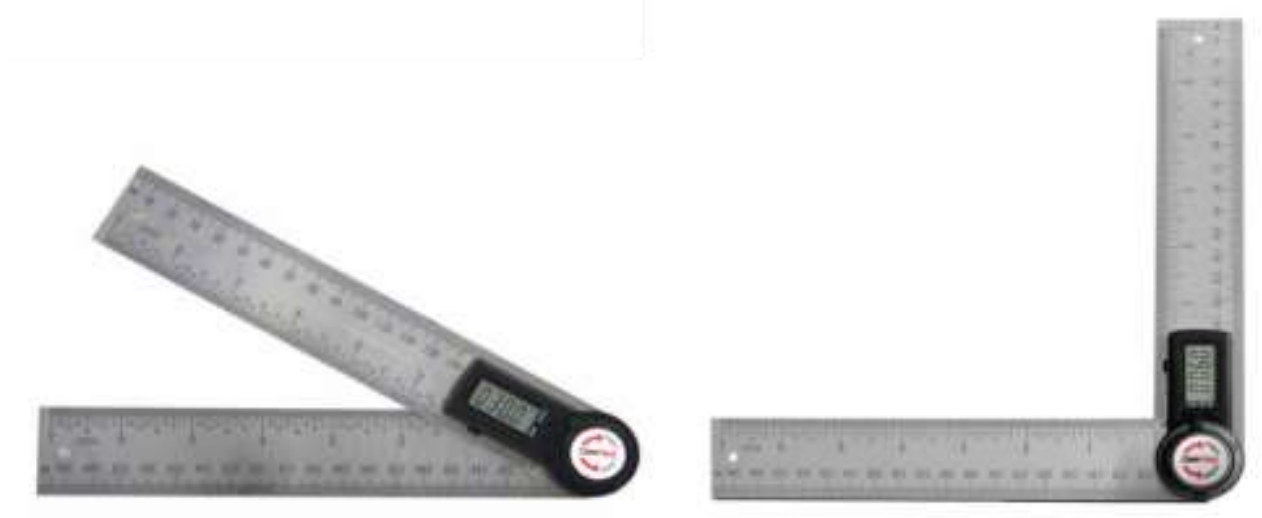

Figure 8: Digital angle protractor

\subsubsection{Experimental design}

A full factorial design was used in this research. Factor 1, shoulder joint angle, were treated at two fixed levels: $60^{\circ}$ and $120^{\circ}$. Shoulder elevation angles were selected such that a range of postures during routine industry tasks can be captured. An interval of $60^{\circ}$ was used to separate the shoulder joint angles, i.e. below shoulder level $\left(60^{\circ}\right)$ and above shoulder level or overhead elevation $\left(120^{\circ}\right)$. Similar angles were previously used in a number of studies (Antony \& Keir, 2010; Garg et al., 2006; Sporrong et al., 1995). Factor 2, shoulder/anatomical plane, were treated at two fixed levels: sagittal plane and scapular plane. The selection of these planes was partly motivated by the findings of Antony \& 
Keir, (2010), Kai et al.,(2012), and Sporrong et al., (1995). They reported that shoulder planes, (sagittal and scapular), had a significant effect on the EMG signals. Furthermore, these planes when combined with the selected joint angles cover majority of reach and force exertion envelop for the shoulder joint. Factor 3, force level, were treated at three fixed levels: $0 \mathrm{lb}$., $2.5 \mathrm{lb}$, and $5 \mathrm{lb}$. The force levels were determined based on the findings of preliminary testing. During this testing, we found that force levels greater than $5 \mathrm{lb}$. were very difficult for some participants to resist for 10 seconds and had a higher chance of causing injury or developing muscle fatigue. In addition, we were interested in evaluating the impact of low and mid force levels on the EMG signals. Therefore, a difference of 2.5 lb. was maintained between the force levels. Factor 4, force direction, were treated at five fixed levels: pull back (PB), pull down (PD), pull left (PL), pull right (PR), and pull up (PU). The force directions were based on the findings of our preliminary study Alasim et al. (2019). In this study, we evaluated the effect of force direction and force level on shoulder muscle activity, and we found that pull up and pull right had the highest activation followed by pull left.

Thus, there were a total of 60 different experimental conditions ( 2 shoulder joint angles $\times 2$ shoulder planes $\times 3$ force levels $\times 5$ force direction). Each task was performed for 10 seconds, and a 1-minute resting time was provided between the tasks. Each condition was repeated twice, and therefore, a total of 120 tasks were performed by each participant. The trial order was randomized. 

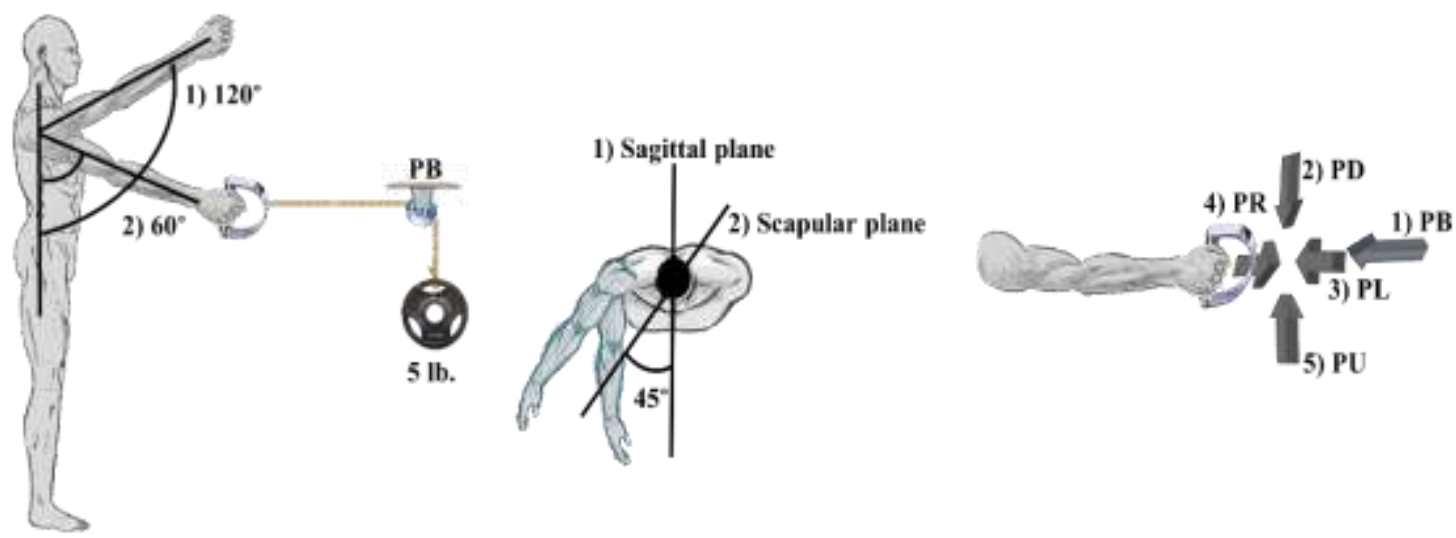
(A) shoulder joint angle
(B) shoulder plane
(C) Force direction

Figure 9: Independent factors and their levels

\subsubsection{Muscle Selection}

It is important to select appropriate muscles that play contributory roles in stabilizing shoulder joint during manual exertions. In a few studies on static exertions and shoulder stability, the supraspinatus and infraspinatus were found to be the major contributing rotator cuff muscles (Alizadehkhaiyat et al., 2011). The deltoid, biceps and triceps muscles were also identified as contributing shoulder muscles during static arm exertions (Hary et al., 1982; Nussbaum, 2001). Based on the findings from previous SEMG studies on the shoulder complex and the anatomical structure and contribution of individual muscles in stabilizing shoulder joint, the following seven muscles were selected in this study: supraspinatus, infraspinatus, middle deltoid, anterior deltoid, posterior deltoid, biceps, and triceps.

\subsubsection{Experimental Data Collection Procedure}

After participants arrived at the laboratory, they were provided with a tour of the experimental set-up. Equipment, data collection procedures, and specifics of the 
experimental tasks were explained to the participants and their signatures were obtained on a consent form approved by the local Institutional Review Board (Appendix B). A set of anthropometric measures such as height, weight, and age were then recorded for each participant. After that, EMG data collection preparation started. The participants were prepared for SEMG data collection by shaving, rubbing and cleaning the skin with $70 \%$ alcohol prior to the placement of the SEMG electrodes. Table 10 shows the electrode locations for the shoulder muscles.

Participants then performed the experimental trials. They were in a standing position and a few practice trials were performed to get the participants familiarized with the experiment. During the actual trials, the participants were required to resist a force levels ( $0 \mathrm{lb}$., 2.5lb., or $5 \mathrm{lb}$.) in one of the directions (PB, PD, PL, PR, or PU) for 10 seconds using a shoulder angle $\left(60^{\circ}\right.$ or $\left.120^{\circ}\right)$ in one of the shoulder planes (sagittal or scapular). Each trial had two repetitions. A 1- minute resting time was provided between trials. A total of 120 trials were performed and the SEMG data were recorded continuously during the exertions. Figure 10-12 illustrate a few experimental tasks/exertions. In addition, four reference contractions were performed. In each of these contractions, participants were asked to elevate their shoulder $90^{\circ}$ in the sagittal plane, while holding a $4 \mathrm{lb}$. force level for 10 seconds. The main purpose of these contractions was to ensure that the participants did not develop LMF while conducting the experimental trials. The first reference contraction was performed after completing $25 \%$ of the experiment. And second, third and fourth reference contractions were performed after completing $50 \%, 75 \%$, and $100 \%$ of the experiment, respectively. 
Table 10: EMG locations of shoulder muscles.

\begin{tabular}{|c|c|c|}
\hline & Muscle & Electrodes position \\
\hline 1 & Supraspinatus & $\begin{array}{l}\text { Midpoint and two fingers-breadths anterior to the scapular } \\
\text { spine. }\end{array}$ \\
\hline 2 & Infraspinatus & $\begin{array}{l}\text { Midpoint and two fingers-breadths below and parallel to the } \\
\text { scapular spine. }\end{array}$ \\
\hline 3 & Middle deltoid & $\begin{array}{l}\text { Midline of the lateral surface of the arm, one fourth of the } \\
\text { distance from the acromion to the elbow. }\end{array}$ \\
\hline 4 & Anterior deltoid & $\begin{array}{l}\text { Two to three fingers- breadths below the acromion process, } \\
\text { over the muscle belly, in line with the fibers. }\end{array}$ \\
\hline 5 & Posterior deltoid & $\begin{array}{l}\text { Two fingers-widths behind the angle of the acromion, over } \\
\text { the muscle belly, in line with the fibers. }\end{array}$ \\
\hline 6 & Biceps & Midpoint between the acromioclavicular and elbow joint. \\
\hline 7 & Triceps & $\begin{array}{l}\text { Midpoint between acromion of the scapula and the ulna } \\
\text { olecranon. }\end{array}$ \\
\hline
\end{tabular}
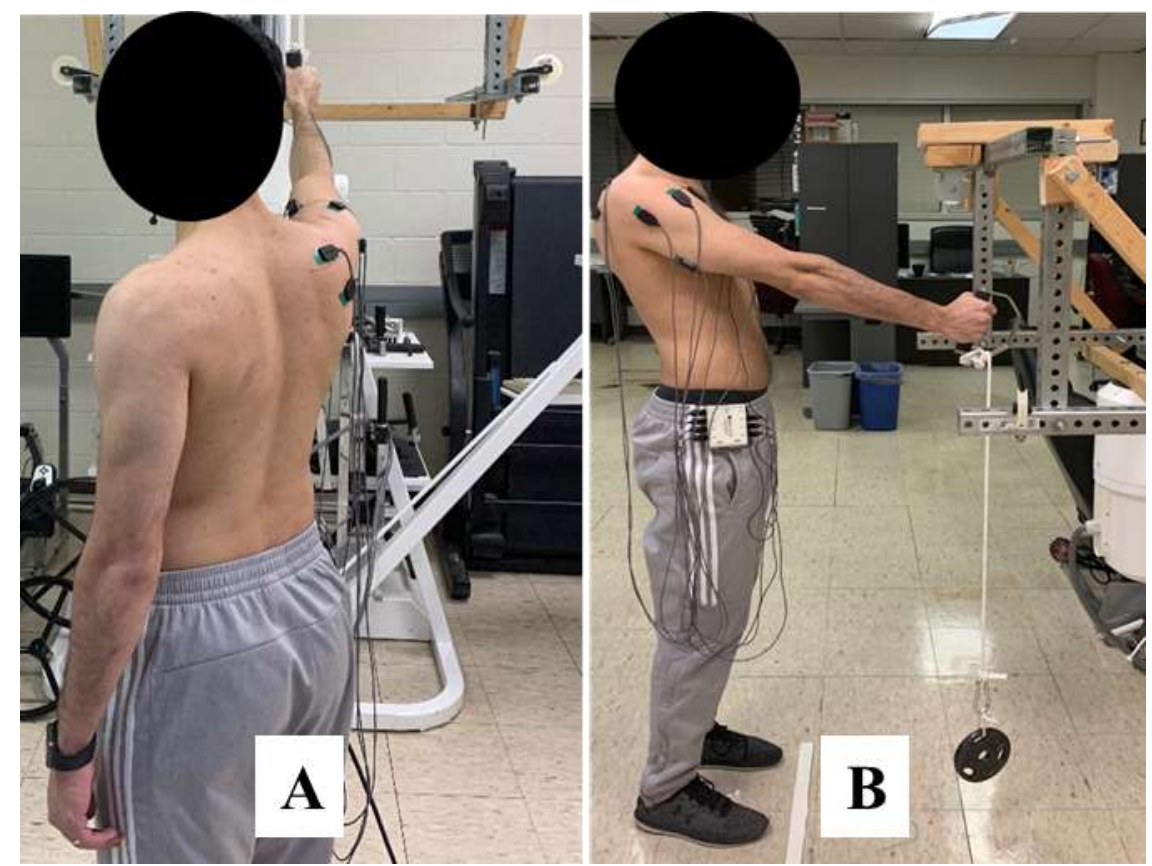

Figure 10: A participant performing pull up (PU) exertion in two different postures: (A) shoulder angle is elevated $120^{\circ}$ in the scapular plane and (B) shoulder angle is elevated $60^{\circ}$ in the sagittal plane 

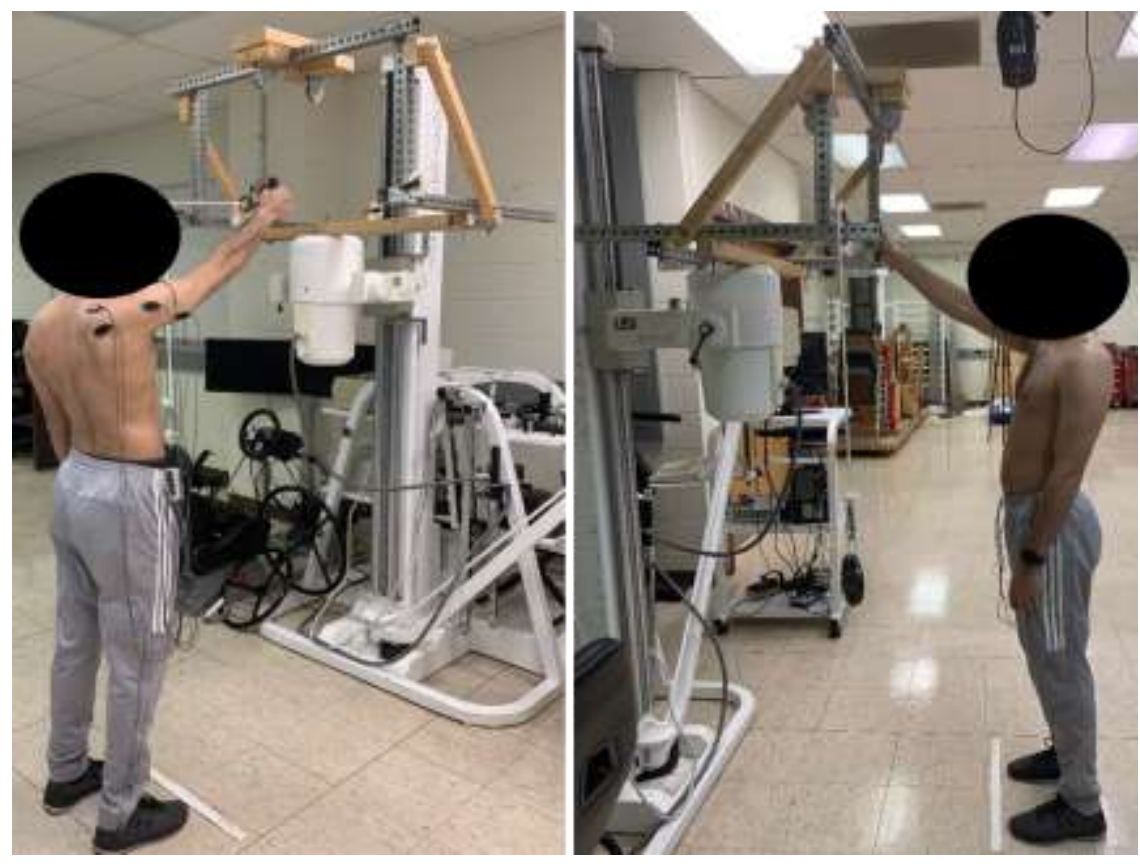

Figure 11: A participant performing a pull right (PR) direction while shoulder angle is elevated $120^{\circ}$ in the sagittal plane.
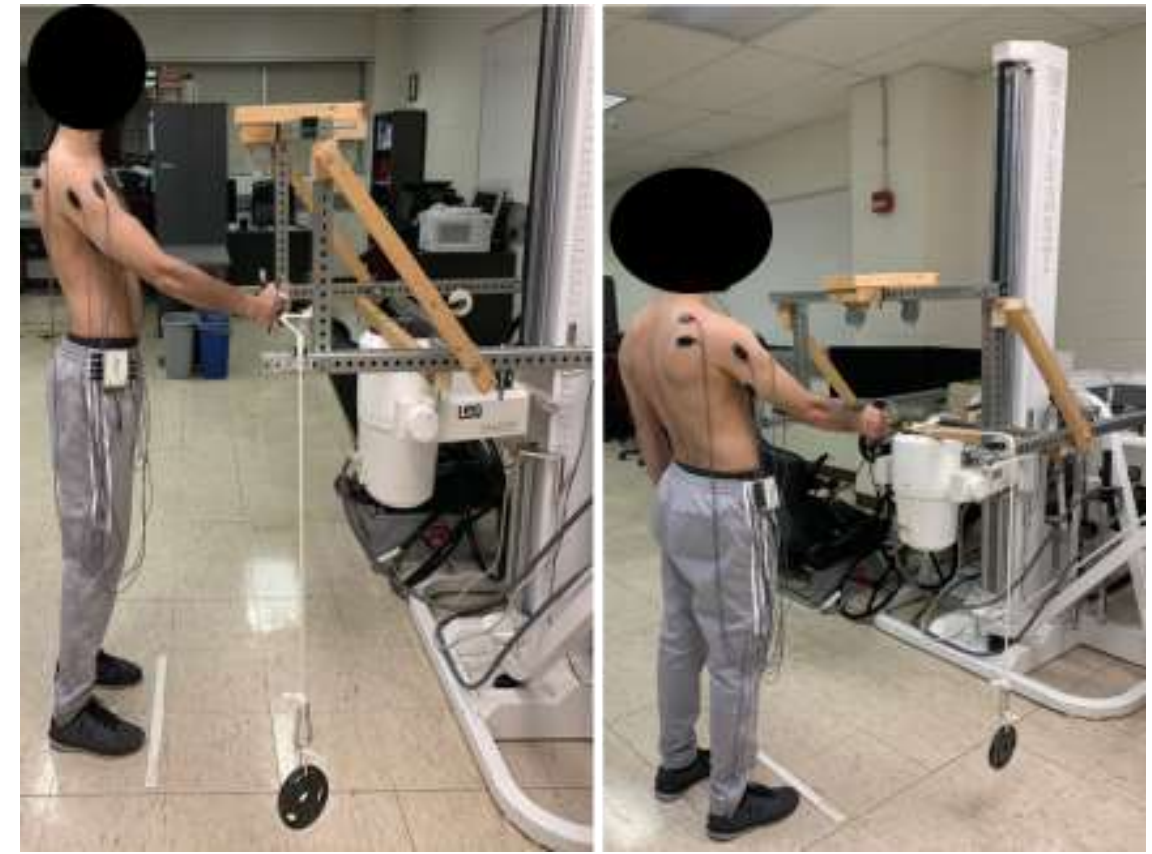

Figure 12: A participant performing a pull left (PL) direction while shoulder angle is elevated $60^{\circ}$ in the sagittal plane.

\subsubsection{Data Processing}

For each experimental trial, the EMG data were recorded for a duration of 10 seconds was subjected to analysis using a window size of half a second. Thus, a total of 20 
windows were estimated per trial, and the first and 20th values were discarded from further analysis. SEMG measures (RMS, MAV, ZC, MnPF, MdPF, and $\mathrm{PFB}_{11-22 \mathrm{~Hz}}$ ) for each participant were normalized with respect to the peak value of all trials.

There are various methods that have been used to quantify variability in the data:

- Sample variance, $V=S D^{2}$, where $S D=\sqrt{\frac{\sum(x-\bar{x})^{2}}{n-1}}$

- Coefficient of variation (applied to the normalized data), C.V $=$ Standard deviation mean

- $\mathrm{r}^{2}$ value associated with a predictor variable in a regression model

- Standard deviation of the residuals $S_{\mathrm{r}}$ or $\mathrm{S}_{\mathrm{Res}}$

- Confidence interval of residual error ( $\pm 2 \mathrm{SE})$

- Square root of ANOVA's Mean Square Error (MSE)

After carefully evaluating the aforementioned methods, the square root of ANOVA's MSE, $(\sqrt{M S E})$, was selected as the most appropriate method as it account for variability due to main and interaction effects of all considered factors (shoulder joint angle, shoulder pane, force level, and force direction). Accordingly, RMS, MAV, ZC, MnPF, MdPF, and $\mathrm{PFB}_{11-22 \mathrm{~Hz}}$ were analyzed using four-way ANOVA for each muscle. Shoulder joint angle, shoulder pane, force level, and force direction factors were treated as fixed factors, and participants were treated as a random factor. Analysis of Variance ANOVA was performed to test the main and interaction effects of the selected factors on each muscle. Additionally, the variability in RMS, MAV, MnPF, MdPF ZC, and PFB ${ }_{11-22}$ $\mathrm{Hz}$ were estimated by using the square root of MSE $(\sqrt{M S E})$ found in ANOVA table. Statistical analysis was performed using Minitab 17. 
Similar data processing was performed on reference contraction trials. The EMG data recorded for a duration of 10 seconds was subjected to analysis using a window size of half a second. Thus, a total of 20 windows were estimated per trial, and the first and 20th values were discarded from further analysis. MdPF for each participant were normalized with respect to the peak value of all trials. Then, a one-way analysis of variance (ANOVA) was performed to test if there were any statistically significant differences across these four reference contractions.

\subsection{Results}

The objective of this study was to quantify the variability of SEMG measures in non-fatigued shoulder muscles. As explained in the experimental design (section (3.3.4)) and the experimental procedures (section (3.3.4.2)), twelve healthy (eight males and four females) right-hand dominant participants were recruited to participate in the data collection. The average height, weight, and age of the participants were $169.33 \pm 9.28 \mathrm{~cm}$, $69.92 \pm 13.94 \mathrm{~kg}$, and $28.5 \pm 3.71$ years, respectively. Table (11) exhibits the anthropometric data for the study participants.

Table 11: Participants anthropometric data

\begin{tabular}{ccccc}
\hline Subject number & Height $(\mathbf{c m})$ & Weight $(\mathbf{k g})$ & Age & Gender \\
\hline $\mathbf{1}$ & 175 & 64 & 30 & Male \\
$\mathbf{2}$ & 156 & 65 & 30 & Male \\
$\mathbf{3}$ & 170 & 90 & 34 & Male \\
$\mathbf{4}$ & 170 & 68 & 30 & Male \\
$\mathbf{5}$ & 173 & 71 & 23 & Male \\
$\mathbf{6}$ & 173 & 68 & 23 & Male \\
$\mathbf{7}$ & 183 & 100 & 33 & Male \\
$\mathbf{8}$ & 185 & 72 & 32 & Male \\
$\mathbf{9}$ & 165 & 50 & 29 & Female \\
$\mathbf{1 0}$ & 165 & 75 & 25 & Female \\
$\mathbf{1 1}$ & 157 & 53 & 26 & Female \\
$\mathbf{1 2}$ & 160 & 63 & 27 & Female \\
\hline Average & 169.33 & 69.92 & 28.50 &
\end{tabular}




\subsubsection{Reference contractions}

As explained in the experimental procedures (section (3.3.4.2)), four reference contractions were performed in between the 120 trials - at $25 \%, 50 \%, 75 \%$, and after completion of the experiment. The EMG data recorded during these contractions was used to track the development of LMF due to the performance of the experimental trials. For each of the seven muscles, a one-way analysis of variance (ANOVA) was performed to test if there were any statistically significant differences in the MdPF values between the four reference contractions. No statistically significant differences in the MdPF values were observed between the four reference contractions in all of the selected muscles except for the anterior deltoid ( $\mathrm{p}$-value $=0.033$ ) (Table 12). Post hoc analysis for the anterior deltoid muscle revealed that there was a statistically significant difference between trials recorded at 25\% completion and 75\% completion (Table (13) and Figure (13)). However, an ascending trend in the MdPF values was observed. Muscle fatigue is expected to decrease the MdPF values due to a shift in the power spectral density to lower frequencies. Thus, although the MdPF values were statistically different, the trend in the values suggest that no LMF was developed for the anterior deltoid muscle.

Table 12: Results of one-way ANOVA analysis for reference contractions

\begin{tabular}{c|ccccccc}
\hline MdPF & Supraspinatus & Infraspinatus & $\begin{array}{c}\text { Middle } \\
\text { deltoid }\end{array}$ & $\begin{array}{c}\text { Anterior } \\
\text { deltoid }\end{array}$ & $\begin{array}{c}\text { Posterior } \\
\text { deltoid }\end{array}$ & Biceps & Triceps \\
\hline p-value & 0.182 & 0.259 & 0.269 & $\mathbf{0 . 0 3 3}$ & 0.460 & 0.057 & 0.146 \\
\hline
\end{tabular}


Table 13: Anterior deltoid post hoc analysis

\begin{tabular}{ccccc}
\hline Anterior deltoid & Trial 1 & Trial 2 & Trial 3 & Trial 4 \\
\hline Mean & 0.6801 & 0.6818 & 0.7025 & 0.6865 \\
& B & B & & B \\
& & A & A & A \\
\hline
\end{tabular}

\section{Anterior deltoid}

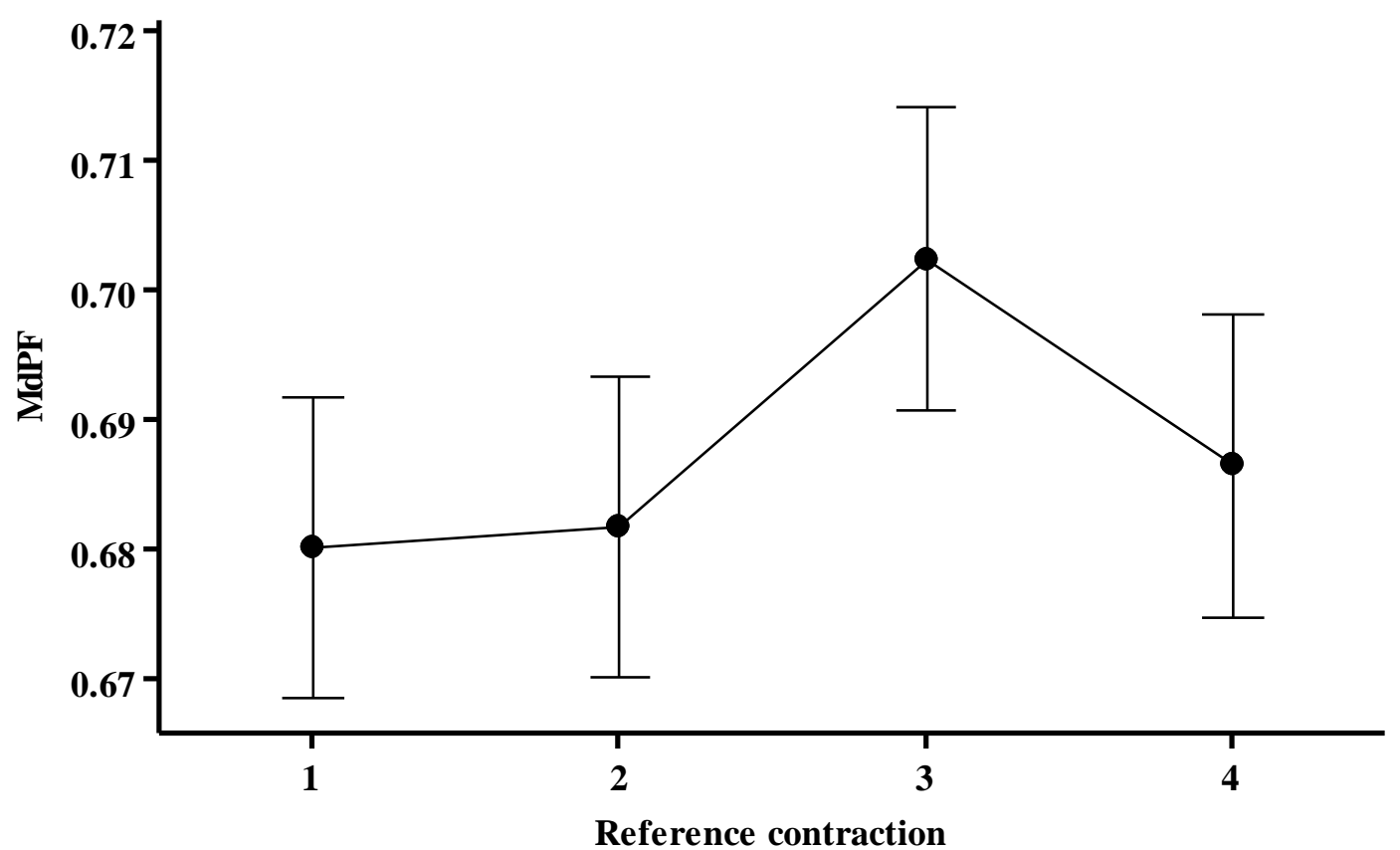

Figure 13: MdPF interval plot for Anterior deltoid. Error bars represent standard deviation

\subsubsection{SEMG measures}

The results for the SEMG measures are organized into six subsections, one per measure in the following sequence RMS, MAV, ZC, MnPF, MdPF, and PFB. ANOVA results and variation, based on the square root of the MSE $(\sqrt{M S E})$, are presented in each subsection. We considered a factor as statistically significant when the p-value is $\leq 0.05$. In addition, error bars in the figures below represent the standard deviation. 


\subsubsection{Root mean square (RMS)}

Among the seven muscles selected in this study, the largest RMS variation was observed for the supraspinatus muscle (11.09\%) and the smallest RMS variation was observed for the posterior deltoid muscle $(7.87 \%)$. Very similar variations were observed for supraspinatus, triceps and anterior deltoid muscles - $(11.09 \%, 11.05 \%$, and $11.00 \%$, respectively). (Table 14). All main effects due to the factors joint angle, force level, force direction, and shoulder plane on RMS were statistically significant ( $\mathrm{p}$-value $\leq 0.001$ ) for all muscles except for the effect of shoulder plane on biceps muscle ( $\mathrm{p}$-value $=0.148$ ). Thus, for RMS, the data rejected the null hypothesis and the alternative hypothesis was accepted. Specifically, the following trends were observed - RMS values increased with the increase of force level in pull right and pull up directions. The RMS values decreased with the increase of force level in pull down direction. 
Table 14: Main effect of joint angle, shoulder plane, force level, and force direction on RMS, and variation based on $\sqrt{M S E}$. Statistically significant p-values are highlighted in bold font

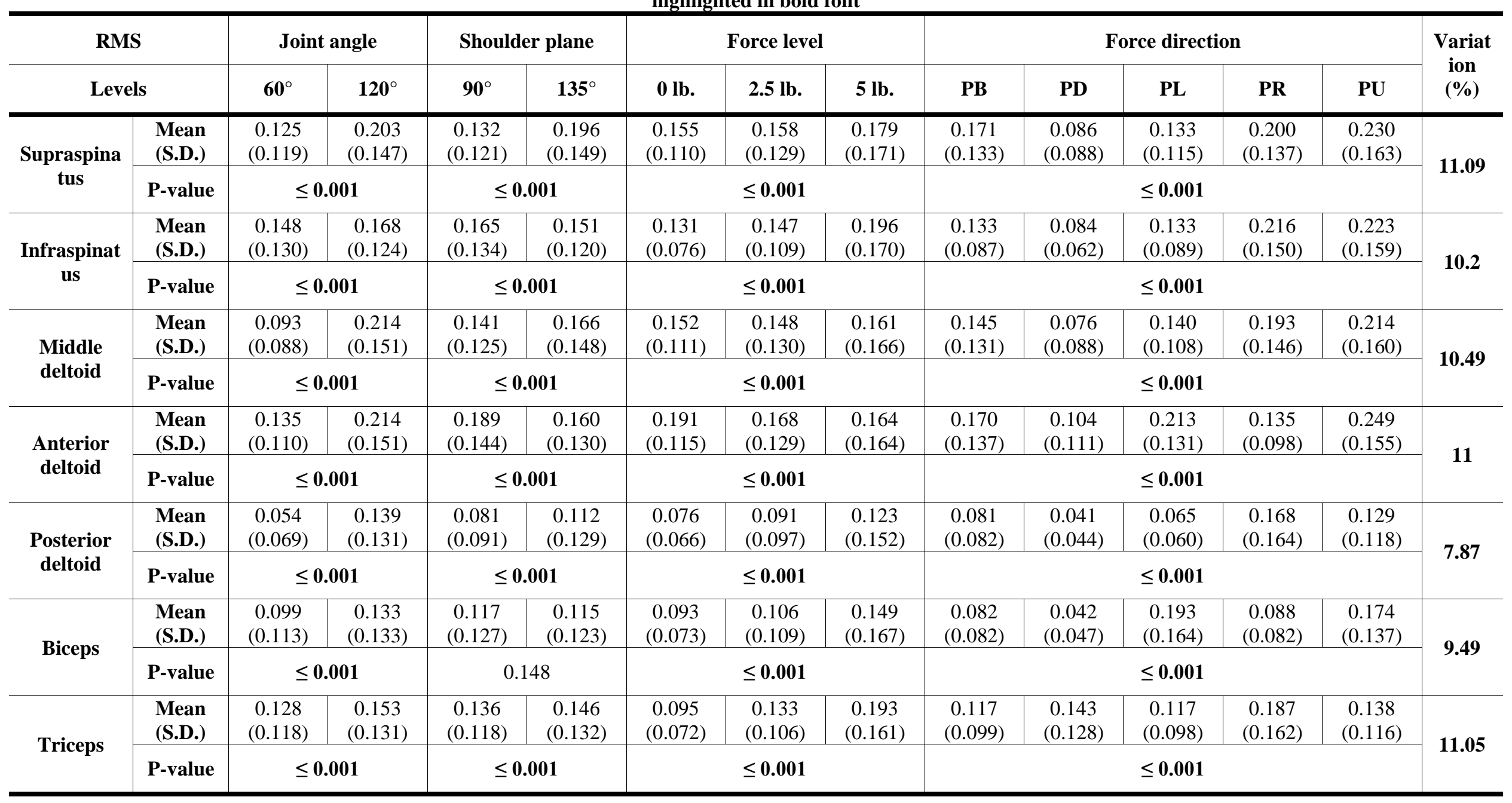


Supraspi natus

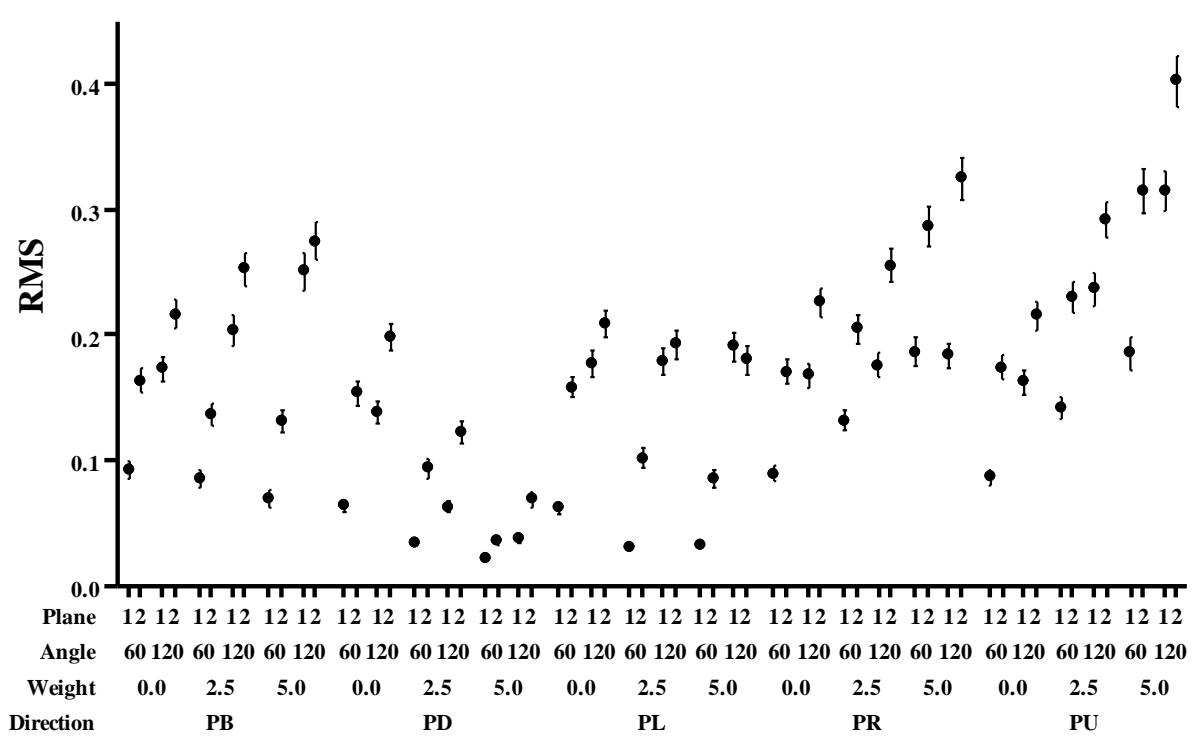

Infraspi natus

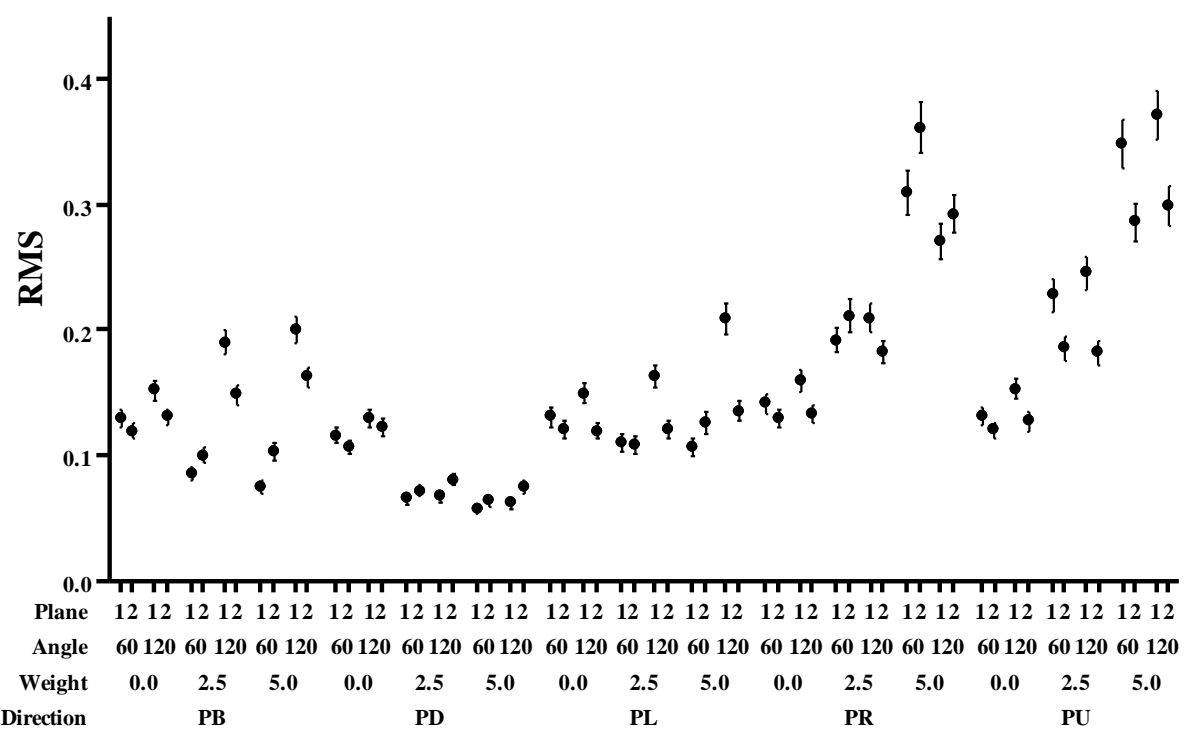

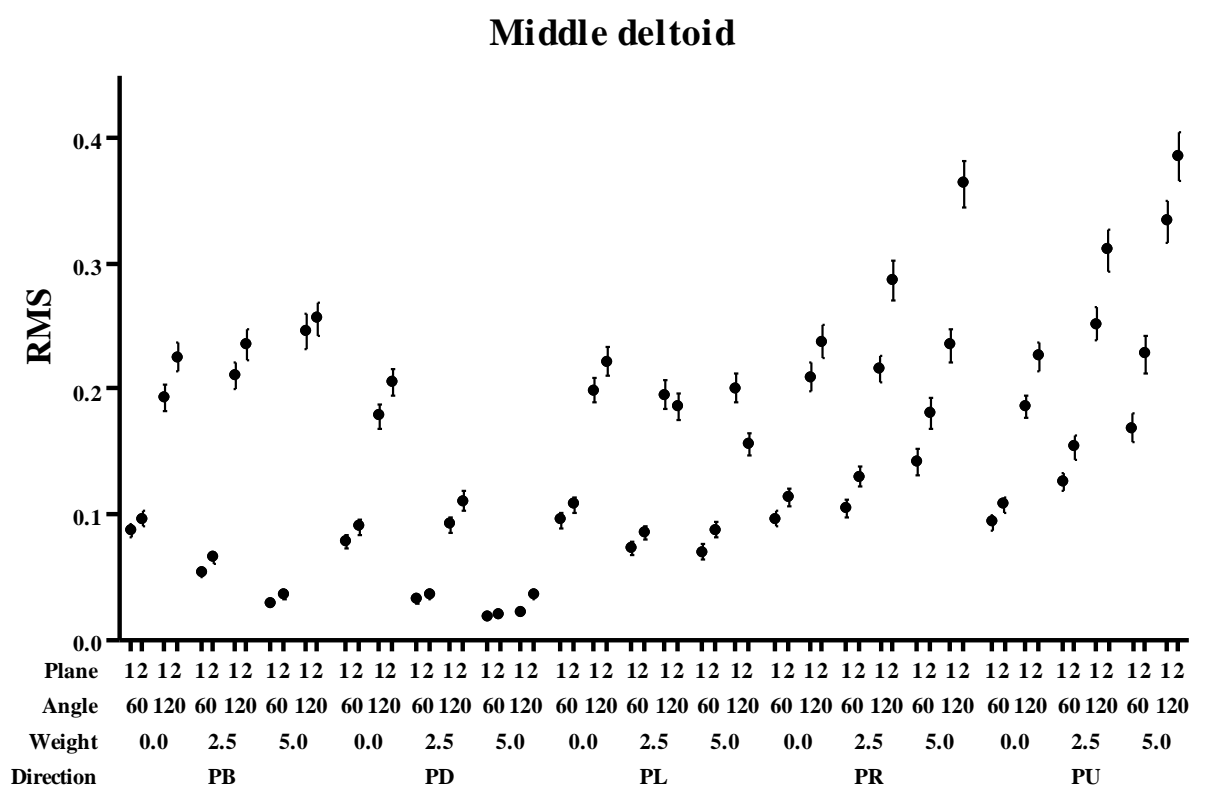

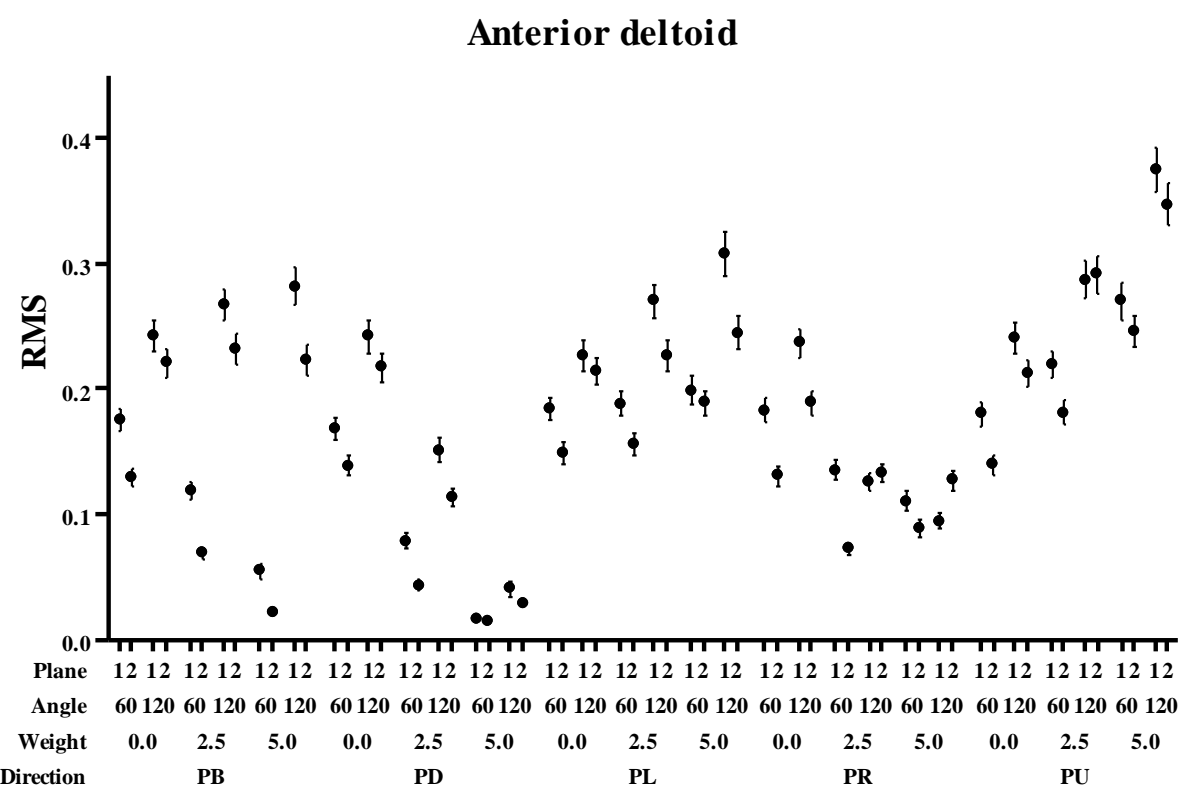



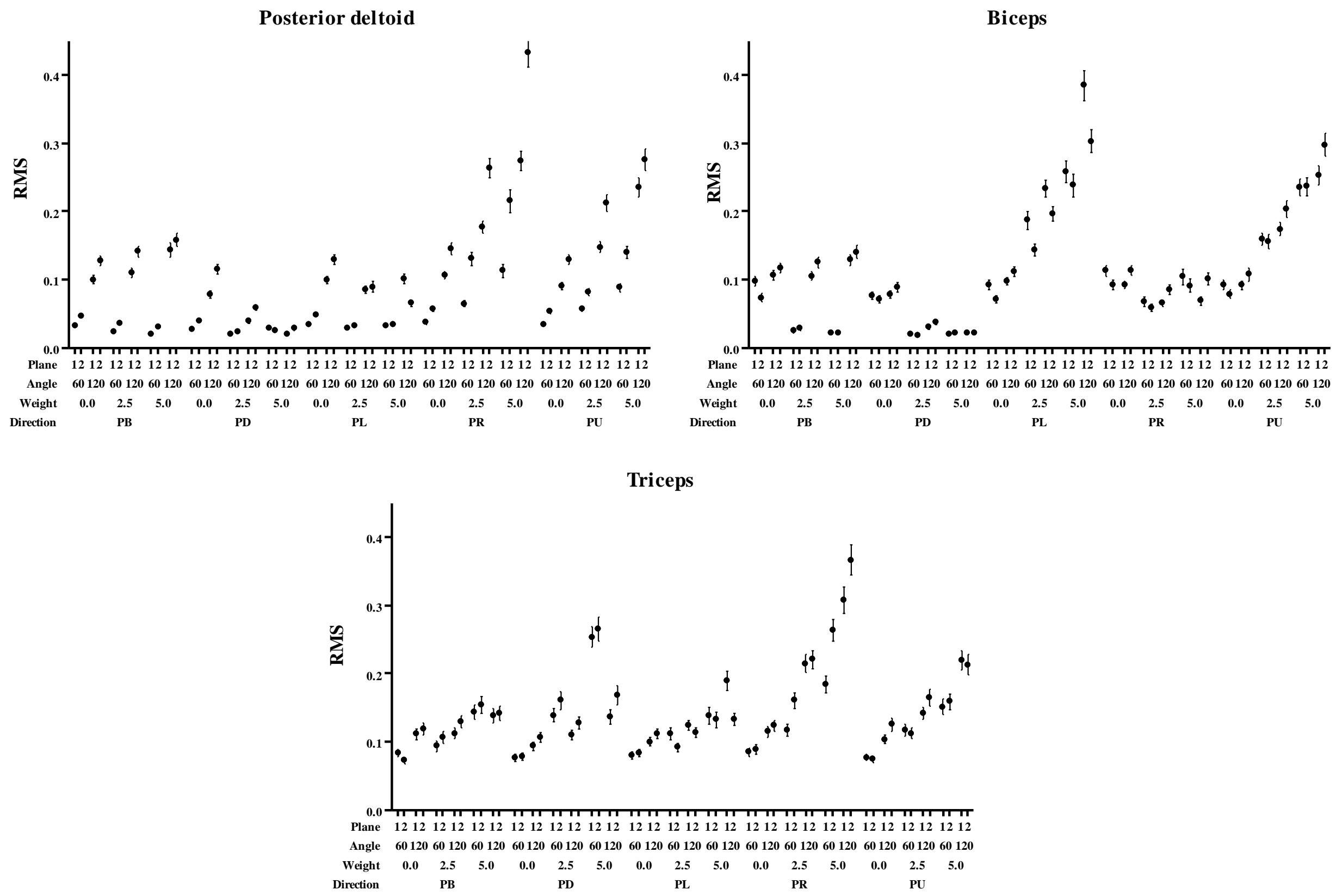

Figure 14: RMS interval plot. Error bars represent standard deviation. Note: Plane axis label represent 1) sagittal $\left.\left(\mathbf{9 0}^{\circ}\right) 2^{2}\right) s^{2 a p u l a r}\left(135^{\circ}\right)$ 


\subsubsection{Mean absolute value (MAV)}

Among the seven muscles selected in this study, the largest MAV variation was observed for the triceps muscle $(10.15 \%)$ and the smallest MAV variation was observed for the posterior deltoid muscle (7.14\%). Very similar variations were observed for the triceps and anterior deltoid muscles - (10.15\%, and $10.10 \%$, respectively) (Table 15). All main effects due to the factors joint angle, force level, force direction, and shoulder plane on MAV were statistically significant (pvalue $\leq 0.001$ ) for all muscles except for the effect of shoulder plane on biceps muscle ( $\mathrm{p}$-value $=$ 0.487). Thus, for MAV, the data rejected the null hypothesis and the alternative hypothesis was accepted. Specifically, the following trends were observed - MAV values increased with the increase of shoulder joint angle. The MAV values decreased with the increase of force level in in pull down direction. 
Table 15: Main effect of joint angle, shoulder plane, force level, and force direction on MAV, and variation based on $\sqrt{M S E}$. Statistically significant p-values are highlighted in bold font

\begin{tabular}{|c|c|c|c|c|c|c|c|c|c|c|c|c|c|c|}
\hline \multirow{2}{*}{\multicolumn{2}{|c|}{$\begin{array}{c}\text { MAV } \\
\text { Levels }\end{array}$}} & \multicolumn{2}{|c|}{ Joint angle } & \multicolumn{2}{|c|}{ Shoulder plane } & \multicolumn{3}{|c|}{ Force level } & \multicolumn{5}{|c|}{ Force direction } & \multirow{2}{*}{$\begin{array}{c}\text { Variatio } \\
\text { n (\%) }\end{array}$} \\
\hline & & $60^{\circ}$ & $120^{\circ}$ & $90^{\circ}$ & $135^{\circ}$ & 0 lb. & $2.5 \mathrm{lb}$ & $5 \mathrm{lb}$. & PB & PD & PL & PR & PU & \\
\hline \multirow{2}{*}{ Supraspinatus } & $\begin{array}{l}\text { Mean } \\
\text { (S.D.) }\end{array}$ & $\begin{array}{c}0.119 \\
(0.109)\end{array}$ & $\begin{array}{c}0.196 \\
(0.135)\end{array}$ & $\begin{array}{c}0.126 \\
(0.112)\end{array}$ & $\begin{array}{c}0.188 \\
(0.136)\end{array}$ & $\begin{array}{c}0.148 \\
(0.098)\end{array}$ & $\begin{array}{c}0.151 \\
(0.119)\end{array}$ & $\begin{array}{c}0.172 \\
(0.160)\end{array}$ & $\begin{array}{c}0.164 \\
(0.123)\end{array}$ & $\begin{array}{c}0.078 \\
(0.079)\end{array}$ & $\begin{array}{c}0.127 \\
(0.103)\end{array}$ & $\begin{array}{c}0.191 \\
(0.121)\end{array}$ & $\begin{array}{c}0.227 \\
(0.151)\end{array}$ & \multirow{2}{*}{9.7} \\
\hline & P-value & \multicolumn{2}{|c|}{$\leq \mathbf{0 . 0 0 1}$} & \multicolumn{2}{|c|}{$\leq \mathbf{0 . 0 0 1}$} & \multicolumn{3}{|c|}{$\leq \mathbf{0 . 0 0 1}$} & \multicolumn{5}{|c|}{$\leq 0.001$} & \\
\hline Infraspinatus & P-value & \multicolumn{2}{|c|}{$\leq 0.001$} & \multicolumn{2}{|c|}{$\leq \mathbf{0 . 0 0 1}$} & \multicolumn{3}{|c|}{$\leq 0.001$} & \multicolumn{5}{|c|}{$\leq 0.001$} & 8.83 \\
\hline \multirow{2}{*}{ Middle deltoid } & $\begin{array}{l}\text { Mean } \\
\text { (S.D.) }\end{array}$ & $\begin{array}{c}0.097 \\
(0.082) \\
\end{array}$ & $\begin{array}{c}0.230 \\
(0.147) \\
\end{array}$ & $\begin{array}{c}0.150 \\
(0.122) \\
\end{array}$ & $\begin{array}{c}0.178 \\
(0.147) \\
\end{array}$ & $\begin{array}{c}0.163 \\
(0.106) \\
\end{array}$ & $\begin{array}{c}0.157 \\
(0.128) \\
\end{array}$ & $\begin{array}{c}0.171 \\
(0.167) \\
\end{array}$ & $\begin{array}{c}0.155 \\
(0.129) \\
\end{array}$ & $\begin{array}{c}0.081 \\
(0.089) \\
\end{array}$ & $\begin{array}{c}0.150 \\
(0.107) \\
\end{array}$ & $\begin{array}{c}0.204 \\
(0.138) \\
\end{array}$ & $\begin{array}{c}0.230 \\
(0.158) \\
\end{array}$ & \multirow{2}{*}{9.49} \\
\hline & P-value & \multicolumn{2}{|c|}{$\leq 0.001$} & \multicolumn{2}{|c|}{$\leq 0.001$} & \multicolumn{3}{|c|}{$\leq 0.001$} & \multicolumn{5}{|c|}{$\leq 0.001$} & \\
\hline \multirow{2}{*}{$\begin{array}{c}\text { Anterior } \\
\text { deltoid }\end{array}$} & $\begin{array}{l}\text { Mean } \\
\text { (S.D.) }\end{array}$ & $\begin{array}{c}0.140 \\
(0.106)\end{array}$ & $\begin{array}{c}0.227 \\
(0.146)\end{array}$ & $\begin{array}{c}0.198 \\
(0.139)\end{array}$ & $\begin{array}{c}0.169 \\
(0.128)\end{array}$ & $\begin{array}{c}0.202 \\
(0.109) \\
\end{array}$ & $\begin{array}{c}0.176 \\
(0.125)\end{array}$ & $\begin{array}{c}0.172 \\
(0.162)\end{array}$ & $\begin{array}{c}0.180 \\
(0.133)\end{array}$ & $\begin{array}{c}0.110 \\
(0.114)\end{array}$ & $\begin{array}{c}0.224 \\
(0.123)\end{array}$ & $\begin{array}{c}0.141 \\
(0.094)\end{array}$ & $\begin{array}{c}0.262 \\
(0.144)\end{array}$ & \multirow{2}{*}{10.1} \\
\hline & P-value & \multicolumn{2}{|c|}{$\leq 0.001$} & \multicolumn{2}{|c|}{$\leq 0.001$} & \multicolumn{3}{|c|}{$\leq 0.001$} & \multicolumn{5}{|c|}{$\leq 0.001$} & \\
\hline \multirow{2}{*}{$\begin{array}{c}\text { Posterior } \\
\text { deltoid }\end{array}$} & $\begin{array}{l}\text { Mean } \\
\text { (S.D.) }\end{array}$ & $\begin{array}{c}0.056 \\
(0.069)\end{array}$ & $\begin{array}{c}0.142 \\
(0.125)\end{array}$ & $\begin{array}{c}0.082 \\
(0.087)\end{array}$ & $\begin{array}{c}0.117 \\
(0.126)\end{array}$ & $\begin{array}{c}0.078 \\
(0.060)\end{array}$ & $\begin{array}{c}0.093 \\
(0.093)\end{array}$ & $\begin{array}{c}0.127 \\
(0.151)\end{array}$ & $\begin{array}{c}0.082 \\
(0.076)\end{array}$ & $\begin{array}{c}0.042 \\
(0.041)\end{array}$ & $\begin{array}{c}0.065 \\
(0.054)\end{array}$ & $\begin{array}{c}0.175 \\
(0.159)\end{array}$ & $\begin{array}{c}0.133 \\
(0.114) \\
\end{array}$ & \multirow{2}{*}{7.14} \\
\hline & P-value & \multicolumn{2}{|c|}{$\leq 0.001$} & \multicolumn{2}{|c|}{$\leq 0.001$} & & $\leq 0.001$ & & & & $\leq 0.001$ & & & \\
\hline Ricens & $\begin{array}{l}\text { Mean } \\
\text { (S.D.) }\end{array}$ & $\begin{array}{c}0.102 \\
(0.108)\end{array}$ & $\begin{array}{c}0.142 \\
(0.130)\end{array}$ & $\begin{array}{c}0.122 \\
(0.122)\end{array}$ & $\begin{array}{c}0.122 \\
(0.121)\end{array}$ & $\begin{array}{c}0.099 \\
(0.073)\end{array}$ & $\begin{array}{c}0.112 \\
(0.107)\end{array}$ & $\begin{array}{c}0.154 \\
(0.161)\end{array}$ & $\begin{array}{c}0.089 \\
(0.086)\end{array}$ & $\begin{array}{c}0.047 \\
(0.050)\end{array}$ & $\begin{array}{c}0.196 \\
(0.150)\end{array}$ & $\begin{array}{c}0.098 \\
(0.088)\end{array}$ & $\begin{array}{c}0.181 \\
(0.131)\end{array}$ & 906 \\
\hline & P-value & $\leq$ & & & & & $\leq 0.001$ & & & & $\leq 0.001$ & & & \\
\hline Tricens & $\begin{array}{l}\text { Mean } \\
\text { (S.D.) }\end{array}$ & $\begin{array}{c}0.132 \\
(0.113)\end{array}$ & $\begin{array}{c}0.161 \\
(0.125)\end{array}$ & $\begin{array}{c}0.141 \\
(0.111)\end{array}$ & $\begin{array}{c}0.152 \\
(0.128)\end{array}$ & $\begin{array}{c}0.099 \\
(0.068)\end{array}$ & $\begin{array}{c}0.140 \\
(0.101)\end{array}$ & $\begin{array}{c}0.201 \\
(0.152)\end{array}$ & $\begin{array}{c}0.121 \\
(0.094)\end{array}$ & $\begin{array}{c}0.153 \\
(0.126)\end{array}$ & $\begin{array}{c}0.117 \\
(0.0840\end{array}$ & $\begin{array}{c}0.198 \\
(0.153)\end{array}$ & $\begin{array}{c}0.143 \\
(0.110)\end{array}$ & 1015 \\
\hline & P-value & $\leq$ & & $\leq$ & & & $\leq 0.001$ & & & & $\leq 0.001$ & & & \\
\hline
\end{tabular}



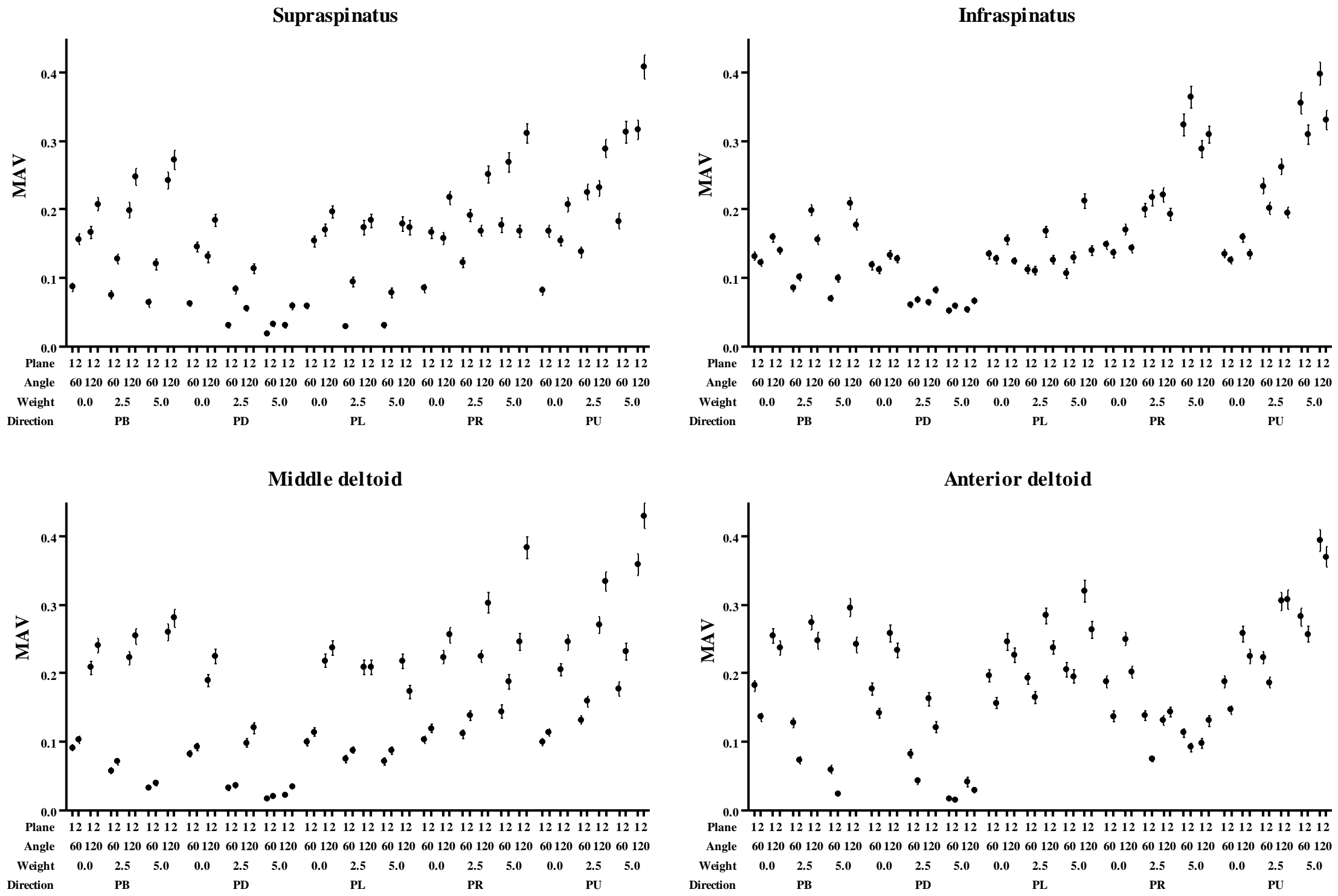

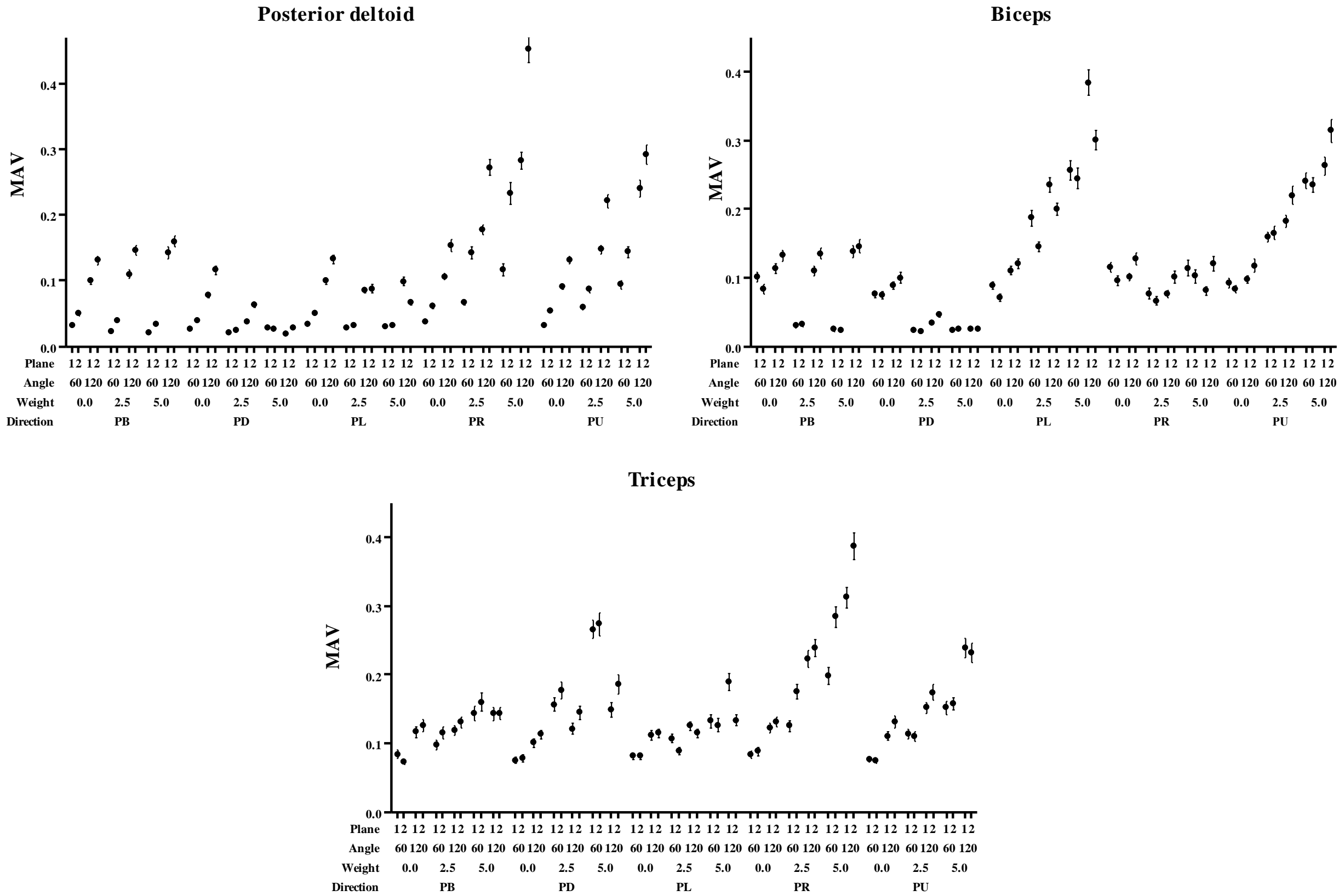

Figure 15: MAV interval plot for each muscle. Error bars represent standard deviation. Note: Plane axis label represent 1) sagittal $\left.\left(90^{\circ}\right) 2\right)$ scapular $\left(135^{\circ}\right)$ 


\subsubsection{Zero crossing (ZC)}

Among the seven muscles tested in this study, the largest $\mathrm{ZC}$ variation was observed for the middle deltoid muscle $(11.00 \%)$ and the smallest $\mathrm{ZC}$ variation was observed for the posterior deltoid muscle (10.20\%). Very similar variations were observed for the supraspinatus, anterior deltoid, biceps, and triceps muscles - $(10.69 \%, 10.65 \%$, $10.68 \%$ and $10.68 \%$, respectively) (Table 16). All main effects due to the factors joint angle, force level, force direction, and shoulder plane on ZC were statistically significant (p-value $\leq 0.001$ ) for all muscles except for the effect of shoulder joint angle on supraspinatus muscle ( $\mathrm{p}$-value $=0.554$ ), and the effect of force level on middle deltoid muscle $(\mathrm{p}$-value $=0.335)$. Thus, for $\mathrm{ZC}$, the data rejected the null hypothesis and the alternative hypothesis was accepted. Specifically, the following trends were observed - ZC values increased with the increases of shoulder joint angle. The ZC values decreased with the increases of force level. 
Table 16: Main effect of joint angle, shoulder plane, force level, and force direction on $\mathrm{ZC}$, and variation based on $\sqrt{M S E}$. Statistically significant p-values are

\begin{tabular}{|c|c|c|c|c|c|c|c|c|c|c|c|c|c|c|}
\hline \multirow{2}{*}{\multicolumn{2}{|c|}{$\begin{array}{c}\text { ZC } \\
\text { Levels }\end{array}$}} & \multicolumn{2}{|c|}{ Joint angle } & \multicolumn{2}{|c|}{ Shoulder plane } & \multicolumn{3}{|c|}{ Force level } & \multicolumn{5}{|c|}{ Force direction } & \multirow{2}{*}{$\begin{array}{l}\text { Variatio } \\
\text { n }(\%)\end{array}$} \\
\hline & & \multirow{2}{*}{$\begin{array}{c}\mathbf{6 0}^{\circ} \\
0.585 \\
(0.120)\end{array}$} & \multirow{2}{*}{$\begin{array}{c}\mathbf{1 2 0}^{\circ} \\
0.584 \\
(0.106)\end{array}$} & \multirow{2}{*}{$\begin{array}{c}\mathbf{9 0}^{\circ} \\
0.591 \\
(0.120)\end{array}$} & \multirow{2}{*}{$\begin{array}{c}\mathbf{1 3 5}^{\circ} \\
0.578 \\
(0.105)\end{array}$} & \multirow{2}{*}{$\begin{array}{c}\text { 0 lb. } \\
0.571 \\
(0.103) \\
\end{array}$} & \multirow{2}{*}{$\begin{array}{c}\mathbf{2 . 5} \mathbf{l b} . \\
0.583 \\
(0.113) \\
\end{array}$} & \multirow{2}{*}{$\begin{array}{c}\mathbf{5} \mathbf{~ l b .} \\
0.599 \\
(0.122)\end{array}$} & \multirow{2}{*}{$\begin{array}{c}\text { PB } \\
0.576 \\
(0.105)\end{array}$} & \multirow{2}{*}{$\begin{array}{c}\text { PD } \\
0.613 \\
(0.127) \\
\end{array}$} & \multirow{2}{*}{$\begin{array}{c}\mathbf{P L} \\
0.592 \\
(0.122)\end{array}$} & \multirow{2}{*}{$\begin{array}{c}\text { PR } \\
0.561 \\
(0.101)\end{array}$} & \multirow{2}{*}{$\begin{array}{c}\text { PU } \\
0.580 \\
(0.101)\end{array}$} & \\
\hline \multirow{2}{*}{ ipraspinatus } & $\begin{array}{l}\text { Mean } \\
\text { (S.D.) }\end{array}$ & & & & & & & & & & & & & \multirow{2}{*}{10.69} \\
\hline & P-value & \multicolumn{2}{|c|}{0.554} & \multicolumn{2}{|c|}{$\leq 0.001$} & \multicolumn{3}{|c|}{$\leq 0.001$} & \multicolumn{5}{|c|}{$\leq 0.001$} & \\
\hline \multirow{2}{*}{ Infraspinatus } & $\begin{array}{l}\text { Mean } \\
\text { (S.D.) }\end{array}$ & $\begin{array}{c}0.663 \\
(0.110)\end{array}$ & $\begin{array}{c}0.728 \\
(0.099)\end{array}$ & $\begin{array}{c}0.686 \\
(0.110)\end{array}$ & $\begin{array}{c}0.705 \\
(0.108)\end{array}$ & $\begin{array}{c}0.697 \\
(0.104)\end{array}$ & $\begin{array}{c}0.698 \\
(0.111)\end{array}$ & $\begin{array}{c}0.692 \\
(0.113)\end{array}$ & $\begin{array}{c}0.699 \\
(0.106)\end{array}$ & $\begin{array}{c}0.684 \\
(0.126)\end{array}$ & $\begin{array}{c}0.690 \\
(0.106)\end{array}$ & $\begin{array}{c}0.705 \\
(0.107)\end{array}$ & $\begin{array}{c}0.700 \\
(0.100)\end{array}$ & \multirow{2}{*}{10.25} \\
\hline & P-value & \multicolumn{2}{|c|}{$\leq 0.001$} & \multicolumn{2}{|c|}{$\leq \mathbf{0 . 0 0 1}$} & \multicolumn{3}{|c|}{$\leq \mathbf{0 . 0 0 1}$} & \multicolumn{5}{|c|}{$\leq 0.001$} & \\
\hline \multirow{2}{*}{ Middle deltoid } & $\begin{array}{l}\text { Mean } \\
\text { (S.D.) }\end{array}$ & $\begin{array}{c}0.633 \\
(0.113)\end{array}$ & $\begin{array}{c}0.681 \\
(0.113)\end{array}$ & $\begin{array}{c}0.652 \\
(0.116)\end{array}$ & $\begin{array}{c}0.662 \\
(0.115)\end{array}$ & $\begin{array}{c}0.656 \\
(0.112)\end{array}$ & $\begin{array}{c}0.657 \\
(0.113)\end{array}$ & $\begin{array}{c}0.658 \\
(0.121)\end{array}$ & $\begin{array}{c}0.659 \\
(0.109)\end{array}$ & $\begin{array}{c}0.687 \\
(0.122) \\
\end{array}$ & $\begin{array}{c}0.648 \\
(0.120)\end{array}$ & $\begin{array}{c}0.642 \\
(0.110)\end{array}$ & $\begin{array}{c}0.647 \\
(0.110)\end{array}$ & \multirow{2}{*}{11} \\
\hline & P-value & \multicolumn{2}{|c|}{$\leq 0.001$} & \multicolumn{2}{|c|}{$\leq 0.001$} & & 0.335 & & & & $\leq \mathbf{0 . 0 0 1}$ & & & \\
\hline Anterior & $\begin{array}{l}\text { Mean } \\
\text { (S.D.) }\end{array}$ & $\begin{array}{c}0.612 \\
(0.115)\end{array}$ & $\begin{array}{c}0.637 \\
(0.110)\end{array}$ & $\begin{array}{c}0.631 \\
(0.115)\end{array}$ & $\begin{array}{c}0.618 \\
(0.111)\end{array}$ & $\begin{array}{c}0.633 \\
(0.113)\end{array}$ & $\begin{array}{c}0.619 \\
(0.111)\end{array}$ & $\begin{array}{c}0.621 \\
(0.116)\end{array}$ & $\begin{array}{c}0.623 \\
(0.107)\end{array}$ & $\begin{array}{c}0.657 \\
(0.115) \\
\end{array}$ & $\begin{array}{c}0.635 \\
(0.114)\end{array}$ & $\begin{array}{c}0.577 \\
(0.102)\end{array}$ & $\begin{array}{c}0.629 \\
(0.113)\end{array}$ & 1065 \\
\hline & P-value & & & & & & $\leq \mathbf{0 . 0 0 1}$ & & & & $\leq \mathbf{0 . 0 0 1}$ & & & \\
\hline Posterior & $\begin{array}{l}\text { Mean } \\
\text { (S.D.) }\end{array}$ & $\begin{array}{c}0.646 \\
(0.109)\end{array}$ & $\begin{array}{c}0.662 \\
(0.102)\end{array}$ & $\begin{array}{c}0.643 \\
(0.110)\end{array}$ & $\begin{array}{c}0.665 \\
(0.102) \\
\end{array}$ & $\begin{array}{c}0.655 \\
(0.101)\end{array}$ & $\begin{array}{c}0.660 \\
(0.108)\end{array}$ & $\begin{array}{c}0.647 \\
(0.109) \\
\end{array}$ & $\begin{array}{c}0.656 \\
(0.102)\end{array}$ & $\begin{array}{c}0.681 \\
(0.114)\end{array}$ & $\begin{array}{c}0.651 \\
(0.104) \\
\end{array}$ & $\begin{array}{c}0.642 \\
(0.105)\end{array}$ & $\begin{array}{c}0.640 \\
(0.101)\end{array}$ & 10.2 \\
\hline & P-value & & & & & & $\leq 0.001$ & & & & $\leq 0.001$ & & & \\
\hline Bicens & $\begin{array}{l}\text { Mean } \\
\text { (S.D.) }\end{array}$ & $\begin{array}{c}0.591 \\
(0.140)\end{array}$ & $\begin{array}{c}0.607 \\
(0.132)\end{array}$ & $\begin{array}{c}0.596 \\
(0.140)\end{array}$ & $\begin{array}{c}0.602 \\
(0.133)\end{array}$ & $\begin{array}{c}0.583 \\
(0.119)\end{array}$ & $\begin{array}{c}0.616 \\
(0.143)\end{array}$ & $\begin{array}{c}0.598 \\
(0.144)\end{array}$ & $\begin{array}{c}0.616 \\
(0.130)\end{array}$ & $\begin{array}{c}0.704 \\
(0.136) \\
\end{array}$ & $\begin{array}{c}0.528 \\
(0.114)\end{array}$ & $\begin{array}{c}0.609 \\
(0.113)\end{array}$ & $\begin{array}{c}0.537 \\
(0.107)\end{array}$ & 1068 \\
\hline & P-value & & & & & & $\leq 0.001$ & & & & $\leq 0.001$ & & & \\
\hline cens. & $\begin{array}{l}\text { Mean } \\
\text { (S.D.) }\end{array}$ & $\begin{array}{c}0.606 \\
(0.137)\end{array}$ & $\begin{array}{c}0.637 \\
(0.118)\end{array}$ & $\begin{array}{c}0.620 \\
(0.128)\end{array}$ & $\begin{array}{c}0.623 \\
(0.129)\end{array}$ & $\begin{array}{c}0.598 \\
(0.117)\end{array}$ & $\begin{array}{c}0.647 \\
(0.139)\end{array}$ & $\begin{array}{c}0.619 \\
(0.125)\end{array}$ & $\begin{array}{c}0.632 \\
(0.132)\end{array}$ & $\begin{array}{c}0.684 \\
(0.133) \\
\end{array}$ & $\begin{array}{c}0.545 \\
(0.102) \\
\end{array}$ & $\begin{array}{c}0.664 \\
(0.114)\end{array}$ & $\begin{array}{c}0.583 \\
(0.107)\end{array}$ & 10.68 \\
\hline & P-value & & & & & & $\leq 0.001$ & & & & $\leq 0.001$ & & & \\
\hline
\end{tabular}


Supraspinatus

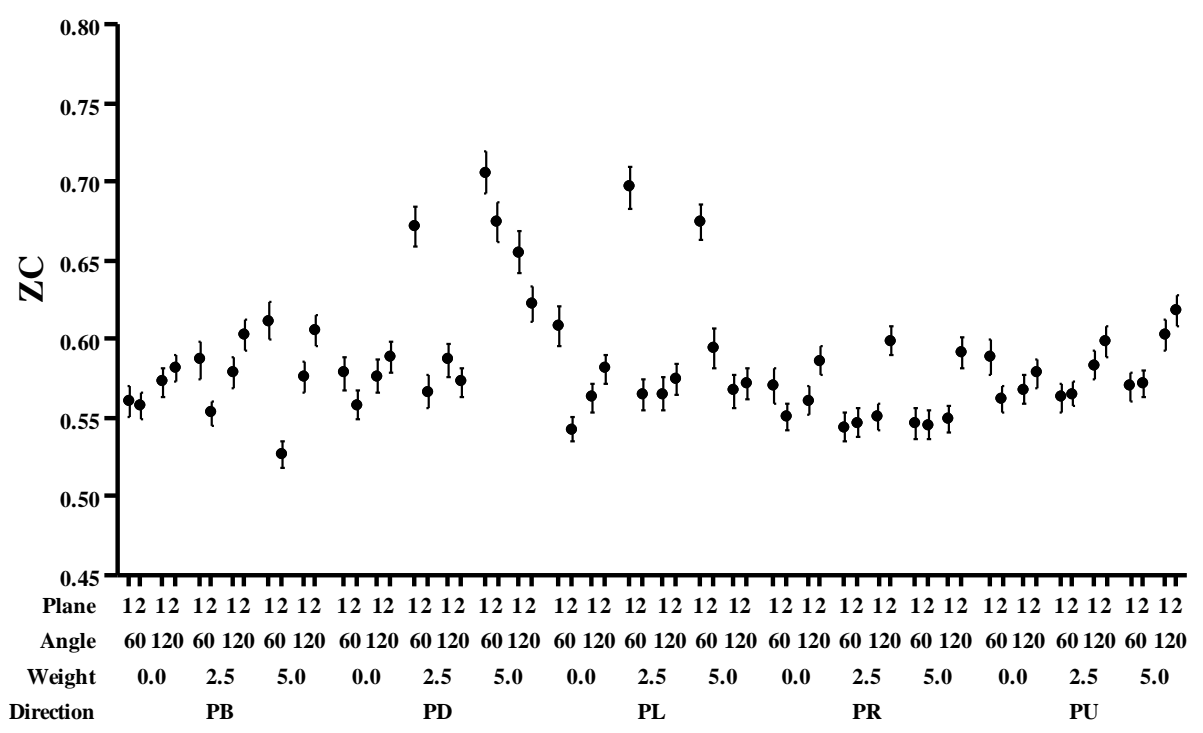

Infraspinatus

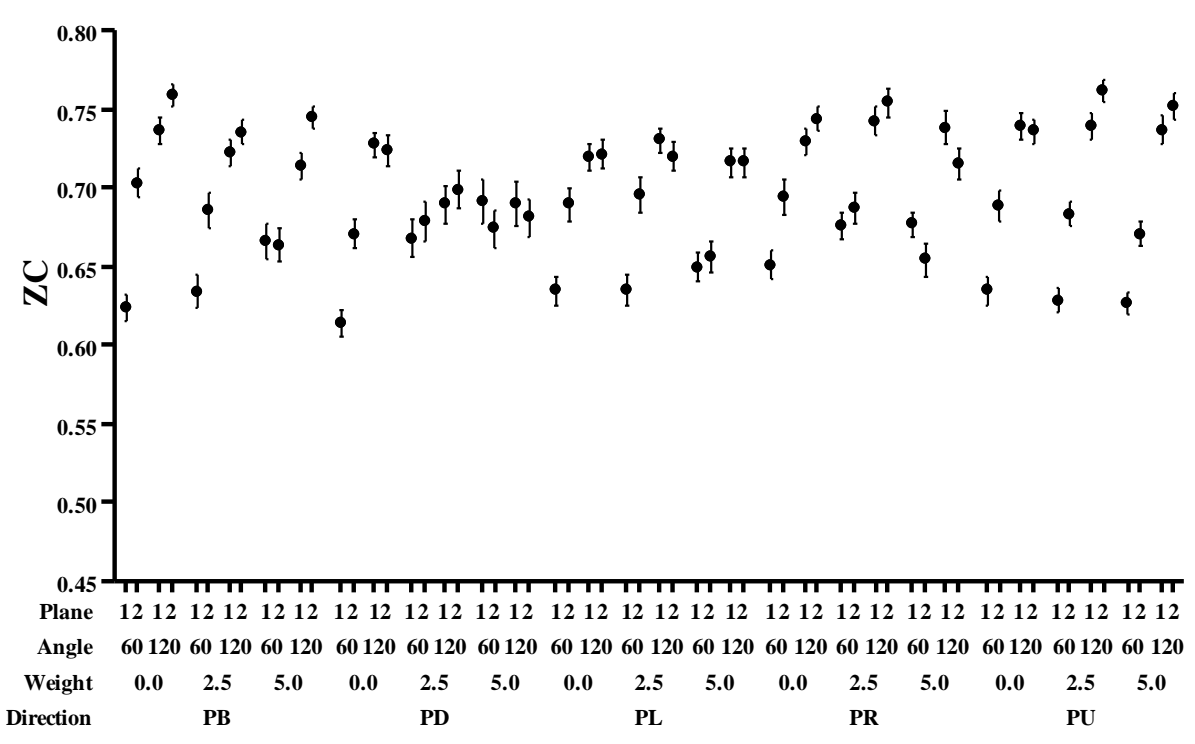

\section{Anterior deltoid}

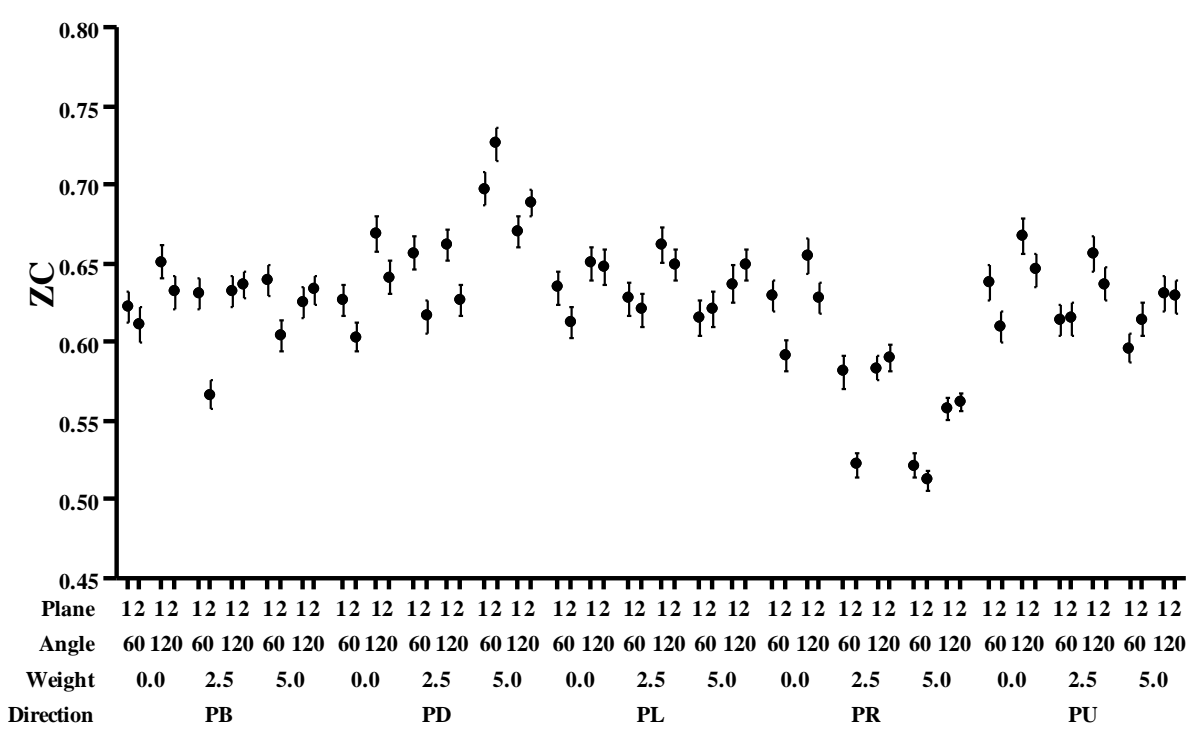


Posterior deltoid

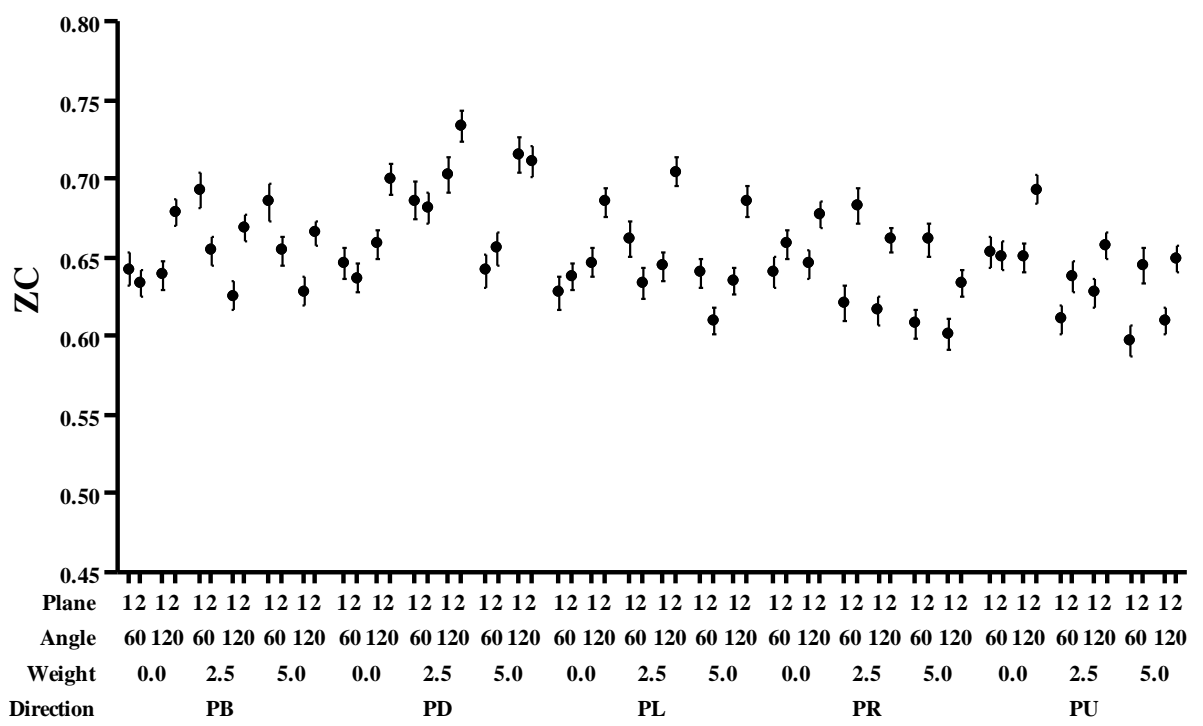

Biceps

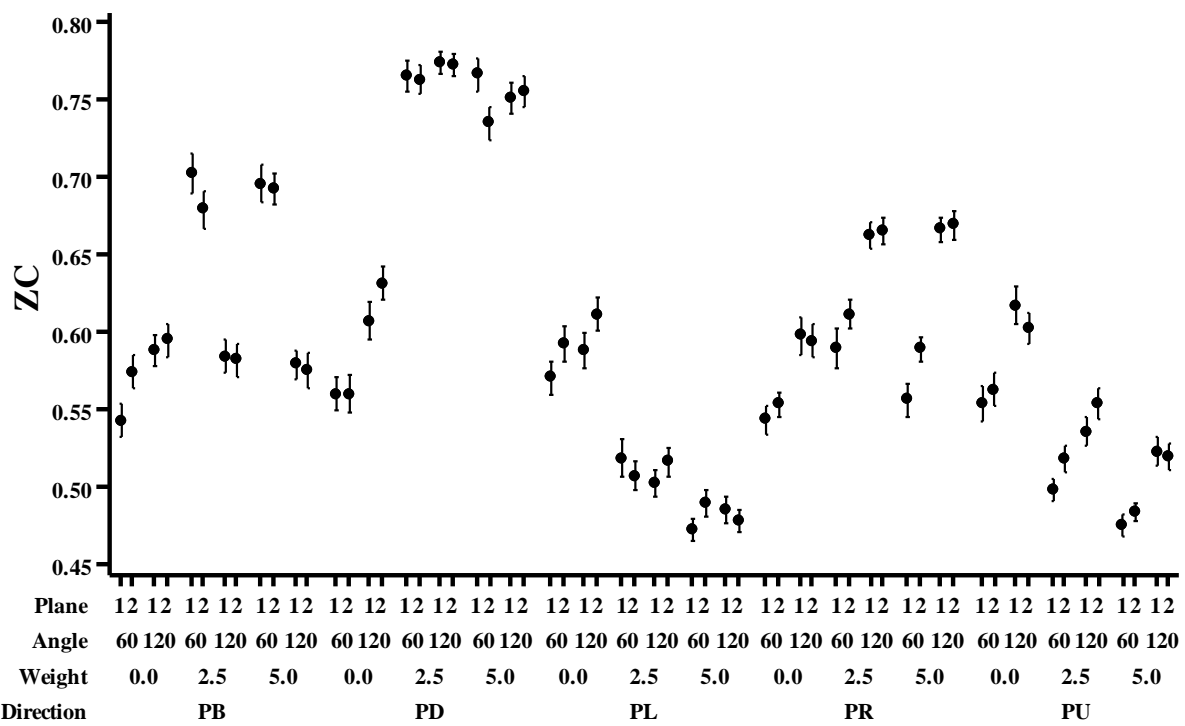

\section{Triceps}

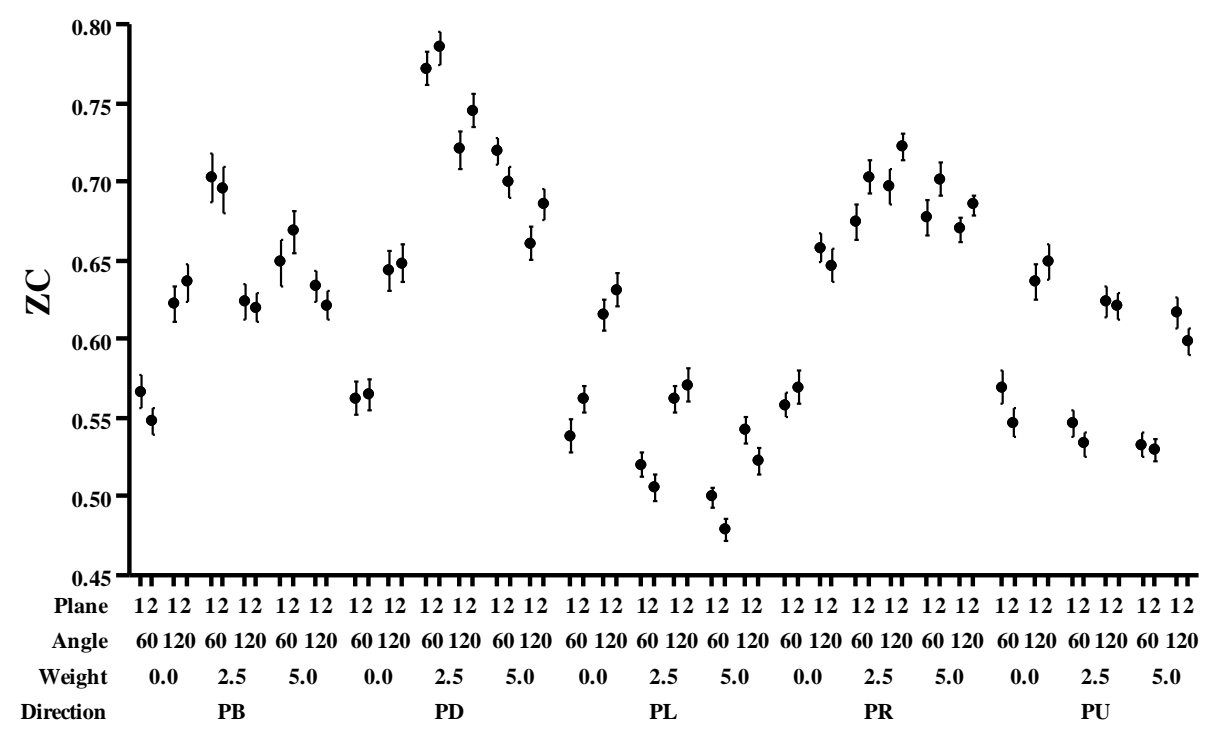

Figure 16: ZC interval plot for each muscle. Error bars represent standard deviation. Note: Plane axis label represent 1) sagittal $\left.\left(90^{\circ}\right) 2\right)$ scapular $\left(135^{\circ}\right)$ 


\subsubsection{Mean power frequency (MnPF)}

The largest MnPF variation was observed for the biceps and triceps muscles (11.45\%) and the smallest MnPF variation was observed for the middle deltoid muscle $(8.60 \%)$, among the seven muscles tested in this study. Very similar variations were observed for supraspinatus and posterior deltoid muscles - $(10.45 \%$ and $10.68 \%$, respectively) (Table 17). All main effects due to the factors joint angle, force level, force direction, and shoulder plane on MnPF were statistically significant (p-value $\leq 0.001$ ) for all muscles except for the effect of shoulder joint angle on triceps muscle ( $\mathrm{p}$-value $=0.535)$, and the effect of shoulder plane on biceps and triceps muscles ( $p$-value $=0.692$ and $p$-value $=0.153$, respectively). Thus, for MnPF, the data rejected the null hypothesis and the alternative hypothesis was accepted. Specifically, the following trends were observed MnPF values increased with the increase of shoulder joint angle. The MnPF values decreased with the increase of force level. 
Table 17: Main effect of joint angle, shoulder plane, force level, and force direction on MnPF, and variation based on $\sqrt{M S E}$. Statistically significant p-values are highlighted in bold font

\begin{tabular}{|c|c|c|c|c|c|c|c|c|c|c|c|c|c|c|}
\hline \multicolumn{2}{|c|}{ MnPF } & \multicolumn{2}{|c|}{ Joint angle } & \multicolumn{2}{|c|}{ Shoulder plane } & \multicolumn{3}{|c|}{ Force level } & \multicolumn{5}{|c|}{ Force direction } & \multirow[b]{2}{*}{$\begin{array}{c}\text { Variatio } \\
\text { n }(\%)\end{array}$} \\
\hline \multicolumn{2}{|c|}{ Levels } & $60^{\circ}$ & $120^{\circ}$ & $90^{\circ}$ & $135^{\circ}$ & 0 lb. & $2.5 \mathrm{lb}$ & $5 \mathrm{lb}$. & PB & PD & PL & PR & $\mathbf{P U}$ & \\
\hline Supraspinatus & $\begin{array}{l}\text { Mean } \\
\text { (S.D.) }\end{array}$ & $\begin{array}{c}0.560 \\
(0.132) \\
\end{array}$ & $\begin{array}{c}0.554 \\
(0.101) \\
\end{array}$ & $\begin{array}{c}0.565 \\
(0.131) \\
\end{array}$ & $\begin{array}{c}0.548 \\
(0.101) \\
\end{array}$ & $\begin{array}{c}0.539 \\
(0.103) \\
\end{array}$ & $\begin{array}{c}0.554 \\
(0.116) \\
\end{array}$ & $\begin{array}{c}0.577 \\
(0.129)\end{array}$ & $\begin{array}{c}0.539 \\
(0.099)\end{array}$ & $\begin{array}{c}0.605 \\
(0.148)\end{array}$ & $\begin{array}{c}0.571 \\
(0.128)\end{array}$ & $\begin{array}{c}0.521 \\
(0.090)\end{array}$ & $\begin{array}{c}0.546 \\
(0.094)\end{array}$ & 10.45 \\
\hline \multirow{2}{*}{ Infraspinatus } & $\begin{array}{l}\text { Mean } \\
\text { (S.D.) }\end{array}$ & $\begin{array}{c}0.636 \\
(0.100) \\
\end{array}$ & $\begin{array}{c}0.686 \\
(0.102)\end{array}$ & $\begin{array}{c}0.654 \\
(0.107) \\
\end{array}$ & $\begin{array}{c}0.668 \\
(0.101) \\
\end{array}$ & $\begin{array}{c}0.659 \\
(0.099)\end{array}$ & $\begin{array}{c}0.666 \\
(0.103) \\
\end{array}$ & $\begin{array}{c}0.659 \\
(0.110) \\
\end{array}$ & $\begin{array}{c}0.658 \\
(0.099) \\
\end{array}$ & $\begin{array}{c}0.668 \\
(0.109) \\
\end{array}$ & $\begin{array}{c}0.654 \\
(0.097)\end{array}$ & $\begin{array}{c}0.664 \\
(0.108) \\
\end{array}$ & $\begin{array}{c}0.662 \\
(0.105) \\
\end{array}$ & \multirow{2}{*}{9.85} \\
\hline & P-value & \multicolumn{2}{|c|}{$\leq 0.001$} & \multicolumn{2}{|c|}{$\leq \mathbf{0 . 0 0 1}$} & \multicolumn{3}{|c|}{$\leq \mathbf{0 . 0 0 1}$} & \multicolumn{5}{|c|}{$\leq 0.001$} & \\
\hline \multirow{2}{*}{ Middle deltoid } & $\begin{array}{l}\text { Mean } \\
\text { (S.D.) }\end{array}$ & $\begin{array}{c}0.591 \\
(0.101) \\
\end{array}$ & $\begin{array}{c}0.641 \\
(0.088) \\
\end{array}$ & $\begin{array}{c}0.611 \\
(0.101) \\
\end{array}$ & $\begin{array}{c}0.621 \\
(0.095) \\
\end{array}$ & $\begin{array}{c}0.607 \\
(0.086) \\
\end{array}$ & $\begin{array}{c}0.614 \\
(0.094) \\
\end{array}$ & $\begin{array}{c}0.627 \\
(0.113) \\
\end{array}$ & $\begin{array}{c}0.615 \\
(0.090) \\
\end{array}$ & $\begin{array}{c}0.668 \\
(0.112) \\
\end{array}$ & $\begin{array}{c}0.609 \\
(0.099) \\
\end{array}$ & $\begin{array}{c}0.593 \\
(0.085) \\
\end{array}$ & $\begin{array}{c}0.596 \\
(0.085) \\
\end{array}$ & \multirow{2}{*}{8.6} \\
\hline & P-value & \multicolumn{2}{|c|}{$\leq 0.001$} & \multicolumn{2}{|c|}{$\leq 0.001$} & \multicolumn{3}{|c|}{$\leq 0.001$} & \multicolumn{5}{|c|}{$\leq 0.001$} & \\
\hline \multirow{2}{*}{$\begin{array}{c}\text { Anterior } \\
\text { deltoid }\end{array}$} & $\begin{array}{l}\text { Mean } \\
\text { (S.D.) }\end{array}$ & $\begin{array}{c}0.620 \\
(0.110) \\
\end{array}$ & $\begin{array}{c}0.650 \\
(0.105) \\
\end{array}$ & $\begin{array}{c}0.638 \\
(0.105) \\
\end{array}$ & $\begin{array}{c}0.631 \\
(0.112) \\
\end{array}$ & $\begin{array}{c}0.642 \\
(0.103) \\
\end{array}$ & $\begin{array}{c}0.629 \\
(0.106) \\
\end{array}$ & $\begin{array}{c}0.633 \\
(0.117) \\
\end{array}$ & $\begin{array}{c}0.632 \\
(0.098) \\
\end{array}$ & $\begin{array}{c}0.677 \\
(0.119) \\
\end{array}$ & $\begin{array}{c}0.644 \\
(0.103) \\
\end{array}$ & $\begin{array}{c}0.584 \\
(0.099) \\
\end{array}$ & $\begin{array}{c}0.636 \\
(0.103) \\
\end{array}$ & \multirow{2}{*}{9.99} \\
\hline & P-value & \multicolumn{2}{|c|}{$\leq 0.001$} & \multicolumn{2}{|c|}{$\leq 0.001$} & \multicolumn{3}{|c|}{$\leq 0.001$} & \multicolumn{5}{|c|}{$\leq 0.001$} & \\
\hline \multirow{2}{*}{$\begin{array}{c}\text { Posterior } \\
\text { deltoid }\end{array}$} & $\begin{array}{l}\text { Mean } \\
\text { (S.D.) }\end{array}$ & $\begin{array}{c}0.621 \\
(0.123)\end{array}$ & $\begin{array}{c}0.619 \\
(0.110) \\
\end{array}$ & $\begin{array}{c}0.611 \\
(0.120) \\
\end{array}$ & $\begin{array}{c}0.629 \\
(0.112) \\
\end{array}$ & $\begin{array}{c}0.613 \\
(0.105) \\
\end{array}$ & $\begin{array}{c}0.626 \\
(0.120) \\
\end{array}$ & $\begin{array}{c}0.622 \\
(0.123) \\
\end{array}$ & $\begin{array}{c}0.625 \\
(0.111) \\
\end{array}$ & $\begin{array}{c}0.676 \\
(0.118) \\
\end{array}$ & $\begin{array}{c}0.618 \\
(0.118) \\
\end{array}$ & $\begin{array}{c}0.593 \\
(0.107) \\
\end{array}$ & $\begin{array}{c}0.589 \\
(0.107) \\
\end{array}$ & \multirow{2}{*}{10.68} \\
\hline & P-value & \multicolumn{2}{|c|}{0.045} & & & & $\leq \mathbf{0 . 0 0 1}$ & & & & $\leq \mathbf{0 . 0 0 1}$ & & & \\
\hline Bicens & $\begin{array}{l}\text { Mean } \\
\text { (S.D.) }\end{array}$ & $\begin{array}{c}0.559 \\
(0.176) \\
\end{array}$ & $\begin{array}{c}0.552 \\
(0.137)\end{array}$ & $\begin{array}{c}0.555 \\
(0.162) \\
\end{array}$ & $\begin{array}{c}0.556 \\
(0.153)\end{array}$ & $\begin{array}{c}0.530 \\
(0.127)\end{array}$ & $\begin{array}{c}0.571 \\
(0.166) \\
\end{array}$ & $\begin{array}{c}0.566 \\
(0.174)\end{array}$ & $\begin{array}{c}0.586 \\
(0.158) \\
\end{array}$ & $\begin{array}{c}0.694 \\
(0.161)\end{array}$ & $\begin{array}{c}0.474 \\
(0.127)\end{array}$ & $\begin{array}{c}0.540 \\
(0.112)\end{array}$ & $\begin{array}{c}0.484 \\
(0.116)\end{array}$ & 11. \\
\hline & P-value & & & & & & $\leq 0.001$ & & & & $\leq 0.001$ & & & \\
\hline Tricens & $\begin{array}{l}\text { Mean } \\
\text { (S.D.) }\end{array}$ & $\begin{array}{c}0.613 \\
(0.162) \\
\end{array}$ & $\begin{array}{c}0.612 \\
(0.115) \\
\end{array}$ & $\begin{array}{c}0.611 \\
(0.140) \\
\end{array}$ & $\begin{array}{c}0.613 \\
(0.140) \\
\end{array}$ & $\begin{array}{c}0.607 \\
(0.117) \\
\end{array}$ & $\begin{array}{c}0.643 \\
(0.154) \\
\end{array}$ & $\begin{array}{c}0.587 \\
(0.142) \\
\end{array}$ & $\begin{array}{c}0.644 \\
(0.135) \\
\end{array}$ & $\begin{array}{c}0.689 \\
(0.140) \\
\end{array}$ & $\begin{array}{c}0.529 \\
(0.120) \\
\end{array}$ & $\begin{array}{c}0.641 \\
(0.130) \\
\end{array}$ & $\begin{array}{c}0.560 \\
(0.110) \\
\end{array}$ & 11.45 \\
\hline & P-value & & & & & & $\leq 0.001$ & & & & $\leq 0.001$ & & & \\
\hline
\end{tabular}


Supraspinatus

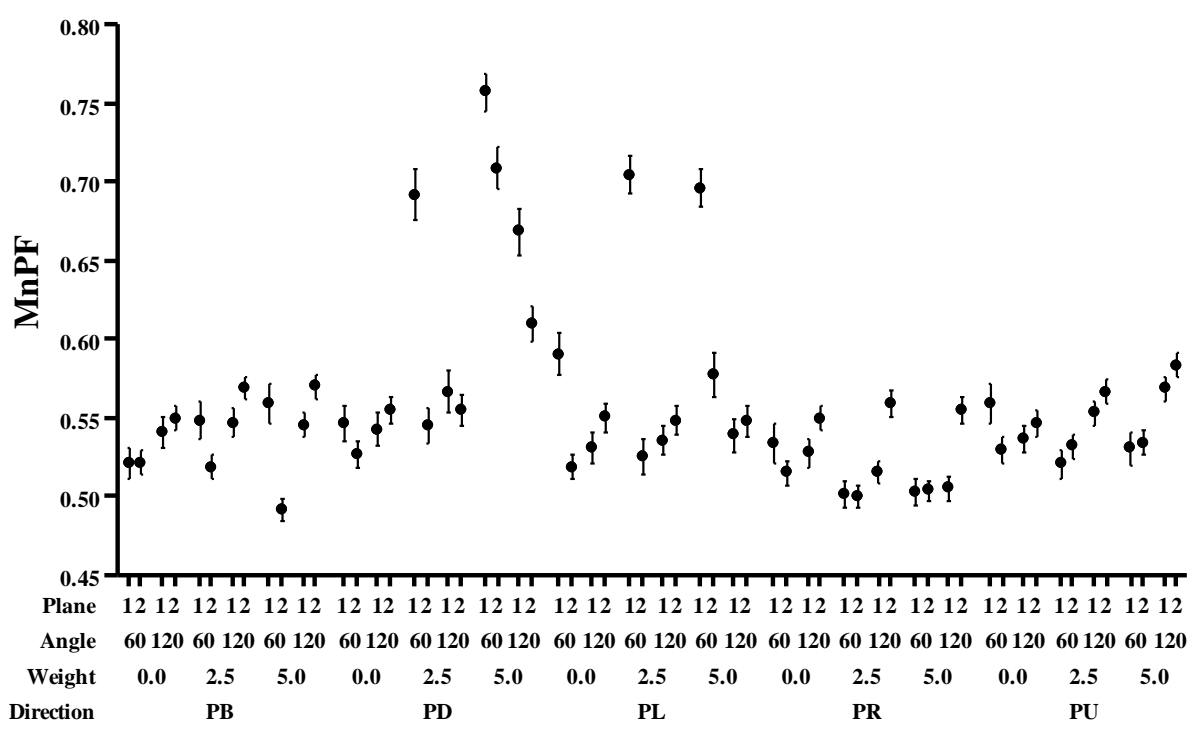

Infraspinatus

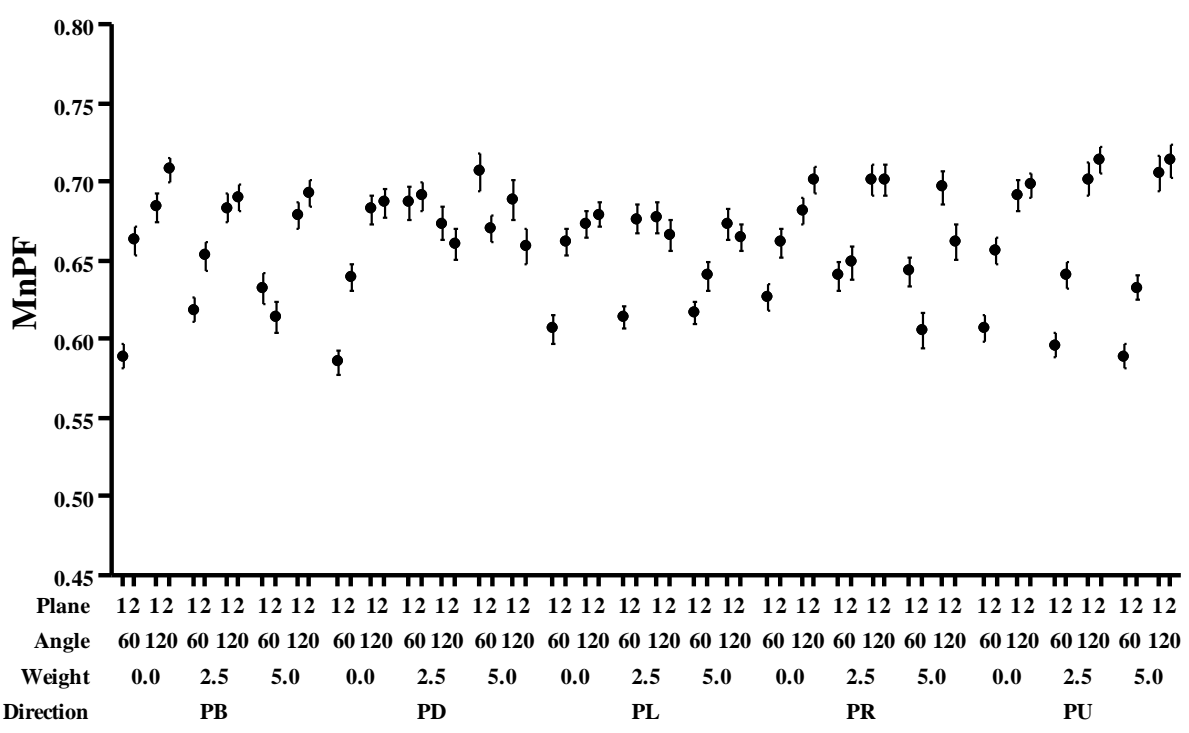

\section{Middle deltoid}

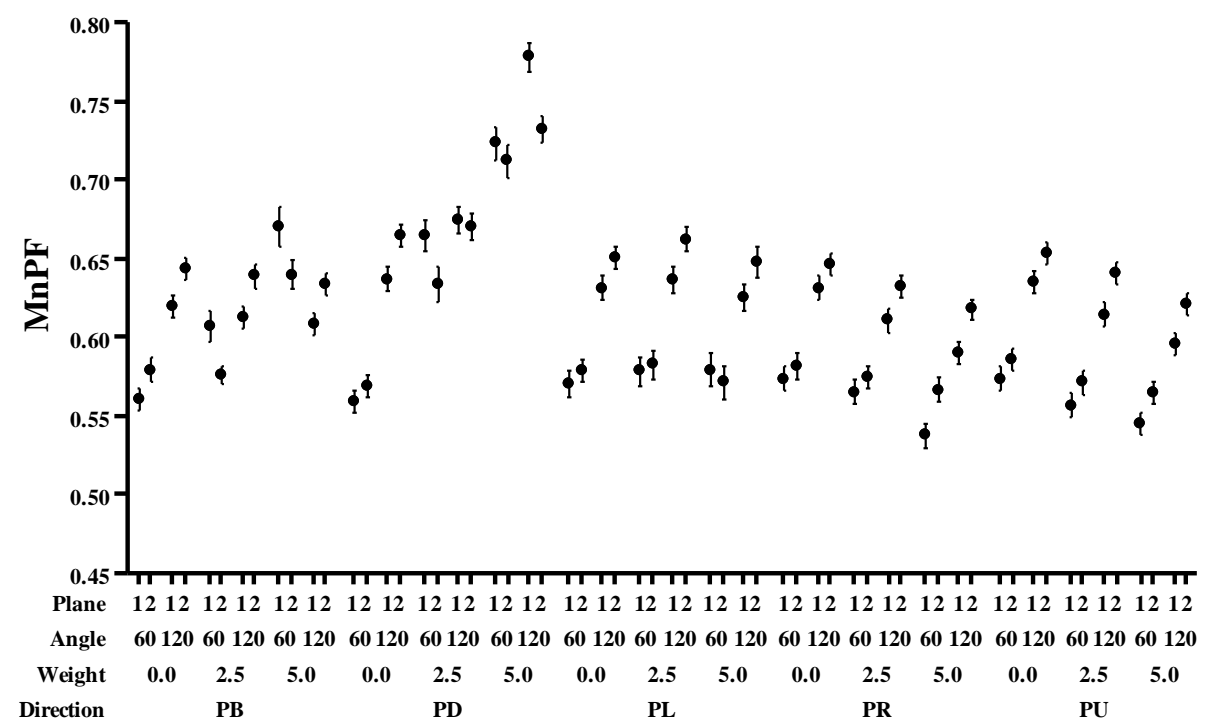


Posterior deltoid

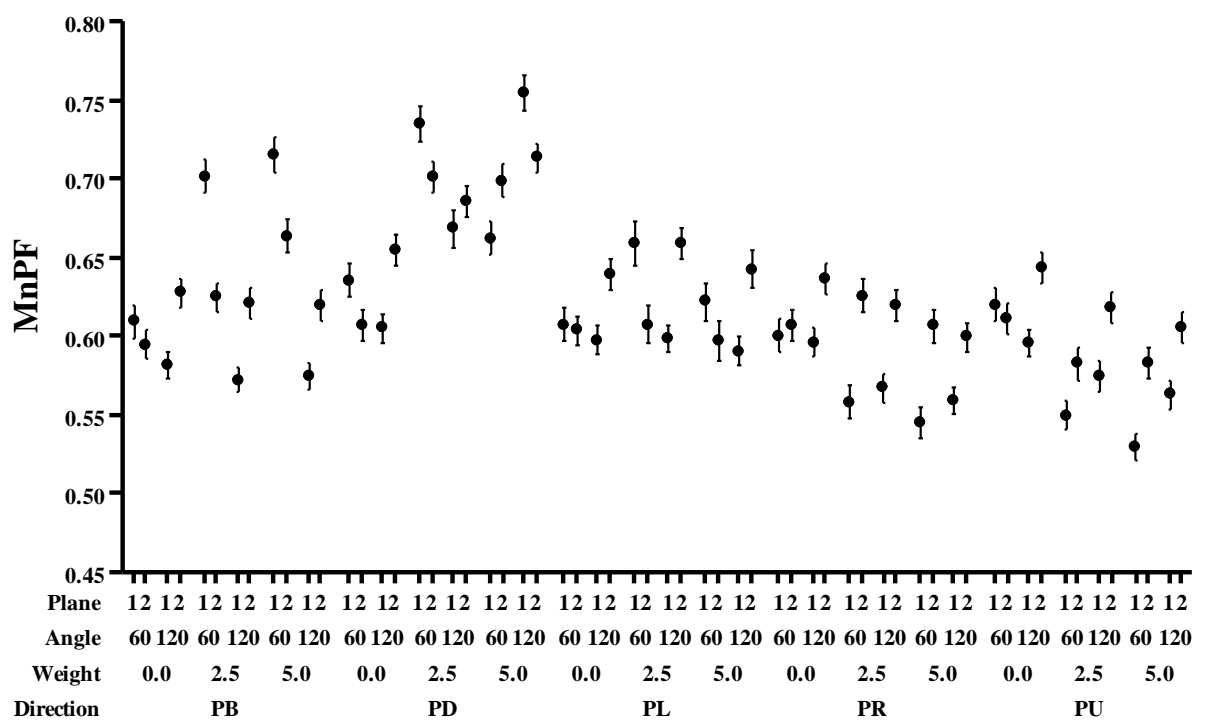

Biceps

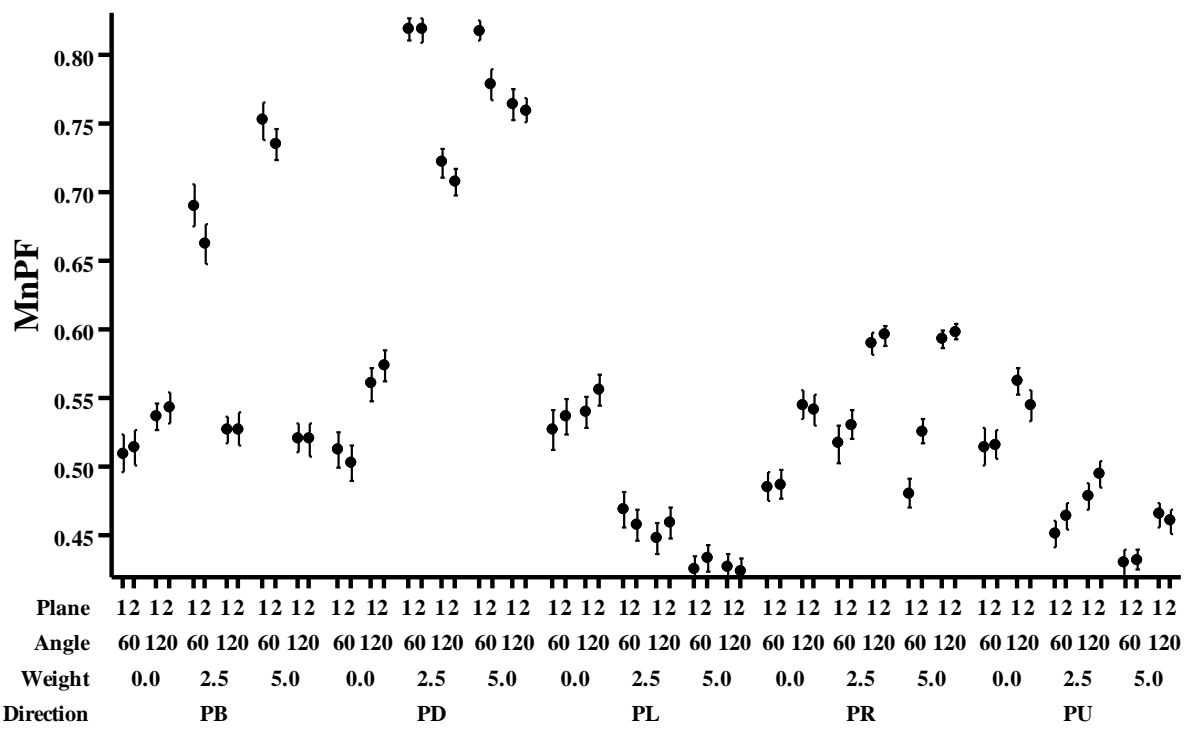

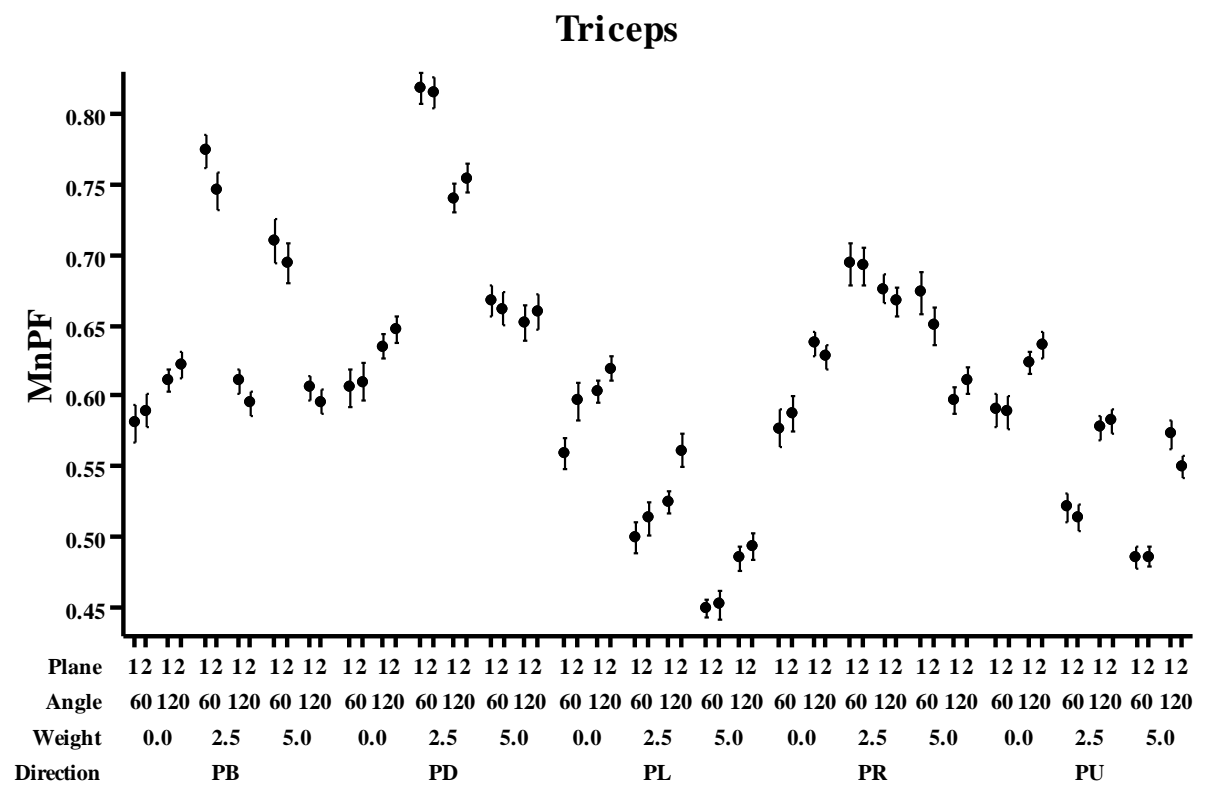

Figure 17: MnPF interval plot for each muscle. Error bars represent standard deviation. Note: Plane axis label represent 1) sagittal $\left.\left(90^{\circ}\right) 2^{2}\right) s\left(a p u l a r\left(135^{\circ}\right)\right.$ 


\subsubsection{Median power frequency (MdPF)}

The largest MdPF variation was observed for the biceps muscle (12.25\%) and the smallest MdPF variation was observed for the middle deltoid muscle (8.72\%), among the seven muscles studied in this research. Very similar variations were observed for anterior deltoid and infraspinatus muscles - (10.82\% and $10.72 \%$, respectively) (Table 18). All main effects due to the factors joint angle, force level, force direction, and shoulder plane on MdPF were statistically significant ( $\mathrm{p}$-value $\leq 0.001$ ) for all muscles except for the effect of shoulder plane on biceps muscle ( $\mathrm{p}$-value $=0.506$ ). Thus, for MdPF, the data rejected the null hypothesis and the alternative hypothesis was accepted. Specifically, the following trends were observed - MdPF values increased with the increase of shoulder joint angle, and MdPF values were higher in scapular plane compared to sagittal plane. No clear decreasing trend was found for MdPF values. 
Table 18: Main effect of joint angle, shoulder plane, force level, and force direction on MdPF, and variation based on $\sqrt{M S E}$. Statistically significant p-values are

\begin{tabular}{|c|c|c|c|c|c|c|c|c|c|c|c|c|c|c|}
\hline \multirow{2}{*}{\multicolumn{2}{|c|}{$\begin{array}{l}\text { MdPF } \\
\text { Levels }\end{array}$}} & \multicolumn{2}{|c|}{ Joint angle } & \multicolumn{2}{|c|}{ Shoulder plane } & \multicolumn{3}{|c|}{ Force level } & \multicolumn{5}{|c|}{ Force direction } & \multirow{2}{*}{$\begin{array}{c}\text { Variatio } \\
\mathbf{n}(\%)\end{array}$} \\
\hline & & $60^{\circ}$ & $120^{\circ}$ & $90^{\circ}$ & $135^{\circ}$ & 0 lb. & $2.5 \mathrm{lb}$ & $5 \mathrm{lb}$. & PB & PD & PL & PR & PU & \\
\hline \multirow{2}{*}{ Supraspinatus } & $\begin{array}{l}\text { Mean } \\
\text { (S.D.) }\end{array}$ & $\begin{array}{c}0.561 \\
(0.123) \\
\end{array}$ & $\begin{array}{c}0.604 \\
(0.122)\end{array}$ & $\begin{array}{c}0.580 \\
(0.129) \\
\end{array}$ & $\begin{array}{c}0.585 \\
(0.119) \\
\end{array}$ & $\begin{array}{c}0.578 \\
(0.125)\end{array}$ & $\begin{array}{c}0.583 \\
(0.124) \\
\end{array}$ & $\begin{array}{c}0.587 \\
(0.124)\end{array}$ & $\begin{array}{c}0.575 \\
(0.123) \\
\end{array}$ & $\begin{array}{c}0.590 \\
(0.135)\end{array}$ & $\begin{array}{c}0.593 \\
(0.131)\end{array}$ & $\begin{array}{c}0.560 \\
(0.110) \\
\end{array}$ & $\begin{array}{c}0.595 \\
(0.117) \\
\end{array}$ & \multirow{2}{*}{12.04} \\
\hline & P-value & \multicolumn{2}{|c|}{$\leq 0.001$} & \multicolumn{2}{|c|}{0.002} & \multicolumn{3}{|c|}{$\leq \mathbf{0 . 0 0 1}$} & \multicolumn{5}{|c|}{$\leq 0.001$} & \\
\hline \multirow{2}{*}{ Infraspinatus } & $\begin{array}{l}\text { Mean } \\
\text { (S.D.) }\end{array}$ & $\begin{array}{c}0.571 \\
(0.108) \\
\end{array}$ & $\begin{array}{c}0.626 \\
(0.119)\end{array}$ & $\begin{array}{c}0.596 \\
(0.116) \\
\end{array}$ & $\begin{array}{c}0.601 \\
(0.118)\end{array}$ & $\begin{array}{c}0.603 \\
(0.103) \\
\end{array}$ & $\begin{array}{c}0.603 \\
(0.116) \\
\end{array}$ & $\begin{array}{c}0.589 \\
(0.130)\end{array}$ & $\begin{array}{c}0.592 \\
(0.112)\end{array}$ & $\begin{array}{c}0.556 \\
(0.123) \\
\end{array}$ & $\begin{array}{c}0.591 \\
(0.107)\end{array}$ & $\begin{array}{c}0.627 \\
(0.122) \\
\end{array}$ & $\begin{array}{c}0.626 \\
(0.104)\end{array}$ & \multirow{2}{*}{10.72} \\
\hline & P-value & \multicolumn{2}{|c|}{$\leq 0.001$} & \multicolumn{2}{|c|}{$\leq 0.001$} & \multicolumn{3}{|c|}{$\leq 0.001$} & \multicolumn{5}{|c|}{$\leq 0.001$} & \\
\hline \multirow{2}{*}{ Middle deltoid } & $\begin{array}{l}\text { Mean } \\
\text { (S.D.) }\end{array}$ & $\begin{array}{c}0.605 \\
(0.090) \\
\end{array}$ & $\begin{array}{c}0.684 \\
(0.086) \\
\end{array}$ & $\begin{array}{c}0.636 \\
(0.094) \\
\end{array}$ & $\begin{array}{c}0.653 \\
(0.099) \\
\end{array}$ & $\begin{array}{c}0.650 \\
(0.088) \\
\end{array}$ & $\begin{array}{c}0.649 \\
(0.095)\end{array}$ & $\begin{array}{c}0.635 \\
(0.105) \\
\end{array}$ & $\begin{array}{c}0.642 \\
(0.088)\end{array}$ & $\begin{array}{c}0.654 \\
(0.109) \\
\end{array}$ & $\begin{array}{c}0.648 \\
(0.105)\end{array}$ & $\begin{array}{c}0.636 \\
(0.091)\end{array}$ & $\begin{array}{c}0.642 \\
(0.087)\end{array}$ & \multirow{2}{*}{8.72} \\
\hline & P-value & \multicolumn{2}{|c|}{$\leq 0.001$} & \multicolumn{2}{|c|}{$\leq 0.001$} & \multicolumn{3}{|c|}{$\leq 0.001$} & \multicolumn{5}{|c|}{$\leq 0.001$} & \\
\hline \multirow{2}{*}{$\begin{array}{c}\text { Anterior } \\
\text { deltoid }\end{array}$} & $\begin{array}{l}\text { Mean } \\
\text { (S.D.) }\end{array}$ & $\begin{array}{c}0.613 \\
(0.114) \\
\end{array}$ & $\begin{array}{c}0.657 \\
(0.113) \\
\end{array}$ & $\begin{array}{c}0.645 \\
(0.110) \\
\end{array}$ & $\begin{array}{c}0.625 \\
(0.120) \\
\end{array}$ & $\begin{array}{c}0.656 \\
(0.102) \\
\end{array}$ & $\begin{array}{c}0.637 \\
(0.113) \\
\end{array}$ & $\begin{array}{c}0.611 \\
(0.126) \\
\end{array}$ & $\begin{array}{c}0.629 \\
(0.112) \\
\end{array}$ & $\begin{array}{c}0.640 \\
(0.128) \\
\end{array}$ & $\begin{array}{c}0.656 \\
(0.105) \\
\end{array}$ & $\begin{array}{c}0.598 \\
(0.121) \\
\end{array}$ & $\begin{array}{c}0.651 \\
(0.099) \\
\end{array}$ & \multirow{2}{*}{10.82} \\
\hline & P-value & \multicolumn{2}{|c|}{$\leq 0.001$} & \multicolumn{2}{|c|}{$\leq 0.001$} & \multicolumn{3}{|c|}{$\leq 0.001$} & \multicolumn{5}{|c|}{$\leq 0.001$} & \\
\hline \multirow{2}{*}{$\begin{array}{l}\text { Posterior } \\
\text { deltoid }\end{array}$} & $\begin{array}{l}\text { Mean } \\
\text { (S.D.) }\end{array}$ & $\begin{array}{c}0.587 \\
(0.101)\end{array}$ & $\begin{array}{c}0.637 \\
(0.088)\end{array}$ & $\begin{array}{c}0.593 \\
(0.094)\end{array}$ & $\begin{array}{c}0.632 \\
(0.097)\end{array}$ & $\begin{array}{c}0.611 \\
(0.088)\end{array}$ & $\begin{array}{c}0.618 \\
(0.100)\end{array}$ & $\begin{array}{c}0.608 \\
(0.105)\end{array}$ & $\begin{array}{c}0.613 \\
(0.088)\end{array}$ & $\begin{array}{c}0.631 \\
(0.108)\end{array}$ & $\begin{array}{c}0.596 \\
(0.103)\end{array}$ & $\begin{array}{c}0.614 \\
(0.096)\end{array}$ & $\begin{array}{c}0.608 \\
(0.089)\end{array}$ & \multirow{2}{*}{9} \\
\hline & P-value & \multicolumn{2}{|c|}{$\leq \mathbf{0 . 0 0 1}$} & \multicolumn{2}{|c|}{$\leq 0.001$} & & $\leq \mathbf{0 . 0 0 1}$ & & & & $\leq \mathbf{0 . 0 0 1}$ & & & \\
\hline Bicens & $\begin{array}{l}\text { Mean } \\
\text { (S.D.) }\end{array}$ & $\begin{array}{c}0.515 \\
(0.156) \\
\end{array}$ & $\begin{array}{c}0.527 \\
(0.139)\end{array}$ & $\begin{array}{c}0.522 \\
(0.151) \\
\end{array}$ & $\begin{array}{c}0.521 \\
(0.145)\end{array}$ & $\begin{array}{c}0.506 \\
(0.131) \\
\end{array}$ & $\begin{array}{c}0.533 \\
(0.155) \\
\end{array}$ & $\begin{array}{c}0.524 \\
(0.156)\end{array}$ & $\begin{array}{c}0.541 \\
(0.143) \\
\end{array}$ & $\begin{array}{c}0.628 \\
(0.150) \\
\end{array}$ & $\begin{array}{c}0.454 \\
(0.132)\end{array}$ & $\begin{array}{c}0.514 \\
(0.120) \\
\end{array}$ & $\begin{array}{c}0.469 \\
(0.127) \\
\end{array}$ & 1225 \\
\hline & P-value & & & & & & $\leq 0.001$ & & & & $\leq 0.001$ & & & \\
\hline Tricens & $\begin{array}{l}\text { Mean } \\
\text { (S.D.) }\end{array}$ & $\begin{array}{c}0.542 \\
(0.167) \\
\end{array}$ & $\begin{array}{c}0.562 \\
(0.112) \\
\end{array}$ & $\begin{array}{c}0.548 \\
(0.142) \\
\end{array}$ & $\begin{array}{c}0.555 \\
(0.144) \\
\end{array}$ & $\begin{array}{c}0.534 \\
(0.121) \\
\end{array}$ & $\begin{array}{c}0.587 \\
(0.158) \\
\end{array}$ & $\begin{array}{c}0.534 \\
(0.140) \\
\end{array}$ & $\begin{array}{c}0.580 \\
(0.140) \\
\end{array}$ & $\begin{array}{c}0.627 \\
(0.152) \\
\end{array}$ & $\begin{array}{c}0.458 \\
(0.112) \\
\end{array}$ & $\begin{array}{c}0.587 \\
(0.129) \\
\end{array}$ & $\begin{array}{c}0.507 \\
(0.106) \\
\end{array}$ & 1127 \\
\hline & P-value & $\leq 0$ & & $\leq 0$ & & & $\leq 0.001$ & & & & $\leq 0.001$ & & & \\
\hline
\end{tabular}


Supraspinatus

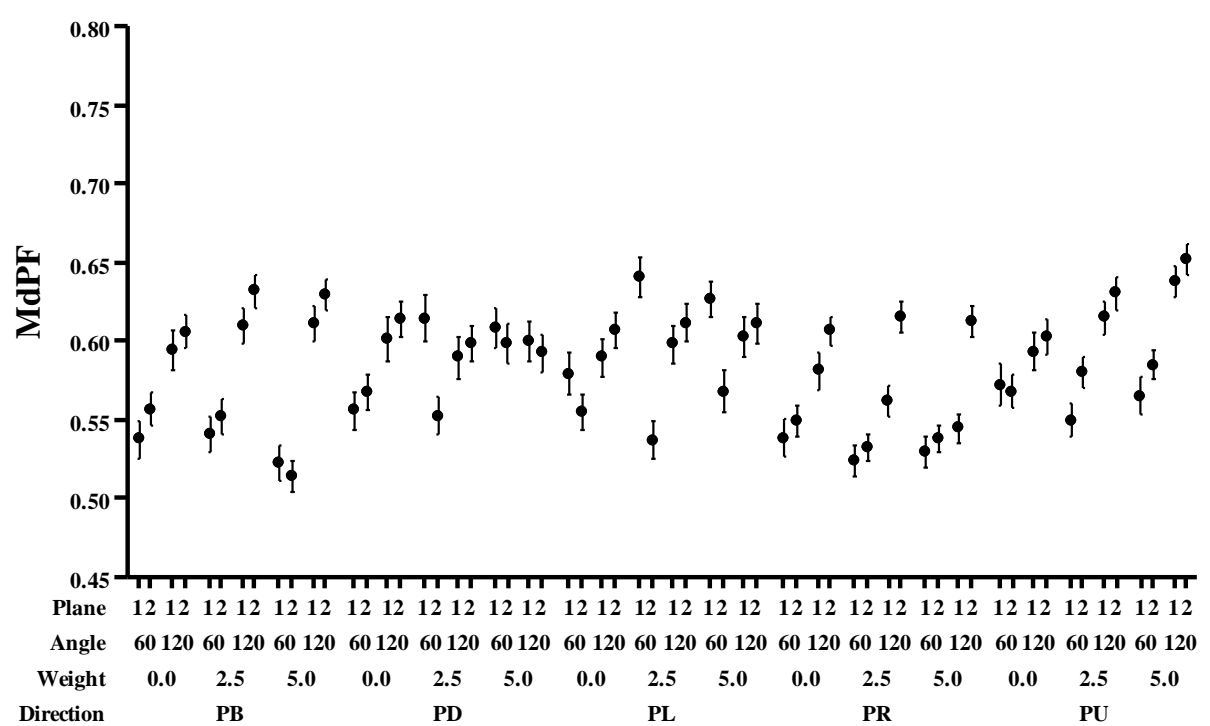

\section{Middle deltoid}

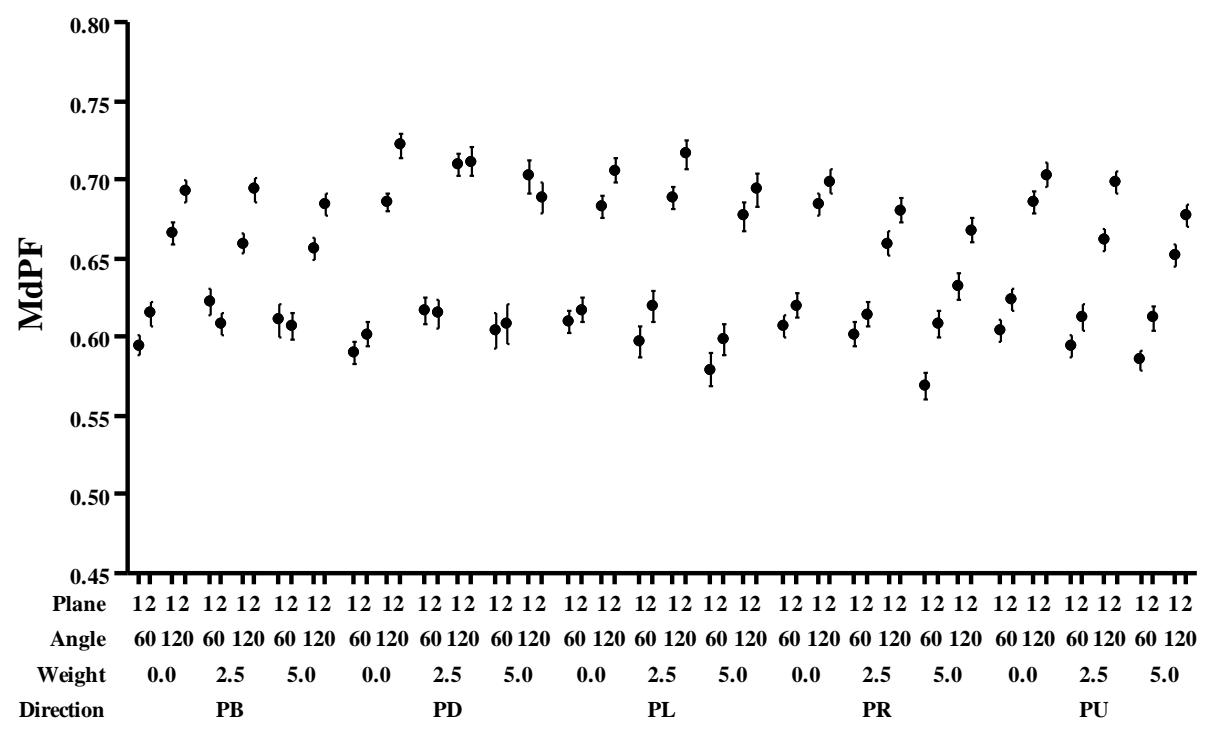

Infraspinatus

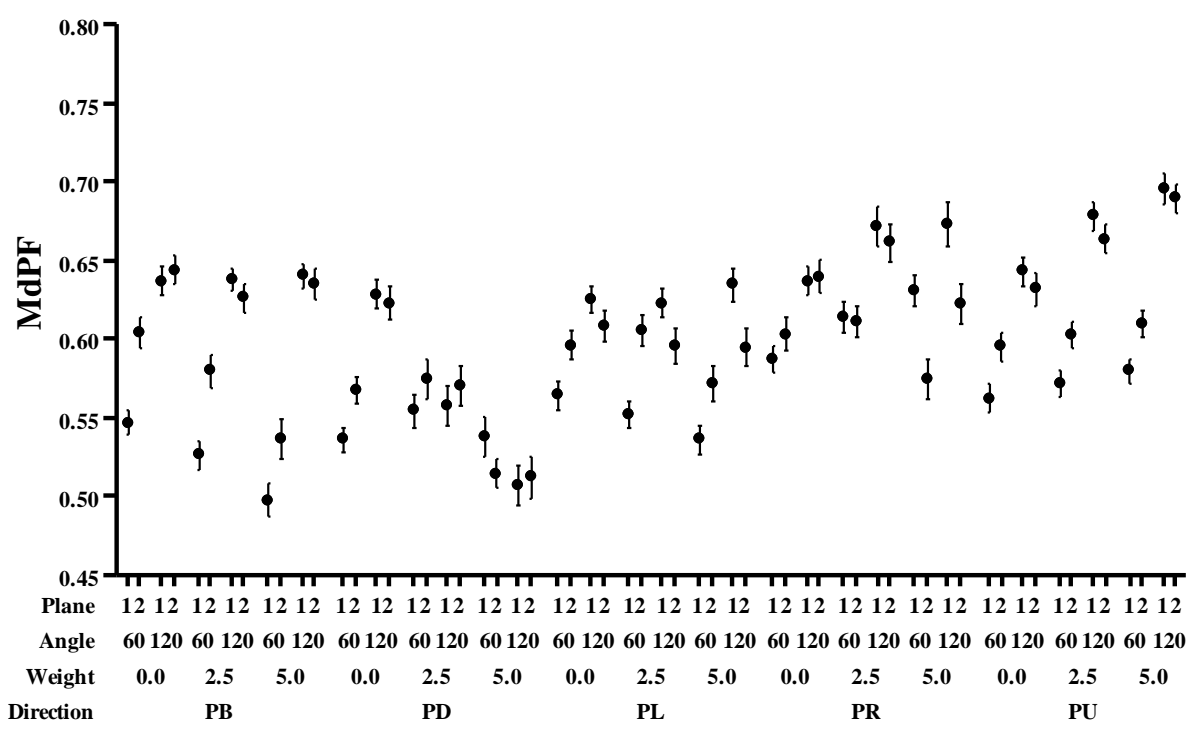

\section{Anterior deltoid}

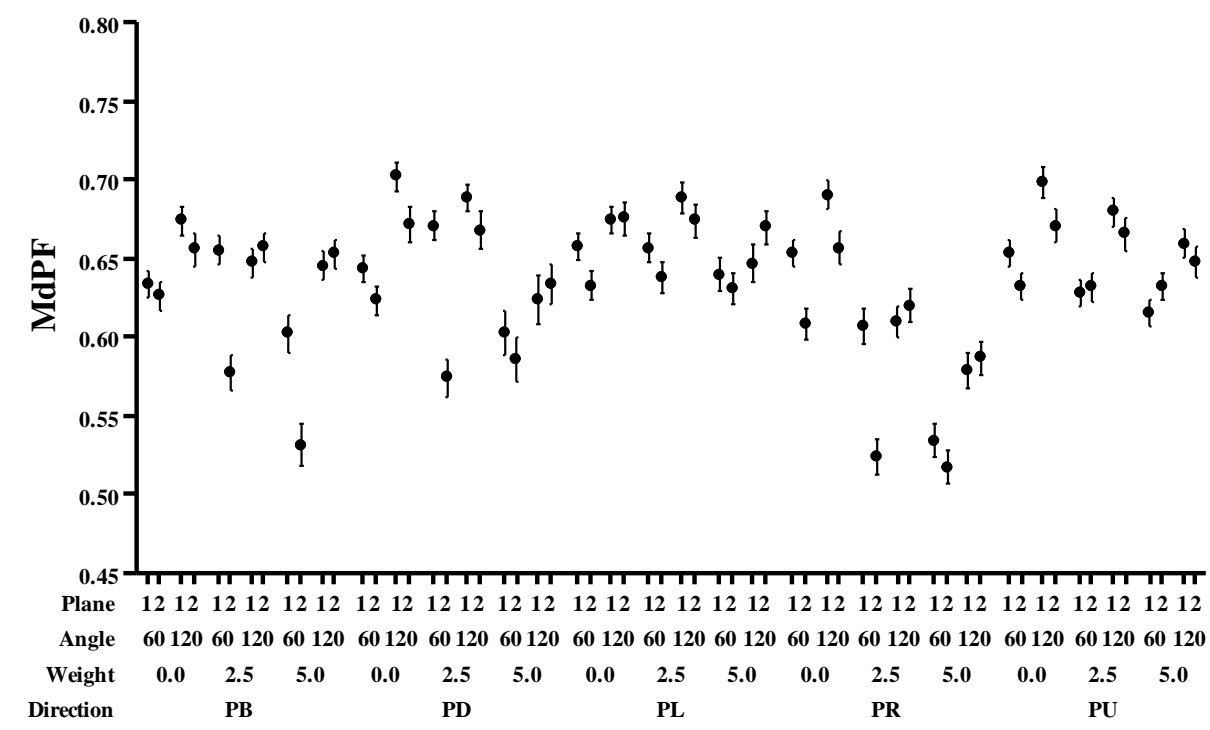


Posterior deltoid

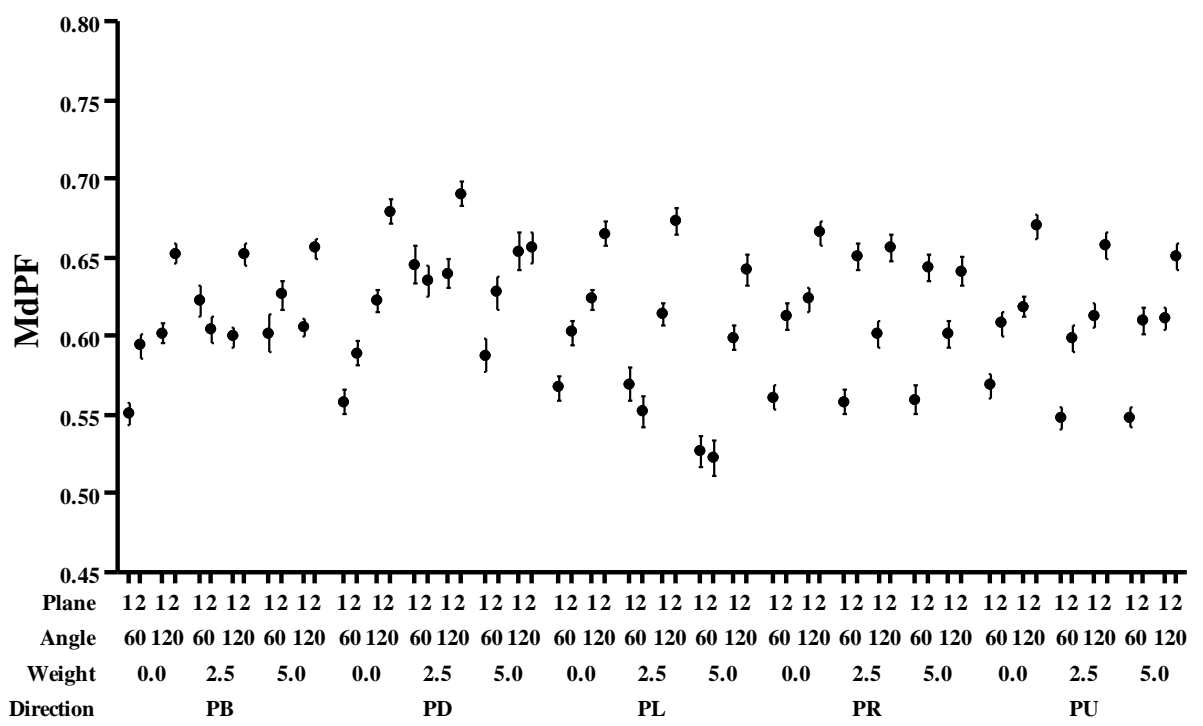

Biceps

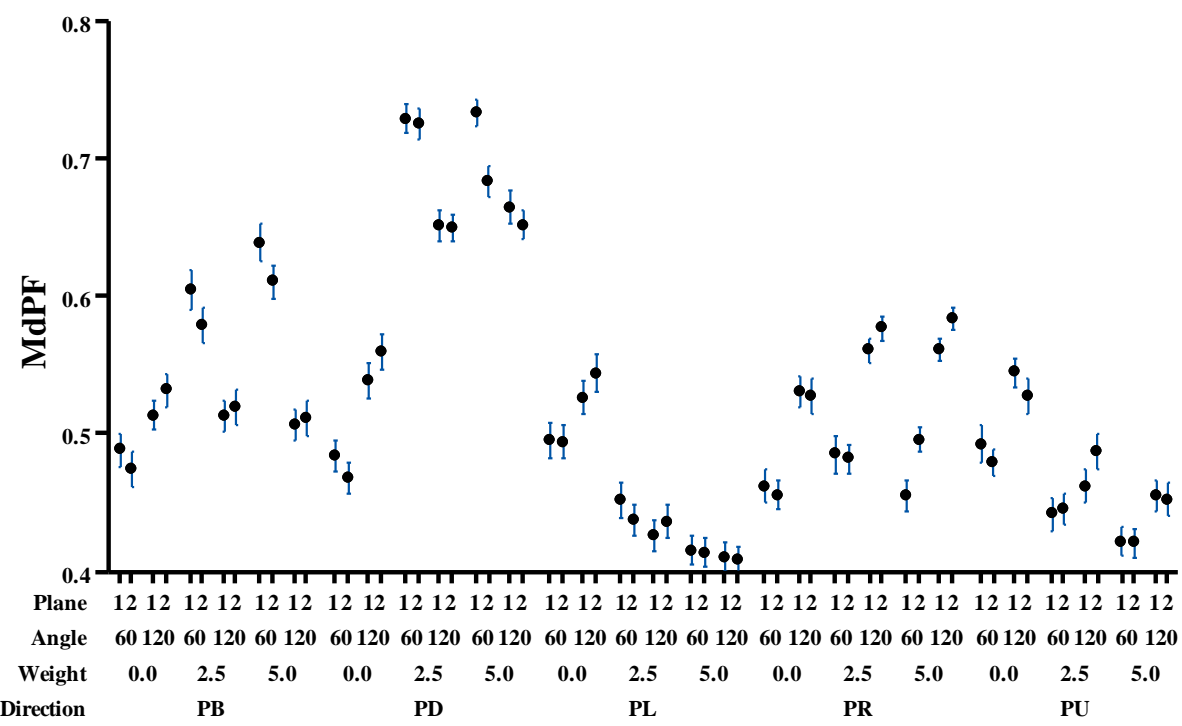

Triceps

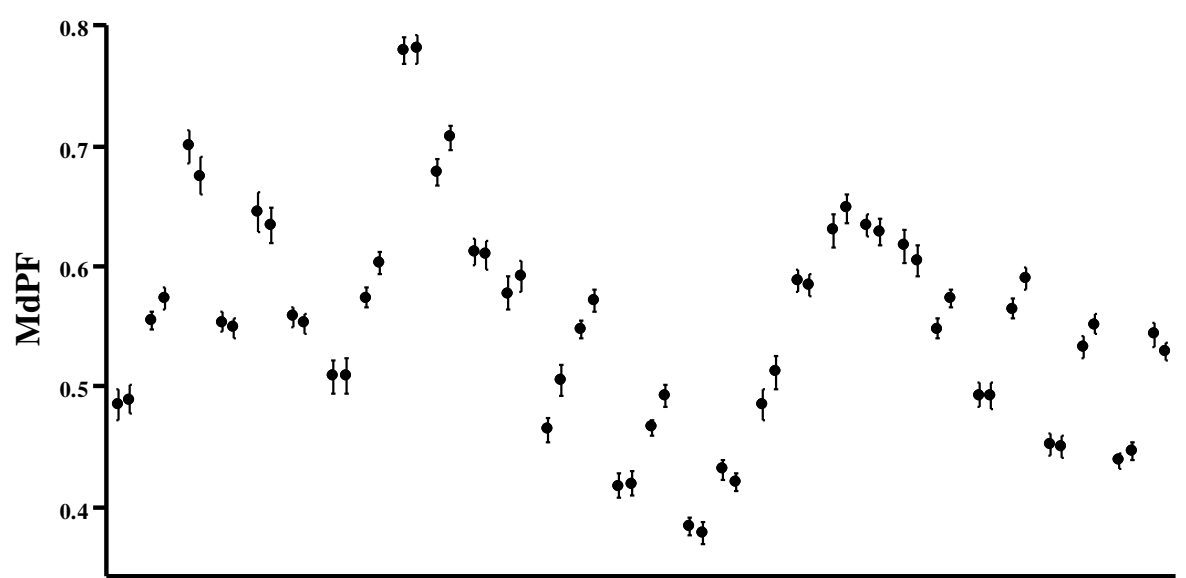

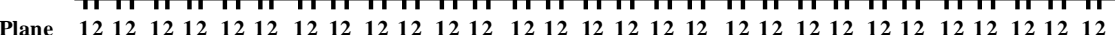

Angle 601206012060120601206012060120601206012060120601206012060120601206012060120

$\begin{array}{llllllllllllllll}\text { Weight } & 0.0 & 2.5 & 5.0 & 0.0 & 2.5 & 5.0 & 0.0 & 2.5 & 5.0 & 0.0 & 2.5 & 5.0 & 0.0 & 2.5 & 5.0\end{array}$

$\begin{array}{llllll}\text { Direction } & \text { PB } & \text { PD } & \text { PL } & \text { PR } & \text { PU }\end{array}$

Figure 18: MdPF interval plot for each muscle. Error bars represent standard deviation. Note: Plane axis label represent 1$)$ sagittal $\left(90^{\circ}\right)$ 2) scapular $\left(135^{\circ}\right)$ 


\subsubsection{Power frequency band (PFB)}

Among the seven muscles tested in this study, the largest $\mathrm{PFB}_{11-22 \mathrm{~Hz}}$ variation was observed for the supraspinatus muscle (7.91\%) and the smallest $\mathrm{PFB}_{11-22 \mathrm{~Hz}}$ variation was observed for the posterior deltoid muscle (5.32\%). Very similar variations were observed for supraspinatus and anterior deltoid muscles - $(7.91 \%$ and $7.48 \%$, respectively) (Table 19). All main effects due to the factors joint angle, force level, force direction, and shoulder plane on $\mathrm{PFB}_{11-22 \mathrm{~Hz}}$ were statistically significant (p-value $\leq 0.001$ ) for all muscles. Thus, for $\mathrm{PFB}_{11-22 \mathrm{~Hz}}$, the data rejected the null hypothesis and the alternative hypothesis was accepted. Specifically, the following trends were observed - $\mathrm{PFB}_{11-22 \mathrm{~Hz}}$ values increased with the increase of force level in all force directions except for pulling down direction were $\mathrm{PFB}_{11-22 \mathrm{~Hz}}$ values decreased with the increases of force level. 
Table 19: Main effect of joint angle, shoulder plane, force level, and force direction on $\mathrm{PFB}_{11-22 \mathrm{~Hz}}$, and variation based on $\sqrt{M S E}$. Statistically significant p-values are highlighted in bold font

\begin{tabular}{|c|c|c|c|c|c|c|c|c|c|c|c|c|c|c|}
\hline \multirow{2}{*}{\multicolumn{2}{|c|}{$\begin{array}{c}\text { PFB }_{11-22 H z} \\
\text { Levels }\end{array}$}} & \multicolumn{2}{|c|}{ Joint angle } & \multicolumn{2}{|c|}{ Shoulder plane } & \multicolumn{3}{|c|}{ Force level } & \multicolumn{5}{|c|}{ Force direction } & \multirow{2}{*}{$\begin{array}{c}\text { Variatio } \\
\mathbf{n}(\%)\end{array}$} \\
\hline & & $60^{\circ}$ & $120^{\circ}$ & $90^{\circ}$ & $135^{\circ}$ & 0 lb. & $2.5 \mathrm{lb}$ & $5 \mathrm{lb}$. & PB & PD & PL & PR & $\mathbf{P U}$ & \\
\hline \multirow{2}{*}{ Supraspinatus } & $\begin{array}{l}\text { Mean } \\
\text { (S.D.) }\end{array}$ & $\begin{array}{c}0.047 \\
(0.078)\end{array}$ & $\begin{array}{c}0.084 \\
(0.104)\end{array}$ & $\begin{array}{c}0.047 \\
(0.071)\end{array}$ & $\begin{array}{c}0.084 \\
(0.109)\end{array}$ & $\begin{array}{c}0.052 \\
(0.060)\end{array}$ & $\begin{array}{c}0.060 \\
(0.081)\end{array}$ & $\begin{array}{c}0.084 \\
(0.125)\end{array}$ & $\begin{array}{c}0.062 \\
(0.081)\end{array}$ & $\begin{array}{c}0.023 \\
(0.037)\end{array}$ & $\begin{array}{c}0.047 \\
(0.067)\end{array}$ & $\begin{array}{c}0.091 \\
(0.106)\end{array}$ & $\begin{array}{c}0.105 \\
(0.127)\end{array}$ & \multirow{2}{*}{7.91} \\
\hline & P-value & \multicolumn{2}{|c|}{$\leq \mathbf{0 . 0 0 1}$} & \multicolumn{2}{|c|}{$\leq 0.001$} & \multicolumn{3}{|c|}{$\leq \mathbf{0 . 0 0 1}$} & \multicolumn{5}{|c|}{$\leq \mathbf{0 . 0 0 1}$} & \\
\hline Infraspinatus & P-value & \multicolumn{2}{|c|}{$\leq 0.001$} & \multicolumn{2}{|c|}{$\leq 0.001$} & \multicolumn{3}{|c|}{$\leq \mathbf{0 . 0 0 1}$} & \multicolumn{5}{|c|}{$\leq \mathbf{0 . 0 0 1}$} & 5.92 \\
\hline \multirow{2}{*}{ Middle deltoid } & $\begin{array}{l}\text { Mean } \\
\text { (S.D.) }\end{array}$ & $\begin{array}{c}0.020 \\
(0.039) \\
\end{array}$ & $\begin{array}{c}0.075 \\
(0.095) \\
\end{array}$ & $\begin{array}{c}0.043 \\
(0.069) \\
\end{array}$ & $\begin{array}{c}0.052 \\
(0.085) \\
\end{array}$ & $\begin{array}{c}0.041 \\
(0.055) \\
\end{array}$ & $\begin{array}{c}0.044 \\
(0.070) \\
\end{array}$ & $\begin{array}{c}0.059 \\
(0.099) \\
\end{array}$ & $\begin{array}{c}0.043 \\
(0.066) \\
\end{array}$ & $\begin{array}{c}0.015 \\
(0.032) \\
\end{array}$ & $\begin{array}{c}0.036 \\
(0.050) \\
\end{array}$ & $\begin{array}{c}0.066 \\
(0.090) \\
\end{array}$ & $\begin{array}{c}0.079 \\
(0.108) \\
\end{array}$ & 6.48 \\
\hline & P-value & \multicolumn{2}{|c|}{$\leq 0.001$} & \multicolumn{2}{|c|}{$\leq 0.001$} & \multicolumn{3}{|c|}{$\leq 0.001$} & \multicolumn{5}{|c|}{$\leq 0.001$} & \\
\hline \multirow{2}{*}{$\begin{array}{c}\text { Anterior } \\
\text { deltoid }\end{array}$} & $\begin{array}{l}\text { Mean } \\
\text { (S.D.) }\end{array}$ & $\begin{array}{c}0.040 \\
(0.065)\end{array}$ & $\begin{array}{c}0.080 \\
(0.100) \\
\end{array}$ & $\begin{array}{c}0.066 \\
(0.089) \\
\end{array}$ & $\begin{array}{c}0.054 \\
(0.083) \\
\end{array}$ & $\begin{array}{c}0.060 \\
(0.067) \\
\end{array}$ & $\begin{array}{c}0.054 \\
(0.076) \\
\end{array}$ & $\begin{array}{c}0.066 \\
(0.110) \\
\end{array}$ & $\begin{array}{c}0.056 \\
(0.083)\end{array}$ & $\begin{array}{c}0.026 \\
(0.049)\end{array}$ & $\begin{array}{c}0.077 \\
(0.088) \\
\end{array}$ & $\begin{array}{c}0.036 \\
(0.048)\end{array}$ & $\begin{array}{c}0.104 \\
(0.119) \\
\end{array}$ & 7.4. \\
\hline & P-value & \multicolumn{2}{|c|}{$\leq 0.001$} & \multicolumn{2}{|c|}{$\leq 0.001$} & \multicolumn{3}{|c|}{$\leq 0.001$} & \multicolumn{5}{|c|}{$\leq 0.001$} & \\
\hline \multirow{2}{*}{$\begin{array}{c}\text { Posterior } \\
\text { deltoid }\end{array}$} & $\begin{array}{l}\text { Mean } \\
\text { (S.D.) }\end{array}$ & $\begin{array}{c}0.011 \\
(0.028)\end{array}$ & $\begin{array}{c}0.049 \\
(0.087)\end{array}$ & $\begin{array}{c}0.024 \\
(0.054)\end{array}$ & $\begin{array}{c}0.036 \\
(0.078) \\
\end{array}$ & $\begin{array}{c}0.016 \\
(0.027)\end{array}$ & $\begin{array}{c}0.026 \\
(0.054)\end{array}$ & $\begin{array}{c}0.047 \\
(0.097)\end{array}$ & $\begin{array}{c}0.021 \\
(0.042)\end{array}$ & $\begin{array}{c}0.007 \\
(0.016)\end{array}$ & $\begin{array}{c}0.013 \\
(0.028)\end{array}$ & $\begin{array}{c}0.065 \\
(0.107) \\
\end{array}$ & $\begin{array}{c}0.043 \\
(0.078)\end{array}$ & 53 \\
\hline & P-value & \multicolumn{2}{|c|}{$\leq \mathbf{0 . 0 0 1}$} & \multicolumn{2}{|c|}{$\leq 0.001$} & \multicolumn{3}{|c|}{$\leq 0.001$} & \multicolumn{5}{|c|}{$\leq 0.001$} & \\
\hline \multirow{2}{*}{ Biceps } & $\begin{array}{l}\text { Mean } \\
\text { (S.D.) }\end{array}$ & $\begin{array}{c}0.024 \\
(0.056)\end{array}$ & $\begin{array}{c}0.042 \\
(0.089)\end{array}$ & $\begin{array}{c}0.035 \\
(0.082)\end{array}$ & $\begin{array}{c}0.030 \\
(0.067)\end{array}$ & $\begin{array}{c}0.014 \\
(0.021)\end{array}$ & $\begin{array}{c}0.027 \\
(0.054)\end{array}$ & $\begin{array}{c}0.058 \\
(0.112)\end{array}$ & $\begin{array}{c}0.013 \\
(0.020)\end{array}$ & $\begin{array}{c}0.004 \\
(0.009) \\
\end{array}$ & $\begin{array}{c}0.071 \\
(0.116)\end{array}$ & $\begin{array}{c}0.014 \\
(0.036)\end{array}$ & $\begin{array}{c}0.061 \\
(0.096)\end{array}$ & 6 \\
\hline & P-value & $\leq 0$ & & $\leq 0$ & & & $\leq 0.001$ & & & & $\leq 0.001$ & & & \\
\hline Tricens & $\begin{array}{l}\text { Mean } \\
\text { (S.D.) }\end{array}$ & $\begin{array}{c}0.041 \\
(0.064) \\
\end{array}$ & $\begin{array}{c}0.055 \\
(0.087) \\
\end{array}$ & $\begin{array}{c}0.045 \\
(0.072) \\
\end{array}$ & $\begin{array}{c}0.051 \\
(0.082) \\
\end{array}$ & $\begin{array}{c}0.024 \\
(0.030) \\
\end{array}$ & $\begin{array}{c}0.039(0.05 \\
1) \\
\end{array}$ & $\begin{array}{c}0.081 \\
(0.112) \\
\end{array}$ & $\begin{array}{c}0.030 \\
(0.044) \\
\end{array}$ & $\begin{array}{c}0.040 \\
(0.063) \\
\end{array}$ & $\begin{array}{c}0.047 \\
(0.073) \\
\end{array}$ & $\begin{array}{c}0.069 \\
(0.104) \\
\end{array}$ & $\begin{array}{c}0.054 \\
(0.082) \\
\end{array}$ & 69 \\
\hline & P-value & $\leq 0$ & & $\leq 0$ & & & $\leq 0.001$ & & & & $\leq \mathbf{0 . 0 0 1}$ & & & \\
\hline
\end{tabular}


Supraspi natus

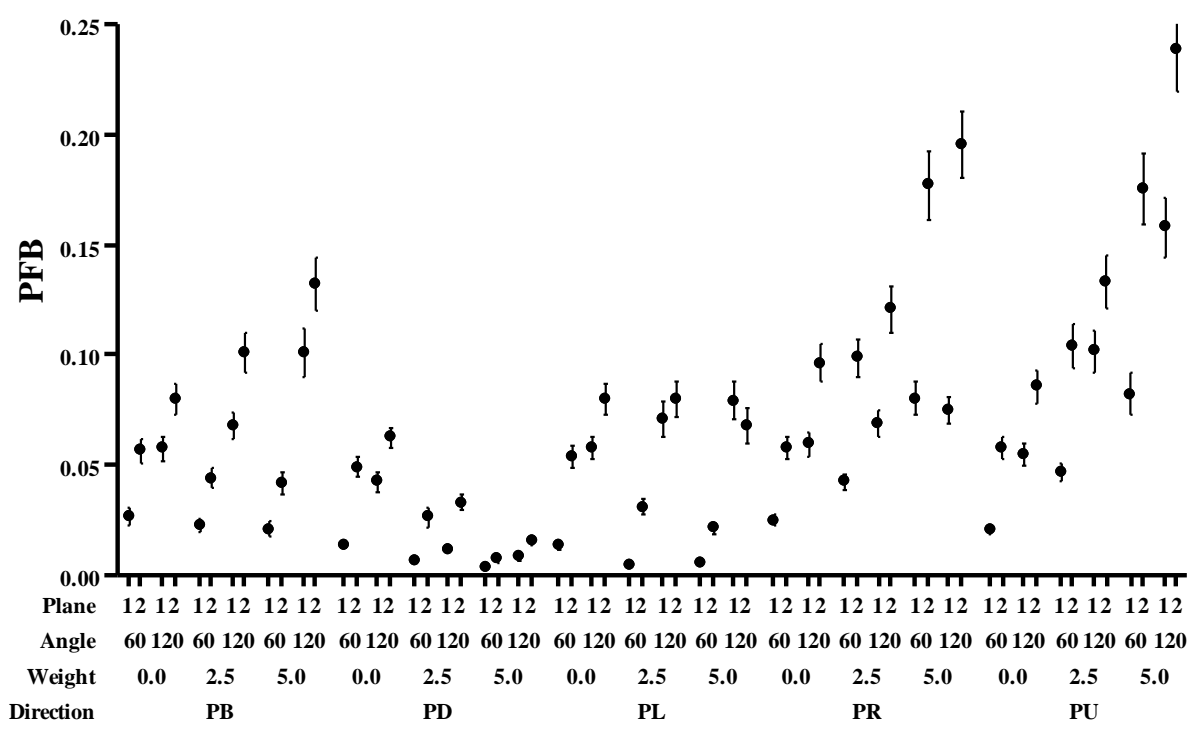

Infraspi natus

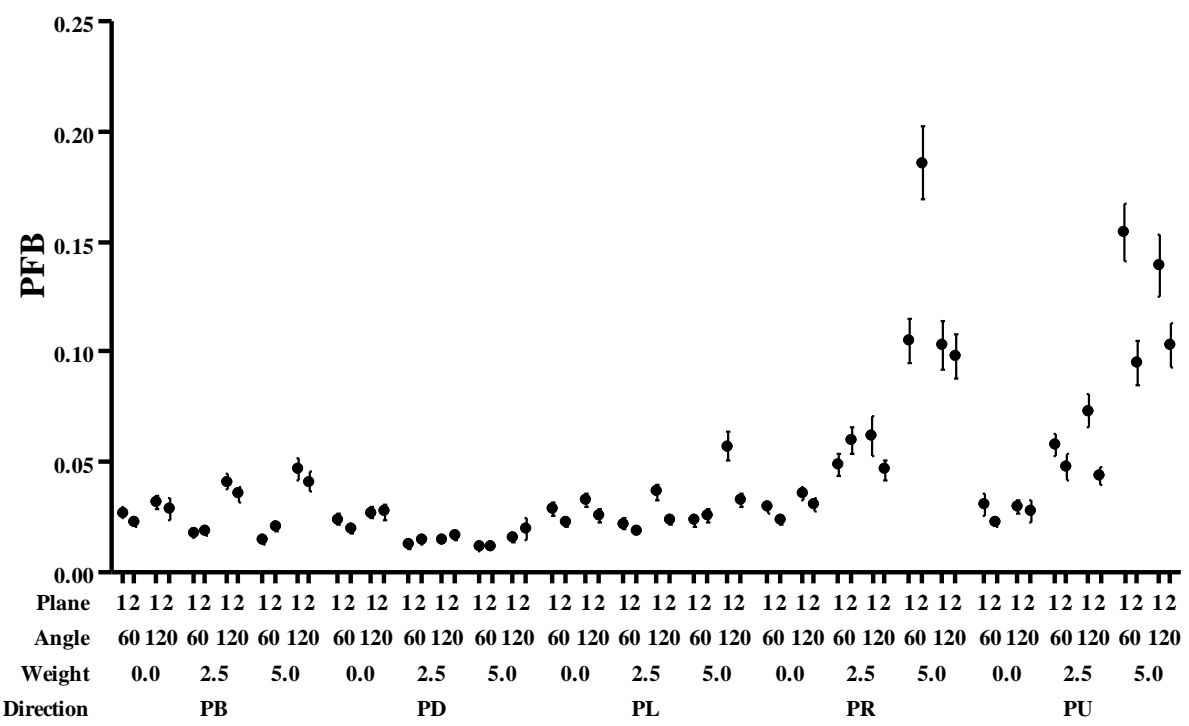

\section{Middle deltoid}

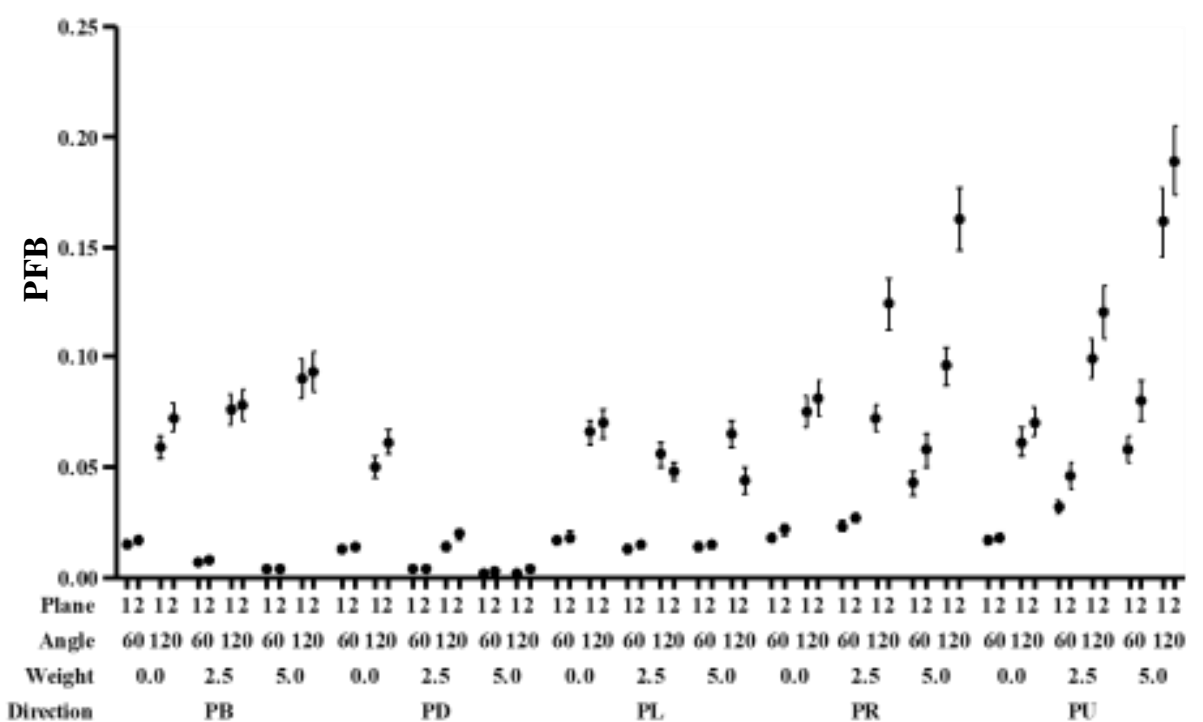

\section{Anterior deltoid}

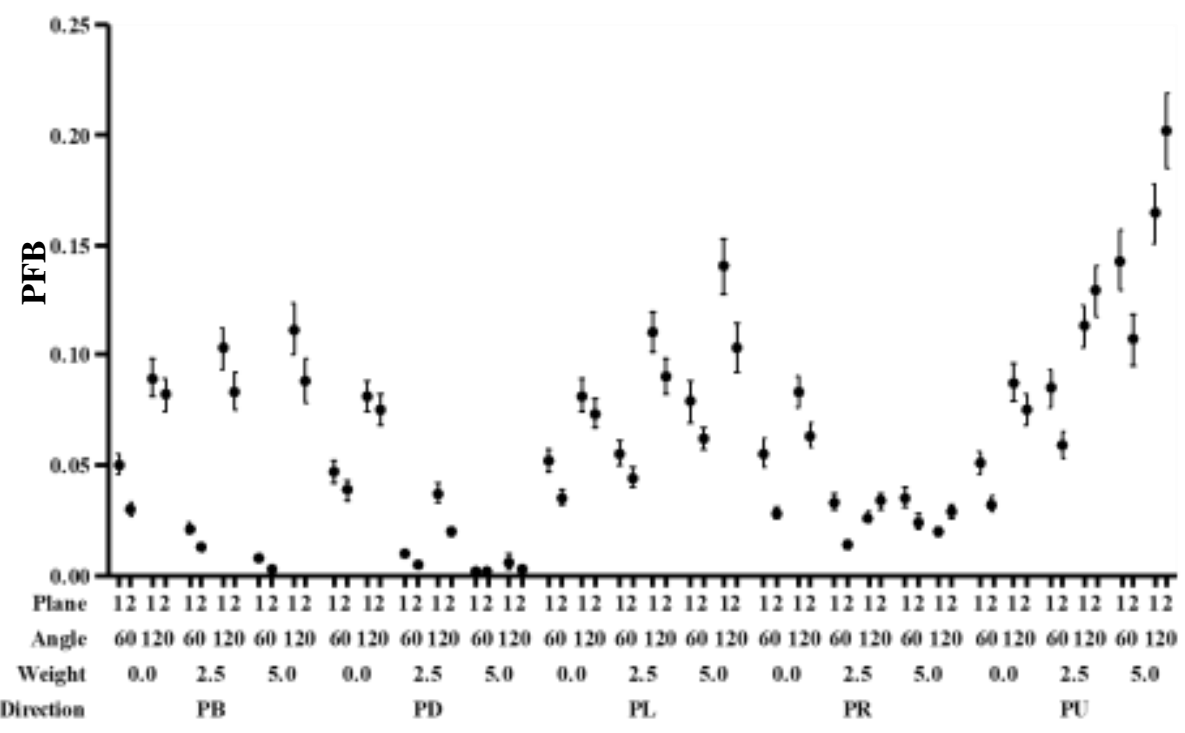


Posterior deltoid

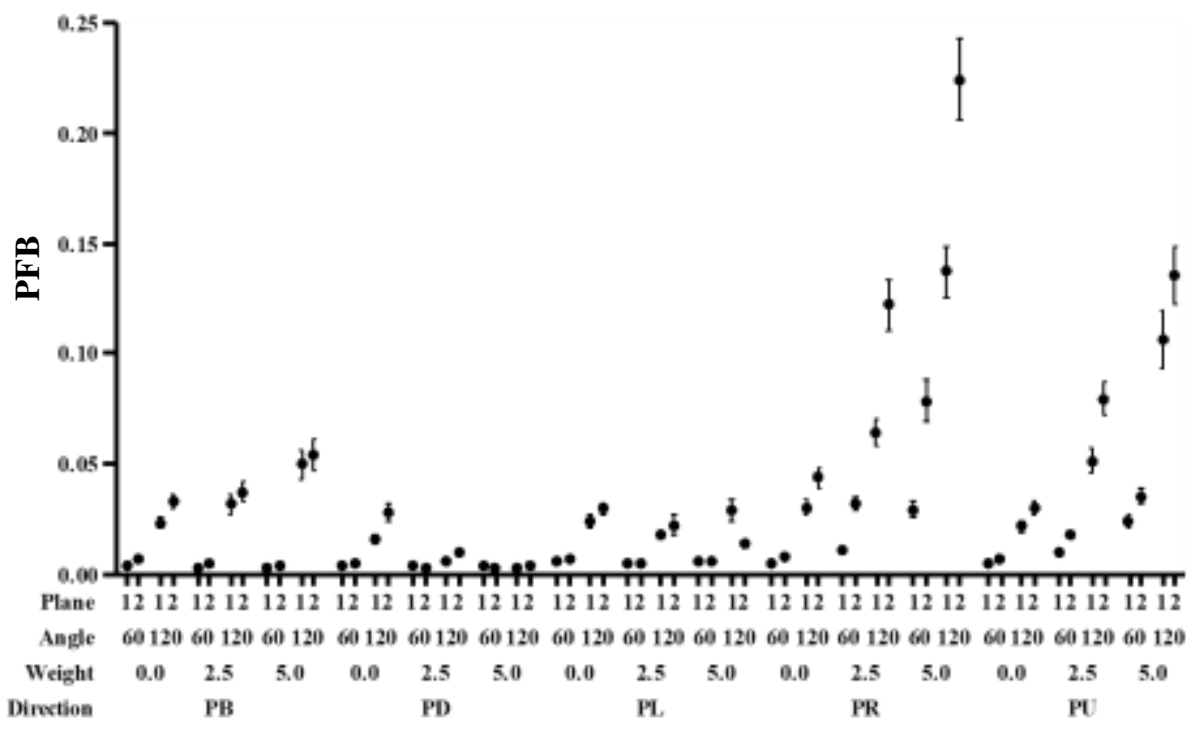

Biceps

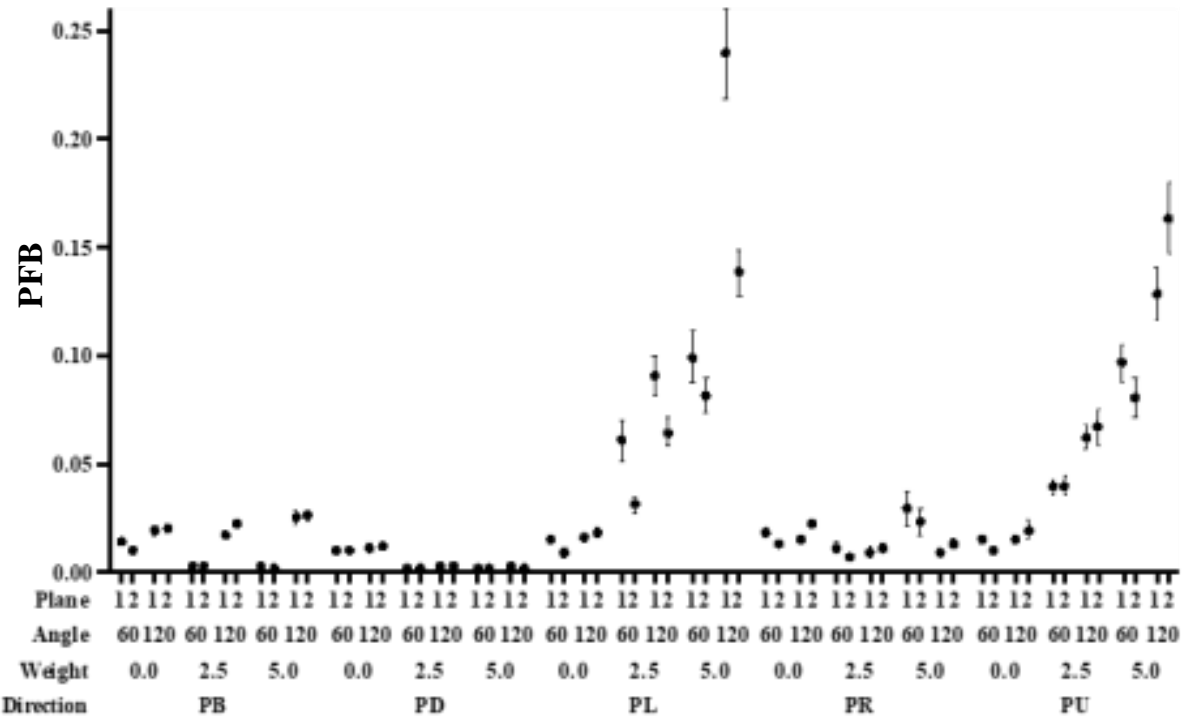

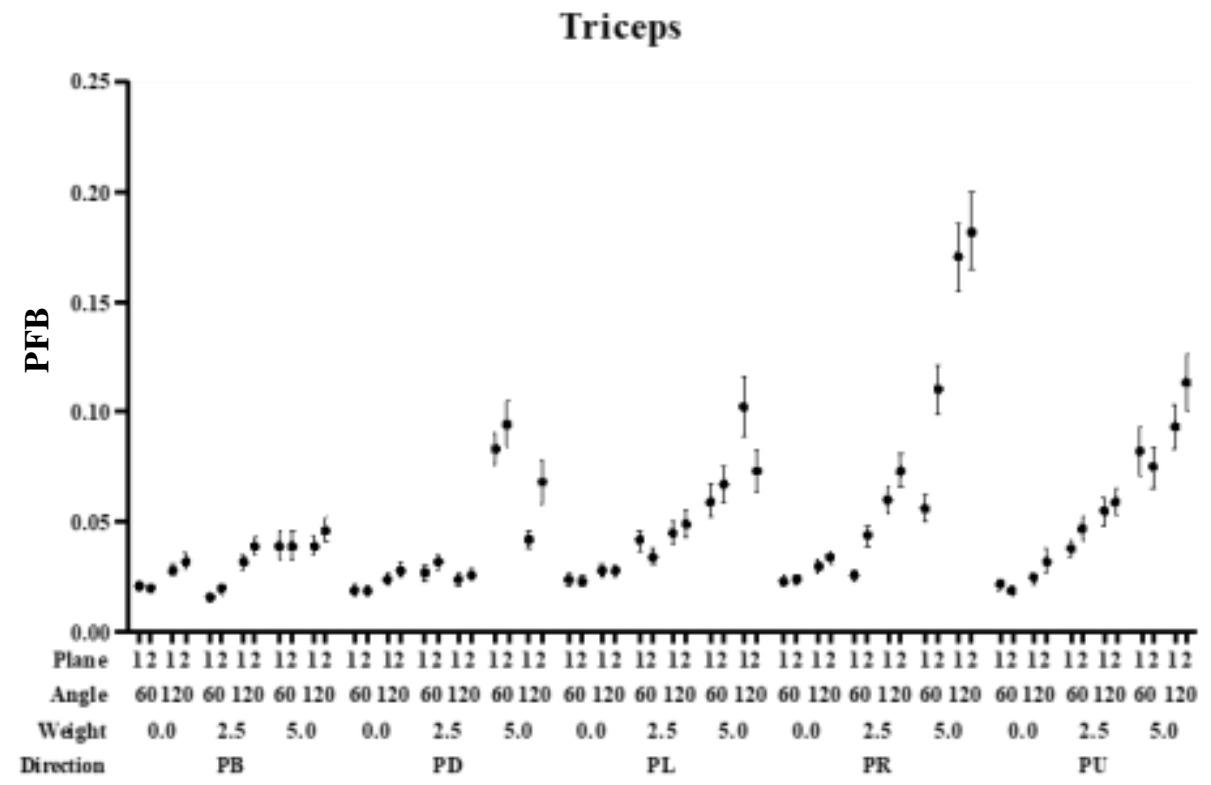

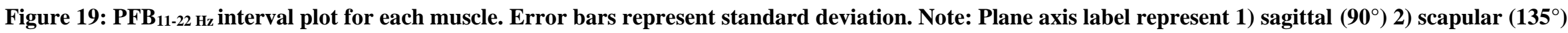


occupational factors and their interactions had significant effects on the SEMG measures, thus the data rejected the hypothesis. Under no-fatigue conditions, the values of SEMG measures varied considerably simply due to change in the way the exertions were performed.

The SEMG measures and their variability were affected by occupational factors such as shoulder joint angle, shoulder plane, force level, and force direction. In general, there was a positive relationship between shoulder joint angle and SEMG measures. An increase in shoulder joint angle from $60^{\circ}$ to $120^{\circ}$ resulted in an increase in SEMG measures for all shoulder muscles. A similar trend was reported in previous studies (Antony \& Keir, 2010; Brookham et al. 2010; and Gerdle et al. 1988). All muscles exhibited higher muscle activity in the scapular plane except for infraspinatus, anterior deltoid, and biceps muscles. The effect of shoulder plane on MnPF was also significant in Kai et al. (2012) study. In their study, the authors compared shoulder muscle fatigability during resisted arm elevation in sagittal and scapular planes, and they reported faster muscle fatigue to the infraspinatus muscle in the sagittal plane. Sporrong et al. (1995) reported an increase in the muscle activity for supraspinatus in the sagittal plane, and a decrease in its activity in the scapular plane. However, in their study the muscles were assessed when participants were performing a hand griping force of $30 \%$ and $50 \%$ MVC which may explain the differences in the results.

The increase in force level from $0 \mathrm{lb}$. to $5 \mathrm{lb}$. resulted in an increase in SEMG measures. All muscles shared a positive relationship between their activity and force level except for middle deltoid and anterior deltoid. Middle deltoid had its lowest muscle activity in the $2.5 \mathrm{lb}$. condition and anterior deltoid had a negative relationship between their activity and force level, i.e., the muscle activity decreased with the increase in force level. A positive trend between force level and RMS was also reported in the previous studies (Sigholm et al., 1984; and Öberg, 1995).

The values of SEMG measures for shoulder muscles were higher when performing pulling up exertions compared to exertions in other directions, except for posterior deltoid, biceps, and triceps muscles. The posterior deltoid and triceps exhibited higher muscle activity when performing pulling right exertions, and biceps exhibited 
higher muscle activity when performing pulling left exertions. The higher muscle activity of posterior deltoid when performing a pulling right exertion has also been reported in Alasim et al., (2019) study.

The ranges of variability for RMS, MAV, ZC, MnPF, MdPF, and PFB $11-22 \mathrm{~Hz}$ were $7.87 \%$ to $11.09 \%$, $7.14 \%$ to $10.15 \%, 10.20 \%$ to $11.00 \%, 8.60 \%$ to $11.45 \%, 8.72 \%$ to $12.25 \%$, and $5.32 \%$ to $7.91 \%$, respectively. The narrowest range of variability was observed for ZC $(0.8 \%)$, and the broadest range of variability was observed for MdPF (3.53\%). Larivière, Arsenault, Gravel, Gagnon, and Loisel (2002) stated that ZC is easily affected by noise compared to MdPF. ZC measures SEMG signal in the time domain and MdPF measures SEMG signal in the frequency domain. Szeto, Straker, and O'Sullivan (2005) stated that MnPF and MdPF are frequently used to asses muscle fatigue, compared to ZC, and these three SEMG measures are often referred to as "muscle fatigue indexes." They also stated that MdPF is considered more sensitive to the change in the SEMG signals. Kupa, Roy, Kandarian, and De Luca, (1995) suggested that MdPF has a high sensitivity to muscle fiber composition. The high sensitivity of MdPF to changes in the SEMG signals might explain its broad range of variability.

The average variability of $\mathrm{ZC}, \mathrm{MnPF}$, and MdPF was very similar at $10.59 \%, 10.35 \%$, and $10.68 \%$, respectively. This finding is in agreement with the previous studies which showed that ZC behaves similarly to MnPF and MdPF (Cifrek et al., 2009; Hägg \& Suurküla, 1991). A few other studies found that the variability of MdPF was higher than that for MnPF(Bartuzi and Roman-Liu, 2014; Nussbaum, 2001; Van Dieen and Vrielink, 1996). Most of these studies used longer task durations and mostly looked at variability under post fatigue conditions. The average variability of RMS at $10.17 \%$ was found to be comparable with the other measures stated earlier. This finding is in contradiction with Nussbaum (2001) who reported that the RMS amplitude was associated with the highest variability when compared to MnPF and MdPF. However, the task duration in Nussbaum's (2001) study was 300 seconds and the task duration in our study was only 10 seconds, suggesting that difference in the task duration can also attribute to the variability. The variability of PFB $11-22 \mathrm{~Hz}$ was lower than all other SEMG measures. The low variability in $\mathrm{PFB}_{11-22 \mathrm{~Hz}}$ can be attributed to PFB's low sensitivity to muscle contraction. Cioni et al. (1994) and Roman-Liu and Konarska (2009) evaluated the effect of muscle 
contraction level on changes in PFBs. They reported that low PFB, 2.5-17.5Hz and 6-15Hz, had a low sensitivity to muscle contraction.

Shoulder muscles can be categorized as rotator cuff muscles and non-rotator cuff muscles. Supraspinatus and infraspinatus are the rotator cuff muscles. These two muscles contribute significantly to the stabilization of the glenohumeral joint, and infraspinatus muscle plays a significant role in the scapular (mid-abduction) plane abduction (Wuelker, Korell, and Thren, 1998). The non-rotator cuff muscles are the deltoid, biceps and triceps muscles. Itoi, Kuechle, Newman, Morrey, and An (1993) reported that the biceps muscle also plays a significant role in the stabilization of the glenohumeral joint as an anterior stabilizer when the shoulder is in an abducted and externally rotated posture. Deltoid muscles function was described by previous studies as the primary movers for shoulder joint abduction in scapular (mod-abduction) plane (Alpert, Pink, Jobe, McMahon, \& Mathiyakom, 2000). Escamilla, Yamashiro, Paulos, and Andrews (2009) reported that deltoid muscles were more effective as shoulder joint abductors at high abduction angles $\left(60^{\circ}-90^{\circ}\right)$. The biceps and triceps muscles function was described by previous studies as the elbow flexors/extensor muscles (Gatti et al., 2008; Lee et al., 2015). In summary, the shoulder muscles investigated in this study have diverse functions and actions, which is absolutely required to support the flexibility and the large range of motion of shoulder joint. Despite such differences in the functionality of the shoulder muscles, the variabilities in their SEMG measures were not very different. Supraspinatus and infraspinatus muscles' highest variability were $12.04 \%$ and $10.72 \%$, respectively. Middle deltoid, anterior deltoid, and posterior deltoid muscles' highest variability were $11.00 \%, 11.00 \%$, and $10.68 \%$, respectively. The biceps and triceps muscles' highest variability were $12.25 \%$ and $11.45 \%$, respectively. If the muscles would have been very different in terms of maximum variability, then such differences could be due to the possibility that some muscles were activated more than the others. The closely spaced maximum variabilities observed in this study may further suggest that the experimental protocol used in this study was successful in activating all the studied muscles to their maximum or close to maximum activation levels. 
The seven shoulder muscles investigated in this study are very different from each other in terms of their anatomical structures and physiology. The PCSA (Physiological Cross-Sectional Areas), muscle volume, muscle length, and/or muscle fiber type for the shoulder muscles are reported in Table 20 . We investigated the relationship between the anatomical structures and the variability using correlations analysis. A negative correlation was observed $(r=-0.71$ and $r=-0.85)$ between the overall average of variabilities across all SEMG measures and muscle volume and muscle length. This suggests that when muscle volume and muscle length increases, the average variability under non-fatigued conditions decreases. The RMS, MAV, and PFB ${ }_{11-22} \mathrm{~Hz}$ variability had a strong correlation $(r=-0.84, r=-0.78$, and $r=-0.86)$ with muscle length only. The variability of MnPF and MdPF had a strong correlation $(r=-0.82$ and $r=-0.92)$ with muscle volume only. A weak correlation was observed for ZC with PCSA, muscle volume, muscle length, or muscle fiber type. In general, PCSA and muscle fiber type showed a weak correlation with the variability of SEMG measures under non-fatigued conditions.

Table 20: musculoskeletal parameters for the selected muscles including physiological cross-sectional areas (PCSA), muscle volumes, muscle length, and muscle fiber type

\begin{tabular}{lcccc}
\hline Muscle & PCSA $\left(\mathbf{c m}^{2}\right)$ & Muscle volume $\left(\mathbf{c m}^{\mathbf{3}}\right)$ & Muscle length $(\mathbf{c m})$ & Slow twitch fibers \\
\hline Supraspinatus & $4.02^{\mathrm{a}}$ & $54.39^{\mathrm{e}}$ & $11.65^{\mathrm{e}}$ & $54^{\mathrm{h}}$ \\
Infraspinatus & $10.71^{\mathrm{b}}$ & $129.25^{\mathrm{e}}$ & $13.23^{\mathrm{e}}$ & $41^{\mathrm{h}}$ \\
Middle deltoid & $7.93^{\mathrm{b}}$ & $167.62^{\mathrm{e}}$ & $13.5^{\mathrm{e}}$ & $60^{\mathrm{g}}$ \\
Anterior deltoid & $8.2^{\mathrm{c}}$ & $111.88^{\mathrm{e}}$ & $12.6^{\mathrm{b}}$ & $60^{\mathrm{g}}$ \\
Posterior deltoid & $4.69^{\mathrm{b}}$ & $134.38^{\mathrm{e}}$ & $15.3^{\mathrm{b}}$ & $60^{\mathrm{g}}$ \\
Biceps & $6.29^{\mathrm{d}}$ & $33.4^{\mathrm{f}}$ & $13.2^{\mathrm{c}}$ & $46^{\mathrm{g}}$ \\
Triceps & $11.61^{\mathrm{d}}$ & $66.6^{\mathrm{f}}$ & $13.4^{\mathrm{c}}$ & $33^{\mathrm{g}}$ \\
\hline
\end{tabular}

**letters next to the values represents the following literature sources: a) (Keating, Waterworth, Shaw-Dunn, \& Crossan, 1993), b) (Langenderfer, Jerabek, Thangamani, Kuhn, \& Hughes, 2004), c) (Holzbaur, Murray, \& Delp, 2005), d) (Ramsay, Hunter, \& Gonzalez, 2009), e) (Wu, Lee, Bryant, Galea, \& Ackland, 2016), f) (An, Hui, Morrey, Linscheid, \& Chao, 1981), g) (Nieminen et al., 1995), and $h$ )(Lovering \& Russ, 2008).

As discussed previously, there are several studies that have considered an increase in RMS, MAV, and PFB $11-22$ $\mathrm{Hz}$ or a drop in ZC, MnPF, and MdPF as a sign of fatigue for shoulder muscles (Dickerson et al., 2015; Herberts \& Kadefors, 1976; Herberts et al., 1980; Klaver-Król et al., 2010; Marina et al., 2013; D Roman-Liu \& Konarska, 2009; Sigholm et al., 1984; Takala et al., 1993; Yung et al., 2012). The results of this study, however, indicate 
that there can be alterations in the RMS, MAV, ZC, MnPF, MdPF, and PFB $11-22 \mathrm{~Hz}$ due to factors other than muscle fatigue. Öberg et al. (1990) reported that a variation of up to $\pm 8 \%$ in MnPF and MdPF in trapezius muscle cannot be associated with muscle fatigue. Then, our preliminary study concluded that MnPF and MdPF can vary/change up to $6 \%$ due to factors other than muscle fatigue. Various papers have used a drop of $8 \%$ in MnPF and MdPF to estimate LMF. The variabilities in SEMG measures observed in this study, specially MnPF and MdPF, were slightly higher than what has been reported by Öberg et al. (1990) and by our preliminary study. This is mainly due to the limited scope of these previous studies. For example, Öberg et al. (1990) only considered one shoulder muscle, the trapezius muscle, and only evaluated variability due to shoulder joint angle, shoulder plane, and force level. Our preliminary study was also limited to only force level and force direction. Furthermore, both of these previous studies only used male participants. Our study, on the other hand, used a comprehensive approach by considering all factors that are occupationally relevant.

\section{Chapter 4. Specific Aim\#2}

\subsection{Introduction}

Development of Localized Muscle Fatigue (LMF) is a continuous process (Chowdhury \& Nimbarte, 2015; Chowdhury, Nimbarte, Jaridi, \& Creese, 2013; Nussbaum, 2001). If LMF is used as a surrogate measure of injury risk, then identifying a point in this process at which risk level has risen above baseline is critically important. As discussed earlier, several studies have considered a relative change in the in MnPF and/or MdPF as a sign of LMF (e.g., Chaffin, 1973; Christensen, 1986; Herberts \& Kadefors, 1976; Herberts et al., 1980; Hermans \& Spaepen, 1997; Jensen et al., 1993; Sundelin \& Hagberg, 1992; Sundelin, 1993; Takala et al., 1993). The results of our preliminary study and Specific Aim \# 1 study, however, indicate that SEMG measures can be altered due to factors other than fatigue. Öberg et al. (1990) performed a study somewhat similar to ours, concluding that “...there is a need for an initial calibration contraction, to which other MnPF values can be related. Changes within $\pm 8 \%$ of this initial value cannot be regarded as clinically significant." (p.368) This recommendation of $\pm 8 \%$ of initial MnPF was based on the trapezius muscle's variation of $\pm 7.8 \%$ observed in MnPF for changes in joint torque. The recommended $\pm 8 \%$ was then used in several studies to quantify shoulder muscle fatigue (Borstad et 
al., 2009; Chopp et al., 2010; Ebaugh et al., 2006a, 2006b; Lin et al., 2004; Szucs et al., 2009; Tsai et al., 2003).

While $\pm 8 \%$ encompasses the range of variabilities observed in our preliminary study, it is considered smaller than the variabilities in SEMG measures observed in Specific Aim \# 1. In preliminary study, the maximum variabilities in MnPF and MdPF due to changes in force level were 5.2\% and 6.0\%, respectively. In Specific Aim \# 1 study, the maximum variability across all SEMG measures due to factors other than muscle fatigue was $12.25 \%$.

Using the knowledge on the intrinsic variability in the SEMG measures, specific guidelines regarding clinically significant points during muscular exertions can be identified to predict LMF. For example, if variability in a SEMG measure is $10 \%$ then a drop greater than $10 \%$ can be used to predict muscle fatigue. This approach is very similar to that of Öberg et al. (1990). However, making such claim purely based on the variability may be perplexing without adequate cross-validation. In other words, it is critically important that implications of variability in the electromyographic measures on the prediction of LMF are carefully validated prior to its application in research and practice.

Subjective assessments have been used to measure individual discomfort, fatigue, and exertion and to create acceptable perceived exertion ratings. Robertson and Noble (1997) defined perceived exertion as “subjective intensity of effort, strain, discomfort or fatigue, experienced during physical exercise." Different scales were developed and used to quantify perceived exertion rating such as Borg's category ratio (CR-10) scale (Borg, 1982; Borg, 1990), Borg's 15-partition scale (Borg, 1990) and the Pittsburgh fatigability scale (Glynn et al., 2015; Robertson \& Noble, 1997). Among these scales, Borg's CR-10 scale is the most widely used by the ergonomics researchers and practitioners.

Since 1962, Borg has been developing scales to measure individuals' perceived exertion of muscle fatigue and discomfort. The Borg's CR- 10 scale (Borg, 1982; Borg, 1990) provides ratio scaling and exertion level estimations where the categorical expressions of an individual's perceived exertion are connected to a quantitative number. The scale ranged from 0 through 10 , where 0 corresponds to "nothing at all" and 10 corresponds to “extremely strong." Table 21 shows Borg’s CR- 10 scale. 


\begin{tabular}{ccc}
\hline $\mathbf{0}$ & Nothing at all & \\
$\mathbf{0 . 5}$ & Extremely weak & (just noticeable) \\
$\mathbf{1}$ & Very weak & \\
$\mathbf{2}$ & Weak & (light) \\
$\mathbf{3}$ & Moderate & \\
$\mathbf{4}$ & & \\
$\mathbf{5}$ & Strong & (heavy) \\
$\mathbf{6}$ & & \\
$\mathbf{7}$ & Very strong & \\
$\mathbf{8}$ & & \\
$\mathbf{9}$ & & \\
$\mathbf{1 0}$ & Extremely strong & (almost max) \\
\hline
\end{tabular}

Several researchers have used Borg's CR-10 scale to evaluate fatigue and discomfort during simulated industrial tasks. Armstrong, Punnett, and Ketner (1989) used Borg's CR- 10 scale to evaluate worker's perception of hand tools in automobile assembly tasks such as tool mass, grip force, handle size, and work location. In another simulated assembly line study, Ulin, Ways, Armstrong, and Snook (1990) compared different types of scales while evaluating perceived exertion during industrial tasks using light tools, and the participants preferred using Borg's CR- 10 scale.

Many studies have found a positive correlation between the subjective ratings of perceived exertion and the objective assessments of muscle's fatigue and activation (Dedering, Németh, \& Harms-Ringdahl, 1999; Dickerson, Martin, \& Chaffin, 2006; Hummel et al., 2005; Iridiastadi \& Nussbaum, 2006b). Dedering et al. (1999) reported a significant correlation between perceived exertion ratings and muscle fatigue, which was represented by both MnPF and MdPF, during a static back extension task that was performed until exhaustion. Hummel et al. (2005) reported a similar result regarding the correlation between perceived exertion ratings and muscle fatigue, which was represented by MnPF, during a static shoulder elevation endurance task. Dickerson et al. $(2006,2007)$ stated that the perception of shoulder muscular effort was correlated with physical measures of loading, such as shoulder torque, muscle force, and EMG. Öberg (1994) evaluated subjective and objective assessments for shoulder muscle fatigue while performing a $90^{\circ}$ abduction using no hand load and $2 \mathrm{~kg}$ hand load. The author 
reported that there was a high correlation between ratings of Borg's CR-10 scale and MnPF, which occurred at a high load level. In contrast, Strimpakos, Georgios, Eleni, Vasilios, and Jacqueline (2005) evaluated neck muscles fatigue during sustained static exertions. They reported that subjective assessments had more reliability than objective assessments, and there was no correlation between Borg scale and MdPF and RMS. In overhead exertion tasks, Sood et al. (2007) reported similar results regarding subjective assessments having higher reliability compared to objective assessments.

There are also studies that offered some guidance on the acceptable level of perceived exertion ratings. According to Garg and colleagues, a mean rating of 3.5 or less is considered as the acceptable level (Garg et al., 2006). In their study, automotive assembly tasks using a combination of workpiece weight, tool weight and different work-related postures including overhead configuration were performed. Similarly, other studies recommended perceived exertion ratings of 3.5 to 4.0 as the acceptable levels (Jakobsen, Sundstrup, Persson, Andersen, \& Andersen, 2014; Rashedi \& Nussbaum, 2016). One study suggested that the perceived discomfort rating should be around 5 as an acceptable standard level (Iridiastadi and Nussbaum, 2006).

Each assessment method has its own advantages and disadvantages. Some of the major advantages of objective assessment are the ability to evaluate inter muscle differences, and participants' lack of control over the EMG signals. However, the objective assessment requires expensive equipment, and is considered as impracticable for field uses. On the other hand, subjective assessment methods when compared to the objective assessment methods are easy to use, administer and interpret. However, the ambiguous definitions of scale ratings and time effects can result in some confusion while using subjective assessment. A few studies have reported high variability in participants' ratings (Forster, Simon, Augat, \& Claes, 2004; Shen \& Parsons, 1997) and, therefore, Borg's CR- 10 scale needs to be explained clearly and should be reported instantaneously in order to prevent poor reliability.

\subsection{Objective and hypotheses}

Our literature review indicates that a high correlation exists between objective (EMG) and subjective (CR10 scale) assessment methods. Furthermore, the standard acceptable level of perceived exertion ratings has been 
used in previous studies to assess the risk of WMSD. Thus, subjective perceived exertion ratings can be used to identify a point in the LMF development process to predict risk level. In other words, the standard acceptable level of perceived exertion ratings can be used to validate the prediction of LMF based on the variability in the SEMG measures. Therefore, the objective in Specific Aim \# 2 was to understand the implications of variability in the electromyographic measures on the prediction of LMF using subjective perceived exertion ratings.

Based on the intrinsic variability in the SEMG measures (findings from aim\#1), a crucial point in the fatigue development process can be defined as the one at which relative change in an SEMG measure during a physical exertion exceeds its intrinsic variability. Based on the subjective assessment method, a crucial point in the fatigue development process can be defined as the one at which a perceived discomfort of 4 is reported during a physical exertion. Our research hypothesis was that these two points (in time domain) would concur with each other.

\subsection{Methodology}

\subsubsection{Approach}

An experiment was performed in the laboratory settings to compare continuous change in the "objective (EMG) measures" with "subjective (CR-10) measures" during fatigue inducing exertions. Human subjects performed muscle specific static arm exertions and the SEMG and perceived exertion ratings were monitored continuously. Seven muscles (same as Aim\#1) were tested in this aim.

\subsubsection{Participants}

A total of 12 right-hand dominant participants were recruited for this study, of which 4 were female participants and the remaining 8 were male participants. The inclusion criteria were the same as Aim\#1. All participants, who meet the inclusion criteria, read and signed a consent form approved by the local Institutional Review Board prior to their participation in the study. Copy of the consent form is included in Appendix C. 


\subsubsection{Equipment}

Most of the equipment including Custom-Made Force Exertion Device, Surface Electromyography (SEMG) system, weights were the same as Aim\#1. Please see section 3.3.3. Equipment.

\subsubsection{Experimental design}

Human participants performed muscle specific static arm exertions. The duration of the exertions was controlled between 10 to 45 seconds. During the exertions, SEMG and perceived exertion ratings were recorded continuously. The data collection was ceased when the participants report a perceived exertion of 7 or 8 ("Very strong”, Table 21). A rest period of 5-minute was provided between the exertions. Each exertion was repeated two times and the trial order was randomized.

Seven shoulder muscles (same as Aim\#1): the supraspinatus, infraspinatus, middle deltoid, anterior deltoid, posterior deltoid, biceps, and triceps, were studied. Muscle specific exertions were identified from the results of Aim\#1. A muscle specific exertion was defined as the exertion that consistently activates the specific muscle to the highest level compared with other exertions. From the 60 exertions tested in Aim\#1, seven exertions, one per muscle were initially identified (Table 22). Since for the four out the seven muscles, the same exertion produced the highest activation, four exertions were finally identified for this study (Table 23).

Table 22: Muscle specific exertions

\begin{tabular}{ccccc}
\hline Muscle & $\begin{array}{c}\text { Shoulder } \\
\text { joint angle }\end{array}$ & Shoulder plane & Force level & Force direction \\
\hline Supraspinatus & $120^{\circ}$ & Scapular & $5 \mathrm{lb}$. & Pull up \\
\hline Infraspinatus & $120^{\circ}$ & Sagittal & $5 \mathrm{lb}$. & Pull up \\
\hline Middle deltoid & $120^{\circ}$ & Scapular & $5 \mathrm{lb}$. & Pull up \\
\hline Anterior deltoid & $120^{\circ}$ & Scapular & $5 \mathrm{lb}$. & Pull up \\
\hline Posterior deltoid & $120^{\circ}$ & Scapular & $5 \mathrm{lb}$. & Pull right \\
\hline Biceps & $120^{\circ}$ & Sagittal & $5 \mathrm{lb}$. & Pull left \\
\hline Triceps & $120^{\circ}$ & Scapular & $5 \mathrm{lb}$. & Pull right \\
\hline
\end{tabular}


Table 23: Exertions used to develop muscle fatigue

\begin{tabular}{ccccc}
\hline Exertion & $\begin{array}{c}\text { Shoulder } \\
\text { joint angle }\end{array}$ & Shoulder plane & Force level & Force direction \\
\hline $\mathbf{1}$ & $120^{\circ}$ & Sagittal & $5 \mathrm{lb}$. & Pull left \\
\hline $\mathbf{2}$ & $120^{\circ}$ & Sagittal & $5 \mathrm{lb}$. & Pull up \\
\hline $\mathbf{3}$ & $120^{\circ}$ & Scapular & $5 \mathrm{lb}$. & Pull right \\
\hline $\mathbf{4}$ & $120^{\circ}$ & Scapular & $5 \mathrm{lb}$. & Pull up \\
\hline
\end{tabular}

\subsubsection{Experimental Data Collection Procedure}

The basic SEMG data collection process was the same as Aim\#1. Ratings of perceived exertion were recorded using CR-10 scale. As noted, these ratings were recorded continuously during the physical exertion. The perceived exertion ratings were recorded using an audio file. This file was time synchronized with the EMG data file. During a muscle specific exertion, the participants were asked to focus on that muscle only while they provide ratings of perceived exertion. For example, if the participants are performing an exertion for bicep then they were asked to focus on it and provide perceived exertion ratings for bicep only.

\subsubsection{Data Analysis}

The recorded EMG data were subjected to amplitude and spectral analysis using a window size of half a second. The SEMG measures were normalized with respect to the peak value of all trials. For each muscle, the relative change in the normalized SEMG measures with respect to time was quantified using regression analysis. Time instance and the total duration at which the relative change in an SEMG measure exceeds its intrinsic variability were identified. Similarly, time instance and time duration at which perceived exertion ratings of 4 was reported were also identified.

\subsection{Results}

The objective of this study was to understand the implications of variability in the electromyographic measures on the ability to predict LMF using subjective perceived exertion ratings. As explained in the experimental design (section (4.3.4)) and the experimental procedures (section (4.3.4.1)), twelve healthy (eight 
males and four females) right-hand dominant participants were recruited to participate in the data collection process. The average height, weight, and age of the participants were $168.33 \pm 9.74 \mathrm{~cm}, 67.58 \pm 12.41 \mathrm{~kg}$, and $28.00 \pm 3.67$ years. Table (24) exhibits the anthropometric data for each participant.

Table 24: Participants anthropometric data

\begin{tabular}{ccccc}
\hline Subject number & Height $(\mathbf{c m})$ & Weight $(\mathbf{k g})$ & Age & Gender \\
\hline $\mathbf{1}$ & 170 & 64 & 31 & Male \\
$\mathbf{2}$ & 157 & 53 & 26 & Female \\
$\mathbf{3}$ & 180 & 80 & 25 & Male \\
$\mathbf{4}$ & 185 & 72 & 32 & Male \\
$\mathbf{5}$ & 173 & 68 & 23 & Male \\
$\mathbf{6}$ & 165 & 65 & 31 & Male \\
$\mathbf{7}$ & 155 & 50 & 29 & Female \\
$\mathbf{8}$ & 162 & 82 & 25 & Female \\
$\mathbf{9}$ & 173 & 71 & 23 & Male \\
$\mathbf{1 0}$ & 170 & 90 & 34 & Male \\
$\mathbf{1 1}$ & 175 & 64 & 30 & Male \\
$\mathbf{1 2}$ & 155 & 52 & 27 & Female \\
\hline Average & 168.33 & 67.58 & 28.00 & \\
S.D. & 9.74 & 12.41 & 3.67 & \\
\hline
\end{tabular}

\subsubsection{Fatigue onset}

Table (25) shows the exact time -in seconds- when participants reported muscle fatigue onset, based on their subjective perceived exertion ratings, for all trials. As stated earlier, the subjective perceived exertion rating of 4, based on Borg's CR-10 scale, was used to define muscle fatigue. The results showed that female participants' fatigue onset occurred faster compared to male participants (Figure 22). The fatigue onset for female participants started approximately 20 seconds after performing the specified exertion. On the other hand, fatigue onset for male participants started approximately 29 seconds after starting the specified exertion. The overall combined average of fatigue onset occurred at the $26^{\text {th }}$ second. Exertion 4 exhibited the fastest onset of muscle fatigue. In this exertion, participants pulled up a $5 \mathrm{lb}$. weight while their shoulder remained elevated at $120^{\circ}$ in the scapular plane. Exertion 3 resulted in the slowest development of muscle fatigue overall. In this exertion, participants were asked to pull right a $5 \mathrm{lb}$. weight while their shoulder was elevated at $120^{\circ}$ in the scapular plane. See figure (22). 
Table 25: Fatigue onset in seconds based on subjective perceived exertion ratings of "4" using Borg's scale CR-10

\begin{tabular}{c|cc|cc|cc|cc|c}
\hline \multirow{2}{*}{$\begin{array}{c}\text { Subject } \\
\text { number }\end{array}$} & \multicolumn{2}{|c|}{ Exertion 1 } & \multicolumn{2}{|c|}{ Exertion 2 } & \multicolumn{2}{c|}{ Exertion 3 } & \multicolumn{2}{c|}{ Exertion 4 } & \multirow{2}{*}{ GENDER } \\
\cline { 2 - 8 } & Trial 1 & Trial 2 & Trial 3 & Trial 4 & Trial 5 & Trial 6 & Trial 7 & Trial 8 & \\
\hline $\mathbf{1}$ & 34 & 33 & 36 & 26 & 33 & 36 & 20 & 22 & Male \\
$\mathbf{2}$ & 23 & 14 & 17 & 21 & 21 & 16 & 20 & 16 & Female \\
$\mathbf{3}$ & 33 & 35 & 33 & 25 & 32 & 42 & 27 & 24 & Male \\
$\mathbf{4}$ & 14 & 24 & 29 & 28 & 34 & 26 & 29 & 18 & Male \\
$\mathbf{5}$ & 30 & 32 & 32 & 30 & 32 & 30 & 31 & 38 & Male \\
$\mathbf{6}$ & 33 & 32 & 30 & 30 & 38 & 28 & 22 & 28 & Male \\
$\mathbf{7}$ & 11 & 11 & 11 & 11 & 21 & 18 & 12 & 8 & Female \\
$\mathbf{8}$ & 15 & 12 & 35 & 29 & 36 & 36 & 40 & 20 & Female \\
$\mathbf{9}$ & 13 & 17 & 13 & 17 & 18 & 19 & 18 & 11 & Male \\
$\mathbf{1 0}$ & 35 & 37 & 29 & 31 & 39 & 42 & 32 & 25 & Male \\
$\mathbf{1 1}$ & 42 & 30 & 27 & 31 & 37 & 36 & 30 & 29 & Male \\
$\mathbf{1 2}$ & 19 & 19 & 22 & 21 & 26 & 21 & 18 & 19 & Female \\
\hline Avg & 25.17 & 24.67 & 26.17 & 25.00 & 30.58 & 29.17 & 24.92 & 21.50 & \\
S.D. & 10.55 & 9.61 & 8.48 & 6.32 & 7.27 & 9.29 & 7.87 & 8.16 & \\
\hline
\end{tabular}

Fatigue onset

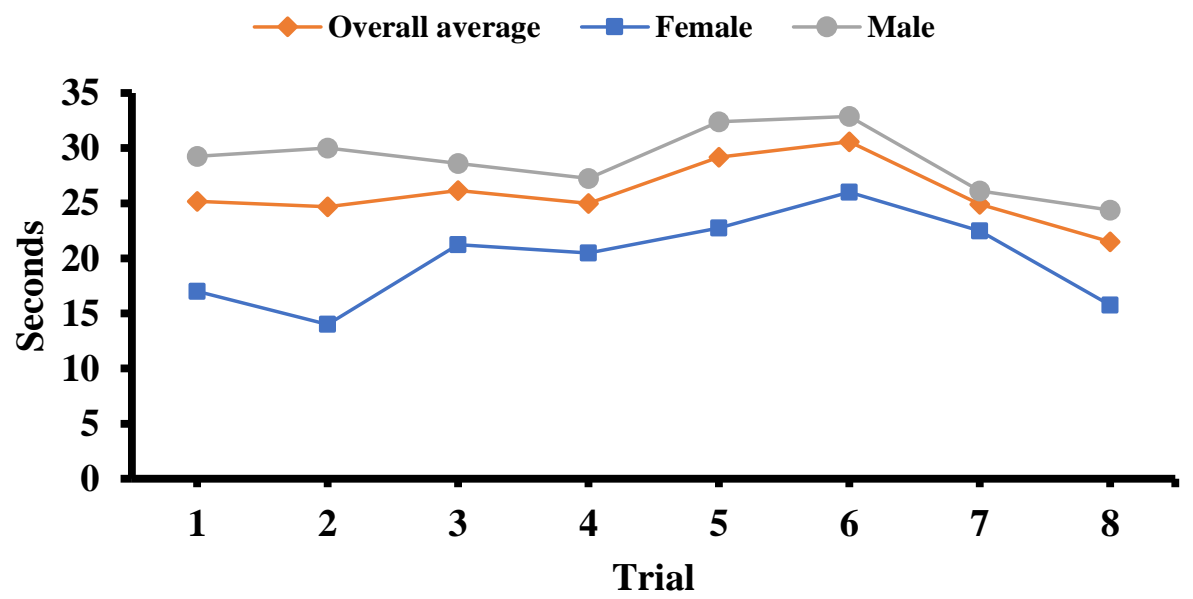

Figure 22: Fatigue onset in second based on a rating of 4 using the subjective perceived exertion ratings

\subsubsection{Relative change of SEMG measures with respect to fatigue occurrence}

Table (26) shows the relative change in different SEMG measures for each muscle. The relative change in SEMG measures was estimated during the start of the exertion and the moment at which participants reported a perceived discomfort of 4 . For RMS, the supraspinatus muscle showed the largest relative change at $28.45 \%$ and followed by the anterior deltoid muscle at $28.18 \%$. On the other hand, the triceps muscle exhibited the 
smallest relative change at $17.39 \%$. The average of RMS relative change for the seven shoulder muscles resulting from muscle fatigue was roughly $24 \%$ (Table 26, Figure 23). For MAV, the anterior deltoid muscle showed the largest relative change at $26.51 \%$, followed by the supraspinatus muscle at $24.09 \%$. On the other hand, the posterior deltoid muscle exhibited the smallest relative change at $11.26 \%$. The average of MAV relative change for the seven shoulder muscles resulting from muscle fatigue was roughly $18 \%$ (Table 26, Figure 23). For ZC, the middle deltoid muscle showed the largest relative change at $15.90 \%$ and followed by the posterior deltoid muscle at $13.25 \%$. On the other hand, the supraspinatus muscle exhibited the smallest relative change at $9.79 \%$. The average of $\mathrm{ZC}$ relative change for the seven shoulder muscles resulting from muscle fatigue was roughly $12.60 \%$ (Table 26, Figure 23). For MnPF, the posterior deltoid muscle showed the largest relative change at $14.32 \%$ and followed by the middle deltoid muscle at $14.03 \%$. On the other hand, the supraspinatus muscle exhibited the smallest relative change at $9.08 \%$. The average of MnPF relative change for the seven shoulder muscles resulting from muscle fatigue was roughly $12.33 \%$ (Table 26, Figure 23). For MdPF, the triceps muscle showed the largest relative change at $14.03 \%$ and followed by the posterior deltoid muscle at $13.05 \%$. On the other hand, the supraspinatus muscle exhibited the smallest relative change at $10.04 \%$. The average of MdPF relative change for the seven shoulder muscles resulting from muscle fatigue was roughly $12.30 \%$ (Table 26, Figure 23). For $\mathrm{PFB}_{11-22 \mathrm{~Hz}}$, the infraspinatus muscle showed the largest relative change at $160.84 \%$ and followed by the middle deltoid muscle at $150.20 \%$. On the other hand, the posterior deltoid muscle exhibited the smallest relative change at $88.16 \%$. The average of $\mathrm{PFB}_{11-22 \mathrm{~Hz}}$ relative change for the seven shoulder muscles resulting from muscle fatigue was roughly $113.71 \%$ (Table 26, Figure 23).

Table 26: Relative change -in percent- when participants reported a "4" subjective rating compared to the start point

\begin{tabular}{cccccccc}
\hline \% drop & Supraspinatus & Infraspinatus & $\begin{array}{c}\text { Middle } \\
\text { deltoid }\end{array}$ & $\begin{array}{c}\text { Anterior } \\
\text { deltoid }\end{array}$ & $\begin{array}{c}\text { Posterior } \\
\text { deltoid }\end{array}$ & Biceps & Triceps \\
\hline RMS & 28.45 & 26.00 & 22.73 & 28.18 & 17.58 & 27.04 & 17.39 \\
MAV & 24.09 & 21.76 & 13.55 & 26.51 & 11.26 & 15.78 & 12.85 \\
ZC & 9.79 & 12.73 & 15.90 & 11.84 & 13.25 & 11.59 & 13.09 \\
MnPF & 9.08 & 12.98 & 14.03 & 11.80 & 14.32 & 11.24 & 12.88 \\
MdPF & 10.04 & 12.78 & 12.65 & 11.99 & 13.05 & 11.51 & 14.03 \\
PFB & 99.55 & 160.84 & 150.20 & 100.63 & 88.16 & 95.96 & 100.64 \\
\hline
\end{tabular}


RMS

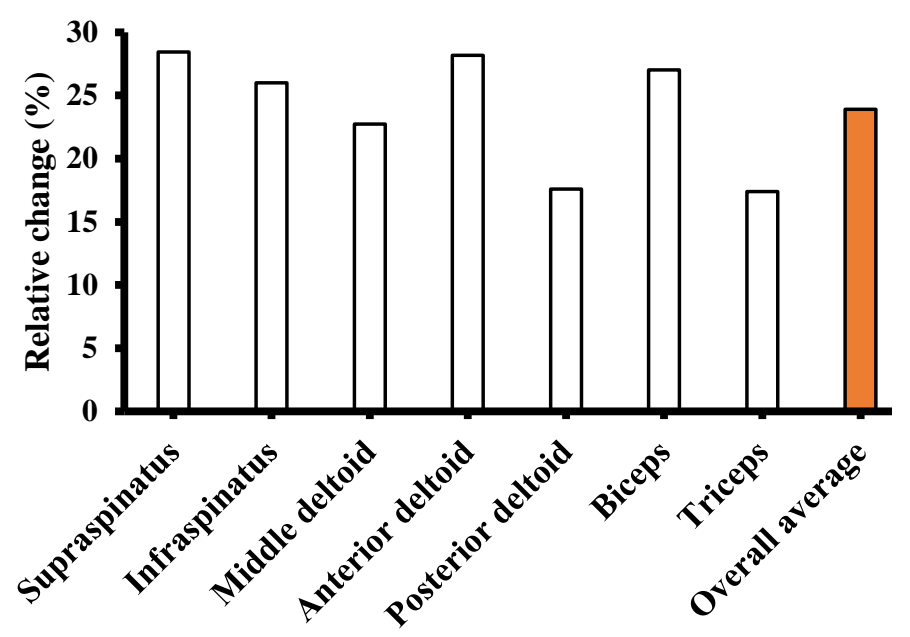

$\mathbf{Z C}$

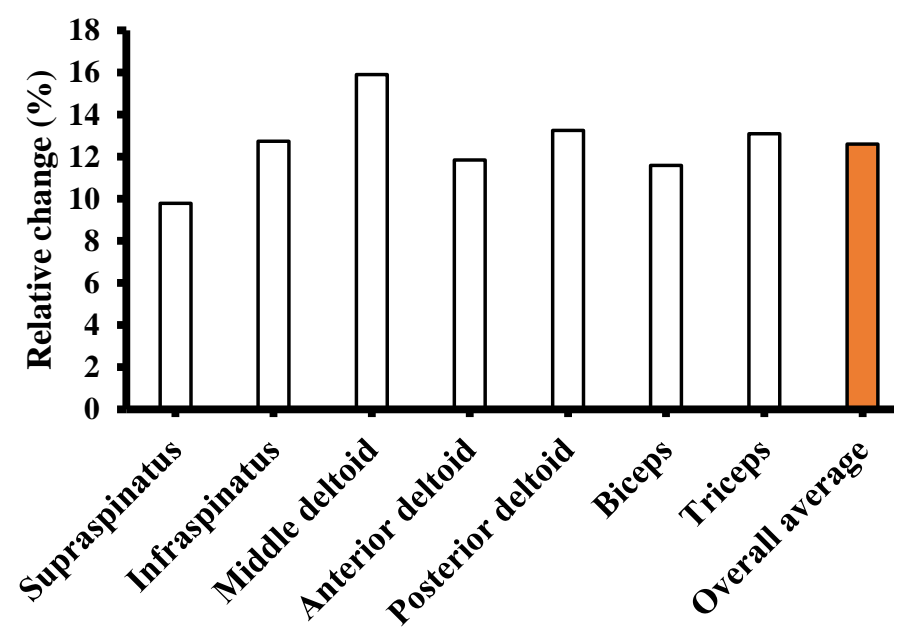

MdPF

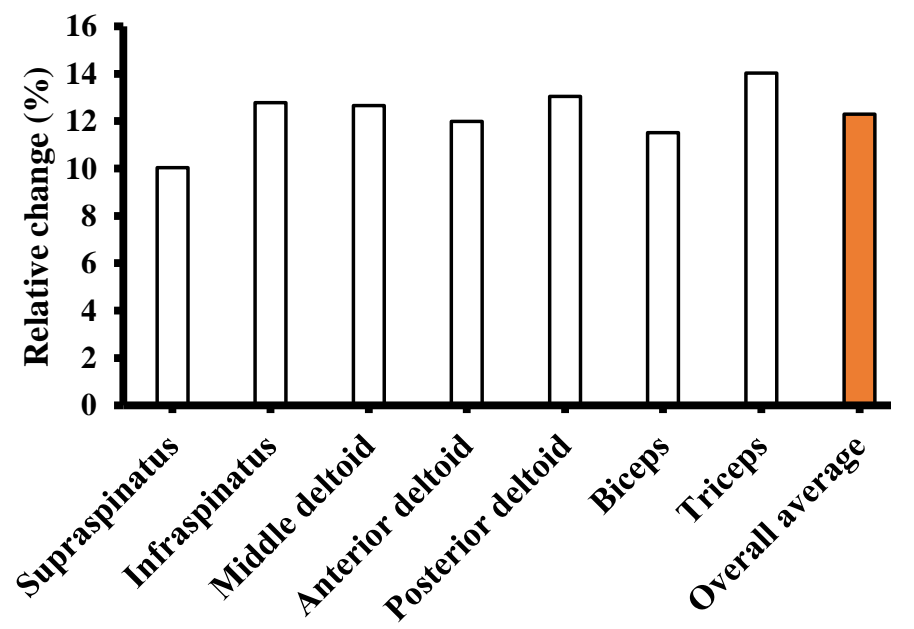

MAV

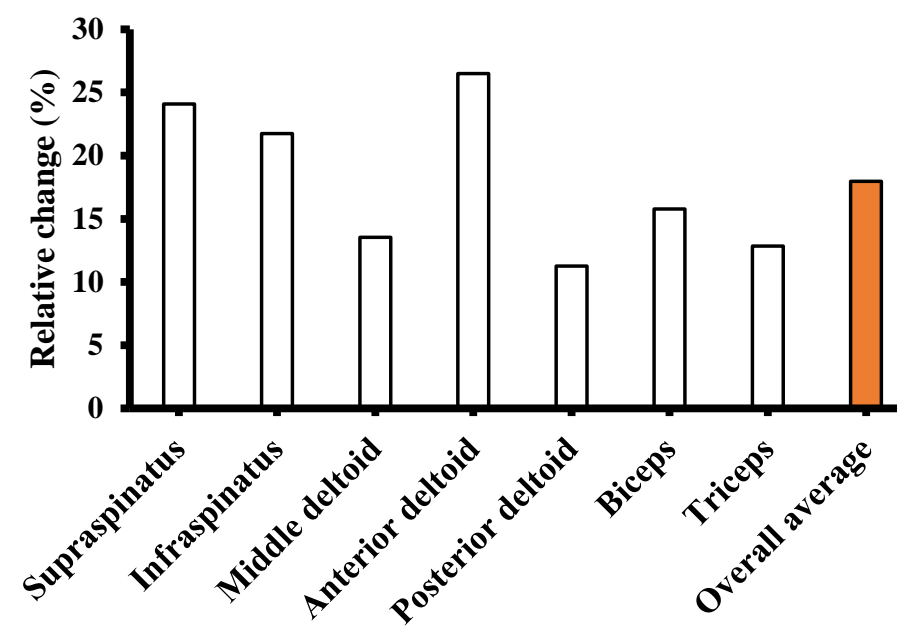

MnPF

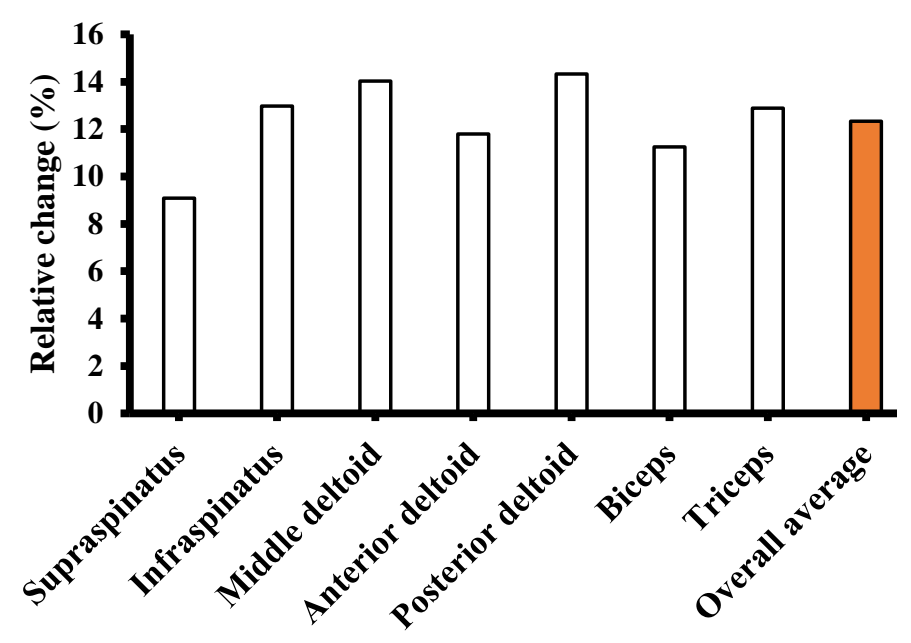

PFB

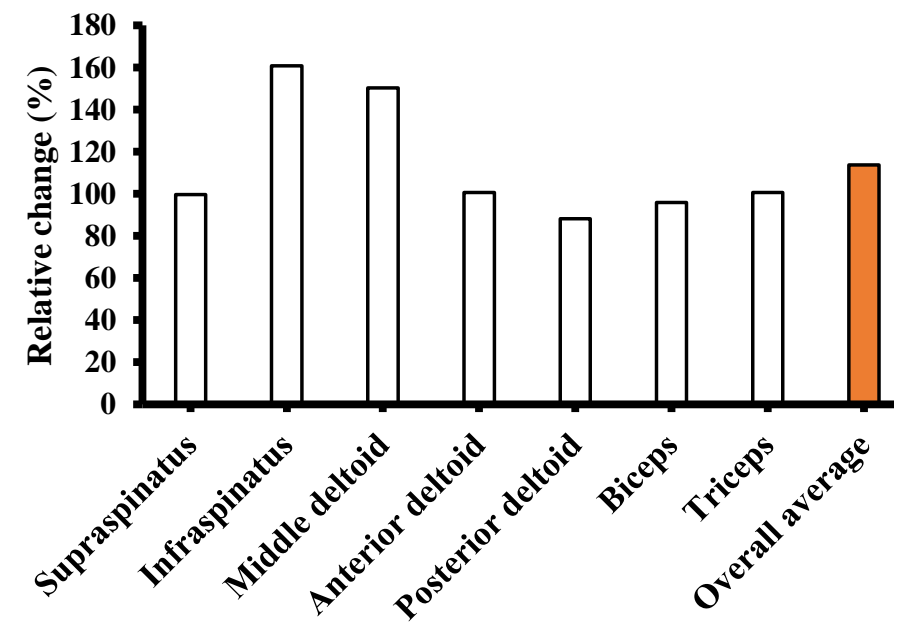

Figure 23: Relative change as a percentage when participants reported a " 4 " subjective rating compared to the start point 


\subsection{Discussion}

In this study, an evaluation was made to assess if the variability values in SEMG measures under non-fatigued condition can be used to predict LMF. The perceived exertion ratings were recorded using Borg's CR-10 scale continuously during fatiguing exertion and compared with the relative change in the simultaneously recorded SEMG data. For a few SEMG measures, a good agreement between the variability and the relative change due to LMF was observed but for a few other SEMG measures the relative change in SEMG measures due to LMF surpassed the variability values.

The relative changes in SEMG measures were either increasing or decreasing with the development of LMF. The values of increasing change were found to be higher than decreasing change. The increasing change was observed for RMS, MAV, and $\mathrm{PFB}_{11-22 \mathrm{~Hz}}$ and the corresponding values were $24 \%, 18 \%$, and $113.71 \%$, respectively. The decreasing change was observed for $\mathrm{ZC}, \mathrm{MnPF}$, and $\mathrm{MdPF}$ and the corresponding values were $12.60 \%, 12.33 \%$, and $12.30 \%$, respectively. Similar trends have been reported by previous studies. For intermittent overhead exertions performed over a duration of three hours, Nussbaum (2001) found that the change in values was low for MnPF, slightly higher for MdPF, and the highest for RMS amplitude when expressed as a percent of initial value during a combination of static and dynamic exertions. Fedorowich et al. (2013) reported shoulder muscle fatigue based on a significant increase in RMS values. The increased RMS values due to fatigue, reported in their study, were similar to the values observed in this study. Both studies reported the same increase in RMS values, $28 \%$, for the supraspinatus muscle. However, RMS values for the middle deltoid and biceps muscles increased by $13 \%$ and $38 \%$ in their study, and RMS values for the same muscles increased by $22 \%$ and $27 \%$ in this study. 
Multiple studies reported a strong correlation between subjective perceived exertion ratings and objective assessments of muscle fatigue and activation (Dedering et al., 1999; Dickerson et al., 2006; Hummel et al., 2005; Iridiastadi \& Nussbaum, 2006b). Most of these studies considered only one or two SEMG measures to assess muscle fatigue. Particularly, MnPF and MdPF were frequently used in muscle fatigue assessments. In this study, we evaluated the relationship between subjective perceived exertion ratings and objective assessments of muscle fatigue. A good agreement has been found between subjective perceived exertion ratings with $\mathrm{ZC}, \mathrm{MnPF}$, and MdPF variabilities under non-fatigued conditions. The differences between variabilities of ZC, MnPF, and MdPF under no fatigue condition and relative changes of SEMG measures due to muscle fatigue were very small. For ZC, the differences between its variability under no fatigue condition and the relative change due to muscle fatigue ranged from $0.9 \%$ for the supraspinatus muscle to $4.9 \%$ for the middle deltoid muscle, and the average difference across all muscles was 2.26\%. For MnPF, the differences between its variability under no fatigue condition and the relative change due to muscle fatigue ranged from $0.21 \%$ for the biceps muscle to $5.43 \%$ for the middle deltoid muscle, and the average difference across all muscles was $2.43 \%$. For MdPF, the difference between its variability under no fatigue condition and the relative change due to muscle fatigue ranged from $0.74 \%$ for the biceps muscle to $4.05 \%$ for the posterior deltoid muscle, and the average difference across all muscles was 2.38\%. Generally, ZC, MnPF, and MdPF values decrease as a result of muscle fatigue manifestation, and similar behavior between these three SEMG measures have been noted in previous papers too (Cifrek et al., 2009; Hägg \& Suurküla, 1991).

On the other hand, we found a poor agreement between RMS and MAV variability under non-fatigued conditions with subjective perceived exertion ratings. The differences between 
variability of RMS and MAV under no fatigue condition and relative changes of SEMG measures due to muscle fatigue were large. For RMS, the differences between its variability under no fatigue condition and the relative change due to LMF ranged from $6.34 \%$ for the triceps muscle to $17.55 \%$ for the biceps muscle, and the average difference across all muscles was $13.74 \%$. For MAV, the differences between its variability under no fatigue condition and the relative change due to muscle fatigue ranged from $2.7 \%$ for the triceps muscle to $16.41 \%$ for the anterior deltoid muscle, and the average difference across all muscles was $8.76 \%$.

The differences between variability of $\mathrm{PFB}_{11-22 \mathrm{~Hz}}$ under no fatigue condition and the relative change of SEMG measures due to muscle fatigue were huge, but it is for the frequency band of 11-22 Hz. The differences between $\mathrm{PFB}_{11-22 \mathrm{~Hz}}$ variability under no fatigue condition and the relative change due to muscle fatigue ranged from $82.84 \%$ for the posterior deltoid muscle to $154.92 \%$ for the infraspinatus muscle, and the average difference across all muscles was $107.13 \%$.

Fatigue onset was identified based on subjective perceived exertion ratings of 4 (Garg et al., 2006; Iridiastadi \& Nussbaum, 2006b; Jakobsen et al., 2014; Rashedi \& Nussbaum, 2016). Based on the tasks and conditions used in this study, participants developed muscle fatigue around the $26^{\text {th }}$ second. Female participants' fatigue onset was faster than male participants, with almost 9 seconds difference. The average fatigue onset for female participants was around the $20^{\text {th }}$ second, and the average for male participants was around the $29^{\text {th }}$ second. This result contradicts with other papers that stated female participants' capability to resist muscle fatigue is higher than male participants (Avin et al., 2010; Hicks, Kent-Braun, \& Ditor, 2001; Hunter, Butler, Todd, Gandevia, \& Taylor, 2006; Zhang et al., 2014). In a study that evaluated intermittent overhead tasks using a light tool, Nussbaum et al (2001) stated that female participants' endurance time was longer than male participants. On the other hand, Sood et al. (2017) evaluated the effect of different tool 
weights and duty cycles on endurance time while participants performed overhead tasks. They reported that female participants' endurance time was longer than male participants only when using lighter tool weights, 0.75 and $1.25 \mathrm{~kg}$ (1.65 and $2.75 \mathrm{lbs}$.). And male participants' endurance time was longer than female participants when using heavier tool weights, $2 \mathrm{~kg}(4.4 \mathrm{lbs}$.). The force value used in our study was higher with that of Sood et al, (2017) and thus could be responsible for faster fatigue for female participants compared with male participants.

As discussed previously, there are several studies that have considered an increase in RMS, MAV, and $\mathrm{PFB}_{11-22 \mathrm{~Hz}}$ or a drop in $\mathrm{ZC}, \mathrm{MnPF}$, and MdPF as a sign of fatigue for shoulder muscles (Dickerson et al., 2015; Herberts \& Kadefors, 1976; Herberts et al., 1980; Klaver-Król et al., 2010; Marina et al., 2013; D Roman-Liu \& Konarska, 2009; Sigholm et al., 1984; Takala et al., 1993; Yung et al., 2012). The results of Aim\#1 study, however, indicate that there can be alterations in the RMS, MAV, ZC, MnPF, MdPF, and $\mathrm{PFB}_{11-22 \mathrm{~Hz}}$ due to factors other than muscle fatigue. Öberg et al. (1990) reported a variation up to $\pm 8 \%$ in MnPF and MdPF due to factors other than muscle fatigue, and the value of " $\pm 8 \%$ " have been used in several studies to quantify shoulder muscle fatigue (Borstad, Szucs, \& Navalgund, 2009; Chopp, O’Neill, Hurley, \& Dickerson, 2010; Ebaugh et al., 2006a, 2006b; Lin, Liang, Lin, \& Hwang, 2004; Szucs, Navalgund, \& Borstad, 2009; Tsai, McClure, \& Karduna, 2003). But, to our knowledge, no study has validated the accuracy of LMF prediction value of " $\pm 8 \%$ ". Our Aim\#1 study concluded that the variabilities in ZC, MnPF, and MdPF were higher than " $\pm 8 \%$ " and they were in the range of $11 \%$ to $12 \%$ and the findings from Aim\#2 study further validate these numbers, suggesting that change in the SEMG measures (ZC, $\mathrm{MnPF}$, and MdPF) within $11 \%$ to $\pm 2 \%$ of initial value cannot be regarded as clinically significant. 


\section{Chapter 5. Conclusion}

LMF is a precursor of WMSDs and therefore accurate LMF estimation methods are essential to reduce and prevent WMSDs. Development of LMF during a physical exertion is a continuous process and identifying a point in this process at which risk level has risen above baseline is critically important for accurate prediction of LMF. In this study, we used a two step process to identify such point in the LMF development process. In the first step (Aim\#1), a variability study was completed. The results of Aim\#1 study concluded that the SEMG measures of shoulder muscles can change and vary due to factors other than muscle fatigue. Under no-fatigue condition, the values of RMS, MAV, ZC, MnPF, MdPF, and PFB $11-22 \mathrm{~Hz}$ were found to change/vary by $11.09 \%, 10.15 \%, 11.00 \%, 11.45 \%, 12.25 \%$, and $7.91 \%$, respectively, due to various workrelated factors. In the second step (Aim\#2), we compared the variability values with the change expected purely due to LMF. A fatigue inducing study was completed. The LMF and the corresponding change in the SEMG measures were obtained using subjective perceived exertion methods. The results of Aim\#2 study concluded that with the development of LMF, the values of RMS, MAV, ZC, MnPF, MdPF, and $\mathrm{PFB}_{11-22 \mathrm{~Hz}}$ can change/vary by $28.45 \%, 26.51 \%, 15.9 \%$, $14.32 \%, 14.03 \%$, and $160.84 \%$, respectively. A good agreement was observed between the variability and $\mathrm{LMF}$ induced change for $\mathrm{ZC}, \mathrm{MnPF}$, and MdPF. Thus, the study concludes that for the shoulder muscles a change higher than $11.00 \%, 11.45 \%$, and $12.25 \%$ in ZC, MnPF, and MdPF, respectively, can be an indication of LMF.

\subsection{Industrial applications}

Shoulder exertions are common characteristics of many occupational tasks in various industries. It has been identified that these physical exertions, if not monitored, can lead to LMF, which is often associated with workers' lack of productivity. If the signs of LMF are ignored, then 
it could lead to injury and WMSDs, which can cause the organization direct and indirect costs. The results of this study provide specific guidance on expected change in the SEMG measures which can lead to LMF. Using the study findings LMF prediction models and/or methods can be improved. This could be helpful to both the organization's managers and ergonomics practitioners in assessing workers' muscle fatigue at various work places.

One of the important industrial/practical application of this study is to improve real-time fatigue prediction using SEMG measures. Nowadays, deployment of SEMG systems and SEMG sensors in industrial workplaces is much easier compared to the past years. Older SEMG systems and sensors were limited in terms of cables attached to the system and sensors, and in terms of data storage. As a result, a designated area was required for testing and data collection. With the help of new and improved technologies, the SEMG system and sensors are now available with wireless technology and cable free features. The new technology also eliminates the interference of cables in workers' tasks caused by the old SEMG sensors. Furthermore, workers' SEMG data can be tracked and monitored remotely. Using the findings from this study, such newer SEMG systems can be used to track and predict LMF in real-time.

In recent years, many industries with shoulder intensive work are considering the options of using exoskeletons to reduce the risks of WMSDs. Most of these exoskeletons provide passive or active support during physically demanding tasks. Next generation of smart exoskeletons could be designed by incorporating real-time fatigue prediction using SEMG systems. Such exoskeletal will not only provide the support but will also have LMF monitoring ability to provide added safety. 


\subsection{Study limitation and future work}

The findings of this study are a function of the participants and experimental conditions tested and are therefore subjected to several limitations. Our sample consisted of university students with limited manual material handling experience. Workers with manual material handling experience may use different muscle recruitment strategies and may have different variability values. Secondly, in this study only static exertions were tested. In real world, occupational tasks involve static as well as dynamic exertions. Future studies should look at variability due to dynamic exertion using a more diverse sample. Future studies should also look at the impact of relative contribution by a muscle or a group of muscles in force production during a physical exertion and its impact on the variability. 


\section{References}

Al-Mulla, M. R., \& Sepulveda, F. (2010). Predicting the time to localized muscle fatigue using ANN and evolved sEMG feature. 2010 International Conference on Autonomous and Intelligent Systems, AIS 2010, 1-6. https://doi.org/10.1109/AIS.2010.5547025

Al-Mulla, M. R., Sepulveda, F., Colley, M., \& Kattan, a. (2009). Classification of localized muscle fatigue with genetic programming on sEMG during isometric contraction. Proceedings of the 31st Annual International Conference of the IEEE Engineering in Medicine and Biology Society: Engineering the Future of Biomedicine, EMBC 2009, 26332638. https://doi.org/10.1109/IEMBS.2009.5335368

Alasim, H. N., Nimbarte, A. D., \& Jaridi, M. (2019). Impact of pulling direction and magnitude of force exertion on the activation of shoulder muscles. International Journal of Industrial Ergonomics, 69(May 2018), 14-22. https://doi.org/10.1016/j.ergon.2018.09.008

Alizadehkhaiyat, O., Fisher, a. C., Kemp, G. J., Vishwanathan, K., \& Frostick, S. P. (2011). Shoulder muscle activation and fatigue during a controlled forceful hand grip task. Journal of Electromyography and Kinesiology, 21(3), 478-482. https://doi.org/10.1016/j.jelekin.2011.03.002

Allison, G. T., \& Fujiwara, T. (2002). The relationship between EMG median frequency and low frequency band amplitude changes at different levels of muscle capacity. Clinical Biomechanics, 17(6), 464-469. https://doi.org/10.1016/S0268-0033(02)00033-5

Alpert, S. W., Pink, M. M., Jobe, F. W., McMahon, P. J., \& Mathiyakom, W. (2000). Electromyographic analysis of deltoid and rotator cuff function under varying loads and speeds. Journal of Shoulder and Elbow Surgery / American Shoulder and Elbow Surgeons, 9(1), 47-58. https://doi.org/10.1016/S1058-2746(00)90009-0

An, K. N., Hui, F. C., Morrey, B. F., Linscheid, R. L., \& Chao, E. Y. (1981). Muscles Across the Elbow Joint Biomec Analysis.pdf. Journal of Biomechanics, Vol. 14, pp. 659-669.

Anton, D., Shibley, L. D., Fethke, N. B., Hess, J., Cook, T. M., \& Rosecrance, J. (2001). The effect of overhead drilling position on shoulder moment and electromyography. Ergonomics, 44(5), 489-501. https://doi.org/10.1080/00140130120079

Antony, N. T., \& Keir, P. J. (2010). Effects of posture, movement and hand load on shoulder muscle activity. Journal of Electromyography and Kinesiology, 20(2), 191-198. https://doi.org/10.1016/j.jelekin.2009.04.010

Armstrong, T. J., Buckle, P., Fine, L. J., Hagberg, M., Kilbom, A., Kuorinka, I. A. A., ... Viikari-juntura, E. R. A. (1993). Norwegian National Institute of Occupational Health Danish National Research Centre for the Working Environment Finnish Institute of Occupational Health A conceptual model for work-related neck and upper-limb musculoskeletal disorders Institute of Occupat.

Armstrong, T. J., Punnett, L., \& Ketner, P. (1989). Subjective worker assessments of hand tools used in automobile assembly. American Industrial Hygiene Association Journal, 50(12), 639-645. https://doi.org/10.1080/15298668991375290

Avin, K. G., Naughton, M. R., Ford, B. W., Moore, H. E., Monitto-Webber, M. N., Stark, A. M., 
... Law, L. A. F. (2010). Sex differences in fatigue resistance are muscle group dependent. Medicine and Science in Sports and Exercise, 42(10), 1943-1950. https://doi.org/10.1249/MSS.0b013e3181d8f8fa

Balasubramanian, V., \& Jagannath, M. (2014). Detecting motorcycle rider local physical fatigue and discomfort using surface electromyography and seat interface pressure. Transportation Research Part F: Traffic Psychology and Behaviour, 22, 150-158. https://doi.org/10.1016/j.trf.2013.12.010

Balasubramanian, V., Jagannath, M., \& Adalarasu, K. (2014). Muscle fatigue based evaluation of bicycle design. Applied Ergonomics, 45(2 PB), 339-345. https://doi.org/10.1016/j.apergo.2013.04.013

Bartuzi, P., \& Roman-Liu, D. (2014). Assessment of muscle load and fatigue with the usage of frequency and time-frequency analysis of the EMG signal. Acta of Bioengineering and Biomechanics, 16(2), 31-39. https://doi.org/10.5277/abb140204

Borg, G. (1990). Psychophysical scaling with applications in physical work and the perception of exertio. Scandinavian Journal of Work, Environment and Health, 16(1), 55-58.

Borstad, J. D., Szucs, K., \& Navalgund, A. (2009). Scapula kinematic alterations following a modified push-up plus task. Human Movement Science, 28(6), 738-751. https://doi.org/10.1016/j.humov.2009.05.002

Bosch, T., de Looze, M. P., \& van Dieën, J. H. (2007). Development of fatigue and discomfort in the upper trapezius muscle during light manual work. Ergonomics, 50(2), 161-177. https://doi.org/10.1080/00140130600900282

Brookham, R. L., Wong, J. M., \& Dickerson, C. R. (2010). Upper limb posture and submaximal hand tasks influence shoulder muscle activity. International Journal of Industrial Ergonomics, 40(3), 337-344. https://doi.org/10.1016/j.ergon.2009.11.006

Bureau of Labor Statistics. (2016). Nonfatal occupational injuries and illnesses requiring days away from work. Bureau of Labor Statistics U.S. Department of Labor, (USDL-16-2130), 1-28. https://doi.org/USDL 15-2205

Byström, S., \& Fransson-Hall, C. (1994). Acceptability of intermittent handgrip contractions based on physiological response. Human Factors, 36(1), 158-171. https://doi.org/10.1177/0192513X12437708

Cardozo, A. C., Gonçalves, M., \& Dolan, P. (2011). Back extensor muscle fatigue at submaximal workloads assessed using frequency banding of the electromyographic signal. Clinical Biomechanics, 26(10), 971-976. https://doi.org/10.1016/j.clinbiomech.2011.06.001

Chaffin, D. B. (1973). Localized muscle fatigue - definition and measurement. Journal of Occupational Medicine Medicine, 15(4), 346-354.

Chopp, J. N., Fischer, S. L., \& Dickerson, C. R. (2010). The impact of work configuration, target angle and hand force direction on upper extremity muscle activity during sub-maximal overhead work. Ergonomics, 53(1), 83-91. https://doi.org/10.1080/00140130903323232

Chopp, J. N., O’Neill, J. M., Hurley, K., \& Dickerson, C. R. (2010). Superior humeral head 
migration occurs after a protocol designed to fatigue the rotator cuff: A radiographic analysis. Journal of Shoulder and Elbow Surgery, 19(8), 1137-1144. https://doi.org/10.1016/j.jse.2010.03.017

Chowdhury, S. K., \& Nimbarte, A. D. (2015). Comparison of Fourier and wavelet analysis for fatigue assessment during repetitive dynamic exertion. Journal of Electromyography and Kinesiology : Official Journal of the International Society of Electrophysiological Kinesiology, 25(2), 205-213. https://doi.org/10.1016/j.jelekin.2014.11.005

Chowdhury, S. K., Nimbarte, A. D., Jaridi, M., \& Creese, R. C. (2013). Discrete wavelet transform analysis of surface electromyography for the fatigue assessment of neck and shoulder muscles. Journal of Electromyography and Kinesiology, 23(5), 995-1003. https://doi.org/10.1016/j.jelekin.2013.05.001

Christensen, H. (1986). Muscle activity and fatigue in the shoulder muscles during repetitive work - An electromyographic study. European Journal of Applied Physiology and Occupational Physiology, 54(6), 596-601. https://doi.org/10.1007/BF00943347

Christensen, Hanne. (1986). Muscle activity and fatigue in the shoulder muscles of assemblyplant employees. Scandinavian Journal of Work, Environment and Health, 12, 582-587.

Christensen, Monaco, M., \& Fuglsang-Frederiksen, A. (1991). Quantitative needle electromyography during sustained maximal effort. Journal of Electromyography and Kinesiology, 1(2), 130-138. https://doi.org/10.1016/1050-6411(91)90007-R

Cifrek, M., Medved, V., Tonković, S., \& Ostojić, S. (2009). Surface EMG based muscle fatigue evaluation in biomechanics. Clinical Biomechanics, 24(4), 327-340. https://doi.org/10.1016/j.clinbiomech.2009.01.010

Cioni, R., Giannini, F., Paradiso, C., Battistini, N., Navona, C., \& Starita, A. (1994). Sex differences in surface EMG interference pattern power spectrum. Journal of Applied Physiology, 77(5), 2163-2168. https://doi.org/10.1152/jappl.1994.77.5.2163

Cudlip, A. C., Meszaros, K. A., \& Dickerson, C. R. (2016). The Influence of Hand Location and Force Direction on Shoulder Muscular Activity in Females During Nonsagittal Multidirectional Overhead Exertions. Human Factors: The Journal of the Human Factors and Ergonomics Society, 58(1), 120-139. https://doi.org/10.1177/0018720815623523

Cudlip, Alan C., Callaghan, J. P., \& Dickerson, C. R. (2015). Effects of sitting and standing on upper extremity physical exposures in materials handling tasks. Ergonomics, 58(10), 16371646. https://doi.org/10.1080/00140139.2015.1035763

Cutlip, K., \& Nimbarte, A. D. (2016). Multi-directional strength and perceived discomfort of shoulder complex. Occupational Ergonomics, 13(2), 91-99. https://doi.org/10.3233/OER160243

Decker, M. J., Hintermeister, R. A., Faber, K. J., \& Hawkins, R. J. (1999). Serratus anterior muscle activity during selected rehabilitation exercises. The American Journal of Sports Medicine, 27(6), 784-791. Retrieved from http://www.ncbi.nlm.nih.gov/pubmed/10569366

Dedering, Å., Németh, G., \& Harms-Ringdahl, K. (1999). Correlation between electromyographic spectral changes and subjective assessment of lumbar muscle fatigue in 
subjects without pain from the lower back. Clinical Biomechanics, 14(2), 103-111. https://doi.org/10.1016/S0268-0033(98)00053-9

Dickerson, C. R., Martin, B. J., \& Chaffin, D. B. (2006). The relationship between shoulder torques and the perception of muscular effort in loaded reaches. Ergonomics, 49(11), 10361051. https://doi.org/10.1080/00140130600730960

Dickerson, C. R., Martin, B. J., \& Chaffin, D. B. (2007). Predictors of perceived effort in the shoulder during load transfer tasks. Ergonomics, 50(7), 1004-1016. https://doi.org/10.1080/00140130701295947

Dickerson, C. R., Meszaros, K. A., Cudlip, A. C., Chopp-Hurley, J. N., \& Langenderfer, J. E. (2015). The influence of cycle time on shoulder fatigue responses for a fixed total overhead workload. Journal of Biomechanics, 48(11), 2911-2918. https://doi.org/10.1016/j.jbiomech.2015.04.043

Ebaugh, D. D., McClure, P. W., \& Karduna, A. R. (2006a). Effects of shoulder muscle fatigue caused by repetitive overhead activities on scapulothoracic and glenohumeral kinematics. Journal of Electromyography and Kinesiology, 16(3), 224-235. https://doi.org/10.1016/j.jelekin.2005.06.015

Ebaugh, D. D., McClure, P. W., \& Karduna, A. R. (2006b). Scapulothoracic and glenohumeral kinematics following an external rotation fatigue protocol. The Journal of Orthopaedic and Sports Physical Therapy, 36(8), 557-571. https://doi.org/10.2519/jospt.2006.2189

El ahrache, K., \& Imbeau, D. (2009). Comparison of rest allowance models for static muscular work. International Journal of Industrial Ergonomics, 39(1), 73-80. https://doi.org/10.1016/j.ergon.2008.10.012

Engin, A. E., \& Chen, S. M. (1986). Statistical data base for the biomechanical properties of the human shoulder complex-I: Kinematics of the shoulder complex. Journal of Biomechanical Engineering, 108(3), 215-221.

Escamilla, R. F., Yamashiro, K., Paulos, L., \& Andrews, J. R. (2009). Shoulder muscle activity and function in common shoulder rehabilitation exercises. Sports Medicine, 39(8), 663-685. https://doi.org/10.2165/00007256-200939080-00004

Fagarasanu, M., \& Kumar, S. (2003). SHOULDER MUSCULOSKELETAL DISORDERS IN INDUSTRIAL AND OFFICE WORK. Journal of Musculoskeletal Research, 7(1), 1-14.

Fedorowich, L., Emery, K., Gervasi, B., \& Côté, J. N. (2013). Gender differences in neck/shoulder muscular patterns in response to repetitive motion induced fatigue. Journal of Electromyography and Kinesiology, 23(5), 1183-1189. https://doi.org/10.1016/j.jelekin.2013.06.005

Ferguson, S. A., Allread, W. G., Le, P., Rose, J., \& Marras, W. S. (2013). Shoulder muscle fatigue during repetitive tasks as measured by electromyography and near-infrared spectroscopy. Human Factors: The Journal of the Human Factors and Ergonomics Society, 55(6), 1077-1087. https://doi.org/10.1177/0018720813482328

Forster, E., Simon, U., Augat, P., \& Claes, L. (2004). Extension of a state-of-the-art optimization criterion to predict co-contraction. Journal of Biomechanics, 37(4), 577-581. 
https://doi.org/10.1016/j.jbiomech.2003.09.003

Fuller, J. R., Lomond, K. V., Fung, J., \& Côté, J. N. (2009). Posture-movement changes following repetitive motion-induced shoulder muscle fatigue. Journal of Electromyography and Kinesiology, 19(6), 1043-1052. https://doi.org/10.1016/j.jelekin.2008.10.009

Garg, A., Hegmann, K., \& Kapellusch, J. (2006). Short-cycle overhead work and shoulder girdle muscle fatigue. International Journal of Industrial Ergonomics, 36(6), 581-597. https://doi.org/10.1016/j.ergon.2006.02.002

Gatti, C. J., Doro, L. C., Langenderfer, J. E., Mell, A. G., Maratt, J. D., Carpenter, J. E., \& Hughes, R. E. (2008). Evaluation of three methods for determining EMG-muscle force parameter estimates for the shoulder muscles. Clinical Biomechanics, 23, 166-174. https://doi.org/10.1016/j.clinbiomech.2007.08.026

Gerdle, B., Eriksson, N., Brundin, L., \& Edstrfim, M. (1988). Surface EMG recordings during maximum static shoulder forward flexion in different positions. European Journal of Applied Physiology and Occupational Physiology, 57, 415-419.

Gerleman, D. G., \& Cook, T. M. (1992). Instrumentation. In G. L. Soderberg (Ed.), Selected topics in surface electromyography for use in the occupational setting: expert perspectives. US Department of Health and Human Services, Public Health Service, Centers for Disease Control, National Institute for Occupational Safety and Health.

Glynn, N. W., Santanasto, A. J., Simonsick, E. M., Boudreau, R. M., Beach, S. R., Schulz, R., \& Newman, A. B. (2015). The Pittsburgh fatigability scale for older adults: Development and validation. Journal of the American Geriatrics Society, 63(1), 130-135. https://doi.org/10.1111/jgs.13191

Hägg, G. M., \& Suurküla, J. (1991). Zero crossing rate of electromyograms during occupational work and endurance tests as predictors for work related myalgia in the shoulder/neck region. European Journal of Applied Physiology and Occupational Physiology, 62(6), 436444. https://doi.org/10.1007/BF00626617

Hary, D., Belman, M. J., Propst, J., \& Lewis, S. (1982). A statistical analysis of the spectral moments used in EMG tests of endurance. Journal of Applied Physiology: Respiratory, Environmental and Exercise Physiology, 53(3), 779-783. Retrieved from http://jap.physiology.org/content/53/3/779.abstract

Hawkes, D. H., Alizadehkhaiyat, O., Kemp, G. J., Fisher, a. C., Roebuck, M. M., \& Frostick, S. P. (2015). Electromyographic assessment of muscle fatigue in massive rotator cuff tear. Journal of Electromyography and Kinesiology, 25(1), 93-99. https://doi.org/10.1016/j.jelekin.2014.09.010

Herberts, P., \& Kadefors, R. (1976). A study of painful shoulder in welders. Acta Orthopaedica Scandinavica, 47(4), 381-387. https://doi.org/10.1177/0192513X12437708

Herberts, P., Kadefors, R., \& Broman, H. (1980). Arm positioning in manual tasks An electromyographic study of localized muscle fatigue. Ergonomics, 23(7), 655-665.

Hermans, V., \& Spaepen, A. J. (1997). Muscular activity of the shoulder and neck region during sustained and intermittent exercise. Clinical Physiology, 17(1), 95-104. 
https://doi.org/10.1046/j.1365-2281.1997.01515.x

Hicks, A. L., Kent-Braun, J., \& Ditor, D. S. (2001). Sex differences in human skeletal muscle fatigue. Exercise and Sport Sciences Reviews, 29(3), 109-112.

https://doi.org/10.1097/00003677-200107000-00004

Hintermeister, R. A., Lange, G. W., Schultheis, J. M., Bey, M. J., \& Hawkins, R. J. (1998). Electromyographic activity and applied load during shoulder rehabilitation exercises using elastic resistance. The American Journal of Sports Medicine, 26(2), 210-220. Retrieved from http://www.ncbi.nlm.nih.gov/pubmed/9548114

Holzbaur, K. R. S., Murray, W. M., \& Delp, S. L. (2005). A model of the upper extremity for simulating musculoskeletal surgery and analyzing neuromuscular control. Annals of Biomedical Engineering, 33(6), 829-840. https://doi.org/10.1007/s10439-005-3320-7

HSE, H. and S. E. (2018). Work related musculoskeletal disorders in Great Britain (WRMSDs), 2018. (October), 1-10.

Hummel, A., Läubli, T., Pozzo, M., Schenk, P., Spillmann, S., \& Klipstein, A. (2005).

Relationship between perceived exertion and mean power frequency of the EMG signal from the upper trapezius muscle during isometric shoulder elevation. European Journal of Applied Physiology, 95(4), 321-326. https://doi.org/10.1007/s00421-005-0014-7

Hunter, S. K., Butler, J. E., Todd, G., Gandevia, S. C., \& Taylor, J. L. (2006). Supraspinal fatigue does not explain the sex difference in muscle fatigue of maximal contractions. Journal of Applied Physiology, 101(4), 1036-1044. https://doi.org/10.1152/japplphysiol.00103.2006

Iridiastadi, H., \& Nussbaum, M. A. (2006a). Muscle fatigue and endurance during repetitive intermittent static efforts: development of prediction models. Ergonomics, 49(4), 344-360. https://doi.org/10.1080/00140130500475666

Iridiastadi, H., \& Nussbaum, M. A. (2006b). Muscular fatigue and endurance during intermittent static efforts: effects of contraction level, duty cycle, and cycle time. Human Factors, 48(4), 710-720. https://doi.org/10.1518/001872006779166389

Itoi, E., Kuechle, D. K., Newman, S. R., Morrey, B. F., \& An, K. N. (1993). Stabilising function of the biceps in stable and unstable shoulders. The Journal of Bone and Joint Surgery. British Volume, 75(4), 546-550.

Jakobsen, M. D., Sundstrup, E., Persson, R., Andersen, C. H., \& Andersen, L. L. (2014). Is Borg's perceived exertion scale a useful indicator of muscular and cardiovascular load in blue-collar workers with lifting tasks? A cross-sectional workplace study. European Journal of Applied Physiology, 114(2), 425-434. https://doi.org/10.1007/s00421-013-27829

Jensen, B. R., Schibye, B., Søgaard, K., Simonsen, E. B., \& Sjøgaard, G. (1993). Shoulder muscle load and muscle fatigue among industrial sewing-machine operators. European Journal of Applied Physiology and Occupational Physiology, 67(5), 467-475. https://doi.org/10.1007/BF00376465

Kai, Y., Gotoh, M., Nagata, K., \& Shiba, N. (2012). Infraspinatus fatigue during resisted arm 
elevation with isometric contraction: An electromyographic study. Journal of Shoulder and Elbow Surgery, 21(8), 1104-1109. https://doi.org/10.1016/j.jse.2011.07.021

Keating, J., Waterworth, P., Shaw-Dunn, J., \& Crossan, J. (1993). The Relative Cuff Strengths Muscles of the Rotator Cuff Muscles. A Cadaver Study. J Bone Joint Surg, 75-B(1), 137140.

Klaver-Król, E. G., Henriquez, N. R., Oosterloo, S. J., Klaver, P., Kuipers, H., \& Zwarts, M. J. (2010). Distribution of motor unit potential velocities in the biceps brachii muscle of sprinters and endurance athletes during prolonged dynamic exercises at low force levels. Journal of Electromyography and Kinesiology: Official Journal of the International Society of Electrophysiological Kinesiology, 20(6), 1115-1124. https://doi.org/10.1016/j.jelekin.2010.05.007

Konrad, P. (2005). The abc of emg. In A practical introduction to kinesiological .... https://doi.org/10.1016/j.jacc.2008.05.066

Kupa, E. J., Roy, S. H., Kandarian, S. C., \& De Luca, C. J. (1995). Effects of muscle fiber type and size on EMG median frequency and conduction velocity.

Langenderfer, J., Jerabek, S. A., Thangamani, V. B., Kuhn, J. E., \& Hughes, R. E. (2004). Musculoskeletal parameters of muscles crossing the shoulder and elbow and the effect of sarcomere length sample size on estimation of optimal muscle length. 19, 664-670. https://doi.org/10.1016/j.clinbiomech.2004.04.009

Larivière, C., Arsenault, a. B., Gravel, D., Gagnon, D., \& Loisel, P. (2002). Evaluation of measurement strategies to increase the reliability of EMG indices to assess back muscle fatigue and recovery. Journal of Electromyography and Kinesiology, 12(2), 91-102. https://doi.org/10.1016/S1050-6411(02)00011-1

Lee, C. L., Lu, S. Y., Sung, P. C., \& Liao, H. Y. (2015). Working height and parts bin position effects on upper limb muscular strain for repetitive hand transfer. International Journal of Industrial Ergonomics, 50, 178-185. https://doi.org/10.1016/j.ergon.2015.09.016

LeVeau, B., \& Anderson, G. B. J. (1992). Output Forms: Data Analysis and Applications. In G. L. Soderberg (Ed.), Selected topics in surface electromyography for use in the occupational setting: expert perspectives (p. 132). US Department of Health and Human Services, Public Health Service, Centers for Disease Control, National Institute for Occupational Safety and Health.

Lin, M. I., Liang, H. W., Lin, K. H., \& Hwang, Y. H. (2004a). Electromyographical assessment on muscular fatigue - an elaboration upon repetitive typing activity. Journal of Electromyography and Kinesiology, 14(6), 661-669. https://doi.org/10.1016/j.jelekin.2004.03.004

Lin, M. I., Liang, H. W., Lin, K. H., \& Hwang, Y. H. (2004b). Electromyographical assessment on muscular fatigue - An elaboration upon repetitive typing activity. Journal of Electromyography and Kinesiology, 14(6), 661-669. https://doi.org/10.1016/j.jelekin.2004.03.004

Lovering, R. M., \& Russ, D. W. (2008). Fiber Type Composition of Cadaveric Human Rotator 
Cuff Muscles. Journal of Orthopaedic \& Sports Physical Therapy, 38(11), 674-680. https://doi.org/10.2519/jospt.2008.2878

Malmqvist, R., Ekholm, I., Lindström, L., Petersen, I., \& Örtengren, R. (1981). Measurement of localized muscle fatigue in building work. Ergonomics, 24(9), 695-709.

Mamaghani, N. K., Shimomura, Y., Iwanaga, K., \& Katsuura, T. (2002). Mechanomyogram and electromyogram responses of upper limb during sustained isometric fatigue with varying shoulder and elbow postures. Journal of Physiological Anthropology and Applied Human Science, 21(1), 29-43. https://doi.org/10.2114/jpa.21.29

Marina, M., Torrado, P., Busquets, A., Ríos, J. G., \& Angulo-Barroso, R. (2013). Comparison of an intermittent and continuous forearm muscles fatigue protocol with motorcycle riders and control group. Journal of Electromyography and Kinesiology, 23(1), 84-93. https://doi.org/10.1016/j.jelekin.2012.08.008

Marras, W. S. (1992). OVERVIEW OF ELECTROMYOGRAPHY IN ERGONOMICS. In G. L. Soderberg (Ed.), Selected topics in surface electromyography for use in the occupational setting: expert perspectives (Vol. 24, p. 132). https://doi.org/10.1016/0003-6870(93)90098-t

Masuda, K., Masuda, T., Sadoyama, T., Mitsuharu Inaki, \& Katsuta, S. (1999). Changes in surface EMG parameters during static and dynamic fatiguing contractions. Journal of Electromyography and Kinesiology, 9, 39-46. https://doi.org/10.1016/S10506411(98)00021-2

Minning, S., Eliot, C. a., Uhl, T. L., \& Malone, T. R. (2007). EMG analysis of shoulder muscle fatigue during resisted isometric shoulder elevation. Journal of Electromyography and Kinesiology, 17(2), 153-159. https://doi.org/10.1016/j.jelekin.2006.01.008

Motabar, H., Nimbarte, A. D., \& Raub, E. (2019). Strength, endurance and fatigue response of rotator cuff muscles during isometric exertions. International Journal of Industrial Ergonomics, 71(April), 128-135. https://doi.org/10.1016/j.ergon.2019.03.001

Nargol, A., Jones, A., Kelly, P., \& Greenough, C. (1999). Factors in the Reproducibility of Electromyographic Power Spectrum Analysis of Lumbar Paraspinal Muscle Fatigue. Spine, 24(9), 883-888.

Nieminen, H., Takala, E. P., Niemi, J., \& Viikari-Juntura, E. (1995). Muscular synergy in the shoulder during a fatiguing static contraction. Clinical Biomechanics, 10(6), 309-317. https://doi.org/10.1016/0268-0033(95)00041-I

Nussbaum, M. A. (2001). Static and dynamic myoelectric measures of shoulder muscle fatigue during intermittent dynamic exertions of low to moderate intensity. European Journal of Applied Physiology, 85(3-4), 299-309. https://doi.org/10.1177/0192513X12437708

Öberg, T. (1994). Subjective and objective evaluation of shoulder muscle fatigue. Ergonomics, 37(8), 1323-1333. https://doi.org/10.1177/0192513X12437708

Öberg, T. (1995). Muscle fatigue and calibration of EMG measurements. Journal of Electromyography and Kinesiology, 5(4), 239-243. https://doi.org/10.1016/10506411(96)85582-9 
Öberg, T., Sandsjö, L., \& Kadefors, R. (1990). Electromyogram mean power frequency in nonfatigued trapezius muscle. European Journal of Applied Physiology and Occupational Physiology, 61(5-6), 362-369. https://doi.org/10.1007/BF00236054

Phinyomark, A., Phukpattaranont, P., \& Limsakul, C. (2012). Feature reduction and selection for EMG signal classification. Expert Systems with Applications, 39(8), 7420-7431. https://doi.org/10.1016/j.eswa.2012.01.102

Piscione, J., \& Gamet, D. (2006). Effect of mechanical compression due to load carrying on shoulder muscle fatigue during sustained isometric arm abduction: an electromyographic study. European Journal of Applied Physiology, 97(5), 573-581. https://doi.org/10.1007/s00421-006-0221-x

Ramsay, J. W., Hunter, B. V., \& Gonzalez, R. V. (2009). Muscle moment arm and normalized moment contributions as reference data for musculoskeletal elbow and wrist joint models. Journal of Biomechanics, 42(4), 463-473. https://doi.org/10.1016/j.jbiomech.2008.11.035

Rashedi, E., \& Nussbaum, M. A. (2015). A review of occupationally-relevant models of localised muscle fatigue. International Journal of Human Factors Modelling and Simulation, 5(1), 61-80. https://doi.org/10.1177/0192513X12437708

Rashedi, E., \& Nussbaum, M. A. (2016). Cycle time influences the development of muscle fatigue at low to moderate levels of intermittent muscle contraction. Journal of Electromyography and Kinesiology, 28, 37-45. https://doi.org/10.1016/j.jelekin.2016.03.001

Ringheim, I., Indahl, A., \& Roeleveld, K. (2014). Alternating activation is related to fatigue in lumbar muscles during sustained sitting. Journal of Electromyography and Kinesiology, 24(3), 380-386. https://doi.org/10.1016/j.jelekin.2014.01.011

Robertson, R. J., \& Noble, B. J. (1997). Perception of physical exertion: methods, and applications. Exercise and Sport Science Reviews, 25(1), 407-452.

Roman-Liu, D, \& Konarska, M. (2009). Characteristics of power spectrum density function of EMG during muscle contraction below 30\%MVC. Journal of Electromyography and Kinesiology, 19(5), 864-874. https://doi.org/10.1016/j.jelekin.2008.05.002

Roman-Liu, Danuta. (2016). The influence of confounding factors on the relationship between muscle contraction level and MF and MPF values of EMG signal: A review. International Journal of Occupational Safety and Ergonomics, 22(1), 77-91. https://doi.org/10.1080/10803548.2015.1116817

Shen, W., \& Parsons, K. C. (1997). Validity and reliability of rating scales for seated pressure discomfort. International Journal of Industrial Ergonomics, 20, 441-461.

Sigholm, G., Herberts, P., Almström, C., \& Kadefors, R. (1984). Electromyographic analysis of shoulder muscle load. Journal of Orthopaedic Research, 1(4), 379-386. https://doi.org/10.1002/jor.1100010406

Sommerich, C. M., McGlothun, J. D., \& Marras, W. S. (1993). Occupational risk factors associated with soft tissue disorders of the shoulder: A review of recent investigations in the literature. Ergonomics, 36(6), 697-717. https://doi.org/10.1080/00140139308967931 
Sood, D., Nussbaum, M. A., \& Hager, K. (2007). Fatigue during prolonged intermittent overhead work: reliability of measures and effects of working height. Ergonomics, 50(4), 497-513. https://doi.org/10.1080/00140130601133800

Sood, D., Nussbaum, M. A., Hager, K., \& Nogueira, H. C. (2017). Predicted endurance times during overhead work: influences of duty cycle and tool mass estimated using perceived discomfort. Ergonomics, 60(10), 1405-1414. https://doi.org/10.1080/00140139.2017.1293850

Sparto, P. J., Parnianpour, M., Barria, E. a., \& Jagadeesh, J. M. (2000). Wavelet and short-time fourier transform analysis of electromyography for detection of back muscle fatigue. IEEE Transactions on Rehabilitation Engineering, 8(3), 433-436. https://doi.org/10.1109/86.867887

Sporrong, H., Palmerud, G., \& Herberts, P. (1995). Influences of handgrip on shoulder muscle activity. European Journal of Applied Physiology, 71(6), 485-492. https://doi.org/10.1007/BF00238549

Sporrong, H., Palmerud, G., Kadefors, R., \& Herberts, P. (1998). The effect of light manual precision work on shoulder muscles-an EMG analysis. Journal of Electromyography and Kinesiology, 8(3), 177-184. https://doi.org/10.1016/S1050-6411(97)00032-1

Straker, L. M., Pollock, C. M., \& Mangharam, J. E. (1997). The effect of shoulder posture on performance, discomfort and muscle fatigue whilst working on a visual display unit. International Journal of Industrial Ergonomics, 20(1), 1-10. https://doi.org/10.1016/S01698141(96)00027-3

Strimpakos, N., Georgios, G., Eleni, K., Vasilios, K., \& Jacqueline, O. (2005). Issues in relation to the repeatability of and correlation between EMG and Borg scale assessments of neck muscle fatigue. Journal of Electromyography and Kinesiology: Official Journal of the International Society of Electrophysiological Kinesiology, 15(5), 452-465. https://doi.org/10.1016/j.jelekin.2005.01.007

Sundelin, G. (1993). Patterns of electromyographic shoulder muscle fatigue during MTM-paced repetitive arm work with and without pauses. International Archives of Occupational and Environmental Health, 64(7), 485-493.

Sundelin, G., \& Hagberg, M. (1992). Electromyographic signs of shoulder muscle fatigue in repetitive arm work paced by the Methods Time Measurement system. Scandinavian Journal of Work, Environment and Health, 18(4), 262-268. https://doi.org/10.5271/sjweh.1579

Suurküla, J., \& Hägg, G. M. (1987). Relations between shoulder/neck disorders and EMG zero crossing shifts in female assembly workers using the test contraction method. Ergonomics, $30(11), 1553-1564$.

Szeto, G. P. Y., Straker, L. M., \& O’Sullivan, P. B. (2005). EMG median frequency changes in the neck-shoulder stabilizers of symptomatic office workers when challenged by different physical stressors. Journal of Electromyography and Kinesiology, 15(6), 544-555. https://doi.org/10.1016/j.jelekin.2005.06.004 
Szucs, K., Navalgund, A., \& Borstad, J. D. (2009). Scapular muscle activation and co-activation following a fatigue task. Medical and Biological Engineering and Computing, 47(5 SPEC. ISS.), 487-495. https://doi.org/10.1007/s11517-009-0485-5

Takala, E.-P., Lammi, S., Nieminen, H., \& Viikari-Juntura, E. (1993). Electromyographic changes in the static holding test of the arm. International Journal of Industrial Ergonomics, 12, 85-90. https://doi.org/10.1177/0192513X12437708

Tsai, N. T., McClure, P. W., \& Karduna, A. R. (2003). Effects of muscle fatigue on 3dimensional scapular kinematics. Archives of Physical Medicine and Rehabilitation, 84(7), 1000-1005. https://doi.org/10.1016/S0003-9993(03)00127-8

Ulin, S. S., Ways, C. M., Armstrong, T. J., \& Snook, S. H. (1990). Perceived exertion and discomfort versus work height with a pistol-shaped screwdriver. American Industrial Hygiene Association Journal, 51(11), 588-594.

USBJI, U. S. B. and J. I. (2015). The Burden ofMusculoskeletal Diseases in the United States.

Vasseljen, O., Holte, K. A., \& Westgaard, R. H. (2001). Shoulder and neck complaints in customer relations: Individual risk factors and perceived exposures at work. Ergonomics, 44(4), 355-372. https://doi.org/10.1080/00140130010008101

Veiersted, K. B. (1993). Sustained muscle tension as a risk factor for trapezius myalgia. Ergonomics, 15-19. https://doi.org/10.1177/0192513X12437708

Vøllestad, N. K. (1997). Measurement of human muscle fatigue. Journal of Neuroscience Methods, 74(2), 219-227. Retrieved from http://linkinghub.elsevier.com/retrieve/pii/S0165027097022516

Wiker, S. F., Chaffin, D. B., \& Langolf, G. W. (1990). Shoulder postural fatigue and discomfort: a preliminary finding of no relationship with isometric strength capability in a light-weight manual assembly task. International Journal of Industrial Ergonomics, 5, 133-146.

WSIB. (2007). Resource manual for the MSD prevention guideline for Ontario. Occupational Health and Safety Council of Ontario (OHSCO).

Wu, W., Lee, P. V. S., Bryant, A. L., Galea, M., \& Ackland, D. C. (2016). Subject-specific musculoskeletal modeling in the evaluation of shoulder muscle and joint function. Journal of Biomechanics, 49(15), 3626-3634. https://doi.org/10.1016/j.jbiomech.2016.09.025

Wuelker, N., Korell, M., \& Thren, K. (1998). Dynamic Glenohumeral Joint Stability. Journal of Shoulder and Elbow Surgery, 7(1), 43-52. https://doi.org/10.13140/2.1.3945.0402

Xu, X., McGorry, R. W., \& Lin, J. H. (2014). A regression model predicting isometric shoulder muscle activities from arm postures and shoulder joint moments. Journal of Electromyography and Kinesiology, 24, 419-429. https://doi.org/10.1016/j.jelekin.2014.02.004

Yassierli, \& Nussbaum, M. a. (2008). Utility of traditional and alternative EMG-based measures of fatigue during low-moderate level isometric efforts. Journal of Electromyography and Kinesiology, 18(1), 44-53. https://doi.org/10.1016/j.jelekin.2006.08.003 
Yung, M., Mathiassen, S. E., \& Wells, R. P. (2012). Variation of force amplitude and its effects on local fatigue. European Journal of Applied Physiology, 112(11), 3865-3879. https://doi.org/10.1007/s00421-012-2375-z

Zhang, Z., Li, K. W., Zhang, W., Ma, L., \& Chen, Z. (2014). Muscular fatigue and maximum endurance time assessment for male and female industrial workers. International Journal of Industrial Ergonomics, 44(2), 292-297. https://doi.org/10.1016/j.ergon.2012.08.006 
Appendix A: IRB approved consent form for the preliminary study 


\section{Only Minimal Risk \\ Consent Information and HIPAA Form}

Principal Investigator

Department

Protocol Number

Study Title

Co-Investigator(s)

Sponsor (if any)
Dr. Ashish Nimbarte

ENGINEERING-Industrial and Management Systems Engineering 1511900923

Effect of force and direction on shoulder complex

Hamad Alasim

N/A

\section{Contact Persons}

In the event you experience any side effects or injury related to this research, you should contact Dr. Ashish Nimbarte at (304) 293-9473. If you have any questions, concerns, or complaints about this research, you can contact Dr. Ashish Nimbarte (304)293-9473.

For information regarding your rights as a research subject, to discuss problems, concerns, or suggestions related to the research, to obtain information or offer input about the research, contact the Office of Research Compliance at (304) 293-7073.-9473.

In addition if you would like to discuss problems, concerns, have suggestions related to research, or would like to offer input about the research, contact the Office of Research Integrity and Compliance at 304-293-7073.In addition if you would like to discuss problems, concerns, have suggestions related to research, or would like to offer input about the research, contact the Office of Research Integrity and Compliance at 304-293-7073.cuss problems, concerns, have suggestions related to research, or would like to offer input about the research, contact the Office of Research Integrity and Compliance at 304-293-7073.In addition if you would like to dis

Phone: $304-293-7073$

Fax: 304-293-3098 http://oric.research.wvu.edu
Chestnut Ridge Research Building

886 Chestnut Ridge Road

PO Box 6845

Morgantown, WV 26506-6845
$P$ a g e | 121

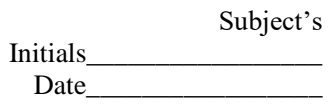




\section{Introduction}

You, have been asked to participate in this research study, which has been explained to you by Mr. Hamad. This study is being conducted by Dr. Ashish Nimbarte (PhD) and Hamad Alasim in the Department of Industrial and Management System Engineering at West Virginia University.stem Engineering at West Virginia University.

\section{Purpose(s) of the Study}

The purpose of this study is to find out if static hand load exertions in five different directions, which are front, right, left, up and down direction, can develop shoulder fatigue and shoulder instability.

\section{Description of Procedures}

Upon arrival, the procedures of the experiment will be explained to you in detail and you will be asked to sign an informed consent form. Next, basic anthropometric data including age, body weight, height and elbow height will be measured. You will be then given a 10 minutes training session in order to become familiar with the tasks to be performed and also to warm-up your shoulder muscles. Surface EMG electrodes will be placed over the skin at the following muscles: supraspinatus, infraspinatus, teres major, anterior deltoid, middle deltoid, posterior deltoid, biceps and triceps. You will be asked to perform maximum voluntary contraction (MVC) exertions in order to measure the maximum exertion using EMG from all selected muscles. Each maximum voluntary contraction trial will be five seconds long and a one minute rest period will be provided between exertions in order to reduce the chance of fatigue and injury. Then you will move to the testing area and perform designated tasks. In each trial you are required to hold a D-shape handle attached to one of the weight levels which are $\left(10,7.5,5 \mathrm{lb}\right.$.) for 60 second with a $15^{\circ}-20^{\circ}$ flexed elbow joint and a $70^{\circ}-80^{\circ}$ flexed shoulder joint. You will perform this task in five different direction which are right, left, front, up and down. Each trial will have two repetition. A 3 minutes rest time is will be provided between trials. A total of 30 trials will be performed. After the completion of each task, you will be asked to numerically rate your perceived exertion caused by the hand load exertion using Borg's CR-10 scale. The Borg CR-10 scale contains two columns, one for subjective categories ranging from "nothing at all" to "extremely strong" and the other for numerical ratios ranging on a scale of 0 to 10 that are associated with the different categories. The purpose of performing static hand load exertions during those trials was to generate fatigue in the shoulder muscles. During performing static hand load exertions you will be seated in the wooden chair in upright position and buckle up with the four-point harness to prevent any upper body movement which could interfere with the data collection.

Phone: 304-293-7073

Fax: 304-293-3098 http://oric.research.wvu.edu
Chestnut Ridge Research Building

886 Chestnut Ridge Road

PO Box 6845

Morgantown, WV 26506-6845
P a g e | 122

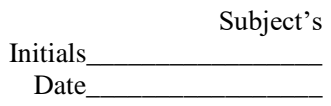




\section{Discomforts}

There is a minimal risk for shoulder muscles strain and fatigue while performing the maximum exertions. Therefore, you will be required to complete a warm up before these tasks and sufficient rest between trials.

\section{Alternatives}

You do not have to participate in this study.

\section{Benefits}

You may not receive any direct benefit from this study. The knowledge gained from this study may eventually benefit others.

\section{Financial Considerations}

You will not receive any compensation for participation in the study and will not incur any costs related to the study. It is very important for you to understand that neither the investigator nor WVU or it associated affiliates has the funds set aside to pay for the cost work wages or any care or treatment that might be necessary because you get hurt or sick taking part in this study. Any injuries that may result from this study would not be eligible for workers' Compensation as this is not a job related injury. Understand that any treatments necessary will be billed to the participant or to your personal health insurance, and you may wish to consult your insurance provider before participating in this study. pay for the cost work wages or any care or treatment that might be necessary because you get hurt or sick taking part in this study. Any injuries that may result from this study would not be eligible for workers' Compensation as this is not a job related injury. Understand that any treatments necessary will be billed to the participant or to your personal health insurance, and you may wish to consult your insurance provider before participating in this study.

\section{Confidentiality}

Any information about you that is obtained as a result of your participation in this research will be kept as confidential as legally possible. Your research records and test results, just like hospital records, may be subpoenaed by court order or may be inspected by the study sponsor or federal regulatory authorities (including the FDA if applicable) without your additional consent.

Phone: $304-293-7073$

Fax: 304-293-3098 http://oric.research.wvu.edu
Chestnut Ridge Research Building

886 Chestnut Ridge Road

PO Box 6845

Morgantown, WV 26506-6845
P a g e | 123

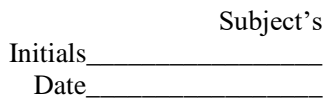




\section{Voluntary Participation}

Participation in this study is voluntary. You are free to withdraw your consent to participate in this study at any time.

Refusal to participate or withdrawal will not affect [your class standing or grades, as appropriate] and will involve no penalty to you. Refusal to participate or withdrawal will not affect your future care, or your employee status at West Virginia University.

In the event new information becomes available that may affect your willingness to participate in this study, this information will be given to you so that you can make an informed decision about whether or not to continue your participation.

You have been given the opportunity to ask questions about the research, and you have received answers concerning areas you did not understand.

Upon signing this form, you will receive a copy.

I willingly consent to participate in this research.

\section{Signatures}

Signature of Subject

Printed Name

Date

Time

The participant has had the opportunity to have questions addressed. The participant willingly agrees to be in the study.

Signature of Investigator or Co-Investigator

\begin{tabular}{lll}
\hline Printed Name & Date Time
\end{tabular}

Phone: 304-293-7073

Fax: 304-293-3098 http://oric.research.wvu.edu
Chestnut Ridge Research Building

886 Chestnut Ridge Road

PO Box 6845

Morgantown, WV 26506-6845
$\mathrm{P}$ a g e | 124

Initials__ Subject's
Date


Appendix B: IRB approved consent form for Aim \#1 study 


\section{Only Minimal Risk \\ Consent Information Form (without HIPAA)}

Principal Investigator

Dr. Ashish Nimbarte

Department

ENGINEERING-Industrial and Management Systems

Protocol Number

1903485280

Study Title

FATIGUE EVALUATION PARAMETERS VARIABILITY IN NON-FATIGUED SHOULDER

MUSCLES

Co-Investigator(s) Hamad Nasser Alasim

Sponsor (if any)

N/A

\section{Contact Persons}

In the event you experience any side effects or injury related to this research, you should contact Dr. Ashish Nimbarte at (304) 293-9473. If you have any questions, concerns, or complaints about this research, you can contact Dr. Ashish Nimbarte at (304) 293-9473.

For information regarding your rights as a research subject, to discuss problems, concerns, or suggestions related to the research, to obtain information or offer input about the research, contact the Office of Research Integrity and Compliance at (304) 293-9473.

In addition if you would like to discuss problems, concerns, have suggestions related to research, or would like to offer input about the research, contact the Office of Research Integrity and Compliance at 304-293-7073.

Phone: 304-293-7073

Fax: 304-293-3098 http://oric.research.wvu.edu
Chestnut Ridge Research Building

886 Chestnut Ridge Road

PO Box 6845

Morgantown, WV 26506-6845
P a g e | 126

Initials_ Subject's




\author{
Human Research Protocol \\ Only Minimal Risk Consent \\ Form \\ Without HIPAA
}

\title{
Introduction
}

You, , have been asked to participate in this research study, which has been explained to you by Mr. Hamad Alasim. This study is being conducted by Dr. Ashish Nimbarte and Hamad Alasim in the Department of Industrial and Management System Engineering at West Virginia University.stem Engineering at West Virginia University.

\section{Purpose(s) of the Study}

The purpose of this study is to test the hypothesis that muscle fatigue evaluation parameters, under non-fatigued/fresh conditions, will not be affected by different work-related factors.

\section{Description of Procedures}

1) Upon arrival, the procedures of the experiment will be explained to participants and informed consents will be obtained. 2) Basic anthropocentric measurements including age, body weight, height and elbow height will be measured. 3) Participants will then be given a 10 minutes training session in order to become familiar with the tasks to be performed. 4) Surface EMG electrodes will be placed over the skin at shoulder muscles, two electrodes will be placed on the upper right side of the human back and five electrodes will be placed on the upper arm. 5) Participants will be asked to perform the designated tasks in a standing posture. In each trial, the participant will be required to resist a hand load (0, 2.5 or $5 \mathrm{lb}$.) in one of five directions (Pull Back, Pull Down, Pull Left, Pull Right or Pull Up) for 10 seconds with an elevated shoulder angle $\left(60^{\circ}\right.$ or $\left.120^{\circ}\right)$ in one of those planes (sagittal or scapular). Each trial will have two repetitions. A 1-minute rest time will be provided between trials. A total of 120 trials will be performed and the SEMG data will be recorded continuously during the exertions.

\section{Discomforts}

There is a minimal risk for shoulder muscles strain and fatigue while performing the maximum exertions. Therefore, you will be required to complete a warm-up before these tasks and sufficient rest between trials. There is a minimal risk for shoulder muscles strain and fatigue while performing the maximum exertions. Therefore, you will be required to complete a warm-up before these tasks and sufficient rest between trials. strain and fatigue while performing the maximum exertions. Therefore, you will be required to complete a warm-up before these tasks and sufficient rest between trials.

Phone: 304-293-7073

Fax: 304-293-3098 http://oric.research.wvu.edu
Chestnut Ridge Research Building

886 Chestnut Ridge Road

PO Box 6845

Morgantown, WV 26506-6845
P a g e | 127

Initials_ Subject's
Date




\section{Alternatives}

You do not have to participate in this study.

\section{Benefits}

You may not receive any direct benefit from this study. The knowledge gained from this study may eventually benefit others.

\section{Confidentiality}

Any information about you that is obtained as a result of your participation in this research will be kept as confidential as legally possible. Your research records and test results, just like hospital records, may be subpoenaed by court order or without your additional consent. your additional consent.

\section{Voluntary Participation}

Participation in this study is voluntary. You are free to withdraw your consent to participate in this study at any time. Refusal to participate or withdrawal will not affect your class standing or grades, as appropriate, and will involve no penalty to you. Refusal to participate or withdrawal will not affect your future care, or your employee status, as appropriate, at West Virginia University.

In the event new information becomes available that may affect your willingness to participate in this study, this information will be given to you so that you can make an informed decision about whether or not to continue your participation.

You have been given the opportunity to ask questions about the research, and you have received answers concerning areas you did not understand. Upon signing this form, you will receive a copy.

Phone: 304-293-7073

Fax: 304-293-3098 http://oric.research.wvu.edu
Chestnut Ridge Research Building

886 Chestnut Ridge Road

PO Box 6845

Morgantown, WV 26506-6845
P a g e | 128

Subject's 


\section{WestVirginiaUniversity.}

Human Research Protocol

Only Minimal Risk Consent

Form

Without HIPAA

I willingly consent to participate in this research.

\section{Signatures}

Signature of Subject

Printed Name

Date

Time

The participant has had the opportunity to have questions addressed. The participant willingly agrees to be in the study.

Signature of Investigator or Co-Investigator

$\begin{array}{lll}\text { Printed Name } & \text { Date }\end{array}$


Appendix C: IRB approved consent form for Aim \#2 study 


\section{Only Minimal Risk \\ Consent Information Form (without HIPAA)}

Principal Investigator

Department

Protocol Number

Study Title

Fatigue

Co-Investigator(s)

Sponsor (if any)
Dr. Ashish Nimbarte

ENGINEERING-Industrial and Management Systems Engineering

Validation of The Parameters Variability as An Indicator of Shoulder Muscles

Hamad Nasser Alasim

N/A

\section{Contact Persons}

In the event you experience any side effects or injury related to this research, you should contact Dr. Ashish Nimbarte at (304) 293-9473. If you have any questions, concerns, or complaints about this research, you can contact Dr. Ashish Nimbarte at (304) 293-9473.

For information regarding your rights as a research subject, to discuss problems, concerns, or suggestions related to the research, to obtain information or offer input about the research, contact the Office of Research Integrity and Compliance at (304) 293-7073.

In addition, if you would like to discuss problems, concerns, have suggestions related to research, or would like to offer input about the research, contact the Office of Research Integrity and Compliance at 304-293-7073.

\section{Introduction}

You, have been asked to participate in this research study (Student Project), which has been explained to you by Mr. Hamad Alasim. This study is being conducted by Dr. Ashish Nimbarte and Hamad Alasim in the Department of Industrial and Management System Engineering at West Virginia University.

\section{Purpose(s) of the Study}

Phone: 304-293-7073

Fax: 304-293-3098 http://oric.research.wvu.edu
Chestnut Ridge Research Building

886 Chestnut Ridge Road

PO Box 6845

Morgantown, WV 26506-6845
P a g e | 131

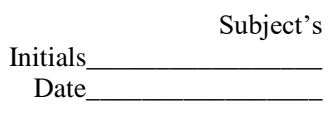




\section{Human Research Protocol Only Minimal Risk Consent \\ Form \\ Without HIPAA}

Student Project-The purpose of this study is to understand the implications of variability in electromyography (EMG) measures on the prediction of Localized Muscle Fatigue (LMF) using subjective perceived exertion ratings.

\section{Description of Procedures}

1) Upon arrival, the procedures of the experiment will be explained to participants and informed consents will be obtained.

2) Basic anthropocentric data including age, body weight, height and elbow height will be measured. 3) Participants will then be given a 10 minutes training session in order to become familiar with the tasks to be performed. 4) Surface EMG (SEMG) electrodes will be placed over the skin of the upper arm and shoulder area, for more specification, SEMG will be placed at the supraspinatus, infraspinatus, anterior deltoid, middle deltoid, posterior deltoid, biceps and triceps muscles. 5) Participants will be asked to perform four preidentified exertions in a standing posture. In the first exertion, participants will be required to resist a hand load $(5 \mathrm{lb}$.) by pulling left direction for 10-45 seconds with an elevated shoulder angle at (120 degrees) in the sagittal plane (performing shoulder flexion). In the second exertion, participants will be required to resist a hand load (5 lb.) by pulling up direction for 10-45 seconds with an elevated shoulder angle at (120 degrees) in the sagittal plane (performing shoulder flexion). In the third exertion, participants will be required to resist a hand load (5 lb.) by pulling right direction for 10-45 seconds with an elevated shoulder angle at (120 degrees) in the scapular plane (performing shoulder mid-abduction). In the fourth exertion, participants will be required to resist a hand load (5 lb.) by pulling up direction for 10-45 seconds with an elevated shoulder angle at (120 degrees) in the scapular plane (shoulder performing mid-abduction). Each trial will have two repetitions. 5 minutes of rest time will be provided between trials. A total of 8 trials will be performed and the SEMG and perceived exertion rating data will be recorded continuously during the exertions.

\section{Discomforts}

There is a minimal risk for shoulder muscles strain and fatigue while performing the maximum exertions. Therefore, you will be required to complete a warm-up before these tasks and sufficient rest between trials.

\section{Alternatives}

You do not have to participate in this study.

Phone: 304-293-7073

Fax: 304-293-3098 http://oric.research.wvu.edu
Chestnut Ridge Research Building

886 Chestnut Ridge Road

PO Box 6845

Morgantown, WV 26506-6845
P a g e | 132

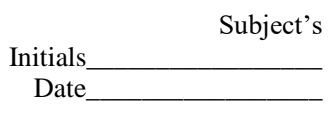




\section{Benefits}

You may not receive any direct benefit from this study. The knowledge gained from this study may eventually benefit others.

\section{Confidentiality}

Any information about you that is obtained as a result of your participation in this research will be kept as confidential as legally possible. Your research records and test results, just like hospital records, may be subpoenaed by court order or without your additional consent.

\section{Voluntary Participation}

Participation in this study is voluntary. You are free to withdraw your consent to participate in this study at any time. Refusal to participate or withdrawal will not affect your class standing or grades, as appropriate, and will involve no penalty to you. Refusal to participate or withdrawal will not affect your future care, or your employee status, as appropriate, at West Virginia University.

In the event new information becomes available that may affect your willingness to participate in this study, this information will be given to you so that you can make an informed decision about whether or not to continue your participation.

You have been given the opportunity to ask questions about the research, and you have received answers concerning areas you did not understand. Upon signing this form, you will receive a copy.

Phone: 304-293-7073

Fax: 304-293-3098 http://oric.research.wvu.edu
Chestnut Ridge Research Building

886 Chestnut Ridge Road

PO Box 6845

Morgantown, WV 26506-6845
P a g e | 133

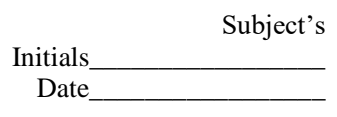




\section{WestVirginiaUniversity.}

Human Research Protocol

Only Minimal Risk Consent

Form

Without HIPAA

I willingly consent to participate in this research.

\section{Signatures}

Signature of Subject

Printed Name

Date

Time

The participant has had the opportunity to have questions addressed. The participant willingly agrees to be in the study.

Signature of Investigator or Co-Investigator

$\begin{array}{lll}\text { Printed Name } & \text { Date Time }\end{array}$

Phone: 304-293-7073

Fax: 304-293-3098 http://oric.research.wvu.edu
Chestnut Ridge Research Building 886 Chestnut Ridge Road

PO Box 6845

Morgantown, WV 26506-6845
P a g e | 134

Subject's
Initials

Date 
Appendix D: PAR-Q 
(A Queztionnaire for People Aged 15 to 69)

Regular physical activity is fun and healthy, and increasingly more people are starting to become more active every day. Being more active is very safe for most people. However, some people should chect with their doctor before they start becoming much more physically active.

If you are planning to become much more physically active than you are now, start by answering the seven questions in the bax belowe If you are between the ages of 15 and 69 , the PAR-Q will tell you if you should chect with your doctor before you start. If you are over 69 years of age, and you are not used to being very active, check with your doctor.

Common sense is your best guide when you answer these questions. Please read the questions carefilly and answer each one honesth. chect Yes or NO.

\begin{tabular}{|c|c|c|c|}
\hline $\begin{array}{l}\text { YES } \\
\square\end{array}$ & $\begin{array}{l}\text { mo } \\
\square\end{array}$ & 1. & $\begin{array}{l}\text { Has your doctor ever zaid that you have a heart condition and that you should only do physical activity } \\
\text { recommended by a doctor? }\end{array}$ \\
\hline$\square$ & $\square$ & 2. & Do you feel pain in your cheat when you do physical activity? \\
\hline$\square$ & $\square$ & 3. & In the past month, have you had cheat pais when you were not doing physical activity? \\
\hline$\square$ & $\square$ & 4. & Do you lose your balance because of dizziness or do you ever lose consciousness? \\
\hline$\square$ & $\square$ & 5. & $\begin{array}{l}\text { Do you have a bone or joint problem (for example, back, linee or hip) that could be made worse by a } \\
\text { change in your physical activity? }\end{array}$ \\
\hline$\square$ & $\square$ & 6. & $\begin{array}{l}\text { Is your doctor currently preseribing drugs (for example, water pills) for your blood pressure or heart con- } \\
\text { dition? }\end{array}$ \\
\hline$\square$ & $\square$ & 7. & Do you know of any other reazon why you should not do physical activity? \\
\hline
\end{tabular}
your doctor about the PAR-Q and which questione you answersd YES.

- You may be ablo to do any activity you want - ze long as you start slowly and buld up gradualy. Or, you may need to restrict your activites to tcese which are safe for you. Tall with your doctor about the tinds of activibes you wish to participate in and tollow his/her advice.

- Find out ahich community progans are safe and helptul for you.

\section{NO to all questions}

If you answersd NO honestly to al AAR-Q quection, you can be rezeorably sure that you car:

- start bocoming much more phyaicaly active - bogin slowly and build up gradually. Thie is the safest and exsiest way to go.

- tale part in a fivess appraisal-thie is an oxcollent vay 20 determine your basic fteress $s 0$ that you can plan the best way for you to five actively it is also highly recommendod that you havo your blood presoure evaluatod. Ff your reasing is cver 144/94, tali with your doctor before you start becoming mudh more physically active.

DELAY BECOMING MUCH MORE ACTIVE:

- If you are not feoling well because of a temporary innezs such $\mathbf{z}$ 2 cold or 2 fever - wait until you feel better; or

- If you are or may be pregnart - talt to your doctor before you start becoming more active.

PLEASE NOTE: If your health changes 30 that you then anower YES to any of the above questiona, tall your ftress or health professional. Ast wether you should change your physical activty plan.

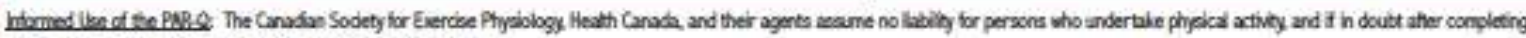

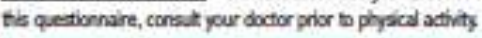

Mo changez permitted. You are encouraged to photocopy the PAR-Q but only if you use the entire form.

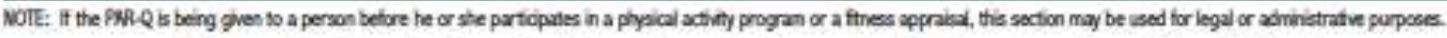

7 have read, understood and completed this questionnaire. Any questions I had were answered to my full satisfaction."

MuE

SaNTHE

SENATHE OF RAFI

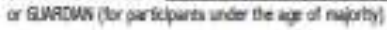

DMTE

UnVESS

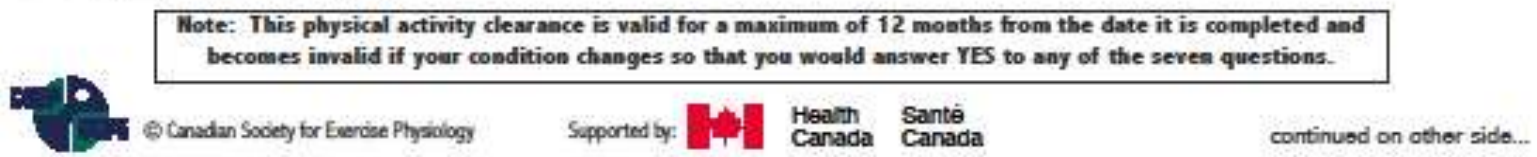


Appendix E: Analysis of Variance 


\section{Supraspinatus Analysis of Variance}

Source

Angle

Plane

Weight (lb)

Direction

Angle*Plane

Angle*Weight (lb)

Angle*Direction

Plane*Weight (lb)

Plane*Direction

Weight (lb)*Direction

Angle*Plane*Weight (Ib)

Angle*Plane*Direction

Angle*Weight (lb)*Direction

Plane*Weight $(\mathrm{lb}) *$ Direction

Angle*Plane*Weight $(\mathrm{Ib}) *$ Direction

Error

Total

\section{Infraspinatus Analysis of Variance}

Source

Angle

Plane

Weight (lb)

Direction

Angle*Plane

Angle*Weight (lb)

Angle* Direction

Plane*Weight (lb)

Plane*Direction

Weight (lb)*Direction

Angle*Plane*Weight (Ib)

Angle*Plane* Direction

Angle*Weight $(\mathrm{lb}) *$ Direction

Plane*Weight (lb)*Direction

Angle*Plane*Weight $(\mathrm{lb}) *$ Direction

Error

Total

\begin{tabular}{|c|c|c|c|c|}
\hline DF & Adj SS & Adj MS & F-Value & P-Value \\
\hline 1 & 0.224 & 0.22405 & 20.53 & 0 \\
\hline 1 & 1.97 & 1.96995 & 180.5 & 0 \\
\hline 2 & 6.37 & 3.18511 & 291.84 & 0 \\
\hline 4 & 21.994 & 5.49852 & 503.81 & 0 \\
\hline 1 & 5.927 & 5.92664 & 543.04 & 0 \\
\hline 2 & 0.617 & 0.30866 & 28.28 & 0 \\
\hline 4 & 9.882 & 2.47044 & 226.36 & 0 \\
\hline 2 & 0.448 & 0.22388 & 20.51 & 0 \\
\hline 4 & 5.084 & 1.27109 & 116.47 & 0 \\
\hline 8 & 14.357 & 1.79466 & 164.44 & 0 \\
\hline 2 & 0.537 & 0.26834 & 24.59 & 0 \\
\hline 4 & 2.663 & 0.66564 & 60.99 & 0 \\
\hline 8 & 4.022 & 0.50277 & 46.07 & 0 \\
\hline 8 & 1.978 & 0.24726 & 22.66 & 0 \\
\hline 8 & 1.705 & 0.21316 & 19.53 & 0 \\
\hline 25860 & 282.23 & 0.01091 & & \\
\hline 919 & 360.008 & & & \\
\hline
\end{tabular}

\begin{tabular}{rrrrr} 
DF & \multicolumn{1}{c}{ Adj SS } & Adj MS & F-Value & P-Value \\
1 & 15.786 & 15.786 & 1628.56 & 0 \\
1 & 1.158 & 1.1582 & 119.49 & 0 \\
2 & 0.332 & 0.1658 & 17.11 & 0 \\
4 & 0.638 & 0.1595 & 16.45 & 0 \\
1 & 1.114 & 1.114 & 114.92 & 0 \\
2 & 0.379 & 0.1896 & 19.56 & 0 \\
4 & 3.769 & 0.9423 & 97.21 & 0 \\
2 & 1.777 & 0.8885 & 91.66 & 0 \\
4 & 1.072 & 0.2679 & 27.64 & 0 \\
8 & 1.362 & 0.1703 & 17.57 & 0 \\
2 & 0.388 & 0.1941 & 20.02 & 0 \\
4 & 0.419 & 0.1048 & 10.81 & 0 \\
8 & 2.466 & 0.3083 & 31.8 & 0 \\
8 & 0.64 & 0.08 & 8.25 & 0 \\
8 & 0.3 & 0.0375 & 3.87 & 0 \\
25860 & 250.666 & 0.0097 & & \\
25919 & 282.267 & & &
\end{tabular}


Middle deltoid Analysis of Variance

Source
Angle
Plane
Weight (lb)
Direction
Angle*Plane
Angle*Weight (lb)
Angle*Direction
Plane*Weight (lb)
Plane*Direction
Weight (lb)*Direction
Angle*Plane*Weight (lb)
Angle*Plane*Direction
Angle*Weight (lb)*Direction
Plane*Weight (lb)*Direction
Angle*Plane*Weight (lb)*Direction
Error
Total

Anterior deltoid Analysis of Variance

Source

Angle

Plane

Weight (lb)

Direction

Angle*Plane

Angle*Weight (lb)

Angle* Direction

Plane*Weight (lb)

Plane*Direction

Weight (lb)*Direction

Angle*Plane*Weight (Ib)

Angle*Plane* Direction

Angle*Weight $(\mathrm{lb}) *$ Direction

Plane*Weight $(\mathrm{lb}) *$ Direction

Angle*Plane*Weight $(\mathrm{Ib}) *$ Direction

Error

Total

\begin{tabular}{rrrrr} 
DF & \multicolumn{1}{c}{ Adj SS } & Adj MS & F-Value & P-Value \\
1 & 16.436 & 16.4356 & 2208.85 & 0 \\
1 & 0.554 & 0.5543 & 74.49 & 0 \\
2 & 1.898 & 0.9489 & 127.52 & 0 \\
4 & 18.904 & 4.7261 & 635.16 & 0 \\
1 & 0.389 & 0.3886 & 52.23 & 0 \\
2 & 1.267 & 0.6335 & 85.13 & 0 \\
4 & 1.612 & 0.4029 & 54.15 & 0 \\
2 & 0.151 & 0.0757 & 10.18 & 0 \\
4 & 0.73 & 0.1825 & 24.53 & 0 \\
8 & 15.627 & 1.9534 & 262.53 & 0 \\
2 & 0.089 & 0.0444 & 5.97 & 0.003 \\
4 & 0.291 & 0.0728 & 9.78 & 0 \\
8 & 1.881 & 0.2351 & 31.59 & 0 \\
8 & 0.628 & 0.0786 & 10.56 & 0 \\
8 & 0.382 & 0.0477 & 6.42 & 0 \\
25860 & 192.419 & 0.0074 & & \\
25919 & 253.258 & & &
\end{tabular}

\begin{tabular}{|c|c|c|c|c|}
\hline DF & Adj SS & Adj MS & F-Value & P-Value \\
\hline 1 & 5.96 & 5.95972 & 597.15 & 0 \\
\hline 1 & 0.374 & 0.3735 & 37.42 & 0 \\
\hline 2 & 0.823 & 0.4117 & 41.25 & 0 \\
\hline 4 & 23.199 & 5.79982 & 581.12 & 0 \\
\hline 1 & 0.513 & 0.51295 & 51.4 & 0 \\
\hline 2 & 0.842 & 0.42082 & 42.16 & 0 \\
\hline 4 & 0.678 & 0.16947 & 16.98 & 0 \\
\hline 2 & 0.845 & 0.42239 & 42.32 & 0 \\
\hline 4 & 0.503 & 0.12573 & 12.6 & 0 \\
\hline 8 & 15.455 & 1.93189 & 193.57 & 0 \\
\hline 2 & 0.211 & 0.10545 & 10.57 & 0 \\
\hline 4 & 0.52 & 0.12993 & 13.02 & 0 \\
\hline 8 & 0.895 & 0.11191 & 11.21 & 0 \\
\hline 8 & 0.423 & 0.05288 & 5.3 & 0 \\
\hline 8 & 0.549 & 0.06867 & 6.88 & 0 \\
\hline 25860 & 258.092 & 0.00998 & & \\
\hline 919 & 309.881 & & & \\
\hline
\end{tabular}


Posterior deltoid Analysis of Variance

Source
Angle
Plane
Weight (lb)
Direction
Angle*Plane
Angle*Weight (lb)
Angle*Direction
Plane*Weight (lb)
Plane*Direction
Weight (lb)*Direction
Angle*Plane*Weight (lb)
Angle*Plane*Direction
Angle*Weight (lb)*Direction
Plane*Weight (lb)*Direction
Angle*Plane*Weight (lb)*Direction
Error
Total

\begin{tabular}{|c|c|c|c|c|}
\hline DF & Adj SS & Adj MS & F-Value & P-Value \\
\hline 1 & 0.046 & 0.04591 & 4.02 & 0.045 \\
\hline 1 & 2.199 & 2.19925 & 192.69 & 0 \\
\hline 2 & 0.741 & 0.37038 & 32.45 & 0 \\
\hline 4 & 25.455 & 6.36379 & 557.57 & 0 \\
\hline 1 & 2.817 & 2.8168 & 246.8 & 0 \\
\hline 2 & 0.656 & 0.32786 & 28.73 & 0 \\
\hline 4 & 4.212 & 1.05291 & 92.25 & 0 \\
\hline 2 & 0.029 & 0.01466 & 1.28 & 0.277 \\
\hline 4 & 2.24 & 0.56004 & 49.07 & 0 \\
\hline 8 & 11.027 & 1.37842 & 120.77 & 0 \\
\hline 2 & 0.68 & 0.33981 & 29.77 & 0 \\
\hline 4 & 2.263 & 0.56573 & 49.57 & 0 \\
\hline 8 & 3.664 & 0.45801 & 40.13 & 0 \\
\hline 8 & 0.782 & 0.0978 & 8.57 & 0 \\
\hline 8 & 1.775 & 0.22194 & 19.45 & 0 \\
\hline 25860 & 295.152 & 0.01141 & & \\
\hline 5919 & 353.739 & & & \\
\hline
\end{tabular}

Biceps Analysis of Variance
Source
Angle
Plane
Weight (lb)
Direction
Angle*Plane
Angle*Weight (lb)
Angle*Direction
Plane*Weight (lb)
Plane*Direction
Weight (lb)*Direction
Angle*Plane*Weight (lb)
Angle*Plane*Direction
Angle*Weight (lb)*Direction
Plane*Weight (lb)*Direction
Angle*Plane*Weight (lb)*Direction
Error
Total

\begin{tabular}{|c|c|c|c|c|}
\hline DF & Adj SS & Adj MS & F-Value & P-Value \\
\hline 1 & 0.316 & 0.3158 & 24.03 & 0 \\
\hline 1 & 0.002 & 0.0021 & 0.16 & 0.692 \\
\hline 2 & 8.806 & 4.403 & 334.99 & 0 \\
\hline 4 & 166.094 & 41.5234 & 3159.18 & 0 \\
\hline 1 & 0.01 & 0.0101 & 0.77 & 0.38 \\
\hline 2 & 7.092 & 3.5458 & 269.77 & 0 \\
\hline 4 & 25.934 & 6.4834 & 493.27 & 0 \\
\hline 2 & 0.01 & 0.0051 & 0.39 & 0.679 \\
\hline 4 & 0.348 & 0.0869 & 6.61 & 0 \\
\hline 8 & 86.513 & 10.8141 & 822.76 & 0 \\
\hline 2 & 0.017 & 0.0087 & 0.66 & 0.516 \\
\hline 4 & 0.293 & 0.0731 & 5.56 & 0 \\
\hline 8 & 13.644 & 1.7055 & 129.76 & 0 \\
\hline 8 & 0.505 & 0.0631 & 4.8 & 0 \\
\hline 8 & 0.321 & 0.0401 & 3.05 & 0.002 \\
\hline 25860 & 339.897 & 0.0131 & & \\
\hline 5919 & 649.799 & & & \\
\hline
\end{tabular}


Triceps Analysis of Variance

Source
Angle
Plane
Weight (lb)
Direction
Angle*Plane
Angle*Weight (lb)
Angle*Direction
Plane*Weight (lb)
Plane*Direction
Weight (lb)*Direction
Angle*Plane*Weight (lb)
Angle*Plane*Direction
Angle*Weight (lb)*Direction
Plane*Weight (lb)*Direction
Angle*Plane*Weight (lb)*Direction
Error
Total

\begin{tabular}{|c|c|c|c|c|}
\hline DF & Adj SS & Adj MS & F-Value & P-Value \\
\hline 1 & 0.005 & 0.005 & 0.38 & 0.535 \\
\hline 1 & 0.027 & 0.0267 & 2.04 & 0.153 \\
\hline 2 & 14.149 & 7.0746 & 539.58 & 0 \\
\hline 4 & 89.753 & 22.4382 & 1711.35 & 0 \\
\hline 1 & 0.045 & 0.0452 & 3.44 & 0.063 \\
\hline 2 & 5.255 & 2.6276 & 200.4 & 0 \\
\hline 4 & 14.2 & 3.5499 & 270.75 & 0 \\
\hline 2 & 0.243 & 0.1217 & 9.29 & 0 \\
\hline 4 & 0.606 & 0.1514 & 11.55 & 0 \\
\hline 8 & 40.725 & 5.0906 & 388.26 & 0 \\
\hline 2 & 0.067 & 0.0336 & 2.57 & 0.077 \\
\hline 4 & 0.03 & 0.0076 & 0.58 & 0.677 \\
\hline 8 & 8.11 & 1.0137 & 77.32 & 0 \\
\hline 8 & 0.193 & 0.0241 & 1.84 & 0.065 \\
\hline 8 & 0.336 & 0.042 & 3.2 & 0.001 \\
\hline 25860 & 339.061 & 0.0131 & & \\
\hline 919 & 512.806 & & & \\
\hline
\end{tabular}




\section{Supraspinatus Analysis of Variance}

Source

Angle

Plane

Weight (lb)

Direction

Angle*Plane

Angle*Weight (lb)

Angle* Direction

Plane*Weight (lb)

Plane*Direction

Weight (lb)*Direction

Angle*Plane*Weight (Ib)

Angle*Plane*Direction

Angle*Weight (lb)*Direction

Plane*Weight $(\mathrm{lb}) *$ Direction

Angle*Plane*Weight $(\mathrm{Ib}) *$ Direction

Error

Total

\section{Infraspinatus Analysis of Variance}

Source

Angle

Plane

Weight (lb)

Direction

Angle*Plane

Angle*Weight (lb)

Angle*Direction

Plane*Weight (lb)

Plane*Direction

Weight (lb)*Direction

Angle*Plane*Weight (Ib)

Angle*Plane* Direction

Angle*Weight $(\mathrm{lb}) *$ Direction

Plane*Weight (lb)*Direction

Angle*Plane*Weight $(\mathrm{lb}) *$ Direction

Error

Total

\begin{tabular}{|c|c|c|c|c|}
\hline DF & Adj SS & Adj MS & F-Value & P-Value \\
\hline 1 & 12.073 & 12.0735 & 834.65 & 0 \\
\hline 1 & 0.142 & 0.1417 & 9.8 & 0.002 \\
\hline 2 & 0.338 & 0.1688 & 11.67 & 0 \\
\hline 4 & 4.588 & 1.1471 & 79.3 & 0 \\
\hline 1 & 1.42 & 1.4196 & 98.14 & 0 \\
\hline 2 & 0.007 & 0.0035 & 0.24 & 0.783 \\
\hline 4 & 3.375 & 0.8438 & 58.33 & 0 \\
\hline 2 & 0.084 & 0.0419 & 2.89 & 0.055 \\
\hline 4 & 2.302 & 0.5756 & 39.79 & 0 \\
\hline 8 & 1.165 & 0.1457 & 10.07 & 0 \\
\hline 2 & 0.301 & 0.1507 & 10.42 & 0 \\
\hline 4 & 1.177 & 0.2943 & 20.35 & 0 \\
\hline 8 & 1.717 & 0.2146 & 14.83 & 0 \\
\hline 8 & 0.833 & 0.1041 & 7.2 & 0 \\
\hline 8 & 0.595 & 0.0744 & 5.14 & 0 \\
\hline 25860 & 374.071 & 0.0145 & & \\
\hline 5919 & 404.188 & & & \\
\hline
\end{tabular}

\begin{tabular}{rrrrr} 
DF & \multicolumn{1}{c}{ Adj SS } & Adj MS & F-Value & P-Value \\
1 & 20.017 & 20.0168 & 1737.65 & 0 \\
1 & 0.223 & 0.2234 & 19.39 & 0 \\
2 & 1.167 & 0.5834 & 50.65 & 0 \\
4 & 17.866 & 4.4665 & 387.74 & 0 \\
1 & 1.965 & 1.9646 & 170.55 & 0 \\
2 & 0.168 & 0.084 & 7.29 & 0.001 \\
4 & 4.234 & 1.0585 & 91.89 & 0 \\
2 & 0.583 & 0.2915 & 25.3 & 0 \\
4 & 1.108 & 0.2771 & 24.05 & 0 \\
8 & 5.861 & 0.7327 & 63.6 & 0 \\
2 & 0.091 & 0.0457 & 3.96 & 0.019 \\
4 & 1.073 & 0.2683 & 23.29 & 0 \\
8 & 3.207 & 0.4009 & 34.8 & 0 \\
8 & 0.625 & 0.0781 & 6.78 & 0 \\
8 & 0.257 & 0.0321 & 2.78 & 0.004 \\
25860 & 297.893 & 0.0115 & & \\
25919 & 356.339 & & &
\end{tabular}


Middle deltoid Analysis of Variance

Source
Angle
Plane
Weight (lb)
Direction
Angle*Plane
Angle*Weight (lb)
Angle*Direction
Plane*Weight (lb)
Plane*Direction
Weight (lb)*Direction
Angle*Plane*Weight (lb)
Angle*Plane*Direction
Angle*Weight (lb)*Direction
Plane*Weight (lb)*Direction
Angle*Plane*Weight (lb)*Direction
Error
Total

Anterior deltoid Analysis of Variance

Source

Angle

Plane

Weight (lb)

Direction

Angle*Plane

Angle*Weight (lb)

Angle* Direction

Plane*Weight (lb)

Plane*Direction

Weight (lb)*Direction

Angle*Plane*Weight (Ib)

Angle*Plane* Direction

Angle*Weight $(\mathrm{lb}) *$ Direction

Plane*Weight $(\mathrm{lb}) *$ Direction

Angle*Plane*Weight $(\mathrm{Ib}) *$ Direction

Error

Total

\begin{tabular}{rrrrr} 
DF & \multicolumn{1}{c}{ Adj SS } & Adj MS & F-Value & P-Value \\
1 & 40.607 & 40.6067 & 5370.42 & 0 \\
1 & 2.031 & 2.0312 & 268.64 & 0 \\
2 & 1.163 & 0.5817 & 76.93 & 0 \\
4 & 0.948 & 0.2369 & 31.33 & 0 \\
1 & 0.132 & 0.132 & 17.46 & 0 \\
2 & 0.102 & 0.0512 & 6.78 & 0.001 \\
4 & 1.065 & 0.2661 & 35.2 & 0 \\
2 & 0.01 & 0.0049 & 0.65 & 0.523 \\
4 & 0.263 & 0.0658 & 8.7 & 0 \\
8 & 0.84 & 0.105 & 13.89 & 0 \\
2 & 0.062 & 0.0312 & 4.13 & 0.016 \\
4 & 0.159 & 0.0398 & 5.26 & 0 \\
8 & 0.217 & 0.0272 & 3.59 & 0 \\
8 & 0.431 & 0.0539 & 7.13 & 0 \\
8 & 0.177 & 0.0221 & 2.92 & 0.003 \\
25860 & 195.532 & 0.0076 & & \\
25919 & 243.74 & & &
\end{tabular}

\begin{tabular}{rrrrr} 
DF & \multicolumn{1}{c}{ Adj SS } & Adj MS & F-Value & P-Value \\
1 & 12.148 & 12.1475 & 1037.57 & 0 \\
1 & 2.503 & 2.5029 & 213.78 & 0 \\
2 & 8.848 & 4.4242 & 377.88 & 0 \\
4 & 10.992 & 2.7481 & 234.73 & 0 \\
1 & 1.069 & 1.0687 & 91.28 & 0 \\
2 & 0.026 & 0.0128 & 1.09 & 0.336 \\
4 & 0.46 & 0.1149 & 9.81 & 0 \\
2 & 0.656 & 0.328 & 28.02 & 0 \\
4 & 0.587 & 0.1468 & 12.54 & 0 \\
8 & 4.245 & 0.5306 & 45.32 & 0 \\
2 & 0.597 & 0.2985 & 25.5 & 0 \\
4 & 0.957 & 0.2393 & 20.44 & 0 \\
8 & 0.846 & 0.1057 & 9.03 & 0 \\
8 & 0.748 & 0.0936 & 7.99 & 0 \\
8 & 0.939 & 0.1173 & 10.02 & 0 \\
25860 & 302.762 & 0.0117 & & \\
25919 & 348.381 & & &
\end{tabular}


Posterior deltoid Analysis of Variance

Source

Angle

Plane

Weight (lb)

Direction

Angle*Plane

Angle*Weight (lb)

Angle* Direction

Plane*Weight (lb)

Plane*Direction

Weight (lb)*Direction

Angle*Plane*Weight (Ib)

Angle*Plane*Direction

Angle*Weight $(\mathrm{lb}) *$ Direction

Plane*Weight (lb)*Direction

Angle*Plane*Weight (lb)*Direction

Error

Total

\section{Biceps Analysis of Variance}

Source

Angle

Plane

Weight (lb)

Direction

Angle*Plane

Angle*Weight (lb)

Angle*Direction

Plane*Weight (lb)

Plane*Direction

Weight (lb)*Direction

Angle*Plane*Weight (Ib)

Angle*Plane* Direction

Angle*Weight $(\mathrm{lb}) *$ Direction

Plane*Weight $(\mathrm{lb}) *$ Direction

Angle*Plane*Weight $(\mathrm{Ib}) *$ Direction

Error

Total

\begin{tabular}{rrrrr} 
DF & \multicolumn{1}{c}{ Adj SS } & Adj MS & F-Value & P-Value \\
1 & 16.04 & 16.0399 & 1984.99 & 0 \\
1 & 10.174 & 10.1742 & 1259.09 & 0 \\
2 & 0.503 & 0.2516 & 31.14 & 0 \\
4 & 3.445 & 0.8613 & 106.59 & 0 \\
1 & 0.232 & 0.2321 & 28.72 & 0 \\
2 & 0.453 & 0.2264 & 28.02 & 0 \\
4 & 2.16 & 0.5401 & 66.84 & 0 \\
2 & 0.082 & 0.0409 & 5.06 & 0.006 \\
4 & 1.115 & 0.2788 & 34.51 & 0 \\
8 & 3.207 & 0.4008 & 49.61 & 0 \\
2 & 0.417 & 0.2086 & 25.82 & 0 \\
4 & 1.177 & 0.2942 & 36.41 & 0 \\
8 & 1.31 & 0.1638 & 20.27 & 0 \\
8 & 0.531 & 0.0664 & 8.21 & 0 \\
8 & 0.745 & 0.0932 & 11.53 & 0 \\
25860 & 208.964 & 0.0081 & & \\
25919 & 250.556 & & &
\end{tabular}

DF

Adj SS

$\begin{array}{ll}1 & 0.98 \\ 1 & 0.00\end{array}$

SS

Adj MS

$\mathrm{F}-$

-Value

P-Value

$0.007 \quad 0.0066$

$0.44 \quad 0.506$

1

3.085

1.542

102.65

1645.17

0

98.893

24.7232

26.66

197.73

231.01

0.73

5.78

0.011

0.0869

431.43

0.87

3.74

53.11

7.04

1.86

0.0279

$\begin{array}{lll}25860 & 388.618 & 0.015\end{array}$

$25919 \quad 571.762$ 
Triceps Analysis of Variance

Source
Angle
Plane
Weight (lb)
Direction
Angle*Plane
Angle*Weight (lb)
Angle*Direction
Plane*Weight (lb)
Plane*Direction
Weight (lb)*Direction
Angle*Plane*Weight (lb)
Angle*Plane*Direction
Angle*Weight (lb)*Direction
Plane*Weight (lb)*Direction
Angle*Plane*Weight (lb)*Direction
Error
Total

\begin{tabular}{rrrrr} 
DF & \multicolumn{1}{c}{ Adj SS } & Adj MS & F-Value & P-Value \\
1 & 2.639 & 2.6392 & 208.11 & 0 \\
1 & 0.309 & 0.3091 & 24.37 & 0 \\
2 & 15.957 & 7.9783 & 629.1 & 0 \\
4 & 96.986 & 24.2464 & 1911.85 & 0 \\
1 & 0.103 & 0.1035 & 8.16 & 0.004 \\
2 & 12.094 & 6.0468 & 476.79 & 0 \\
4 & 15.749 & 3.9373 & 310.46 & 0 \\
2 & 0.366 & 0.1831 & 14.44 & 0 \\
4 & 0.228 & 0.057 & 4.49 & 0.001 \\
8 & 47.375 & 5.9219 & 466.95 & 0 \\
2 & 0.032 & 0.0158 & 1.25 & 0.288 \\
4 & 0.174 & 0.0434 & 3.42 & 0.008 \\
8 & 9.356 & 1.1695 & 92.22 & 0 \\
8 & 0.264 & 0.033 & 2.6 & 0.008 \\
8 & 0.532 & 0.0665 & 5.24 & 0 \\
25860 & 327.961 & 0.0127 & & \\
25919 & 530.125 & & &
\end{tabular}




\section{Supraspinatus Analysis of Variance}

Source

Angle

Plane

Weight (lb)

Direction

Angle*Plane

Angle*Weight (lb)

Angle* Direction

Plane*Weight (lb)

Plane*Direction

Weight (lb)*Direction

Angle*Plane*Weight (Ib)

Angle*Plane*Direction

Angle*Weight (lb)*Direction

Plane*Weight $(\mathrm{lb}) *$ Direction

Angle*Plane*Weight $(\mathrm{Ib}) *$ Direction

Error

Total

\section{Infraspinatus Analysis of Variance}

Source

Angle

Plane

Weight (lb)

Direction

Angle*Plane

Angle*Weight (lb)

Angle* Direction

Plane*Weight (lb)

Plane*Direction

Weight (lb)*Direction

Angle*Plane*Weight (Ib)

Angle*Plane* Direction

Angle*Weight (lb)*Direction

Plane*Weight (lb)*Direction

Angle*Plane*Weight $(\mathrm{lb}) *$ Direction

Error

Total

\begin{tabular}{|c|c|c|c|c|}
\hline DF & Adj SS & Adj MS & F-Value & P-Value \\
\hline 1 & 0.004 & 0.00399 & 0.35 & 0.554 \\
\hline 1 & 1.054 & 1.05398 & 92.26 & 0 \\
\hline 2 & 3.245 & 1.62252 & 142.02 & 0 \\
\hline 4 & 7.661 & 1.91514 & 167.64 & 0 \\
\hline 1 & 4.807 & 4.80681 & 420.75 & 0 \\
\hline 2 & 0.262 & 0.13114 & 11.48 & 0 \\
\hline 4 & 5.023 & 1.25576 & 109.92 & 0 \\
\hline 2 & 0.165 & 0.08233 & 7.21 & 0.001 \\
\hline 4 & 2.943 & 0.73568 & 64.4 & 0 \\
\hline 8 & 5.487 & 0.68586 & 60.04 & 0 \\
\hline 2 & 0.212 & 0.10617 & 9.29 & 0 \\
\hline 4 & 1.256 & 0.31403 & 27.49 & 0 \\
\hline 8 & 2.276 & 0.28445 & 24.9 & 0 \\
\hline 8 & 1.236 & 0.15451 & 13.52 & 0 \\
\hline 8 & 1.101 & 0.13768 & 12.05 & 0 \\
\hline 5860 & 295.433 & 0.01142 & & \\
\hline כנט & 332.164 & & & \\
\hline
\end{tabular}

\begin{tabular}{rrrrr} 
DF & \multicolumn{1}{c}{ Adj SS } & Adj MS & F-Value & P-Value \\
1 & 26.877 & 26.8775 & 2570.01 & 0 \\
1 & 2.423 & 2.423 & 231.69 & 0 \\
2 & 0.22 & 0.1099 & 10.51 & 0 \\
4 & 1.494 & 0.3735 & 35.72 & 0 \\
1 & 1.119 & 1.1189 & 106.99 & 0 \\
2 & 0.277 & 0.1384 & 13.24 & 0 \\
4 & 1.943 & 0.4858 & 46.45 & 0 \\
2 & 1.015 & 0.5075 & 48.52 & 0 \\
4 & 0.818 & 0.2044 & 19.55 & 0 \\
8 & 0.356 & 0.0445 & 4.26 & 0 \\
2 & 0.738 & 0.3689 & 35.27 & 0 \\
4 & 0.28 & 0.0701 & 6.7 & 0 \\
8 & 1.5 & 0.1875 & 17.93 & 0 \\
8 & 0.417 & 0.0521 & 4.98 & 0 \\
8 & 0.398 & 0.0498 & 4.76 & 0 \\
25860 & 270.447 & 0.0105 & & \\
25919 & 310.323 & & &
\end{tabular}


Middle deltoid Analysis of Variance

Source
Angle
Plane
Weight (lb)
Direction
Angle*Plane
Angle*Weight (lb)
Angle*Direction
Plane*Weight (lb)
Plane*Direction
Weight (lb)*Direction
Angle*Plane*Weight (lb)
Angle*Plane*Direction
Angle*Weight (lb)*Direction
Plane*Weight (lb)*Direction
Angle*Plane*Weight (lb)*Direction
Error
Total

Anterior deltoid Analysis of Variance

Source

Angle

Plane

Weight (lb)

Direction

Angle*Plane

Angle*Weight (lb)

Angle* Direction

Plane*Weight (lb)

Plane*Direction

Weight (lb)*Direction

Angle*Plane*Weight (lb)

Angle*Plane* Direction

Angle*Weight $(\mathrm{lb}) *$ Direction

Plane*Weight $(\mathrm{lb}) *$ Direction

Angle*Plane*Weight $(\mathrm{Ib}) *$ Direction

Error

Total

\begin{tabular}{rrrrr} 
DF & \multicolumn{1}{c}{ Adj SS } & Adj MS & F-Value & P-Value \\
1 & 14.669 & 14.6692 & 1215.59 & 0 \\
1 & 0.654 & 0.6541 & 54.2 & 0 \\
2 & 0.026 & 0.0132 & 1.09 & 0.335 \\
4 & 6.809 & 1.7022 & 141.06 & 0 \\
1 & 0.265 & 0.2648 & 21.95 & 0 \\
2 & 0.706 & 0.3528 & 29.24 & 0 \\
4 & 1.465 & 0.3661 & 30.34 & 0 \\
2 & 0.077 & 0.0386 & 3.2 & 0.041 \\
4 & 0.262 & 0.0654 & 5.42 & 0 \\
8 & 6.626 & 0.8282 & 68.63 & 0 \\
2 & 0.022 & 0.0111 & 0.92 & 0.399 \\
4 & 0.156 & 0.039 & 3.23 & 0.012 \\
8 & 0.92 & 0.115 & 9.53 & 0 \\
8 & 0.394 & 0.0493 & 4.09 & 0 \\
8 & 0.3 & 0.0376 & 3.11 & 0.002 \\
25860 & 312.066 & 0.0121 & & \\
25919 & 345.417 & & &
\end{tabular}

\begin{tabular}{|c|c|c|c|c|}
\hline DF & Adj SS & Adj MS & F-Value & P-Value \\
\hline 1 & 3.85 & 3.8495 & 339.54 & 0 \\
\hline 1 & 1.139 & 1.13949 & 100.51 & 0 \\
\hline 2 & 0.997 & 0.4985 & 43.97 & 0 \\
\hline 4 & 17.6 & 4.39996 & 388.09 & 0 \\
\hline 1 & 0.21 & 0.2099 & 18.51 & 0 \\
\hline 2 & 0.383 & 0.19173 & 16.91 & 0 \\
\hline 4 & 0.728 & 0.18196 & 16.05 & 0 \\
\hline 2 & 1.051 & 0.52549 & 46.35 & 0 \\
\hline 4 & 0.248 & 0.0619 & 5.46 & 0 \\
\hline 8 & 10.471 & 1.30891 & 115.45 & 0 \\
\hline 2 & 0.106 & 0.05283 & 4.66 & 0.009 \\
\hline 4 & 0.521 & 0.13013 & 11.48 & 0 \\
\hline 8 & 0.997 & 0.12463 & 10.99 & 0 \\
\hline 8 & 0.482 & 0.06027 & 5.32 & 0 \\
\hline 8 & 0.537 & 0.06712 & 5.92 & 0 \\
\hline 860 & 293.189 & 0.01134 & & \\
\hline 919 & 332.509 & & & \\
\hline
\end{tabular}


Posterior deltoid Analysis of Variance

Source
Angle
Plane
Weight (lb)
Direction
Angle*Plane
Angle*Weight (lb)
Angle*Direction
Plane*Weight (lb)
Plane*Direction
Weight (lb)*Direction
Angle*Plane*Weight (lb)
Angle*Plane*Direction
Angle*Weight (lb)*Direction
Plane*Weight (lb)*Direction
Angle*Plane*Weight (lb)*Direction
Error
Total

\begin{tabular}{|c|c|c|c|c|}
\hline DF & Adj SS & Adj MS & F-Value & P-Value \\
\hline 1 & 1.561 & 1.56075 & 149.92 & 0 \\
\hline 1 & 2.975 & 2.97516 & 285.78 & 0 \\
\hline 2 & 0.822 & 0.41089 & 39.47 & 0 \\
\hline 4 & 5.502 & 1.37548 & 132.12 & 0 \\
\hline 1 & 1.678 & 1.67817 & 161.2 & 0 \\
\hline 2 & 0.308 & 0.1541 & 14.8 & 0 \\
\hline 4 & 2.913 & 0.72828 & 69.95 & 0 \\
\hline 2 & 0.008 & 0.00391 & 0.38 & 0.687 \\
\hline 4 & 1.033 & 0.25814 & 24.8 & 0 \\
\hline 8 & 3.149 & 0.39361 & 37.81 & 0 \\
\hline 2 & 0.108 & 0.05405 & 5.19 & 0.006 \\
\hline 4 & 1.427 & 0.35668 & 34.26 & 0 \\
\hline 8 & 0.8 & 0.09999 & 9.6 & 0 \\
\hline 8 & 0.415 & 0.05186 & 4.98 & 0 \\
\hline 8 & 0.718 & 0.0897 & 8.62 & 0 \\
\hline 25860 & 269.223 & 0.01041 & & \\
\hline 25919 & 292.639 & & & \\
\hline
\end{tabular}

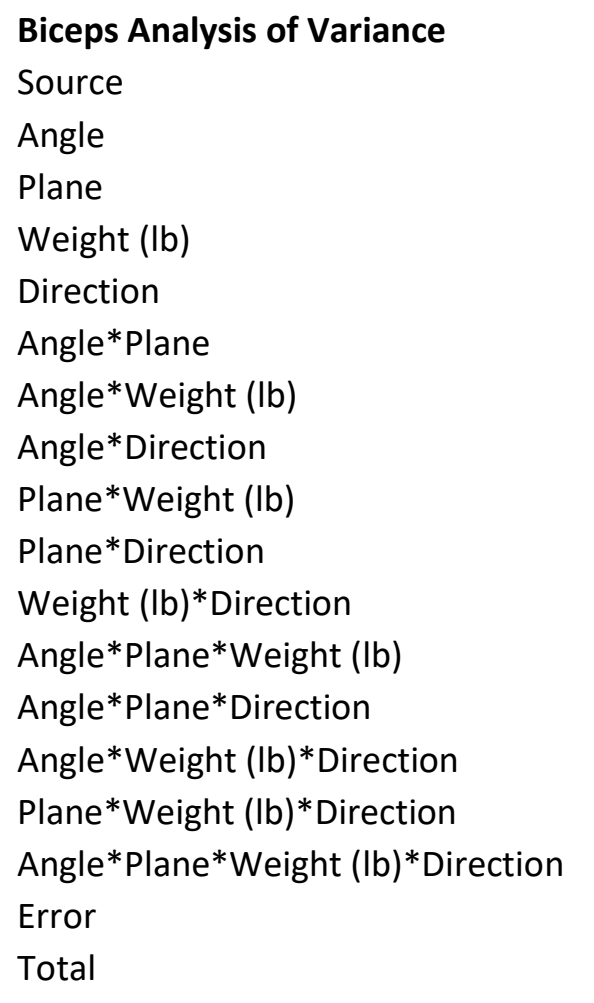

\begin{tabular}{|c|c|c|c|c|}
\hline DF & Adj SS & Adj MS & F-Value & P-Value \\
\hline 1 & 1.538 & 1.5385 & 135.3 & 0 \\
\hline 1 & 0.188 & 0.1876 & 16.5 & 0 \\
\hline 2 & 4.663 & 2.3313 & 205.03 & 0 \\
\hline 4 & 105.31 & 26.3275 & 2315.41 & 0 \\
\hline 1 & 0.012 & 0.0122 & 1.07 & 0.301 \\
\hline 2 & 2.307 & 1.1537 & 101.46 & 0 \\
\hline 4 & 13.131 & 3.2827 & 288.7 & 0 \\
\hline 2 & 0.103 & 0.0514 & 4.52 & 0.011 \\
\hline 4 & 0.143 & 0.0357 & 3.14 & 0.014 \\
\hline 8 & 54.649 & 6.8311 & 600.77 & 0 \\
\hline 2 & 0.052 & 0.0262 & 2.3 & 0.1 \\
\hline 4 & 0.313 & 0.0781 & 6.87 & 0 \\
\hline 8 & 5.331 & 0.6664 & 58.61 & 0 \\
\hline 8 & 0.555 & 0.0694 & 6.11 & 0 \\
\hline 8 & 0.301 & 0.0376 & 3.31 & 0.001 \\
\hline 25860 & 294.043 & 0.0114 & & \\
\hline 25919 & 482.639 & & & \\
\hline
\end{tabular}




\section{Triceps Analysis of Variance}

Source

Angle

Plane

Weight (lb)

Direction

Angle*Plane

Angle*Weight (lb)

Angle* Direction

Plane*Weight (Ib)

Plane*Direction

Weight (lb)*Direction

Angle*Plane*Weight (Ib)

Angle*Plane*Direction

Angle*Weight $(\mathrm{lb}) *$ Direction

Plane*Weight (lb)*Direction

Angle*Plane*Weight $(\mathrm{lb}) *$ Direction

Error

Total
DF

Adj SS

6.503

0.048

10.3

67.575

0.043

7.661

7.816

0.052

0.449

28.086

0.041

0.172

4.354

0.56

0.501

295.847

25860

25919

430.007
Adj MS F-Value P-Value

$6.5031 \quad 568.44$

4.21

450.16

1476.69

3.74

334.83

170.81

2.25

9.81

306.87

1.81

3.75

47.57

6.12

5.47

0.0626

0.0114

0

0 


\section{Supraspinatus Analysis of Variance}

Source

Angle

Plane

Weight (lb)

Direction

Angle*Plane

Angle*Weight (lb)

Angle* Direction

Plane*Weight (lb)

Plane*Direction

Weight (lb)*Direction

Angle*Plane*Weight (Ib)

Angle*Plane*Direction

Angle*Weight (lb)*Direction

Plane*Weight (lb)*Direction

Angle*Plane*Weight $(\mathrm{Ib}) *$ Direction

Error

Total

\section{Infraspinatus Analysis of Variance}

Source

Angle

Plane

Weight (lb)

Direction

Angle*Plane

Angle*Weight (lb)

Angle*Direction

Plane*Weight (lb)

Plane*Direction

Weight (lb)*Direction

Angle*Plane*Weight (Ib)

Angle*Plane*Direction

Angle*Weight (lb)*Direction

Plane*Weight $(\mathrm{lb}) *$ Direction

Angle*Plane*Weight $(\mathrm{lb}) *$ Direction

Error

Total

\begin{tabular}{|c|c|c|c|c|}
\hline DF & Adj SS & Adj MS & F-Value & P-Value \\
\hline 1 & 39.281 & 39.2808 & 3183.97 & 0 \\
\hline 1 & 26.264 & 26.2642 & 2128.89 & 0 \\
\hline 2 & 2.96 & 1.4802 & 119.98 & 0 \\
\hline 4 & 66.483 & 16.6208 & 1347.22 & 0 \\
\hline 1 & 0.893 & 0.893 & 72.39 & 0 \\
\hline 2 & 0.475 & 0.2373 & 19.23 & 0 \\
\hline 4 & 6.779 & 1.6948 & 137.37 & 0 \\
\hline 2 & 0.066 & 0.033 & 2.67 & 0.069 \\
\hline 4 & 2.34 & 0.5849 & 47.41 & 0 \\
\hline 8 & 31.004 & 3.8755 & 314.13 & 0 \\
\hline 2 & 0.131 & 0.0653 & 5.29 & 0.005 \\
\hline 4 & 0.992 & 0.2479 & 20.09 & 0 \\
\hline 8 & 3.426 & 0.4283 & 34.72 & 0 \\
\hline 8 & 2.085 & 0.2606 & 21.12 & 0 \\
\hline 8 & 0.297 & 0.0371 & 3.01 & 0.002 \\
\hline 5860 & 319.036 & 0.0123 & & \\
\hline 919 & 502.511 & & & \\
\hline
\end{tabular}

\begin{tabular}{rrrrr} 
DF & \multicolumn{1}{c}{ Adj SS } & Adj MS & F-Value & P-Value \\
1 & 2.647 & 2.6468 & 255.18 & 0 \\
1 & 1.367 & 1.3665 & 131.75 & 0 \\
2 & 19.627 & 9.8134 & 946.13 & 0 \\
4 & 74.393 & 18.5984 & 1793.1 & 0 \\
1 & 1.209 & 1.2091 & 116.57 & 0 \\
2 & 0.156 & 0.0782 & 7.54 & 0.001 \\
4 & 4.443 & 1.1108 & 107.1 & 0 \\
2 & 0.051 & 0.0253 & 2.44 & 0.087 \\
4 & 2.347 & 0.5869 & 56.58 & 0 \\
8 & 41.91 & 5.2388 & 505.08 & 0 \\
2 & 0.224 & 0.1122 & 10.81 & 0 \\
4 & 0.666 & 0.1665 & 16.05 & 0 \\
8 & 2.732 & 0.3415 & 32.92 & 0 \\
8 & 1.36 & 0.17 & 16.39 & 0 \\
8 & 0.347 & 0.0433 & 4.18 & 0 \\
25860 & 268.225 & 0.0104 & & \\
25919 & 421.705 & & &
\end{tabular}


Middle deltoid Analysis of Variance

Source
Angle
Plane
Weight (lb)
Direction
Angle*Plane
Angle*Weight (lb)
Angle*Direction
Plane*Weight (lb)
Plane*Direction
Weight (lb)*Direction
Angle*Plane*Weight (lb)
Angle*Plane*Direction
Angle*Weight (lb)*Direction
Plane*Weight (lb)*Direction
Angle*Plane*Weight (lb)*Direction
Error
Total

Anterior deltoid Analysis of Variance

Source

Angle

Plane

Weight (lb)

Direction

Angle*Plane

Angle*Weight (lb)

Angle* Direction

Plane*Weight (lb)

Plane*Direction

Weight (lb)*Direction

Angle*Plane*Weight (Ib)

Angle*Plane* Direction

Angle*Weight $(\mathrm{lb}) *$ Direction

Plane*Weight $(\mathrm{lb}) *$ Direction

Angle*Plane*Weight $(\mathrm{Ib}) *$ Direction

Error

Total

\begin{tabular}{rrrrr} 
DF & \multicolumn{1}{c}{ Adj SS } & Adj MS & F-Value & P-Value \\
1 & 94.184 & 94.1838 & 8566.61 & 0 \\
1 & 4.001 & 4.0015 & 363.96 & 0 \\
2 & 0.739 & 0.3697 & 33.63 & 0 \\
4 & 59.888 & 14.972 & 1361.8 & 0 \\
1 & 0.299 & 0.2991 & 27.21 & 0 \\
2 & 0.251 & 0.1254 & 11.41 & 0 \\
4 & 7.945 & 1.9862 & 180.66 & 0 \\
2 & 0.052 & 0.0261 & 2.38 & 0.093 \\
4 & 2.279 & 0.5699 & 51.83 & 0 \\
8 & 29.307 & 3.6634 & 333.21 & 0 \\
2 & 0.037 & 0.0186 & 1.69 & 0.184 \\
4 & 0.882 & 0.2204 & 20.05 & 0 \\
8 & 4.893 & 0.6117 & 55.63 & 0 \\
8 & 1.226 & 0.1532 & 13.94 & 0 \\
8 & 0.721 & 0.0901 & 8.2 & 0 \\
25860 & 284.312 & 0.011 & & \\
25919 & 491.018 & & &
\end{tabular}

\begin{tabular}{|c|c|c|c|c|}
\hline DF & Adj SS & Adj MS & F-Value & P-Value \\
\hline 1 & 40.454 & 40.4542 & 3347.27 & 0 \\
\hline 1 & 5.628 & 5.6276 & 465.64 & 0 \\
\hline 2 & 3.695 & 1.8476 & 152.88 & 0 \\
\hline 4 & 70.219 & 17.5548 & 1452.52 & 0 \\
\hline 1 & 0.149 & 0.1491 & 12.33 & 0 \\
\hline 2 & 0.508 & 0.2542 & 21.03 & 0 \\
\hline 4 & 10.471 & 2.6176 & 216.59 & 0 \\
\hline 2 & 0.188 & 0.094 & 7.78 & 0 \\
\hline 4 & 0.288 & 0.0719 & 5.95 & 0 \\
\hline 8 & 42.211 & 5.2764 & 436.58 & 0 \\
\hline 2 & 0.259 & 0.1293 & 10.7 & 0 \\
\hline 4 & 0.611 & 0.1527 & 12.63 & 0 \\
\hline 8 & 5.265 & 0.6581 & 54.46 & 0 \\
\hline 8 & 0.825 & 0.1031 & 8.53 & 0 \\
\hline 8 & 0.581 & 0.0727 & 6.01 & 0 \\
\hline 25860 & 312.536 & 0.0121 & & \\
\hline 519 & 493.888 & & & \\
\hline
\end{tabular}


Posterior deltoid Analysis of Variance

Source
Angle
Plane
Weight (lb)
Direction
Angle*Plane
Angle*Weight (lb)
Angle*Direction
Plane*Weight (lb)
Plane*Direction
Weight (lb)*Direction
Angle*Plane*Weight (lb)
Angle*Plane*Direction
Angle*Weight (lb)*Direction
Plane*Weight (lb)*Direction
Angle*Plane*Weight (lb)*Direction
Error
Total

\begin{tabular}{|c|c|c|c|c|}
\hline DF & Adj SS & Adj MS & F-Value & P-Value \\
\hline 1 & 46.81 & 46.8096 & 7528.47 & 0 \\
\hline 1 & 6.127 & 6.1271 & 985.43 & 0 \\
\hline 2 & 9.898 & 4.9489 & 795.94 & 0 \\
\hline 4 & 54.159 & 13.5397 & 2177.61 & 0 \\
\hline 1 & 0.333 & 0.3333 & 53.6 & 0 \\
\hline 2 & 0.946 & 0.4732 & 76.11 & 0 \\
\hline 4 & 8.452 & 2.1129 & 339.82 & 0 \\
\hline 2 & 0.108 & 0.054 & 8.69 & 0 \\
\hline 4 & 4.746 & 1.1865 & 190.83 & 0 \\
\hline 8 & 28.482 & 3.5603 & 572.61 & 0 \\
\hline 2 & 0.064 & 0.0319 & 5.13 & 0.006 \\
\hline 4 & 0.267 & 0.0668 & 10.74 & 0 \\
\hline 8 & 4.645 & 0.5806 & 93.38 & 0 \\
\hline 8 & 2.723 & 0.3403 & 54.74 & 0 \\
\hline 8 & 0.348 & 0.0436 & 7.01 & 0 \\
\hline 25860 & 160.789 & 0.0062 & & \\
\hline 25919 & 328.897 & & & \\
\hline
\end{tabular}

Biceps Analysis of Variance
Source
Angle
Plane
Weight (lb)
Direction
Angle*Plane
Angle*Weight (lb)
Angle*Direction
Plane*Weight (lb)
Plane*Direction
Weight (lb)*Direction
Angle*Plane*Weight (lb)
Angle*Plane*Direction
Angle*Weight (lb)*Direction
Plane*Weight (lb)*Direction
Angle*Plane*Weight (lb)*Direction
Error
Total

\begin{tabular}{rrrrr} 
DF & \multicolumn{1}{c}{ Adj SS } & Adj MS & F-Value & P-Value \\
1 & 7.431 & 7.431 & 825.17 & 0 \\
1 & 0.019 & 0.0189 & 2.1 & 0.148 \\
2 & 14.589 & 7.2946 & 810.03 & 0 \\
4 & 87.025 & 21.7564 & 2415.95 & 0 \\
1 & 0.618 & 0.6184 & 68.67 & 0 \\
2 & 1.236 & 0.618 & 68.63 & 0 \\
4 & 5.34 & 1.3351 & 148.25 & 0 \\
2 & 0.002 & 0.0008 & 0.09 & 0.915 \\
4 & 1.531 & 0.3827 & 42.5 & 0 \\
8 & 49.551 & 6.1938 & 687.8 & 0 \\
2 & 0.151 & 0.0755 & 8.39 & 0 \\
4 & 0.482 & 0.1206 & 13.39 & 0 \\
8 & 1.962 & 0.2453 & 27.24 & 0 \\
8 & 0.735 & 0.0919 & 10.2 & 0 \\
8 & 0.478 & 0.0598 & 6.64 & 0 \\
25860 & 232.878 & 0.009 & & \\
25919 & 404.029 & & &
\end{tabular}




\section{Triceps Analysis of Variance}

Source

Angle

Plane

Weight (lb)

Direction

Angle*Plane

Angle*Weight (lb)

Angle* Direction

Plane*Weight (lb)

Plane*Direction

Weight (lb)*Direction

Angle*Plane*Weight (Ib)

Angle*Plane*Direction

Angle*Weight $(\mathrm{lb}) *$ Direction

Plane*Weight (lb)*Direction

Angle*Plane*Weight $(\mathrm{lb}) *$ Direction

Error

Total

\begin{tabular}{|c|c|c|c|c|}
\hline DF & Adj SS & Adj MS & F-Value & P-Value \\
\hline 1 & 3.848 & 3.8479 & 316.24 & 0 \\
\hline 1 & 0.644 & 0.6443 & 52.95 & 0 \\
\hline 2 & 41.991 & 20.9954 & 1725.51 & 0 \\
\hline 4 & 17.065 & 4.2663 & 350.63 & 0 \\
\hline 1 & 0 & 0.0004 & 0.03 & 0.865 \\
\hline 2 & 0.208 & 0.104 & 8.55 & 0 \\
\hline 4 & 9.237 & 2.3093 & 189.79 & 0 \\
\hline 2 & 0.065 & 0.0323 & 2.65 & 0.071 \\
\hline 4 & 1.48 & 0.37 & 30.41 & 0 \\
\hline 8 & 9.717 & 1.2147 & 99.83 & 0 \\
\hline 2 & 0.207 & 0.1035 & 8.51 & 0 \\
\hline 4 & 0.224 & 0.0561 & 4.61 & 0.001 \\
\hline 8 & 5.592 & 0.6991 & 57.45 & 0 \\
\hline 8 & 1.288 & 0.161 & 13.23 & 0 \\
\hline 8 & 0.33 & 0.0413 & 3.39 & 0.001 \\
\hline 360 & 314.655 & 0.0122 & & \\
\hline 5919 & 406.552 & & & \\
\hline
\end{tabular}




\section{Supraspinatus Analysis of Variance}

Source

Angle

Plane

Weight (lb)

Direction

Angle*Plane

Angle*Weight (lb)

Angle*Direction

Plane*Weight (lb)

Plane*Direction

Weight (lb)*Direction

Angle*Plane*Weight (Ib)

Angle*Plane*Direction

Angle*Weight (lb)*Direction

Plane*Weight $(\mathrm{lb}) *$ Direction

Angle*Plane*Weight $(\mathrm{Ib}) *$ Direction

Error

Total

\section{Infraspinatus Analysis of Variance}

Source

Angle

Plane

Weight (lb)

Direction

Angle*Plane

Angle*Weight (lb)

Angle*Direction

Plane*Weight (lb)

Plane*Direction

Weight (lb)*Direction

Angle*Plane*Weight (Ib)

Angle*Plane* Direction

Angle*Weight $(\mathrm{lb}) *$ Direction

Plane*Weight (lb)*Direction

Angle*Plane*Weight $(\mathrm{lb}) *$ Direction

Error

Total

\begin{tabular}{|c|c|c|c|c|}
\hline DF & Adj SS & Adj MS & F-Value & P-Value \\
\hline 1 & 38.359 & 38.3589 & 4064.61 & 0 \\
\hline 1 & 25.089 & 25.0894 & 2658.54 & 0 \\
\hline 2 & 3.063 & 1.5316 & 162.3 & 0 \\
\hline 4 & 67.953 & 16.9883 & 1800.12 & 0 \\
\hline 1 & 0.678 & 0.6781 & 71.86 & 0 \\
\hline 2 & 0.676 & 0.338 & 35.82 & 0 \\
\hline 4 & 7.076 & 1.7689 & 187.44 & 0 \\
\hline 2 & 0.05 & 0.0252 & 2.67 & 0.069 \\
\hline 4 & 2.623 & 0.6558 & 69.49 & 0 \\
\hline 8 & 31.642 & 3.9552 & 419.11 & 0 \\
\hline 2 & 0.205 & 0.1025 & 10.86 & 0 \\
\hline 4 & 1.027 & 0.2568 & 27.21 & 0 \\
\hline 8 & 3.578 & 0.4472 & 47.39 & 0 \\
\hline 8 & 1.901 & 0.2376 & 25.18 & 0 \\
\hline 8 & 0.244 & 0.0304 & 3.23 & 0.001 \\
\hline 860 & 244.048 & 0.0094 & & \\
\hline 919 & 428.212 & & & \\
\hline
\end{tabular}

\begin{tabular}{|c|c|c|c|c|}
\hline DF & Adj SS & Adj MS & F-Value & P-Value \\
\hline 1 & 4.109 & 4.1091 & 523.47 & 0 \\
\hline 1 & 1.09 & 1.0902 & 138.88 & 0 \\
\hline 2 & 20.613 & 10.3065 & 1312.97 & 0 \\
\hline 4 & 89.546 & 22.3866 & 2851.87 & 0 \\
\hline 1 & 1.328 & 1.3283 & 169.21 & 0 \\
\hline 2 & 0.309 & 0.1545 & 19.68 & 0 \\
\hline 4 & 4.946 & 1.2365 & 157.52 & 0 \\
\hline 2 & 0.072 & 0.036 & 4.59 & 0.01 \\
\hline 4 & 1.857 & 0.4642 & 59.14 & 0 \\
\hline 8 & 49.435 & 6.1794 & 787.21 & 0 \\
\hline 2 & 0.201 & 0.1004 & 12.79 & 0 \\
\hline 4 & 0.657 & 0.1643 & 20.94 & 0 \\
\hline 8 & 2.886 & 0.3608 & 45.96 & 0 \\
\hline 8 & 1.069 & 0.1337 & 17.03 & 0 \\
\hline 8 & 0.363 & 0.0454 & 5.79 & 0 \\
\hline 25860 & 202.995 & 0.0078 & & \\
\hline 919 & 381.479 & & & \\
\hline
\end{tabular}


Middle deltoid Analysis of Variance

Source
Angle
Plane
Weight (lb)
Direction
Angle*Plane
Angle*Weight (lb)
Angle*Direction
Plane*Weight (lb)
Plane*Direction
Weight (lb)*Direction
Angle*Plane*Weight (lb)
Angle*Plane*Direction
Angle*Weight (lb)*Direction
Plane*Weight (lb)*Direction
Angle*Plane*Weight (lb)*Direction
Error
Total

Anterior deltoid Analysis of Variance

Source

Angle

Plane

Weight (lb)

Direction

Angle*Plane

Angle*Weight (lb)

Angle*Direction

Plane*Weight (lb)

Plane*Direction

Weight (lb)*Direction

Angle*Plane*Weight (Ib)

Angle*Plane* Direction

Angle*Weight $(\mathrm{lb}) *$ Direction

Plane*Weight $(\mathrm{lb}) *$ Direction

Angle*Plane*Weight $(\mathrm{Ib}) *$ Direction

Error

Total

\begin{tabular}{|c|c|c|c|c|}
\hline DF & Adj SS & Adj MS & F-Value & P-Value \\
\hline 1 & 114.524 & 114.524 & 12487.81 & 0 \\
\hline 1 & 4.988 & 4.988 & 543.94 & 0 \\
\hline 2 & 0.809 & 0.404 & 44.11 & 0 \\
\hline 4 & 68.165 & 17.041 & 1858.18 & 0 \\
\hline 1 & 0.574 & 0.574 & 62.56 & 0 \\
\hline 2 & 0.321 & 0.16 & 17.48 & 0 \\
\hline 4 & 9.034 & 2.258 & 246.27 & 0 \\
\hline 2 & 0.093 & 0.046 & 5.06 & 0.006 \\
\hline 4 & 2.519 & 0.63 & 68.67 & 0 \\
\hline 8 & 33.241 & 4.155 & 453.08 & 0 \\
\hline 2 & 0.016 & 0.008 & 0.85 & 0.427 \\
\hline 4 & 0.996 & 0.249 & 27.16 & 0 \\
\hline 8 & 6.043 & 0.755 & 82.37 & 0 \\
\hline 8 & 1.424 & 0.178 & 19.4 & 0 \\
\hline 8 & 0.581 & 0.073 & 7.92 & 0 \\
\hline 60 & 237.159 & 0.009 & & \\
\hline & 480.487 & & & \\
\hline
\end{tabular}

\begin{tabular}{rrrrr} 
DF & \multicolumn{1}{c}{ Adj SS } & Adj MS & F-Value & P-Value \\
1 & 48.189 & 48.1888 & 4713.62 & 0 \\
1 & 5.721 & 5.7208 & 559.59 & 0 \\
2 & 4.565 & 2.2825 & 223.26 & 0 \\
4 & 78.225 & 19.5562 & 1912.9 & 0 \\
1 & 0.218 & 0.2177 & 21.29 & 0 \\
2 & 0.441 & 0.2204 & 21.56 & 0 \\
4 & 11.131 & 2.7828 & 272.2 & 0 \\
2 & 0.256 & 0.1282 & 12.54 & 0 \\
4 & 0.223 & 0.0557 & 5.45 & 0 \\
8 & 47.006 & 5.8758 & 574.74 & 0 \\
2 & 0.234 & 0.1172 & 11.46 & 0 \\
4 & 0.635 & 0.1588 & 15.53 & 0 \\
8 & 6.138 & 0.7673 & 75.05 & 0 \\
8 & 0.805 & 0.1006 & 9.84 & 0 \\
8 & 0.594 & 0.0742 & 7.26 & 0 \\
25860 & 264.375 & 0.0102 & & \\
25919 & 468.755 & & &
\end{tabular}


Posterior deltoid Analysis of Variance

Source
Angle
Plane
Weight (lb)
Direction
Angle*Plane
Angle*Weight (lb)
Angle*Direction
Plane*Weight (lb)
Plane*Direction
Weight (lb)*Direction
Angle*Plane*Weight (lb)
Angle*Plane*Direction
Angle*Weight (lb)*Direction
Plane*Weight (lb)*Direction
Angle*Plane*Weight (lb)*Direction
Error
Total

\section{Biceps Analysis of Variance}

Source
Angle
Plane
Weight (lb)
Direction
Angle*Plane
Angle*Weight (lb)
Angle*Direction
Plane*Weight (lb)
Plane*Direction
Weight (lb)*Direction
Angle*Plane*Weight (lb)
Angle*Plane*Direction
Angle*Weight (lb)*Direction
Plane*Weight (lb)*Direction
Angle*Plane*Weight (lb)*Direction
Error
Total

\begin{tabular}{rrrrr} 
DF & \multicolumn{1}{c}{ Adj SS } & Adj MS & F-Value & P-Value \\
1 & 47.951 & 47.9506 & 9492.07 & 0 \\
1 & 7.783 & 7.7827 & 1540.62 & 0 \\
2 & 11.047 & 5.5235 & 1093.41 & 0 \\
4 & 60.425 & 15.1061 & 2990.34 & 0 \\
1 & 0.419 & 0.4189 & 82.93 & 0 \\
2 & 1.011 & 0.5056 & 100.1 & 0 \\
4 & 8.48 & 2.1199 & 419.65 & 0 \\
2 & 0.132 & 0.066 & 13.07 & 0 \\
4 & 5.743 & 1.4359 & 284.24 & 0 \\
8 & 31.582 & 3.9477 & 781.47 & 0 \\
2 & 0.05 & 0.0249 & 4.93 & 0.007 \\
4 & 0.265 & 0.0663 & 13.13 & 0 \\
8 & 4.767 & 0.5959 & 117.96 & 0 \\
8 & 2.904 & 0.363 & 71.86 & 0 \\
8 & 0.284 & 0.0354 & 7.02 & 0 \\
25860 & 130.636 & 0.0051 & & \\
25919 & 313.477 & & &
\end{tabular}

\begin{tabular}{|c|c|c|c|c|}
\hline DF & Adj SS & Adj MS & F-Value & P-Value \\
\hline 1 & 9.943 & 9.9433 & 1215.66 & 0 \\
\hline 1 & 0.004 & 0.004 & 0.48 & 0.487 \\
\hline 2 & 14.343 & 7.1713 & 876.76 & 0 \\
\hline 4 & 84.256 & 21.0639 & 2575.27 & 0 \\
\hline 1 & 0.676 & 0.6758 & 82.63 & 0 \\
\hline 2 & 0.9 & 0.4499 & 55.01 & 0 \\
\hline 4 & 5.047 & 1.2619 & 154.27 & 0 \\
\hline 2 & 0.018 & 0.0091 & 1.12 & 0.328 \\
\hline 4 & 1.687 & 0.4218 & 51.57 & 0 \\
\hline 8 & 49.511 & 6.1888 & 756.64 & 0 \\
\hline 2 & 0.127 & 0.0637 & 7.78 & 0 \\
\hline 4 & 0.69 & 0.1724 & 21.08 & 0 \\
\hline 8 & 1.98 & 0.2475 & 30.25 & 0 \\
\hline 8 & 0.599 & 0.0749 & 9.16 & 0 \\
\hline 8 & 0.593 & 0.0742 & 9.07 & 0 \\
\hline 25860 & 211.517 & 0.0082 & & \\
\hline 25919 & 381.892 & & & \\
\hline
\end{tabular}


Triceps Analysis of Variance

Source
Angle
Plane
Weight (lb)
Direction
Angle*Plane
Angle*Weight (lb)
Angle*Direction
Plane*Weight (lb)
Plane*Direction
Weight (lb)*Direction
Angle*Plane*Weight (lb)
Angle*Plane*Direction
Angle*Weight (lb)*Direction
Plane*Weight (lb)*Direction
Angle*Plane*Weight (lb)*Direction
Error
Total

\begin{tabular}{|c|c|c|c|c|}
\hline DF & Adj SS & Adj MS & F-Value & P-Value \\
\hline 1 & 5.582 & 5.5824 & 540.86 & \\
\hline 1 & 0.818 & 0.8177 & 79.22 & \\
\hline 2 & 45.494 & 22.747 & 2203.87 & \\
\hline 4 & 21.787 & 5.4468 & 527.72 & \\
\hline 1 & 0 & 0 & 0 & 0.947 \\
\hline 2 & 0.287 & 0.1435 & 13.9 & \\
\hline 4 & 9.682 & 2.4204 & 234.5 & \\
\hline 2 & 0.14 & 0.0699 & 6.78 & 0.001 \\
\hline 4 & 2.046 & 0.5115 & 49.56 & \\
\hline 8 & 12.223 & 1.5279 & 148.03 & \\
\hline 2 & 0.156 & 0.0779 & 7.54 & 0.001 \\
\hline 4 & 0.232 & 0.0581 & 5.63 & \\
\hline 8 & 5.447 & 0.6808 & 65.96 & \\
\hline 8 & 1.417 & 0.1771 & 17.16 & \\
\hline 8 & 0.37 & 0.0462 & 4.48 & \\
\hline 60 & 266.91 & 0.0103 & & \\
\hline & 372.59 & & & \\
\hline
\end{tabular}




\section{Supraspinatus Analysis of Variance}

Source

Angle

Plane

Weight (Ib)

Direction

Angle*Plane

Angle*Weight (lb)

Angle*Direction

Plane*Weight (lb)

Plane*Direction

Weight (lb)*Direction

Angle*Plane*Weight (Ib)

Angle*Plane*Direction

Angle*Weight $(\mathrm{lb}) *$ Direction

Plane*Weight $(\mathrm{lb}) *$ Direction

Angle*Plane*Weight $(\mathrm{Ib}) *$ Direction

Error

Total

\section{Infraspinatus Analysis of Variance}

Source

Angle

Plane

Weight (lb)

Direction

Angle*Plane

Angle*Weight (lb)

Angle*Direction

Plane*Weight (lb)

Plane*Direction

Weight (lb)*Direction

Angle*Plane*Weight (Ib)

Angle*Plane* Direction

Angle*Weight $(\mathrm{lb}) *$ Direction

Plane*Weight (lb)*Direction

Angle*Plane*Weight $(\mathrm{lb}) *$ Direction

Error

Total

\begin{tabular}{|c|c|c|c|c|}
\hline DF & Adj SS & Adj MS & F-Value & P-Value \\
\hline 1 & 9.064 & 9.06394 & 1447.72 & 0 \\
\hline 1 & 8.704 & 8.70448 & 1390.31 & 0 \\
\hline 2 & 4.741 & 2.37071 & 378.66 & 0 \\
\hline 4 & 22.687 & 5.67181 & 905.92 & 0 \\
\hline 1 & 0.046 & 0.04555 & 7.28 & 0.007 \\
\hline 2 & 0.266 & 0.13295 & 21.24 & 0 \\
\hline 4 & 1.949 & 0.48724 & 77.82 & 0 \\
\hline 2 & 0.287 & 0.14364 & 22.94 & 0 \\
\hline 4 & 2.662 & 0.66544 & 106.29 & 0 \\
\hline 8 & 11.926 & 1.49072 & 238.1 & 0 \\
\hline 2 & 0.02 & 0.00989 & 1.58 & 0.206 \\
\hline 4 & 0.2 & 0.04992 & 7.97 & 0 \\
\hline 8 & 1.248 & 0.15606 & 24.93 & 0 \\
\hline 8 & 1.979 & 0.24739 & 39.51 & 0 \\
\hline 8 & 0.104 & 0.01298 & 2.07 & 0.035 \\
\hline 5860 & 161.905 & 0.00626 & & \\
\hline 919 & 227.788 & & & \\
\hline
\end{tabular}

\begin{tabular}{|c|c|c|c|c|}
\hline DF & Adj SS & Adj MS & F-Value & P-Value \\
\hline 1 & 0.121 & 0.12082 & 34.42 & 0 \\
\hline 1 & 0.146 & 0.14625 & 41.67 & 0 \\
\hline 2 & 6.84 & 3.41997 & 974.41 & 0 \\
\hline 4 & 12.34 & 3.08494 & 878.95 & 0 \\
\hline 1 & 0.164 & 0.16388 & 46.69 & 0 \\
\hline 2 & 0.046 & 0.02314 & 6.59 & 0.001 \\
\hline 4 & 0.679 & 0.16984 & 48.39 & 0 \\
\hline 2 & 0.007 & 0.00351 & 1 & 0.367 \\
\hline 4 & 0.844 & 0.21095 & 60.1 & 0 \\
\hline 8 & 9.786 & 1.22323 & 348.52 & 0 \\
\hline 2 & 0.128 & 0.06424 & 18.3 & 0 \\
\hline 4 & 0.363 & 0.09068 & 25.84 & 0 \\
\hline 8 & 0.825 & 0.10312 & 29.38 & 0 \\
\hline 8 & 0.929 & 0.11616 & 33.1 & 0 \\
\hline 8 & 0.438 & 0.05475 & 15.6 & 0 \\
\hline 860 & 90.763 & 0.00351 & & \\
\hline 919 & 124.419 & & & \\
\hline
\end{tabular}


Middle deltoid Analysis of Variance

Source
Angle
Plane
Weight (lb)
Direction
Angle*Plane
Angle*Weight (lb)
Angle*Direction
Plane*Weight (lb)
Plane*Direction
Weight (lb)*Direction
Angle*Plane*Weight (lb)
Angle*Plane*Direction
Angle*Weight (lb)*Direction
Plane*Weight (lb)*Direction
Angle*Plane*Weight (lb)*Direction
Error
Total

Anterior deltoid Analysis of Variance

Source

Angle

Plane

Weight (lb)

Direction

Angle*Plane

Angle*Weight (lb)

Angle* Direction

Plane*Weight (lb)

Plane*Direction

Weight (lb)*Direction

Angle*Plane*Weight (Ib)

Angle*Plane* Direction

Angle*Weight $(\mathrm{lb}) *$ Direction

Plane*Weight $(\mathrm{lb}) *$ Direction

Angle*Plane*Weight $(\mathrm{Ib}) *$ Direction

Error

Total

\begin{tabular}{rrrrr} 
DF & \multicolumn{1}{c}{ Adj SS } & Adj MS & F-Value & P-Value \\
1 & 19.887 & 19.8869 & 4771.51 & 0 \\
1 & 0.5 & 0.4997 & 119.89 & 0 \\
2 & 1.578 & 0.7891 & 189.34 & 0 \\
4 & 13.184 & 3.296 & 790.8 & 0 \\
1 & 0.117 & 0.1167 & 27.99 & 0 \\
2 & 0.201 & 0.1004 & 24.08 & 0 \\
4 & 2.981 & 0.7452 & 178.8 & 0 \\
2 & 0.043 & 0.0214 & 5.15 & 0.006 \\
4 & 0.658 & 0.1645 & 39.47 & 0 \\
8 & 6.733 & 0.8417 & 201.94 & 0 \\
2 & 0.004 & 0.002 & 0.48 & 0.616 \\
4 & 0.323 & 0.0807 & 19.37 & 0 \\
8 & 1.392 & 0.174 & 41.75 & 0 \\
8 & 0.38 & 0.0475 & 11.4 & 0 \\
8 & 0.201 & 0.0252 & 6.04 & 0 \\
25860 & 107.781 & 0.0042 & & \\
25919 & 155.962 & & &
\end{tabular}

\begin{tabular}{rrrrr} 
DF & \multicolumn{1}{c}{ Adj SS } & Adj MS & F-Value & P-Value \\
1 & 10.101 & 10.1011 & 1811.65 & 0 \\
1 & 0.82 & 0.8203 & 147.13 & 0 \\
2 & 0.654 & 0.3272 & 58.68 & 0 \\
4 & 20.038 & 5.0095 & 898.46 & 0 \\
1 & 0.111 & 0.1114 & 19.98 & 0 \\
2 & 0.017 & 0.0086 & 1.53 & 0.216 \\
4 & 3.133 & 0.7834 & 140.5 & 0 \\
2 & 0.041 & 0.0205 & 3.67 & 0.025 \\
4 & 0.136 & 0.0339 & 6.08 & 0 \\
8 & 12.291 & 1.5364 & 275.56 & 0 \\
2 & 0.004 & 0.0018 & 0.32 & 0.728 \\
4 & 0.556 & 0.139 & 24.93 & 0 \\
8 & 1.217 & 0.1521 & 27.27 & 0 \\
8 & 0.214 & 0.0268 & 4.8 & 0 \\
8 & 0.375 & 0.0468 & 8.4 & 0 \\
25860 & 144.186 & 0.0056 & & \\
25919 & 193.895 & & &
\end{tabular}


Posterior deltoid Analysis of Variance

Source

Angle

Plane

Weight (lb)

Direction

Angle*Plane

Angle*Weight (lb)

Angle* Direction

Plane*Weight (lb)

Plane*Direction

Weight (lb)*Direction

Angle*Plane*Weight (Ib)

Angle*Plane*Direction

Angle*Weight $(\mathrm{lb}) *$ Direction

Plane*Weight (lb)*Direction

Angle*Plane*Weight (lb)*Direction

Error

Total

\section{Biceps Analysis of Variance}

Source

Angle

Plane

Weight (lb)

Direction

Angle*Plane

Angle*Weight (lb)

Angle* Direction

Plane*Weight (lb)

Plane*Direction

Weight (lb)*Direction

Angle*Plane*Weight (Ib)

Angle*Plane* Direction

Angle*Weight $(\mathrm{lb}) *$ Direction

Plane*Weight $(\mathrm{lb}) *$ Direction

Angle*Plane*Weight $(\mathrm{Ib}) *$ Direction

Error

Total

\begin{tabular}{rrrrr} 
DF & \multicolumn{1}{c}{ Adj SS } & Adj MS & F-Value & P-Value \\
1 & 9.31 & 9.30974 & 3289.43 & 0 \\
1 & 0.92 & 0.92003 & 325.08 & 0 \\
2 & 4.26 & 2.12992 & 752.57 & 0 \\
4 & 11.895 & 2.97372 & 1050.71 & 0 \\
1 & 0.174 & 0.17442 & 61.63 & 0 \\
2 & 1.28 & 0.63993 & 226.11 & 0 \\
4 & 4.101 & 1.02531 & 362.28 & 0 \\
2 & 0.129 & 0.06456 & 22.81 & 0 \\
4 & 1.337 & 0.33428 & 118.11 & 0 \\
8 & 7.203 & 0.90037 & 318.13 & 0 \\
2 & 0.011 & 0.00564 & 1.99 & 0.136 \\
4 & 0.181 & 0.04532 & 16.01 & 0 \\
8 & 2.093 & 0.2616 & 92.43 & 0 \\
8 & 0.751 & 0.09392 & 33.18 & 0 \\
8 & 0.09 & 0.01122 & 3.97 & 0 \\
25860 & 73.189 & 0.00283 & & \\
25919 & 116.925 & & &
\end{tabular}

\begin{tabular}{rrrrr} 
DF & \multicolumn{1}{c}{ Adj SS } & Adj MS & F-Value & P-Value \\
1 & 2.004 & 2.00449 & 557.22 & 0 \\
1 & 0.171 & 0.17102 & 47.54 & 0 \\
2 & 8.735 & 4.36755 & 1214.11 & 0 \\
4 & 19.794 & 4.94862 & 1375.64 & 0 \\
1 & 0.007 & 0.00716 & 1.99 & 0.158 \\
2 & 0.898 & 0.44895 & 124.8 & 0 \\
4 & 2.087 & 0.52171 & 145.03 & 0 \\
2 & 0.109 & 0.05463 & 15.19 & 0 \\
4 & 0.997 & 0.24914 & 69.26 & 0 \\
8 & 14.603 & 1.82533 & 507.41 & 0 \\
2 & 0.038 & 0.01923 & 5.35 & 0.005 \\
4 & 0.362 & 0.09042 & 25.13 & 0 \\
8 & 1.861 & 0.23264 & 64.67 & 0 \\
8 & 0.64 & 0.07999 & 22.23 & 0 \\
8 & 0.685 & 0.08563 & 23.8 & 0 \\
25860 & 93.027 & 0.0036 & & \\
25919 & 146.019 & & &
\end{tabular}




\section{Triceps Analysis of Variance}

Source

Angle

Plane

Weight (lb)

Direction

Angle*Plane

Angle*Weight (lb)

Angle* Direction

Plane*Weight (Ib)

Plane*Direction

Weight (lb)*Direction

Angle*Plane*Weight (Ib)

Angle*Plane* Direction

Angle*Weight $(\mathrm{lb}) *$ Direction

Plane*Weight $(\mathrm{lb}) *$ Direction

Angle*Plane*Weight (lb)*Direction

Error

Total

\begin{tabular}{rrrrr} 
DF & \multicolumn{1}{c}{ Adj SS } & Adj MS & F-Value & P-Value \\
1 & 1.397 & 1.39726 & 293.4 & 0 \\
1 & 0.227 & 0.22743 & 47.76 & 0 \\
2 & 15.158 & 7.57883 & 1591.4 & 0 \\
4 & 4.431 & 1.10786 & 232.63 & 0 \\
1 & 0 & 0.0003 & 0.06 & 0.802 \\
2 & 0.239 & 0.11947 & 25.09 & 0 \\
4 & 1.999 & 0.49978 & 104.94 & 0 \\
2 & 0.084 & 0.04224 & 8.87 & 0 \\
4 & 0.312 & 0.0779 & 16.36 & 0 \\
8 & 3.805 & 0.47567 & 99.88 & 0 \\
2 & 0.032 & 0.01601 & 3.36 & 0.035 \\
4 & 0.155 & 0.03866 & 8.12 & 0 \\
8 & 2.013 & 0.2516 & 52.83 & 0 \\
8 & 0.241 & 0.03017 & 6.34 & 0 \\
8 & 0.314 & 0.0392 & 8.23 & 0
\end{tabular}

$\begin{array}{lll}25860 & 123.155 & 0.00476\end{array}$

25919153.563 